\title{
Evaluation of novel sigma receptor antagonists against METH- induced neurotoxicity: in vivo and in vitro studies
}

Nidhi Kaushal

West Virginia University

Follow this and additional works at: https://researchrepository.wvu.edu/etd

\section{Recommended Citation}

Kaushal, Nidhi, "Evaluation of novel sigma receptor antagonists against METH-induced neurotoxicity: in vivo and in vitro studies" (2012). Graduate Theses, Dissertations, and Problem Reports. 4874.

https://researchrepository.wvu.edu/etd/4874

This Dissertation is protected by copyright and/or related rights. It has been brought to you by the The Research Repository @ WVU with permission from the rights-holder(s). You are free to use this Dissertation in any way that is permitted by the copyright and related rights legislation that applies to your use. For other uses you must obtain permission from the rights-holder(s) directly, unless additional rights are indicated by a Creative Commons license in the record and/ or on the work itself. This Dissertation has been accepted for inclusion in WVU Graduate Theses, Dissertations, and Problem Reports collection by an authorized administrator of The Research Repository @ WVU.

For more information, please contact researchrepository@mail.wvu.edu. 


\section{Evaluation of novel sigma receptor antagonists against METH- induced neurotoxicity: in vivo and in vitro studies}

\section{NIDHI KAUSHAL}

A dissertation submitted to the School of Pharmacy at

West Virginia University in partial fulfillment of the requirements for the degree of

\section{Doctor of Philosophy}

In

Pharmaceutical and Pharmacological Sciences

Rae R. Matsumoto, Ph.D., Chair Wayne D. Bowen, Ph.D.

Jason D. Huber, Ph.D.

Fred Minnear, Ph.D.

Yon Rojanasakul, Ph.D.

Department of Basic Pharmaceutical Sciences

Morgantown, West Virginia

2012

Keywords: Methamphetamine, Sigma receptors, Hyperthermia, Neurotoxicity, Dopamine, Serotonin, NG108-15 cells, Reactive oxygen species, Caspase, Apoptosis, Necrosis 


\section{ABSTRACT \\ Evaluation of novel sigma receptor antagonists against METH-induced neurotoxicity: \\ in vivo and in vitro studies \\ NIDHI KAUSHAL}

Methamphetamine (METH) is a highly addictive psychostimulant drug of abuse, causing hyperthermia and neurotoxicity at high doses. Currently, there is no clinically proven pharmacotherapy to treat these effects of $\mathrm{METH}$, necessitating identification of potential novel therapeutic targets. Earlier studies showed that METH binds to sigma receptors in the brain at physiologically relevant concentrations, where it acts in part as an agonist. AC927 (1-(2phenethyl)piperidine oxalate), CM156 (3-(4-(4-cyclohexylpiperazin-1-yl)butyl)benzo[d]thiazole2(3H)-thione) and SN79 (6-acetyl-3-(4-(4-(4-florophenyl)piperazin-1-yl)butyl)benzo[d]oxazol$2(3 H)$-one) were synthesized as putative sigma receptor antagonists with nanomolar affinity and selectivity for sigma receptors over 29-80 other binding sites. AC927, CM156 and SN79 pretreatment afforded protection against METH-induced hyperthermia and striatal dopaminergic and serotonergic neurotoxicity in male Swiss Webster mice (measured as depletions in striatal dopamine and serotonin levels, and reductions in striatal dopamine and serotonin transporter expression levels). To elucidate the mechanism of neuroprotection provided by sigma receptor antagonists, differentiated NG108-15 cells were used as a cell culture model. METH, at physiologically relevant micromolar concentrations, caused apoptosis in NG108-15 cells. At higher concentrations necrotic cell death was observed. At earlier time points, METH caused generation of reactive oxygen/nitrogen species like hydrogen peroxide and nitric oxide and also release of dopamine from the cells. At later time points, caspase-3, -8 and -9 activation was observed indicating activation of both extrinsic and intrinsic caspase-dependent apoptotic pathways. Sigma receptor antagonism attenuated these neurotoxic mediators and cell death. Additionally, DTG, a sigma receptor agonist shifted the dose response curve of METH-induced cell death (especially necrosis) towards left further confirming the involvement of sigma receptors in the neurotoxic effect of METH. Among the two subtypes of sigma receptors, sigma2 receptors are highly upregulated in tumor cells and are implicated in cell death mechanism. Both CM398 and CM775, sigma-2 receptor antagonists also attenuated METH-induced neurotoxicity, providing further evidence for involvement of this subtype in METH-induced cell death mechanisms. In addition to activation of cell death mediators, METH also causes increase in body temperature. METH treatment in NG108-15 cells maintained at $40{ }^{\circ} \mathrm{C}$ versus $37^{\circ} \mathrm{C}$ caused a significant and synergistic increase in cell death, indicating that increase in temperature exacerbates METH-induced toxicity. SN79 was able to attenuate the enhanced cell death observed in the METH treated cells at $40^{\circ} \mathrm{C}$. This can have important implications in in vivo systems where sigma receptor antagonism can protect against toxicity induced by METH at elevated temperature. This study provided evidence for the potential application of sigma receptor antagonists as drug development against METH-induced neurotoxicity, in addition to providing a mechanistic basis of neuroprotection. 
Dedicated to

The loving memory of my late father

\section{Lt. Col. Satyender Nath Kaushal}

My beloved mother

Vijay Kaushal

And my dear sister

Vidushi Kaushal Bahl 


\section{ACKNOWLEDGEMENTS}

First and foremost, I would like express my deepest and sincere gratitude to my mentor Dr. Rae Matsumoto for being a source of inspiration all these years. Her encouragement, guidance and critique have helped me to grow as a scientist. I also want to thank her for encouraging me to participate in various national and international conferences that provided me with the opportunity to learn about the latest developments in the field.

I also want to extend my sincere thanks and gratitude to my committee members Dr. Wayne Bowen, Dr. Fred Minnear, Dr. Yon Rojanasakul and Dr. Jason Huber for their valuable insights and suggestions. I would especially like to thank Dr. Bowen for providing me with the training opportunity in his lab. I also want to thank Dr. Rojanasakul and Dr. Huber for allowing me to perform some of these studies in their respective lab.

Special thanks to Dr. Christopher McCurdy, Dr. Christophe Mesangeau and Dr. Sanju Narayanan from University of Mississippi, and Dr. Andrew Coop from University of Maryland for synthesizing and providing the compounds used in this study

I would like to acknowledge my past and current lab members Dr. Meenal Elliott, Abagail Rosen, Dr. Jim Fishback, Dr. Yantong Xu, Dr. Jamaluddin Shaikh, Michael Seminerio, Matthew Robson, Jason Healy, Christina Byrne-Hoffman and Bahar Noorbakhsh for their help and friendship. I would especially like to thank Anurag Mishra for his support and motivation during all these years.

Finally, there are no words to explain my regards for the love, blessings, motivation and unconditional support I received from my family without which I would have never completed this arduous task. 


\section{TABLE OF CONTENTS}

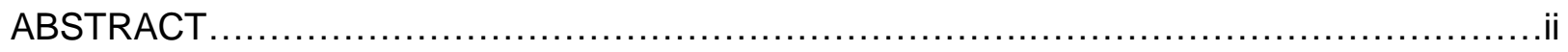

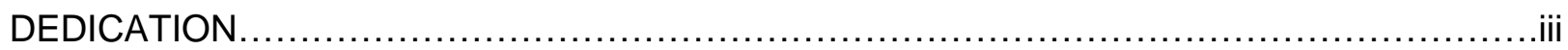

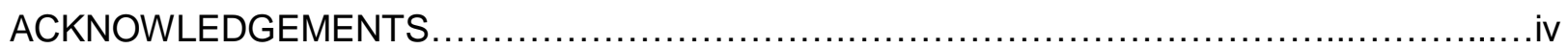

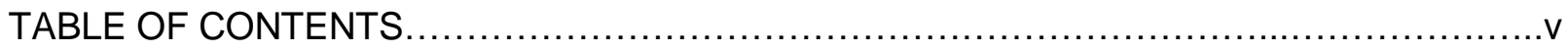

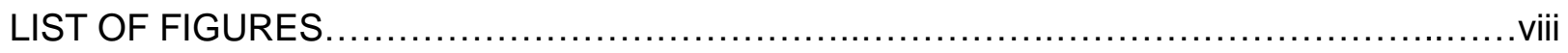

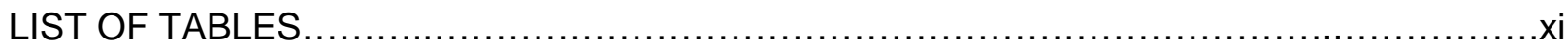

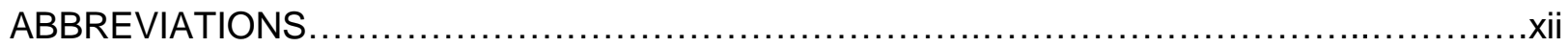

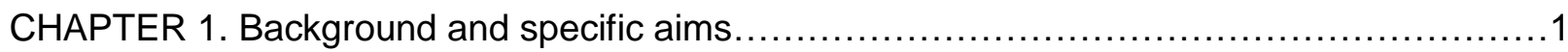

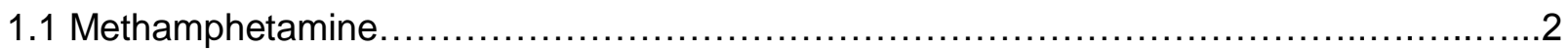

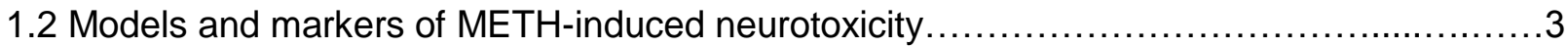

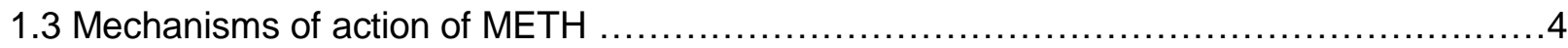

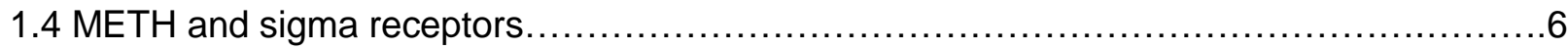

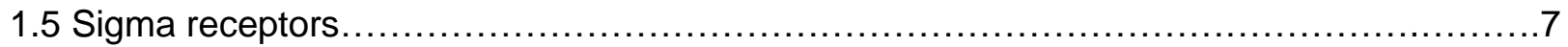

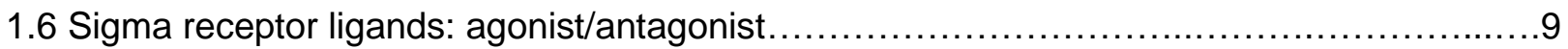

1.7 Potential involvement of $\sigma$ receptors in the mechanisms of METH-induced neurotoxicity.. 11

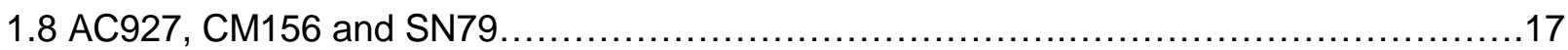

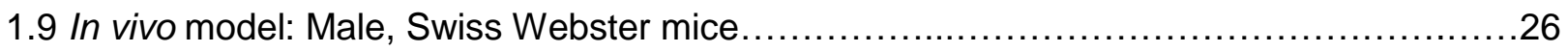

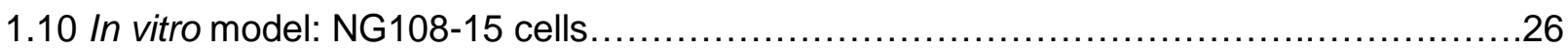

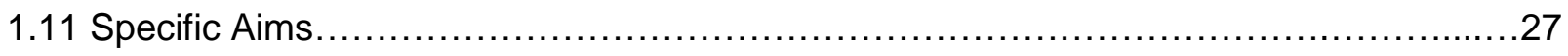

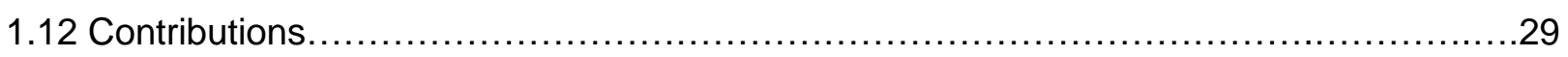

CHAPTER 2. Evaluation of sigma receptor antagonists against METH-induced neurotoxicity:

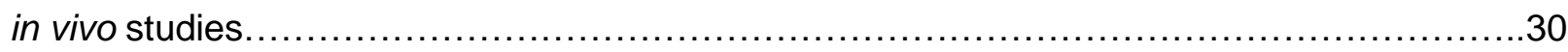

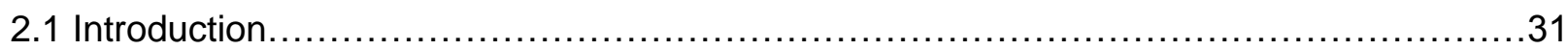

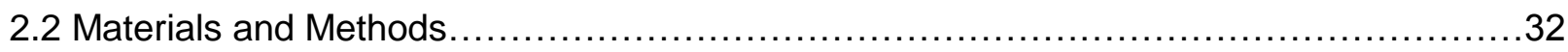

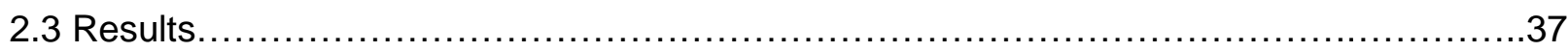

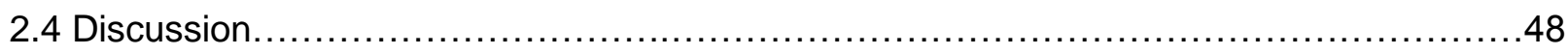

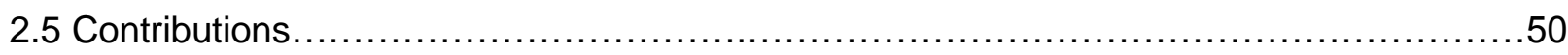


CHAPTER 3. Evaluation of AC927, CM156 and SN79 against meth-induced hyperthermia....51

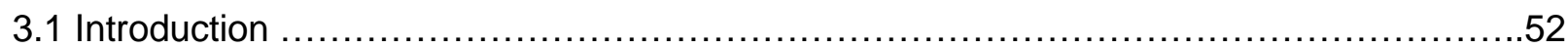

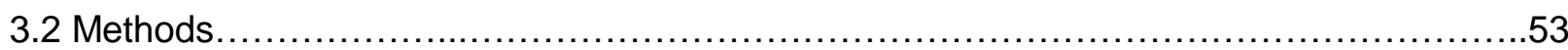

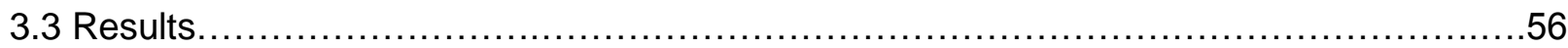

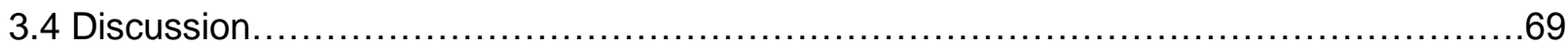

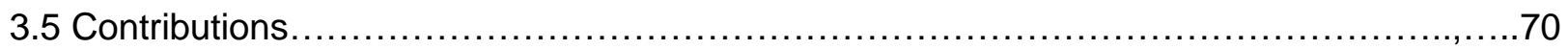

CHAPTER 4. Evaluation of AC927 against meth-induced neurotoxicity: in vitro studies........71

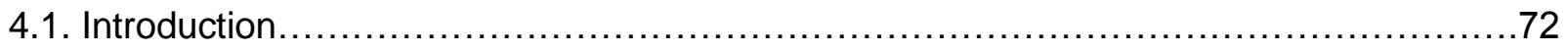

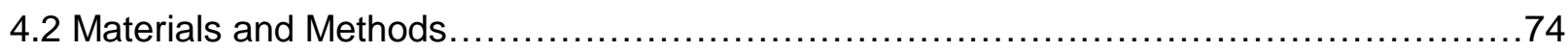

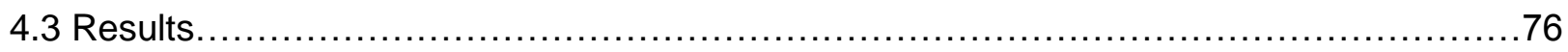

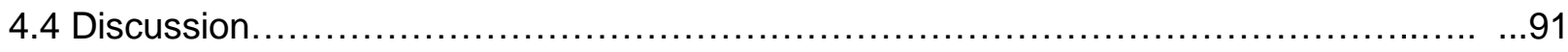

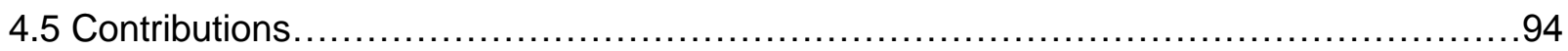

CHAPTER 5. Evaluation of SN79 against meth and elevated temperature-induced

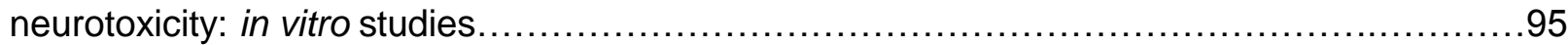

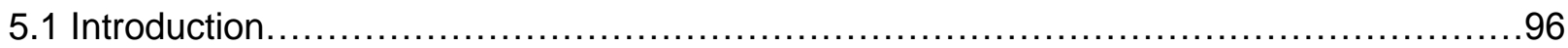

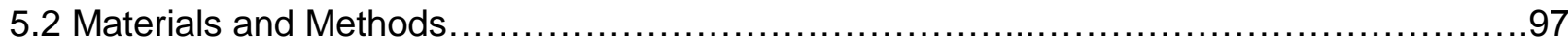

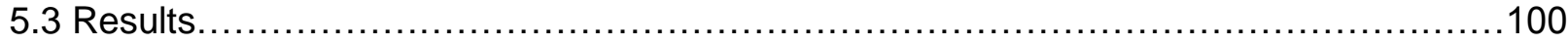

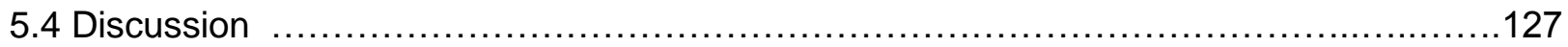

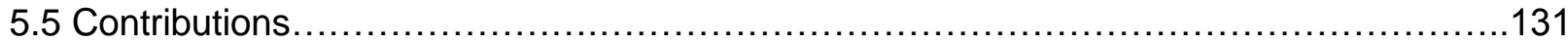

CHAPTER 6. Evaluation of sigma-2 receptor antagonist against meth-induced neurotoxicity in vitro. 132

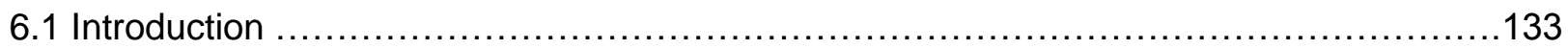

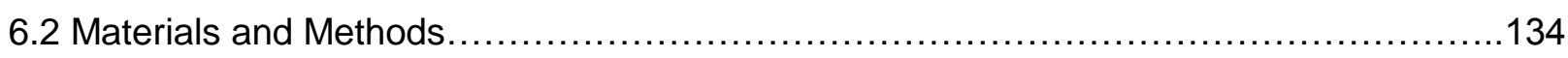

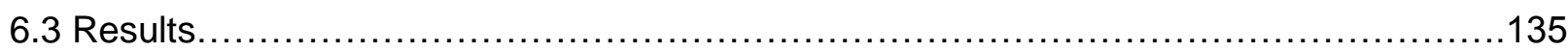

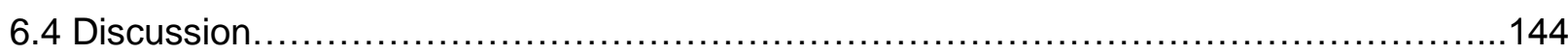

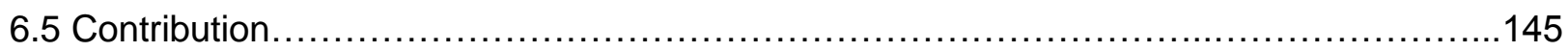


CHAPTER 7. Overall conclusions and future studies.

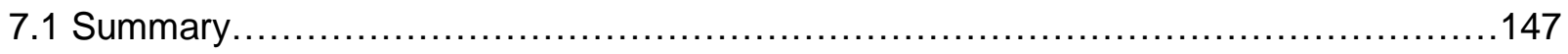

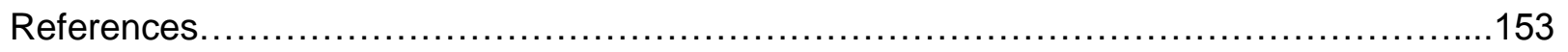

Curriculum Vitae $\ldots \ldots \ldots \ldots \ldots \ldots \ldots \ldots \ldots \ldots \ldots \ldots \ldots \ldots \ldots \ldots \ldots \ldots \ldots \ldots \ldots \ldots \ldots \ldots \ldots \ldots 178$ 


\section{LIST OF FIGURES}

Figure 1.1: Striatal distribution volume of DAT ligand in METH abuser.......................

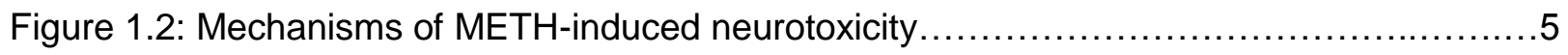

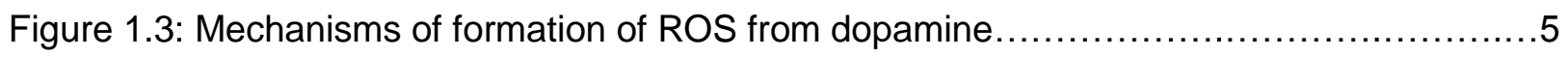

Figure 1.4: Potential involvement of $\sigma$ receptors in the mechanisms of METH-induced neurotoxicity ................................

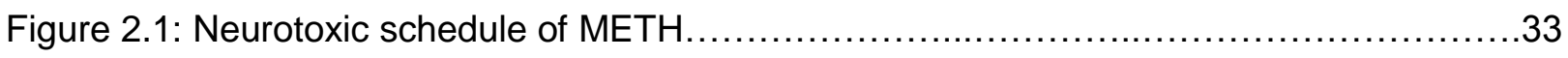

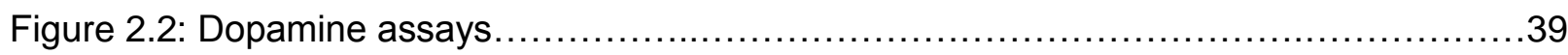

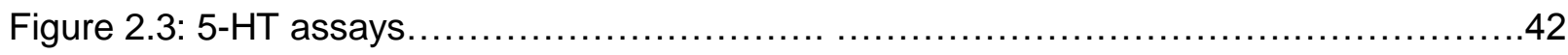

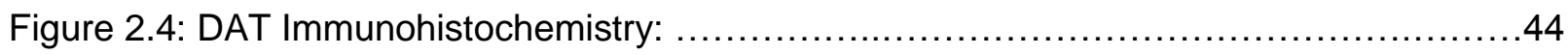

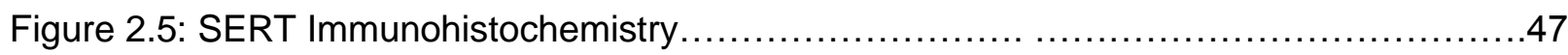

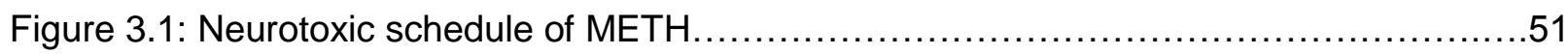

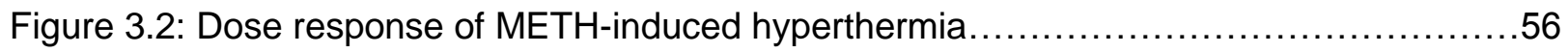

Figure 3.3: Effect of AC927 on basal body temperature, and METH-induced hyperthermia in mice.

Figure 3.4: Effect of CM156 on basal body temperature, and METH (5 and $10 \mathrm{mg} / \mathrm{kg}$ )-induced hyperthermia in mice.

Figure 3.5: Effect of SN79 treatment on basal body temperature, and METH (5 and $10 \mathrm{mg} / \mathrm{kg}$ )-induced hyperthermia in mice.

Figure 3.6: Correlation of body temperature and striatal

(A) dopamine (DA) and (B) 5-HT levels of mice pretreated

with saline or AC927(5-20 mg/kg) prior to saline or METH $(5 \mathrm{mg} / \mathrm{kg})$

Figure 3.7: Correlation of body temperature and striatal

(A) dopamine (DA) and (B) 5-HT levels of mice pretreated with saline or CM156 (5-20 mg/kg) prior to saline or METH (5 and $10 \mathrm{mg} / \mathrm{kg})$.

Figure 3.7: Correlation of body temperature and striatal

(A) dopamine (DA) and (B) 5-HT levels of mice pretreated with saline or SN79 (1-10 mg/kg) prior to saline or METH (5 and $10 \mathrm{mg} / \mathrm{kg})$...

Figure 4.1: Dose response and time course of

METH-induced ROS/RNS generation. .78

Figure 4.2: Effect of antioxidants (A) NAC, (B) catalase,

(C) L-NMMA on METH-induced ROS/RNS generation. 
Figure 4.3: Dose response and time course of AC927-induced ROS/RNS generation.........83

Figure 4.4: Effect of AC927 pretreatment on METH-induced ROS/RNS generation.............85

Figure 4.5: Effect of AC927 pretreatment on METH-induced dopamine release................87

Figure 4.6: Effect of AC927 pretreatment on METH-induced apoptosis and necrosis...........90

Figure 5.1: Effect of SN79 pretreatment on METH-induced apoptosis, necrosis and total cell death 103

Figure 5.2: Effect of DTG pretreatment on METH-induced apoptosis, necrosis and total cell death. 106

Figure 5.3: Effect of temperature $\left(37\right.$ versus $\left.40^{\circ} \mathrm{C}\right)$ on METH-induced apoptosis, necrosis and total cell death

Figure 5.4: Effect of SN79 pretreatment on METH-induced apoptosis, necrosis and total cell death at $40^{\circ} \mathrm{C}$.

Figure 5.5: MTT Assay: A. Dose response of METH-induced decrease in cell viability

B. Effect of SN79 pretreatment on METH $(1000 \mu \mathrm{M})$-induced decrease in cell viability

Figure 5.6: A. Dose response of METH-induced decrease in cell viability

B. Effect of SN79 pretreatment on METH $(1000 \mu \mathrm{M})$-induced decrease in cell viability. .118

Figure 5.7: A. Dose response and time course of METH treatment on Caspase-3 activation B. Effect of SN79 pretreatment on METH-induced Caspase-3 activation at 24 hours.

Figure 5.8: A. Dose response and time course of METH treatment on Caspase- 8 activation B. Effect of SN79 pretreatment on METH-induced Caspase- 3 activation at 9 hours.

Figure 5.9: A. Dose response and time course of METH treatment on Caspase- 9 activation

B. Effect of SN79 pretreatment on METH-induced

Caspase- 9 activation at 24 hours.

Figure 5.10: Effect of SN79 pretreatment on METH-induced ROS/RNS generation 126

Figure 6.1: Effect of CM398 pretreatment on METH-induced apoptosis, necrosis and total cell death.

Figure 6.2: Effect of CM775 pretreatment on METH-induced apoptosis, necrosis and total cell death. 140

Figure 6.3: Effect of CM699 pretreatment on METH-induced apoptosis, 


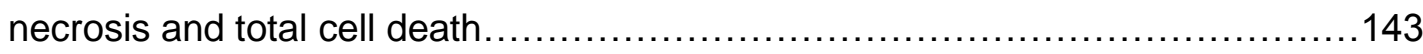

Figure 7.1: Time course of METH-induced activation of neurotoxic

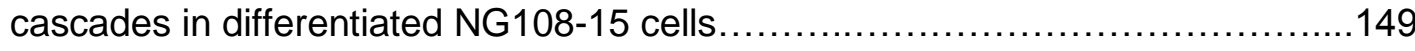

Figure 7.2: Effect of elevated temperature on METH-induced cell death in differentaited NG108-15 cells.............................................. 


\section{LIST OF TABLES}

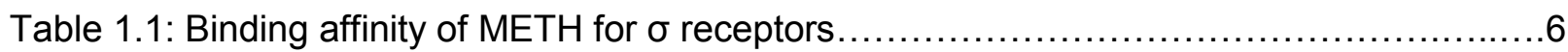

Table 1.2: Binding affinity of AC927, CM156 and SN79 for $\sigma$ and non- $\sigma$ sites................19

Table 1.3 Metabolic stability of CM156 in rat, monkey, and human liver microsomes...........23

Table 1.4: Mean plasma pharmacokinetic parameters of SN79 after

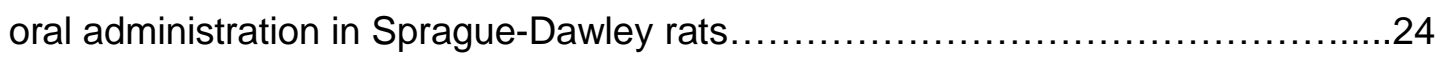

Table 1.5: Human cytochrome P450 inhibition studies................................25

Table 3.1: Correlation of body temperature and striatal dopamine and 5-HT levels of mice pretreated with saline or AC927(5-20 mg/kg) prior to

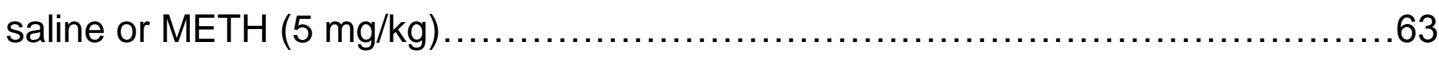

Table 3.2: Correlation of body temperature and striatal dopamine and 5-HT levels of mice pretreated with saline or CM156 (5-20 mg/kg) prior to saline or

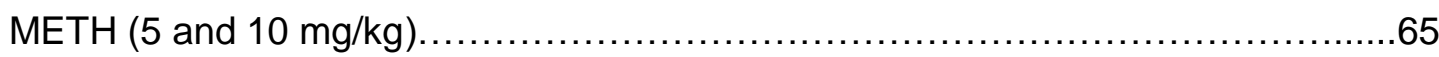

Table 3.3: Correlation of body temperature and striatal dopamine and 5-HT levels of mice pretreated with saline or SN79 (1-10 mg/kg) prior to saline or

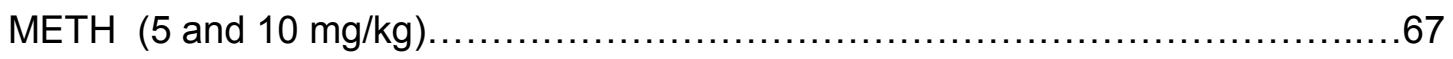

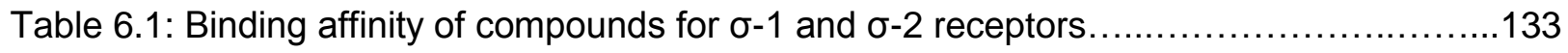




\section{ABBREVIATIONS}

AC927

ANOVA

$\mathrm{BiP}$

BT

CM156

CM- $\mathrm{H}_{2}$ DCFDA

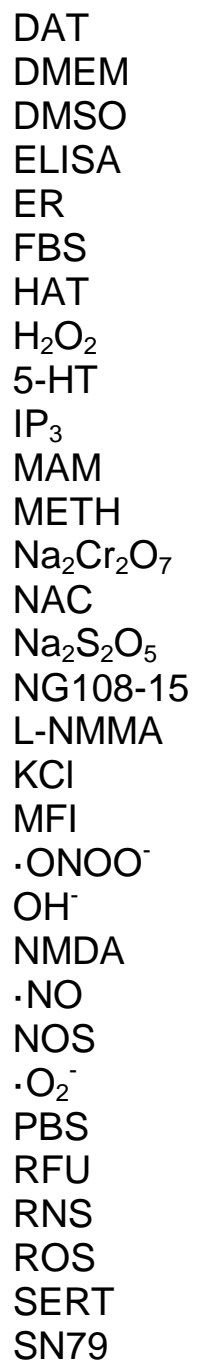

TH

VMAT2
$\mathrm{N}$-phenethylpiperidine oxalate

Analysis of variance

Binding immunoglobulin protein

Body temperature

3-(4-(4-cyclohexylpiperazin-1-yl)butyl)benzo[d] thiazole-2(3H)thione

5-(and-6)-chloromethyl-2',7'-dichlorodihydrofluorescin diacetate, acetyl ester

Dopamine transporter

Dulbecco's modified Eagle's medium

Dimethylsulfoxide

Enzyme-linked immunosorbent assay

Endoplasmic reticulum

Fetal bovine serum

Hypoxanthine-aminopterin-thymidine

Hydrogen peroxide

Serotonin

Inositol trisphosphate

Mitochondria-associated ER membrane

Methamphetamine

Sodium bichromate

$\mathrm{N}$-acetylcysteine

Sodium metabisulfite

Neuroblastomaxglioma hybridoma

$\mathrm{L}-\mathrm{N}^{\mathrm{G}}$-monomethyl arginine citrate

Potassium chloride

Mean fluorescence intensity

Peroxynitrite;

Hydroxyl

$\mathrm{N}$-methyl-D-aspartate

Nitric oxide

Nitric oxide synthase

Superoxide

Phosphate buffered saline

Relative fluorescence units

Reactive nitrogen species

Reactive oxygen species

Serotonin transporter

6-acetyl-3-(4-(4-(4-florophenyl)piperazin-1-

yl)butyl)benzo[d]oxazol-2(3H)-one

Tyrosine hydroxylase

Vesicular monoamine transporter 2 
CHAPTER 1

\section{BACKGROUND AND SPECIFIC AIMS}




\subsection{Methamphetamine}

Methamphetamine (METH) is one of the amphetamine analogs and a psychomotor stimulant. It is a widely abused substance worldwide mainly due to its ease of synthesis from over the counter drugs and its long half life (10-12 h). Due to these factors, it ranks second worldwide after Cannabis as the most extensively abused drug, with an estimated 15-16 million users worldwide (Krasnova and Cadet, 2009).

Apart from its immediate stimulant effects such as euphoria and enhanced energy, METH causes harmful effects upon exposure to repeated or large doses. Some of these harmful effects include hyperthermia, addiction, altered neurological and cognitive functions, psychosis, depression, and neurodegeneration (Krasnova and Cadet, 2009).

The neurodegenerative and neurotoxic effects have been studied using neuroimaging and postmortem studies in humans, depicting damage to dopaminergic and serotonergic neurons in several regions of the brain. This damage can be measured as reductions in dopamine transporters (DAT), serotonin transporters (SERT), and dopamine and serotonin (5HT) levels (Krasnova and Cadet, 2009). In addition, in certain postmortem studies, apoptotic markers like caspase 3 have also been reported (Kitamura et al., 2007). These neurodegenerative effects are a cause of concern because they are implicated in some of the neuropsychiatric symptoms observed due to METH (Volkow et al., 2001; Scott et al., 2007). In addition, retrospective studies have shown that many Parkinson's disease patients were former abusers of METH (Garwood et al., 2006; Kuehn, 2011). Figure 1.1 shows the comparison of DAT levels in a METH user and control brain 80 days after detoxification. 
Figure 1.1 Striatal distribution volume of DAT ligand in METH abuser

FIGURE 1. Striatal Distribution Volume of the Dopamine Transporter Ligand $\left[{ }^{11} \mathrm{C}\right] d$-threo-Methylphenidate in a 33 Year-Old Male Comparison Subject and a 33-Year-Old Male Methamphetamine Abuser

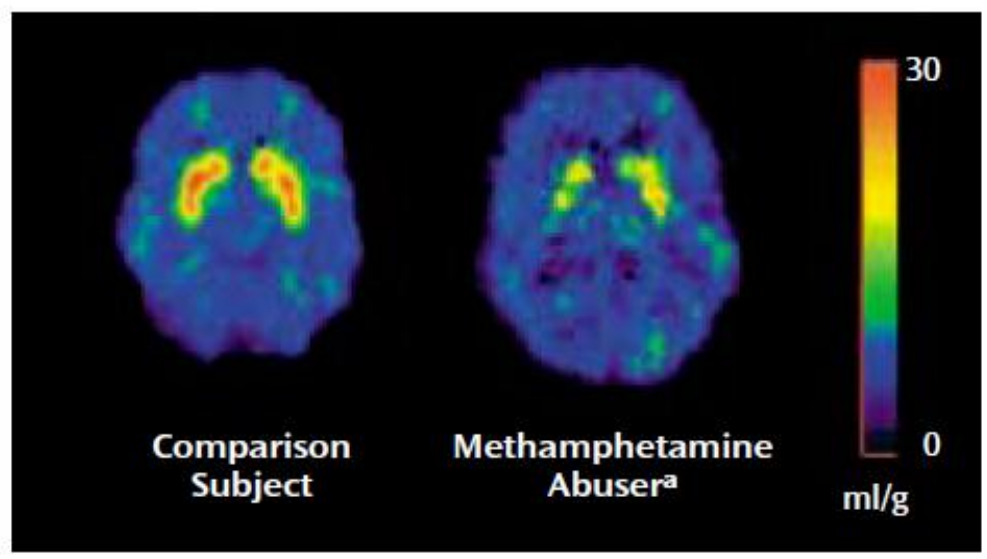

a PET scan was performed 80 days after detoxification.

(Volkow et al., 2001)

\subsection{Models and markers of METH-induced neurotoxicity}

METH-induced neurotoxic damage has been studied by researchers in in vivo and in vitro models. In vivo models include rodents and non-human primates. A $4 \times \mathrm{METH}$ (4 injections of METH at 2 hour intervals) is a commonly used dosing regimen for studying METH's neurotoxic effects as it mimics the binge pattern of METH intake by addicts (Villemagne et al., 1998). In addition, a bolus dose of METH administration has also been used, but it leads to a higher mortality rate (Fukumura et al., 1998). The neurotoxic regimen of METH causes damage to neurons in several brain regions like the striatum, cortex, and hippocampus (Deng et al., 2001). Some of the earlier methods used to detect damage were ATP loss and decrease in regional cerebral glucose utilization (Chan et al., 1994; Huang et al., 1999). METH mainly causes degeneration of nerve terminals which have previously been detected using Fluoro jade staining (Schmued and Bowyer, 1997). Damage to dopamine nerve terminals is observed as a decrease in the levels of dopamine, tyrosine hydroxylase, 
DAT, and vesicular monoamine transporters (VMAT2) (Krasnova and Cadet, 2009). Similarly, damage to serotonin nerve terminals is observed as a decrease in the levels of $5-\mathrm{HT}$, tryptophan hydroxylase, and SERT (Krasnova and Cadet, 2009). In addition, it has been recently observed that METH can also cause apoptosis in these brain regions (Deng et al., 2001; Krasnova and Cadet, 2009).

In vitro studies have been done using primary neuronal cells (fetal mesencephalic dopamine neurons, midbrain neuronal cells, mesencephalic dopamine cells) (Bennett et al., 1993; Cubells et al., 1994; Kanthasamy et al., 2006) and immortalized neuronal cells (neuroblastoma NBP2 cells, CATH.a cells, PC12 cells, human neuroblastoma SH-SY5Y cells, immortalized rat mesencephalon cells) (Adams et al., 1996; Cadet et al., 1997; Hom et al., 1997; Choi et al., 2002; Wang et al., 2008) as models to further understand the mechanisms involved in METH-induced neurotoxicity and cell death (Krasnova and Cadet, 2009). Apoptotic and necrotic types of cell death and some of their mechanisms have been studied using makers like TUNEL staining (Samantaray et al., 2006), Hoechst staining (Larsen et al., 2002), annexin V, propidium iodide (Deng et al., 2002), reactive oxygen species (ROS) (Cubells et al., 1994), proapoptotic factors like Bax, Bid, AIF, and caspase levels (Jayanthi et al., 2004).

\subsection{Mechanisms of action of METH}

Classically, METH is known to cause an enormous increase in dopamine release by the blockade and reversal of DAT (Barr et al., 2006). METH also enters the neuron passively or via DAT and impairs VMAT2 which are present on synaptic vesicles containing the neurotransmitter dopamine. This excessive dopamine in the synapse and cytoplasm causes production of ROS through autooxidation as well as enzyme-mediated reactions (Wrona et al., 1995; Wrona and Dryhurst, 1998; LaVoie and Hastings, 1999a; LaVoie and Hastings, 1999b). This excessive ROS can cause nerve terminal degeneration (by lipid peroxidation and 
oxidation of proteins and phospholipids) and cell death via apoptosis or necrosis (Krasnova and Cadet, 2009). Figure 1.2 shows a simplistic mechanism of METH-induced neurotoxicity. Figure 1.3 shows some mechanisms by which dopamine can lead to ROS generation.

Figure 1.2: Mechanisms of METH-induced neurotoxicity

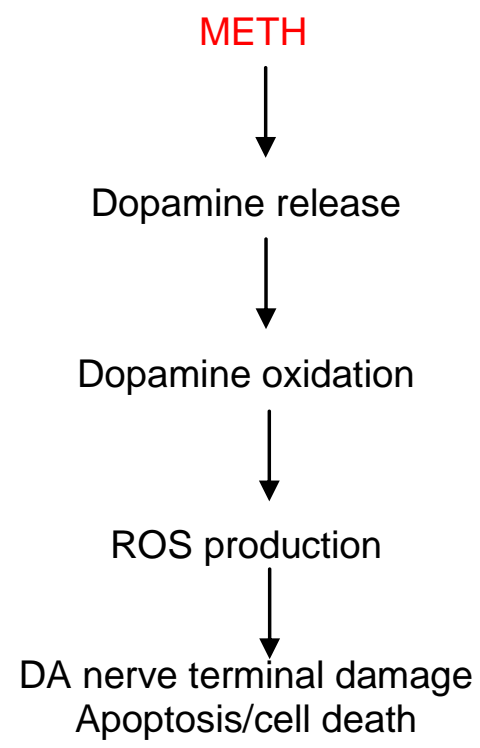

Figure 1.3: Mechanisms of formation of ROS from dopamine

$\begin{array}{ll}\mathrm{DA}+\mathrm{O}_{2}+\mathrm{H}_{2} \mathrm{O} \longrightarrow \mathrm{MAO} & \mathrm{DOPAC}+\mathrm{NH}_{3}+\mathrm{H}_{2} \mathrm{O}_{2} \\ \mathrm{DA}+\mathrm{O}_{2} \longrightarrow \mathrm{SQ}^{\cdot}+\mathrm{O}_{2}^{-}+2 \mathrm{H}^{+} \\ \mathrm{DA}+\mathrm{O}_{2}+2 \mathrm{H}^{+} \longrightarrow \mathrm{SQ}^{\cdot}+\mathrm{H}_{2} \mathrm{O}_{2} \\ \mathrm{H}_{2} \mathrm{O}_{2}+\mathrm{Fe}^{2+} \longrightarrow \mathrm{OH}^{\cdot}+\mathrm{OH}^{-}+\mathrm{Fe}^{2+} \text { (Fenton Reaction) }\end{array}$

(DA: Dopamine, MAO: Monoamine oxidase, SQ: Dopamine quinone)

Apart from the dopamine system, similar damage is seen in the 5-HT system with ROS generation being the major cause (Kita et al., 2003). 


\subsection{METH and sigma receptors}

Until today, there is no effective treatment for psychostimulant abuse. Exploration of a novel target for medication development, and to better understand the mechanisms of METHinduced neurotoxicity led to the discovery that METH interacts with sigma $(\sigma)$ receptors at physiologically relevant concentrations (Table 1.1) (Itzhak, 1993; Nguyen et al., 2005). $\sigma$ Receptors seem to play an important role in many of the effects of METH. They are found to be present in the organs that mediate the actions of METH (e.g. brain, heart, lungs) (Waterhouse et al., 1997). Additionally and more specifically, they are present in the areas of the brain that are damaged by METH (Gundlach et al., 1986).

\section{Table 1.1: Binding affinity of METH for $\sigma$ receptors}

\begin{tabular}{|c|c|c|}
\hline & $\sigma-1$ Receptors $(\mu \mathrm{M})$ & $\sigma-2$ Receptors $(\mu \mathrm{M})$ \\
\hline METH & $2.16 \pm 0.25$ & $46.67 \pm 10.34$ \\
\hline
\end{tabular}

(Nguyen et al., 2005)

Previous studies underscored the importance of targeting $\sigma$ receptors to attenuate some of the behavioral effects of METH in rodent models:

1.4.1 Locomotor stimulant effect: $\sigma-1$ Receptor antisense and antagonists like BD1047 (N[2-(3,4-dichlorophenyl)ethyl]-N-methyl-2-(dimethylamino)ethylamine) and BD1063 (1[2-(3,4-dichlorophenyl)ethyl]-4-methylpiperazine) attenuate METH-induced locomotor stimulation (Nguyen et al., 2005).

1.4.2 Sensitization: $\sigma$ Receptor antagonists like MS377 [(R)-(1)-1-(4-chlorophenyl)-3-[4-(2methoxyethyl)piperazin-1-yl]methyl-2-pyrrolidinone-L-tartrate] and BMY14802 (alpha(4-fluorophenyl)-4-(5-fluoro-2-pyrimidinyl)-1-piperazine-butanol) prevent the 
development of behavioral sensitization to METH (Ujike et al., 1992; Takahashi et al., 2000).

1.4.3 Self administration: Chronic self administration of METH in rats causes an upregulation of $\sigma-1$ receptors and $\mathrm{mRNA}$ in various brain regions including the substantia nigra, frontal cortex, cerebellum, midbrain, and hippocampus (Stefanski et al., 2004; Hayashi et al., 2010).

\section{$1.5 \sigma$ Receptors}

$\sigma$ Receptors are a unique group of drug binding sites (Matsumoto et al., 2003). They were first proposed by the group of Martin in 1976 (Martin et al., 1976). They were called $\sigma$ after the first letter ' $S$ ' of SKF-10047, which was then considered a prototypic $\sigma$ ligand. $\sigma$ Receptors represent a unique class of proteins that are non-opioidergic and non-N-methyl-Daspartate (NMDA) receptors (Vaupel, 1983). They possess a unique drug binding profile and anatomical distribution which is very different from the other mammalian proteins (Matsumoto et al., 2003; Guitart et al., 2004). They are found extensively in the brain and periphery (Guitart et al., 2004). Through various biochemical and pharmacological experiments, the two subtypes of $\sigma$ receptors, $\sigma-1$ and $\sigma-2$, were characterized (Bowen et al., 1989; Hellewell and Bowen, 1990; Walker et al., 1992).

1.5.1 $\sigma-1$ Receptors: They have been cloned and are not homologous to any known protein except for sharing 30\% homology with fungal sterol isomerase (Moebius et al., 1996), but do not possess isomerase activity. They have a 223 amino acid sequence with a double transmembrane structure (Kekuda et al., 1996; Prasad et al., 1998; Seth et al., 1998) and a molecular weight of $25 \mathrm{kDa}$ (Hellewell and Bowen, 1990). Following the binding of ligands, $\sigma-1$ receptors have been shown to operate via protein-protein interactions and translocation between subcellular compartments through chaperone-like functions (Hayashi and Su, 2003a; 
Hayashi and Su, 2007; Su et al., 2010), modulation of G-protein coupled receptors, ion channels and signaling molecules like $\mathrm{IP}_{3}$, protein kinases and calcium (Morin-Surun et al., 1999; Aydar et al., 2002; Hayashi and Su, 2003a; Hayashi and Su, 2007).

1.5.2 $\underline{\sigma-2}$ Receptors: In contrast to $\sigma-1$ receptors, much less is known about $\sigma-2$ receptors, due to a lack of selective ligands and also because they have not yet been cloned. Using photoaffinity labeling studies, $\sigma-2$ receptors have been found to be $18-22 \mathrm{kDa}$ in molecular weight (Hellewell et al., 1994). At the cellular level, they are localized in lipid rafts, the plasma membrane, endoplasmic reticulum (ER), mitochondria, and lysosomes of cells (Gebreselassie and Bowen, 2004; Zeng et al., 2007). $\sigma-2$ Receptors are highly upregulated in rapidly dividing tumor cell lines and have a role in cell death signaling via sphingolipid products (Mach et al., 1997; Bowen, 2000), calcium signaling (Vilner and Bowen, 2000; Cassano et al., 2009), and oxidative stress (Ostenfeld et al., 2005; Hornick et al., 2010). Recent studies also show that they can be valuable in chemotherapy and for tumor imaging studies (John et al., 1999; Bowen, 2000; Tu et al., 2010).

A recent study has proposed $\sigma-2$ receptors to be a binding site in the PGRMC1 (progesterone receptor membrane component 1) complex (Xu et al., 2011). PGRMC1 like $\sigma-2$ receptors are highly expressed in tumor cells in comparison to normal cells (Bowen, 2000; Cahill, 2007). They both are studied as important cancer biomarkers and potential therapeutic targets for anticancer drugs (Bowen, 2000; Cahill, 2007; Mir et al., 2011). This study is very promising given the lack of molecular biology tools to study $\sigma-2$ receptors. The novel compounds used in this study are selective for $\sigma-2$ over $\sigma-1$ receptors. However, additional selectivity profile of those tested compounds over other non-sigma sites may have to be determined in order to further establish the claim. 


\subsection{Sigma receptor ligands: agonist/antagonist}

Several functional studies have been conducted in different systems to characterize agonists and antagonists at $\sigma$ receptors. In classical pharmacological terms, an agonist at a receptor produces a response, whereas an antagonist is able to inhibit the action of agonist without producing any effect on its own. An antagonist causes a concentration-dependent parallel rightward shift in the dose response curve of an agonist. Among some of the early studies, classical $\sigma$ ligands like di-o-tolylguanidine (DTG), (+)-pentazocine, and (+)-SKF 10047 caused a dystonic reaction when injected into the red nucleus of rats, and also increased the burst duration of red nucleus neurons following electrical stimulation of cerebellorubrospinal circuits (Matsumoto et al., 1990; Matsumoto et al., 1999). Data such as these suggested that classical compounds, such as DTG and (+)-pentazocine, act as agonists at $\sigma$ receptors. In contrast, other $\sigma$ compounds like BD1047 and BD1063 decreased the burst duration of red nucleus neurons following stimulation of cerebellorubrospinal circuits (Matsumoto et al., 1999). In addition, when tested in vivo, BD1047 and BD1063 did not show any behavioral effects when injected into the red nucleus of rats, but they prevented the dystonic reactions produced by putative $\sigma$ receptor agonists such as DTG (Matsumoto et al., 1995). Therefore, these latter compounds were termed as putative antagonists.

Using these types of classical designations, the putative agonist actions of many compounds, including DTG and (+)-pentazocine, were demonstrated in other model systems. Putative antagonist actions of compounds such as BD1047 and BD1063 were also confirmed. As one example, $\sigma$ receptor agonists have also been shown to modulate the activity of Gproteins by indirectly enhancing GTPYS binding (Joseph and Bowen, 1998). $\sigma$ Receptor antagonists such as BD1047 and BD1063 do not produce any effects on their own, but are able to attenuate these agonist-stimulated effects on GTPYS binding (Joseph and Bowen, 1998). Similar patterns have also been shown with regard to $\sigma$ receptor agonist-induced 
cognitive enhancing effects which can be prevented by $\sigma$ receptor antagonists (Hashimoto et al., 2007). $\sigma$ Receptor agonists can also promote NGF-induced neurite outgrowth, and this effect is attenuated in the presence of antagonists (Takebayashi et al., 2002).

Recent studies suggest that, at a subcellular level sigma-1 receptor acts as a ligandoperated chaperone at the mitochondria associated ER membrane (MAM) (Hayashi and Su, 2007). At MAM, sigma-1 receptor is found to be associated with another chaperone protein, BiP. Sigma-1 receptor agonists like (+)Pentazocine, (+)SKF-10047 and PRE-084 cause sigma-1 and BiP dissociation, whereas sigma-1 receptor antagonists like NE-100, Progesterone and haloperidol inhibit agonist induced dissociation of sigma-1 and BiP (Hayashi and Su, 2007).

In some later studies, these antagonists were also able to attenuate various behavioral effects of cocaine (Matsumoto et al., 2003), presumably by interfering with the access of cocaine to one of its binding sites, the $\sigma$ receptor (Sharkey et al., 1988). This antagonistic effect through $\sigma$ receptors against cocaine was confirmed by the use of antisense oligonucleotides (ONs) targeting $\sigma-1$ receptors, which led to a reduction in the expression of $\sigma-1$ receptors in the brain by about 40\% (Matsumoto et al., 2001; Matsumoto et al., 2002; Matsumoto et al., 2003). By reducing access of drugs to their target sites, the antisense ONs would be expected to act functionally like pharmacological antagonists. This was indeed confirmed, where reductions in $\sigma-1$ receptors by antisense $\mathrm{ONs}$ also resulted in the attenuation of the behavioral effects of cocaine (Matsumoto et al., 2001). Similar effects were also observed with behavioral effects of METH (as mentioned before), where $\sigma$ receptor antisense ONs or antagonists attenuated the METH-induced locomotor stimulant (Nguyen et al., 2005) and sensitized response (Ujike et al., 1992; Takahashi et al., 2000). Similar confirmation of effects by putative antagonists and antisense ONs were obtained in other 
model systems, including the cognitive enhancing and neurite outgrowth effects mentioned above. Together, the body of literature provides converging lines of evidence to support the designation of antagonist and agonist effects of $\sigma$ receptor ligands, which were first assigned using classical pharmacological definitions. Therefore, with regard to their actions through $\sigma$ receptors, METH is considered a $\sigma$ receptor agonist, whereas $\sigma$ receptor ligands that can block the effects of METH are considered putative antagonists. For all of these definitions, validation of the robustness of the effects across multiple model systems is important.

\subsection{Potential involvement of $\sigma$ receptors in the mechanisms of METH-induced neurotoxicity}

Mechanistically, the neurotoxic effects of METH seem to involve the activation of certain events such as dopamine and $5-\mathrm{HT}$ release, oxidative stress, ER stress and mitochondrial death cascades, excitotoxicity, microglial activation, and hyperthermia (Krasnova and Cadet, 2009). In addition, compelling evidence in the literature indicates that apart from being a direct target of METH, $\sigma$ receptors play an important role in the modulation of other neurotransmitter systems and downstream events involved in METH-induced neurotoxicity. Systematic mechanistic studies, however, have not been conducted in the context of METH. Below are mentioned some of the mechanisms involved in the neurotoxic effects of METH and the potential role that $\sigma$ receptors can play based on evidence from independent studies in the literature. In those instances where the role of an individual subtype of $\sigma$ receptor is known, the subtype is specified. Otherwise, the term $\sigma$ receptor, with no subtype designation, is used. Figure 1.4 shows various pathways of METH's neurotoxicity and the steps at which $\sigma$ receptors could potentially act.

1.7.1 Dopamine and 5-HT release: METH acts through DAT, SERT and VMAT2 to cause excessive release of dopamine and 5-HT into the cytoplasm and synapse (Stephans and 
Yamamoto, 1994; Riddle et al., 2006), which is thought to be one of the initiating factors in METH's neurotoxic cascade.

$\sigma$ Receptors are found in the dopaminergic nerve terminals and cell bodies in the brain (Gundlach et al., 1986) and stimulate dopamine synthesis and release (Booth and Baldessarini, 1991; Bastianetto et al., 1995; Weiser et al., 1995). $\sigma$ Receptor agonists have been shown to facilitate dopamine release, through both $\sigma-1 / 2$ receptors (Booth and Baldessarini, 1991; Bastianetto et al., 1995; Weiser et al., 1995; Derbez et al., 2002). б-2 Receptors modulate DAT and the release of dopamine via protein kinase $\mathrm{C}(\mathrm{PKC})$ and $\mathrm{Ca}^{2+}$ calmodulin systems (Derbez et al., 2002).

$\sigma$ Receptors are also present on 5-HT neurons and have been shown to modulate them (Campbell et al., 1989; Shirayama et al., 1993; Hashimoto et al., 1997).

1.7.2 Glutamate, NMDA and excitotoxicity: Glutamate release and excitotoxic mechanisms have also been implicated in METH-induced neurotoxicity (Krasnova and Cadet, 2009). $\sigma$ Receptors have an important role in modulating the glutamatergic NMDA system and display neuroprotective effects against excitotoxic mechanisms in ischemic stroke models, midbrain and cortical dopaminergic neurons, and retinal ganglion cells (DeCoster et al., 1995; Shimazu et al., 2000; Dun et al., 2007; Shen et al., 2008).

1.7.3 Reactive oxygen and nitrogen species: After excessive dopamine release, autooxidation reactions lead to the formation of harmful ROS, including dopamine quinones, superoxide radicals, hydroxyl radicals, and hydrogen peroxide (Krasnova and Cadet, 2009). Additionally, excessive NMDA receptor stimulation by glutamate causes production of superoxide and nitric oxide (NO) production by activation of neuronal nitric oxide synthase (nNOS) (Lafon-Cazal et al., 1993a; Lafon-Cazal et al., 1993b; Gunasekar et al., 1995).

These ROS can injure neurons and surrounding cells via oxidative damage to cellular components such as lipids, proteins, and DNA (Krasnova and Cadet, 2009). Excess 5-HT also 
leads to the generation of ROS (Wrona et al., 1997; Jiang et al., 1999) and cause similar damage.

$\sigma-2$ Receptor activation has been shown to cause the release of ROS in tumor cells (Ostenfeld et al., 2005; Hornick et al., 2010). In contrast, $\sigma$ receptor antagonism affords protection in brain ischemia, a condition in which ROS are generated (Schetz et al., 2007). In addition, recent studies suggest that $\sigma$ receptors can modulate nNOS activity in animal models of stroke (Yang et al., 2010). These studies indicate a potential connection between $\sigma$ receptors and oxidative/nitrosative stress mechanisms of $\mathrm{METH}$-induced neurotoxicity.

\subsubsection{ER stress, calcium and mitochondrial death cascades: METH causes ER stress and} activation of mitochondrial death cascades partly due to increases in oxidative stress in the cell (Jayanthi et al., 2004). ER stress causes disturbances in cellular calcium homeostasis (Gorlach et al., 2006). ER stress and calcium dysregulation contributes to cell death observed due to METH (Jayanthi et al., 2004). Sustained ER stress and excessive calcium efflux in turn can contribute to METH-induced apoptosis via mitochondrial pore permeabilization (Jayanthi et al., 2004; Kroemer et al., 2007).

$\sigma$ Receptors are located on the ER and mitochondria (Guitart et al., 2004; Zeng et al., 2007). $\sigma-1$ Receptors have been shown to function as chaperones at the mitochondrialassociated ER membrane (MAM). At MAM, $\sigma-1$ receptors play an important role in regulating calcium levels via $\mathrm{IP}_{3}$ receptors and maintaining homeostasis in the cell against oxidative stress and perturbations in calcium (Hayashi and Su, 2007). On the other hand, $\sigma-2$ receptor activation has been shown to cause a biphasic flux of calcium from the ER and mitochondrial stores which leads to apoptotic cell death (Vilner and Bowen, 2000; Cassano et al., 2009).

1.7.5 Apoptotic factors: METH causes apoptotic cell death in certain brain areas including the striatum, cortex, and hippocampus (Deng et al., 2001). The apoptotic process can be either caspase-dependent or independent (Jayanthi et al., 2004). 
б-2 Receptor activation has been shown to cause apoptosis in tumor cells via caspase-dependent and independent processes, depending on the cell type (Bowen, 2000; Crawford and Bowen, 2002). $\sigma-2$ Receptor activation has also been shown to cause apoptotic cell death in tumor cells via alterations in cellular sphingolipid levels (Crawford et al., 2002). In contrast, $\sigma-1$ receptor agonists have been shown to have neuroprotective effects by regulating intracellular calcium levels and preventing activation of pro-apoptotic genes in retinal ganglion cells (Tchedre and Yorio, 2008). $\sigma-1$ Receptor agonists have also been reported to preserve protective genes like bcl-2 in a cerebral focal ischemia model (Yang et al., 2007). $\sigma$ Receptor ligands have been shown to cause cytotoxicity and apoptotic cell death in various cell lines, including rat C6 glioma cells, NG108-15 neuroblastoma-glioma, SK-N-SH neuroblastoma, SHSY5Y neuroblastoma, PC12 pheochromocytoma and COS-7 (Crawford and Bowen, 2002; Crawford et al., 2002).

1.7.6 Microglial activation: Recent studies have underscored the role of accessory cells like microglia in METH-induced neurotoxicity (Thomas et al., 2004; Sekine et al., 2008). Microglial activation has been observed in areas of the brain that have been damaged by METH (Thomas et al., 2004; Sekine et al., 2008). Drugs that attenuate neurotoxic effects also suppress microglial activation (Krasnova and Cadet, 2009). However, the mechanisms by which microglia influence METH's neurotoxic effects are still not very clear. Release of cytokines and ROS/RNS have been suggested as possible contributing mechanisms (Krasnova and Cadet, 2009).

$\sigma$ Receptors are found on microglia and can modulate microglial activation, membrane ruffling and migration (Hall et al., 2009). The subtype of sigma receptors involved in this effect is not clear and additional experiments will need to be performed to address this issue.

1.7.7 Hyperthermia: METH increases body temperature, which is known to exacerbate neurotoxic effects (Bowyer et al., 1994). The production of ROS and release of cytokines like 
IL1 $\beta$ have been implicated in the generation of METH's hyperthermia (Bowyer et al., 1994; Imam et al., 1999; Riedel and Maulik, 1999; Yamashita et al., 2000; Fukami et al., 2004). Moreover, dopaminergic and serotonergic systems are likewise implicated in METH-induced body temperature alterations (Numachi et al., 2007). $\sigma$ Receptor ligands, with their ability to modulate these neurotransmitter systems, cytokines, as well as ROS, can attenuate elevations in body temperature (Campbell et al., 1989; Bastianetto et al., 1995; Derbez et al., 2002; Schetz et al., 2007; Matsumoto et al., 2008). Additionally, $\sigma$ receptors are located in the hypothalamic brain region and have previously been shown to modulate body temperature (Gundlach et al., 1986; Rawls et al., 2002). A combination of all these factors may explain how $\sigma$ receptors can regulate METH-induced hyperthermia.

\subsubsection{Other mechanisms:}

1.7.8.1 Cytoskeleton: METH-induced nerve terminal damage involves the cleavage of cytoskeletal proteins (Wallace et al., 2003). $\sigma-1$ Receptors are found in association with ankyrin, which is a cytoskeletal adaptor protein (Hayashi and Su, 2001).

1.7.8.2 Neurotrophic factors: $\sigma$ Receptors can play a role in signal amplification in several systems especially that of neuotrophins, which are involved in the survival and differentiation of neurons (Cass et al., 2006). $\sigma-1$ Receptor activation enhances BDNF signaling which has a protective role against METH-induced neurotoxicity (Matsuzaki et al., 2004; Yagasaki et al., 2006). 
Figure 1.4: Potential involvement of $\sigma$ receptors in the mechanisms of METH-induced neurotoxicity

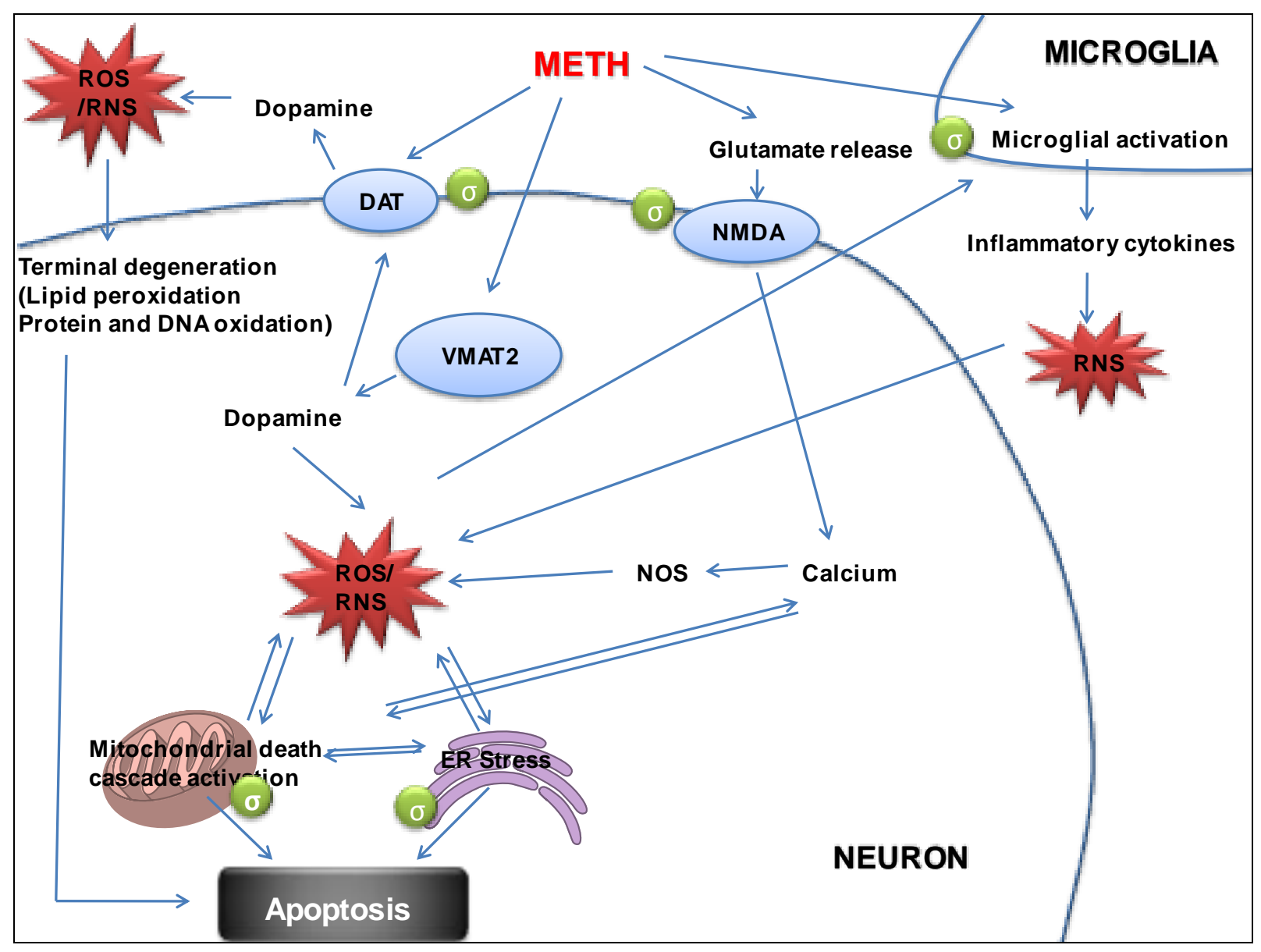




\subsection{AC927, CM156 and SN79}<smiles>c1ccc(CCN2CCCCC2)cc1</smiles>

AC927 (N-phenethylpiperidine oxalate)

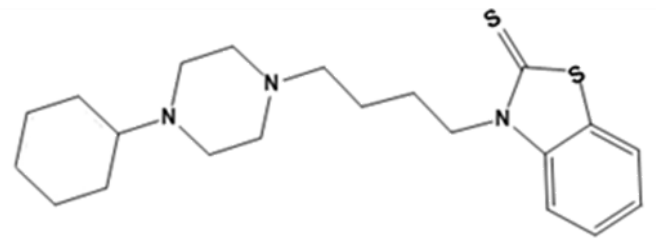

CM156 (3-(4-(4-cyclohexylpiperazin-1-yl)butyl)benzo[d] thiazole-2(3H)-thione)

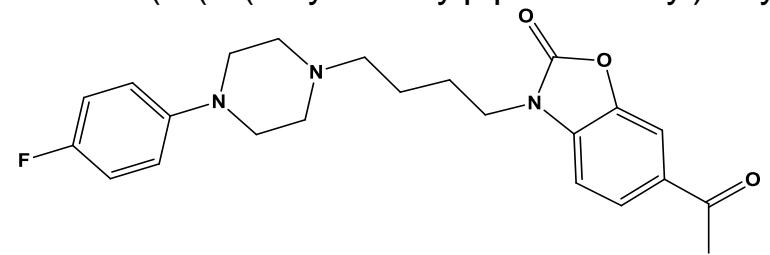

SN79 (6-acetyl-3-(4-(4-(4-florophenyl)piperazin-1-yl)butyl)benzo[d]oxazol-2(3H)-one)

AC927 (N-phenethylpiperidine oxalate), CM156 (3-(4-(4-cyclohexylpiperazin-1yl)butyl)benzo[d] thiazole-2(3H)-thione) and SN79 (6-acetyl-3-(4-(4-(4-florophenyl)piperazin-1yl)butyl)benzo[d]oxazol-2(3H)-one) were synthesized to have high affinity and selectivity for $\sigma$ receptors over other non- $\sigma$ sites (Maeda et al., 2002; Mesangeau et al., 2008; Kaushal et al., 2011a). The affinities of AC927, CM156 and SN79 for $\sigma-1 / 2$ receptors, as well as other receptors, transporters, ion channels and binding sites are listed in Table 1.2. All these compounds have been previously tested against the behavioral effects of cocaine and were found to function as antagonists at $\sigma$ receptors (Xu et al., 2010; Kaushal et al., 2011a; Matsumoto et al., 2011).

1.8.1 Receptor binding assays: The affinity of the novel compounds for $\sigma$ receptors and other non- $\sigma$ binding sites was determined by conducting competition binding assays in 
tissues or cells that were heavily concentrated with the respective proteins of interest. This assay is based on the principle of competition between a radiolabelled ligand (specific for that site) and an unlabelled ligand for binding to a receptor or transporter.

Table 1.2 shows the results obtained from radioligand binding studies for AC927, CM156 and SN79. AC927 has nanomolar affinity for $\sigma-1 / 2$ receptors and micromolar to negligible affinity for the other sites tested. CM156 has high affinity for both $\sigma-1 / 2$ receptors in the nanomolar and subnanomolar range. Compared to its high affinity for $\sigma$ receptors, CM156 had $\geq 1000$-fold weaker affinity for other non- $\sigma$ binding sites tested. SN79 has high nanomolar affinity for $\sigma-1 / 2$ receptors. However, SN79 also exhibits moderate affinity for $5-\mathrm{HT}_{2}$ receptors, SERT and norepinephrine transporters (NET), as well as some affinity for DAT. For all other sites listed in Table 1.2, SN79 displayed negligible affinity (>10,000 nM affinity or $>1,000$-fold selectivity compared to $\sigma$ binding). 
Table 1.2: Binding affinity of AC927, CM156 and SN79 for $\sigma$ and non- $\sigma$ sites

\begin{tabular}{|c|c|c|c|c|c|c|}
\hline \multirow{2}{*}{\begin{tabular}{|c|} 
Binding Site \\
Sigma receptors:
\end{tabular}} & Radioligand & \multirow{2}{*}{\multicolumn{2}{|c|}{ Nonspecific binding }} & \multicolumn{3}{|c|}{$\mathbf{K}_{\mathbf{i}}$} \\
\hline & & & & AC927 & CM156 & SN79 \\
\hline$\sigma_{1}$ & $\begin{array}{l}5 \mathrm{nM}\left[{ }^{3} \mathrm{H}\right](+)- \\
\text { pentazocine }\end{array}$ & $\begin{array}{l}10 \mu \mathrm{M} \\
\text { haloperidol }\end{array}$ & Rat brain & $30 \pm 2$ & $1.3 \pm 0.4$ & $27 \pm 2$ \\
\hline$\sigma_{2}$ & $\begin{array}{l}3 \mathrm{nM}\left[{ }^{3} \mathrm{H}\right] \mathrm{di}-\mathrm{O}- \\
\text { tolylguanidine }\end{array}$ & $\begin{array}{l}10 \mu \mathrm{M} \\
\text { haloperidol }\end{array}$ & Rat brain & $138 \pm 18$ & $0.6 \pm 0.1$ & $7 \pm 0.09$ \\
\hline \multicolumn{7}{|c|}{ Monoamine transporters: } \\
\hline Dopamine & $\begin{array}{l}0.5 \mathrm{nM}\left[{ }^{3} \mathrm{H}\right] \mathrm{WIN} \\
35,428\end{array}$ & $50 \mu \mathrm{M}$ cocaine & Rat striatum & $2939 \pm 452$ & $1175 \pm 100$ & $2610 \pm 57$ \\
\hline Serotonin & $\begin{array}{l}0.2 \mathrm{nM} \\
{\left[{ }^{3} \mathrm{H}\right] \text { paroxetine }}\end{array}$ & $\begin{array}{l}1.5 \mu \mathrm{M} \\
\text { imipramine }\end{array}$ & Rat brainstem & $>10,000$ & $1402 \pm 152$ & $159 \pm 15$ \\
\hline Norepinephrine & $\begin{array}{l}0.5 \mathrm{nM} \\
{\left[{ }^{3} \mathrm{H}\right] \text { nisoxetine }}\end{array}$ & $\begin{array}{l}4 \mu \mathrm{M} \\
\text { desipramine }\end{array}$ & $\begin{array}{l}\text { Rat cerebral } \\
\text { cortex }\end{array}$ & $8828 \pm 1197$ & $>10,000$ & $177 \pm 14$ \\
\hline \multicolumn{7}{|c|}{ Other neurotransmitter receptors: } \\
\hline Adenosine & $4.0 \mathrm{nM}\left[{ }^{3} \mathrm{H}\right] \mathrm{NECA}$ & $1 \mu \mathrm{M}$ NECA & Bovine striatum & $>10,000$ & $>10,000$ & $>10,000$ \\
\hline Adrenergic, beta 1 & $\begin{array}{l}0.04 \mathrm{nM}\left[{ }^{125} \mathrm{I}\right](- \\
\text { )iodocyanopindolol }\end{array}$ & $3 \mu \mathrm{M}$ alprenolol & $\begin{array}{l}\text { Human } \\
\text { Neuroepithelioma }\end{array}$ & $>10,000$ & $>10,000$ & $>10,000$ \\
\hline Cannabinoid, CB1 & $\begin{array}{l}0.5 \mathrm{nM}\left[{ }^{3} \mathrm{H}\right] \mathrm{CP} \\
55940\end{array}$ & $1 \mu \mathrm{M} \mathrm{HU}-210$ & $\begin{array}{l}\text { Human } \\
\text { recombinant } \\
\text { HEK293 cells }\end{array}$ & ND & $>10,000$ & $>10,000$ \\
\hline Cannabinoid, CB2 & $\begin{array}{l}0.5 \mathrm{nM}\left[{ }^{3} \mathrm{H}\right] \mathrm{CP} \\
55940\end{array}$ & $1 \mu \mathrm{M} \mathrm{HU}-210$ & $\begin{array}{l}\text { Human } \\
\text { recombinant } \\
\mathrm{CHO} \text { cells } \\
\end{array}$ & ND & $>10,000$ & $>10,000$ \\
\hline Dopamine $\mathrm{D}_{2}$ & $\begin{array}{l}5 \mathrm{nM}\left[{ }^{3} \mathrm{H}\right](-)- \\
\text { sulpiride }\end{array}$ & $1 \mu \mathrm{M}$ haloperidol & Rat brain & $>10,000$ & $1041 \pm 9$ & $>10,000$ \\
\hline $\begin{array}{l}\text { GABA A, agonist } \\
\text { site }\end{array}$ & $5 \mathrm{nM}\left[{ }^{3} \mathrm{H}\right] \mathrm{GABA}$ & $1 \mu \mathrm{M}$ GABA & $\begin{array}{l}\text { Bovine } \\
\text { cerebellum }\end{array}$ & $>10,000$ & $>10,000$ & $>10,000$ \\
\hline $\begin{array}{l}\text { GABA A, BDZ } \\
\text { alpha } 1\end{array}$ & $\begin{array}{l}\mathrm{nM} \\
{\left[{ }^{3} \mathrm{H}\right] \text { flunitrazepam }}\end{array}$ & $\begin{array}{l}0.5 \mu \mathrm{M} \\
\text { flumazenil }\end{array}$ & Bovine cortex & ND & $>10,000$ & $>10,000$ \\
\hline GABA-B & $\begin{array}{l}1 \mathrm{nM}\left[{ }^{3} \mathrm{H}\right] \mathrm{CGP} \\
54626 \mathrm{~A}\end{array}$ & $100 \mu \mathrm{M}$ baclofen & $\begin{array}{l}\text { Rat cerebral } \\
\text { cortex }\end{array}$ & ND & $>10,000$ & $>10,000$ \\
\hline Glutamate, AMPA & $5 \mathrm{nM}\left[{ }^{3} \mathrm{H}\right] \mathrm{AMPA}$ & $100 \mu \mathrm{M}$ AMPA & Rat forebrain & ND & $>10,000$ & $>10,000$ \\
\hline Glutamate, kainite & $\begin{array}{l}10 \mathrm{nM}\left[{ }^{3} \mathrm{H}\right] \text { kainic } \\
\text { acid }\end{array}$ & $10 \mu \mathrm{M}$ kainic acid & Rat forebrain & ND & $>10,000$ & $>10,000$ \\
\hline $\begin{array}{l}\text { Glutamate, NMDA } \\
\text { agonist }\end{array}$ & $\begin{array}{l}2 \mathrm{nM}\left[{ }^{3} \mathrm{H}\right] \mathrm{CGP} \\
39653\end{array}$ & $300 \mu \mathrm{M}$ NMDA & Rat forebrain & $>10,000$ & $>10,000$ & $>10,000$ \\
\hline $\begin{array}{l}\text { Glutamate, NMDA } \\
\text { glycine }\end{array}$ & $\begin{array}{l}4 \mathrm{nM}\left[{ }^{3} \mathrm{H}\right] \mathrm{MDL}- \\
105,519\end{array}$ & $\begin{array}{l}3 \mu \mathrm{M} \text { MDL- } \\
105,519\end{array}$ & Rat cortex/hippoc & ND & $>10,000$ & $>10,000$ \\
\hline \multirow[t]{2}{*}{$\begin{array}{l}\text { Glutamate, } \\
\text { NMDA/PCP }\end{array}$} & $10 \mathrm{nM}\left[{ }^{3} \mathrm{H}\right] \mathrm{TCP}$ & $\begin{array}{l}100 \mu \mathrm{M}(+)- \\
\mathrm{MK} 801\end{array}$ & Rat forebrain & ND & $>10,000$ & $>10,000$ \\
\hline & $5 \mathrm{nM}\left[{ }^{3} \mathrm{H}\right] \mathrm{TCP}$ & $\begin{array}{l}10 \mu \mathrm{M} \\
\text { cyclazocine }\end{array}$ & Rat brain & ND & $>10,000$ & $>10,000$ \\
\hline $\begin{array}{l}\text { Glutamate, } \\
\text { mGluR1 }\end{array}$ & $\begin{array}{l}20 \mathrm{nM} \\
{\left[{ }^{3} \mathrm{H}\right] q u i s q u a l i c} \\
\end{array}$ & $\begin{array}{l}1 \mathrm{mM} \mathrm{L-} \\
\text { glutamate }\end{array}$ & Rat cerebellum & ND & $>10,000$ & $>10,000$ \\
\hline \begin{tabular}{|l|} 
Glutamate, \\
mGluR5
\end{tabular} & $10 \mathrm{nM}\left[{ }^{3} \mathrm{H}\right] \mathrm{MPEP}$ & $10 \mu \mathrm{M}$ MPEP & Rat brain & ND & $>10,000$ & $>10,000$ \\
\hline Glycine,strychnine & $\begin{array}{l}16 \mathrm{nM} \\
{\left[{ }^{3} \mathrm{H}\right] \text { strychnine }} \\
\end{array}$ & $\begin{array}{l}100 \mu \mathrm{M} \\
\text { strychnine nitrate }\end{array}$ & Rat spinal cord & ND & $>10,000$ & $>10,000$ \\
\hline Histamine $\mathrm{H}_{2}$ & $\begin{array}{l}0.1 \mathrm{nM} \\
{\left[{ }^{125} \text { I]aminopotentidin }\right.} \\
\mathrm{e}\end{array}$ & $3 \mu \mathrm{M}$ tiotidine & $\begin{array}{l}\text { Guinea pig } \\
\text { striatum }\end{array}$ & ND & 2570 & $>10,000$ \\
\hline Muscarinic, central & $0.15 \mathrm{nM}\left[{ }^{3} \mathrm{H}\right] \mathrm{QNB}$ & $0.1 \mu \mathrm{M}$ atropine & $\begin{array}{l}\text { Rat cerebral } \\
\text { cortex }\end{array}$ & $>10,000$ & 3080 & $>10,000$ \\
\hline \begin{tabular}{|l} 
Muscarinic, \\
peripheral
\end{tabular} & $0.3 \mathrm{nM}\left[{ }^{3} \mathrm{H}\right] \mathrm{QNB}$ & $0.1 \mu \mathrm{M}$ atropine & $\begin{array}{l}\text { Guinea pig } \\
\text { bladder }\end{array}$ & $>10,000$ & 2155 & $>10,000$ \\
\hline
\end{tabular}




\begin{tabular}{|c|c|c|c|c|c|c|}
\hline Muscarinic $\mathrm{M}_{1}$ & $\begin{array}{l}0.5 \mathrm{nM}\left[{ }^{3} \mathrm{H}\right] \mathrm{N} \text {-methyl } \\
\text { scopolamine }\end{array}$ & $\begin{array}{l}1 \mu \mathrm{M}(- \\
\text { )scopolamine }\end{array}$ & $\begin{array}{l}\text { Human } \\
\text { recombinant } \\
\text { CHO cells }\end{array}$ & ND & $>10,000$ & $>10,000$ \\
\hline Muscarinic $\mathrm{M}_{2}$ & $\begin{array}{l}0.5 \mathrm{nM}\left[{ }^{3} \mathrm{H}\right] \mathrm{N} \text {-methyl } \\
\text { scopolamine }\end{array}$ & \begin{tabular}{|l|}
$1 \mu \mathrm{M}$ \\
methylscopolami \\
ne
\end{tabular} & $\begin{array}{l}\text { Human } \\
\text { recombinant } \\
\text { CHO cells }\end{array}$ & ND & 1210 & $>10,000$ \\
\hline Nicotinic, muscle & $\begin{array}{l}1 \mathrm{nM}\left[{ }^{125} \mathrm{I}\right] \alpha- \\
\text { bungarotoxin }\end{array}$ & $10 \mu \mathrm{M}$ nicotine & $\begin{array}{l}\text { Human TE671 } \\
\text { cells }\end{array}$ & ND & $>10,000$ & $>10,000$ \\
\hline Nicotinic, neuronal & $\begin{array}{l}0.05 \mathrm{nM} \\
{\left[{ }^{3} \mathrm{H}\right] \text { epibatidine }}\end{array}$ & $\begin{array}{l}20 \mathrm{nM} \\
\text { epibatidine }\end{array}$ & $\begin{array}{l}\text { Human SK-N-F1 } \\
\text { cells }\end{array}$ & ND & $>10,000$ & $>10,000$ \\
\hline $\begin{array}{l}\text { Opioid, non- } \\
\text { selective }\end{array}$ & $\begin{array}{l}0.5 \mathrm{nM} \\
{\left[{ }^{3} \mathrm{H}\right] \text { bremazocine }} \\
1 \mathrm{nM}\left[{ }^{3} \mathrm{H}\right] \text { naloxone }\end{array}$ & $\begin{array}{l}10 \mu \mathrm{M} \\
\text { levallorphan } \\
1 \mu \mathrm{M} \text { naloxone }\end{array}$ & $\begin{array}{l}\text { Rat brain } \\
\text { Rat forebrain }\end{array}$ & $\begin{array}{l}>10,000 \\
>10,000\end{array}$ & $\begin{array}{l}>10,000 \\
>10,000\end{array}$ & $\begin{array}{l}>10,000 \\
>10,000\end{array}$ \\
\hline $5-\mathrm{HT}_{2}$ & $2 \mathrm{nM}\left[^{3} \mathrm{H}\right]$ ketanserin & $1 \mu \mathrm{M}$ mianserin & Rat brain & $>10,000$ & $1376 \pm 159$ & $321 \pm 16$ \\
\hline \multicolumn{7}{|c|}{ Hormone, peptide, steroid receptors: } \\
\hline Angiotensin II, $\mathrm{AT}_{1}$ & $\begin{array}{l}0.06 \mathrm{nM}\left[{ }^{125} \mathrm{I}\right]\left(\mathrm{Sar}^{1}-\right. \\
\left.\mathrm{lle}^{8}\right) \text { angiotensin }\end{array}$ & $\begin{array}{l}1 \mu \mathrm{M} \text { angiotensin } \\
\text { II }\end{array}$ & $\begin{array}{l}\text { Human KAN-TS } \\
\text { cells }\end{array}$ & ND & $>10,000$ & $>10,000$ \\
\hline Angiotensin II, $\mathrm{AT}_{2}$ & $\begin{array}{l}0.1 \mathrm{nM}\left[{ }^{125} \mathrm{I}\right] \mathrm{Tyr}^{4}- \\
\text { angiotensin II }\end{array}$ & \begin{tabular}{|l|}
$0.05 \mu \mathrm{M}$ \\
angiotensin II \\
\end{tabular} & $\begin{array}{l}\text { Bovine } \\
\text { cerebellum }\end{array}$ & ND & $>10,000$ & $>10,000$ \\
\hline Bradykinin, $\mathrm{BK}_{2}$ & $\begin{array}{l}0.2 \mathrm{nM} \\
{\left[{ }^{3} \mathrm{H}\right] \text { bradykinin }}\end{array}$ & $\begin{array}{l}100 \mathrm{nM} \\
\text { bradykinin TFA }\end{array}$ & Guinea pig ileum & ND & $>10,000$ & $>10,000$ \\
\hline $\begin{array}{l}\text { Cholecystokinin, } \\
\text { CCK }_{\mathrm{A}}\end{array}$ & 0.02 nM [ ${ }^{125}$ I]CCK-8 & $1 \mu \mathrm{M}$ CCK-8 & Mouse pancreas & ND & $>10,000$ & $>10,000$ \\
\hline $\begin{array}{l}\text { Cholecystokinin, } \\
\text { CCK }_{B}\end{array}$ & 0.02 nM [ ${ }^{125}$ I]CCK-8 & $1 \mu \mathrm{M}$ CCK- 8 & Mouse forebrain & ND & $>10,000$ & $>10,000$ \\
\hline $\begin{array}{l}\text { CRF, non- } \\
\text { selective } \\
\end{array}$ & $\begin{array}{l}0.1 \mathrm{nM}\left[{ }^{125} \mid\right] \mathrm{Tyr}^{0}- \\
\text { Ocrf }\end{array}$ & $1 \mu \mathrm{M} \mathrm{Tyr}{ }^{0}$-oCRF & $\begin{array}{l}\text { Rat cerebral } \\
\text { cortex }\end{array}$ & ND & $>10,000$ & $>10,000$ \\
\hline Endothelin, $\mathrm{ET}_{\mathrm{A}}$ & $\begin{array}{l}0.033 \mathrm{nM} \\
{\left[{ }^{125} \mid\right] \text { endothelin-1 }}\end{array}$ & $\begin{array}{l}0.1 \mu \mathrm{M} \\
\text { endothelin-1 }\end{array}$ & $\begin{array}{l}\text { Human } \\
\text { neuroblastoma }\end{array}$ & ND & $>10,000$ & $>10,000$ \\
\hline Endothelin, $\mathrm{ET}_{\mathrm{B}}$ & $\begin{array}{l}0.025 \mathrm{nM} \\
\left.{ }^{125} \mid\right] \text { endothelin-1 }\end{array}$ & $\begin{array}{l}0.1 \mu \mathrm{M} \\
\text { endothelin-1 }\end{array}$ & $\begin{array}{l}\text { Human } \\
\text { astrocytoma }\end{array}$ & ND & $>10,000$ & $>10,000$ \\
\hline Estrogen & $\begin{array}{l}0.1 \mathrm{nM}\left[{ }^{125} \mid\right] 3,7 \beta- \\
\text { estradiol }\end{array}$ & $\begin{array}{l}10 \mathrm{nM} 17 \beta- \\
\text { estadiol }\end{array}$ & $\begin{array}{l}\text { Human breast } \\
\text { cancer }\end{array}$ & ND & $>10,000$ & $>10,000$ \\
\hline $\begin{array}{l}\text { Galanin, non- } \\
\text { selective }\end{array}$ & $0.07 \mathrm{nM}\left[{ }^{125} \mathrm{I}\right]$ galanin & $\begin{array}{l}100 \mathrm{nM} \text { galanin } \\
\text { (porcine) }\end{array}$ & Rat brain & ND & $>10,000$ & $>10,000$ \\
\hline Glucocorticoid & $\begin{array}{l}1 \mathrm{nM} \\
{\left[{ }^{3} \mathrm{H}\right] \text { dexamethasone }}\end{array}$ & $\begin{array}{l}10 \mu \mathrm{M} \\
\text { triamcinolone }\end{array}$ & $\begin{array}{l}\text { Human } \\
\text { recombinant }\end{array}$ & ND & $>10,000$ & $>10,000$ \\
\hline Neurokinin, $\mathrm{NK}_{1}$ & $\begin{array}{l}1.4 \mathrm{nM} \\
{\left[{ }^{3} \mathrm{H}\right] \text { substance } \mathrm{P}}\end{array}$ & $\begin{array}{l}1 \mu \mathrm{M} \text { substance } \\
\mathrm{P}\end{array}$ & $\begin{array}{l}\text { Rat submaxillary } \\
\text { gland }\end{array}$ & ND & $>10,000$ & $>10,000$ \\
\hline Neurokinin, $\mathrm{NK}_{2}$ & $\begin{array}{l}0.1 \mathrm{nM} \\
{\left[{ }^{125} \mid\right] \text { neurokinin } \mathrm{A}}\end{array}$ & $\begin{array}{l}1 \mu \mathrm{M} \text { neurokinin } \\
\mathrm{A}\end{array}$ & $\begin{array}{l}\text { Human } \\
\text { recombinant } \\
\mathrm{CHO} \text { cells }\end{array}$ & ND & 1510 & $>10,000$ \\
\hline $\begin{array}{l}\text { Neurokinin, } \mathrm{NK}_{3} \\
\text { (NKB) }\end{array}$ & $\begin{array}{l}0.1 \mathrm{nM} \\
{\left[{ }^{125} \mid\right] \text { eledoisin }}\end{array}$ & $1 \mu \mathrm{M}$ eledoisin & $\begin{array}{l}\text { Rat cerebral } \\
\text { cortex }\end{array}$ & ND & $>10,000$ & $>10,000$ \\
\hline Oxytocin & $1 \mathrm{nM}\left[{ }^{3} \mathrm{H}\right]$ oxytocin & $1 \mu \mathrm{M}$ oxytocin & Rat uterus & ND & $>10,000$ & $>10,000$ \\
\hline $\begin{array}{l}\text { Testosterone, } \\
\text { cytosolic }\end{array}$ & $\begin{array}{l}0.5 \mathrm{nM} \\
{\left[{ }^{3} \mathrm{H}\right] \text { methyltrienolone }}\end{array}$ & \begin{tabular}{|l|}
$0.7 \mu \mathrm{M}$ \\
methyltrienolone
\end{tabular} & $\begin{array}{l}\text { Human LnCAP } \\
\text { cells }\end{array}$ & ND & $>10,000$ & $>10,000$ \\
\hline TRH & $\begin{array}{l}2 \mathrm{nM} \\
\left.{ }^{3} \mathrm{H}\right]\left(3 \mathrm{MeHis}^{2}\right) \mathrm{TRH}\end{array}$ & $10 \mu \mathrm{M}$ TRH & Rat forebrain & ND & $>10,000$ & $>10,000$ \\
\hline VIP, non-selective & $0.05 \mathrm{nM}\left[{ }^{125} \mathrm{l}\right] \mathrm{VIP}$ & $1 \mu \mathrm{M}$ VIP & Rat forebrain & ND & $>10,000$ & $>10,000$ \\
\hline Vasopressin 1 & $\begin{array}{l}0.5 \mathrm{nM} \\
{\left[{ }^{3} \mathrm{H}\right] \text { phenylalanyl- }} \\
3,4,5-\mathrm{v}\end{array}$ & $\begin{array}{l}1 \mu \mathrm{M} \mathrm{Arg}{ }^{8}- \\
\text { vasopressin }\end{array}$ & Rat liver & ND & $>10,000$ & $>10,000$ \\
\hline \multicolumn{7}{|l|}{ Ion channels: } \\
\hline $\begin{array}{l}\text { Calcium, type L } \\
\text { (DHP) }\end{array}$ & $\begin{array}{l}0.2 \mathrm{nM} \\
{\left[{ }^{3} \mathrm{H}\right] \text { nitrendipine }}\end{array}$ & $1 \mu \mathrm{M}$ nifedipine & $\begin{array}{l}\text { Rat cerebral } \\
\text { cortex }\end{array}$ & $>10,000$ & 1710 & $>10,000$ \\
\hline
\end{tabular}




\begin{tabular}{|c|c|c|c|c|c|c|}
\hline Calcium, type N & $\begin{array}{l}0.01 \mathrm{nM}\left[{ }^{125} \mathrm{I}\right] \omega- \\
\text { conotoxin GVIA }\end{array}$ & \begin{tabular}{|l}
$0.1 \mu \mathrm{M} \omega-$ \\
conotoxin GVIA
\end{tabular} & $\begin{array}{l}\text { Rat cerebral } \\
\text { cortex }\end{array}$ & $>10,000$ & $>10,000$ & $>10,000$ \\
\hline $\begin{array}{l}\text { Potassium, ATP- } \\
\text { sensitive }\end{array}$ & $\begin{array}{l}0.2 \mathrm{nM} \\
{\left[{ }^{3} \mathrm{H}\right] \mathrm{glibenclamide}}\end{array}$ & \begin{tabular}{|l|}
$0.1 \mu \mathrm{M}$ \\
glibenclamide
\end{tabular} & $\begin{array}{l}\text { Rat cerebral } \\
\text { cortex }\end{array}$ & $>10,000$ & $>10,000$ & $>10,000$ \\
\hline $\begin{array}{l}\text { Potassium, } \mathrm{Ca}^{2+} \\
\text { act VI }\end{array}$ & $\begin{array}{l}0.05 \mathrm{nM} \\
{\left[{ }^{125} \mid\right] \text { apamin }}\end{array}$ & $100 \mathrm{nM}$ apamin & Rat forebrain & ND & $>10,000$ & $>10,000$ \\
\hline \multicolumn{7}{|c|}{ Enzymes and other miscellaneous: } \\
\hline $\begin{array}{l}\text { Acetylcholine } \\
\text { esterase }\end{array}$ & $\begin{array}{l}0.3 \mathrm{mM} \\
{\left[{ }^{3} \mathrm{H}\right] \text { acethylthiocholi }} \\
\text { ne }\end{array}$ & $\begin{array}{l}100 \mu \mathrm{M} \\
\text { physostigmine }\end{array}$ & $\begin{array}{l}\text { Human } \\
\text { recombinant }\end{array}$ & ND & $>10,000$ & $>10,000$ \\
\hline $\begin{array}{l}\text { Choline } \\
\text { acetyltransferase }\end{array}$ & $\begin{array}{l}0.2 \mathrm{nM}\left[{ }^{14} \mathrm{C}\right] \text { acetyl } \\
\text { coenzyme }\end{array}$ & $\begin{array}{l}0.1 \mu \mathrm{M} \text { Ro } 41- \\
1049 \\
\end{array}$ & $\begin{array}{l}\text { Rat cerebral } \\
\text { cortex }\end{array}$ & ND & $>10,000$ & $>10,000$ \\
\hline $\begin{array}{l}\text { Glutamic acid } \\
\text { decarboxylase }\end{array}$ & $\begin{array}{l}4 \mu \mathrm{M}\left[{ }^{14} \mathrm{C}\right] \mathrm{L}- \\
\text { glutamic acid }\end{array}$ & $\begin{array}{l}100 \mu \mathrm{M} \text { aminooxy } \\
\text { acetic acid }\end{array}$ & Rat striatum & ND & $>10,000$ & $>10,000$ \\
\hline $\begin{array}{l}\text { Leukotriene, } \mathrm{LTB}_{4} \\
\text { (BLT) }\end{array}$ & $\begin{array}{l}0.48 \mathrm{nM} \\
{\left[{ }^{3} \mathrm{H}\right] \text { leukotriene } \mathrm{B}_{4}}\end{array}$ & \begin{tabular}{|l|}
$500 \mathrm{nM}$ \\
leukotriene $\mathrm{B}_{4}$
\end{tabular} & $\begin{array}{l}\text { Guinea pig } \\
\text { spleen }\end{array}$ & ND & $>10,000$ & $>10,000$ \\
\hline $\begin{array}{l}\text { Leukotriene, } \text { LTD }_{4} \\
\text { (CysLT1) }\end{array}$ & $\begin{array}{l}0.2 \mathrm{nM} \\
{\left[{ }^{3} \mathrm{H}\right] \text { leukotriene } \mathrm{D}_{4}}\end{array}$ & $\begin{array}{l}1 \mu \mathrm{M} \text { leukotriene } \\
\mathrm{D}_{4}\end{array}$ & Guinea pig lung & ND & $>10,000$ & $>10,000$ \\
\hline $\begin{array}{l}\text { MAO-A oxidase, } \\
\text { peripheral }\end{array}$ & $50 \mu \mathrm{M}\left[{ }^{14} \mathrm{C}\right] 5-\mathrm{HT}$ & $1 \mu \mathrm{M}$ Ro 41-1049 & \begin{tabular}{|l|} 
Rat liver \\
mitochondria
\end{tabular} & ND & $>10,000$ & $>10,000$ \\
\hline $\begin{array}{l}\text { MAO-B oxidase, } \\
\text { peripheral }\end{array}$ & $\begin{array}{l}10 \mu \mathrm{M} \\
{\left[{ }^{14} \mathrm{C}\right] \text { phenylethylami }} \\
\text { ne }\end{array}$ & $\begin{array}{l}10 \mu \mathrm{M} \text { Ro } 16- \\
6491\end{array}$ & $\begin{array}{l}\text { Rat liver } \\
\text { mitochondria }\end{array}$ & ND & $>10,000$ & $>10,000$ \\
\hline Nitric oxide, NOS & $5 \mathrm{nM}\left[{ }^{3} \mathrm{H}\right] \mathrm{NOARG}$ & $100 \mu \mathrm{M} N O A R G$ & Rat brain & ND & 1220 & $>10,000$ \\
\hline $\begin{array}{l}\text { Platelet activating } \\
\text { factor }\end{array}$ & \begin{tabular}{|l}
$1.7 \mathrm{nM}$ \\
{$\left[{ }^{3} \mathrm{H}\right]$ hexadecyl- } \\
acetyl-PAF \\
\end{tabular} & $1 \mu \mathrm{M} \mathrm{C}_{16}-\mathrm{PAF}$ & Rabbit platelets & ND & $>10,000$ & $>10,000$ \\
\hline $\begin{array}{l}\text { Thromboxane, } \\
\text { TXA }_{2}\end{array}$ & \begin{tabular}{|lrr}
2 & $n M$ & {$\left[{ }^{3} H\right] S Q$} \\
29,548 & \\
\end{tabular} & $\begin{array}{l}10 \mu \mathrm{M} \text { pinane- } \\
\text { thromboxane }\end{array}$ & Human platelets & ND & $>10,000$ & $>10,000$ \\
\hline
\end{tabular}

Affinities $\left(\mathrm{K}_{\mathrm{i}}\right.$ in $\left.\mathrm{nM}\right)$ were determined in tissue or cell homogenates. The values in this table represent the mean \pm S.E.M. from replicate assays. Values of $>10,000$ signify that there was less than $30 \%$ displacement of the radioligand at that concentration. $B T Z=$ benzothiazepine; $C R F=$ corticotrophin releasing factor; $\mathrm{DHA}=$ dihydroalprenolol; $\mathrm{DHP}=$ dihydropyridine; $\mathrm{GABA}=\mathrm{\gamma}$-aminobutyric acid; $\mathrm{LSD}=$ lysergic acid diethylamide; $\mathrm{MAO}=$ monoamine oxidase; $\mathrm{MPEP}=2$-methyl-6-(phenylethynyl)pyridine; $N E C A=5$ '-N-ethylcarboxamidoadenosine; $N O A R G=L-N^{G}$-nitro-arginine; $P A F=$ platelet activating factor; QNB=quinuclidinyl benzilate; $\quad T B O B=t-$ butylbicycloorthobenzoate; $\quad T B P S=t-$ butylbicyclophosphorothionate; TCP=1-[1-)2-thienyl)cyclohexyl]piperidine; $\mathrm{TRH}=$ thyrotropin releasing hormone; VIP=vasoactive intestinal peptide. 
1.8.2 Pharmacokinetic studies: Pharmacokinetic studies were conducted for SN79 and CM156, but not for AC927 as it displayed toxicity at supratherapeutic doses deeming it not suitable as a drug candidate.

1.8.2.1 In vitro liver microsomal assays: The metabolic stability of CM156 was evaluated through the NIDA Medications Development Program in liver microsomes prepared from rat, monkey and human (Table 1.3). Using a Tecan Liquid Handling System (Tecan, Research Triangle Park, NC), CM156 $(5 \mu \mathrm{M})$ was incubated at $37^{\circ} \mathrm{C}$ with the reaction mixture. At designated time points $(0,15,30$ and $60 \mathrm{~min})$ the supernatants were collected and analyzed using LC/MS. 
Table 1.3 Metabolic stability of CM156 in rat, monkey, and human liver microsomes

\begin{tabular}{|c|c|c|c|c|c|c|c|}
\hline Species & $\begin{array}{l}\text { Incubati } \\
\text { on Time } \\
\text { (min) }\end{array}$ & $\begin{array}{l}\text { Cofactor } \\
(+/-)\end{array}$ & $\begin{array}{l}\text { Area } \\
\text { Ratio }\end{array}$ & $\begin{array}{l}\text { Percent Loss } \\
\text { Of Substrate }\end{array}$ & $\begin{array}{l}\text { Percent } \\
\text { Remaining }\end{array}$ & $\begin{array}{l}\text { Half- } \\
\text { Life } \\
\text { (min) }\end{array}$ & $\begin{array}{l}\text { Clearance } \\
(\mathrm{ml} / \mathrm{min} / \mathrm{kg})\end{array}$ \\
\hline \multirow[t]{6}{*}{ Rat } & 0 & + & 143 & $0.0 \%$ & $100 \%$ & \multirow[t]{6}{*}{4.62} & \multirow[t]{6}{*}{270} \\
\hline & 15 & + & 12.7 & $91.2 \%$ & $8.8 \%$ & & \\
\hline & 30 & + & 12.2 & $91.5 \%$ & $8.5 \%$ & & \\
\hline & 60 & + & 11.5 & $92.0 \%$ & $8.0 \%$ & & \\
\hline & 0 & - & 148 & $0.0 \%$ & $100 \%$ & & \\
\hline & 60 & - & 148 & $0.0 \%$ & $100 \%$ & & \\
\hline & & & & & & & \\
\hline \multirow[t]{6}{*}{ Monkey } & 0 & + & 140 & $0.0 \%$ & $100 \%$ & \multirow[t]{6}{*}{2.8} & \multirow[t]{6}{*}{184} \\
\hline & 15 & + & 3.17 & $97.7 \%$ & $2.3 \%$ & & \\
\hline & 30 & + & 2.11 & $98.5 \%$ & $1.5 \%$ & & \\
\hline & 60 & + & 1.81 & $98.7 \%$ & $1.3 \%$ & & \\
\hline & 0 & - & 146 & $0.0 \%$ & $100 \%$ & & \\
\hline & 60 & - & 144 & $1.4 \%$ & $98.6 \%$ & & \\
\hline \multirow{6}{*}{ Human } & 0 & + & 133 & $00 \%$ & $100 \%$ & \multirow{6}{*}{10.6} & \multirow{6}{*}{58.8} \\
\hline & 15 & $\frac{T}{+}$ & 51.4 & $61.3 \%$ & $38.7 \%$ & & \\
\hline & 30 & + & 15.4 & $88.4 \%$ & $11.6 \%$ & & \\
\hline & 60 & + & 7.35 & $94.5 \%$ & $5.5 \%$ & & \\
\hline & 0 & - & 138 & $0.0 \%$ & $100 \%$ & & \\
\hline & 60 & - & 142 & No loss & $103 \%$ & & \\
\hline
\end{tabular}

Values are the mean of triplicate determinations, except for the zero cofactor values that are the mean of duplicate determinations. CM156 was tested at a concentration of $5 \mu \mathrm{M}$. Protein concentration was set at $1.0 \mathrm{mg}$ protein $/ \mathrm{ml}$. 
1.8.2.2 In vivo pharmacokinetic studies: Plasma pharmacokinetic parameters associated with oral dosing of SN79 are summarized in Table 1.4. In this study, blood concentration of orally administered SN79 $(20 \mathrm{mg} / \mathrm{kg})$ was determined in Sprague Dawley rats at different time intervals using ultra performance liquid chromatography. CM156 showed short half life in in vitro microsomal assays due to which it was not tested in in vivo pharmacokinetic studies.

Table 1.4: Mean plasma pharmacokinetic parameters of SN79 after oral administration in Sprague-Dawley rats

\begin{tabular}{|l|l|}
\hline$A U C$ & $117.34 \mu \mathrm{g}-\mathrm{hr} / \mathrm{ml}$ \\
\hline $\mathrm{T}_{1 / 2}$ & $7.51 \mathrm{hr}$ \\
\hline $\mathrm{C}_{\max }$ & $0.205 \mu \mathrm{g} / \mathrm{ml}$ \\
\hline $\mathrm{MRT}$ & $9.87 \mathrm{hr}$ \\
\hline $\mathrm{V}_{\mathrm{d}}$ & $115.10 \mathrm{I} / \mathrm{kg}$ \\
\hline $\mathrm{CL}_{\mathrm{ss}} / \mathrm{F}$ & $0.18 \mathrm{l} / \mathrm{hr} / \mathrm{kg}$ \\
\hline $\mathrm{T}_{\max }$ & $1.5 \mathrm{hr}$ \\
\hline
\end{tabular}

$\mathrm{C}_{\max }$, maximum concentration; $\mathrm{T}_{\max }$, time to reach maximum concentration; $\mathrm{AUC}$, area under the curve concentration; $\mathrm{V}_{\mathrm{d}}$, volume of distribution; $\mathrm{MRT}$, mean residence time; $\mathrm{CL}_{\mathrm{ss}} / \mathrm{F}$, apparent oral clearance at steady state. 
1.8.3 Cytochrome P450 Interactions: Since, SN79 was the most druggable compound out of AC927 and CM156 (it did not display any toxicity like AC927 and had long half life unlike CM156), it was the only compound to be moved forward in the cytochrome P450 studies. The effect of SN79 on a number of human cytochrome P450 enzymes was assessed by NovaScreen CYP Screen (Caliper Life Sciences, Hopkinton, MA). The specific cytochrome P450 enzymes selected were those most likely to cause problematic drug-drug interactions. Table 1.5 provides a synopsis of the assay conditions, with NADPH (nicotinamide adenine dinucleotide phosphate) added to the substrate to catalyze the reaction. SN79 was evaluated at a single screening concentration of $10 \mu \mathrm{M}$, with $50 \%$ used as the criterion for significant inhibition at this concentration.

Table 1.5 Human cytochrome P450 inhibition studies

\begin{tabular}{|l|l|c|}
\hline Cytochrome P450 & \multicolumn{1}{|c|}{ Substrate } & \% Inhibition by SN79 \\
\hline $1 \mathrm{~A} 2$ & $5 \mu \mathrm{M}$ 7-ethoxy-3-cyanocoumarin & $17.8 \%$ \\
\hline $2 \mathrm{~A} 6$ & $3 \mu \mathrm{M}$ coumarin & $-10.4 \%$ \\
\hline $2 \mathrm{C} 19$ & $2.5 \mu \mathrm{M}$ 7-ethoxy-3-cyanocoumarin & $34.8 \%$ \\
\hline $2 \mathrm{C} 9{ }^{*} 1$ & $\begin{array}{l}37.5 \mu \mathrm{M} \text { 7-methoxy-4-trifluouromethyl- } \\
\text { coumarin }\end{array}$ & $15.3 \%$ \\
\hline 2D6 & $0.5 \mu \mathrm{M}$ AMMC & $-1.7 \%$ \\
\hline 3A4 & $0.5 \mu \mathrm{M}$ dibenzyl fluorescein & $29.0 \%$ \\
\hline
\end{tabular}

Duplicate assays were conducted for the inhibition of human recombinant cytochrome P450 enzymes expressed in SF9 cells by SN79. NADPH was added to the substrate to catalyze the reaction. SN79 was evaluated at a single screening concentration of $10 \mu \mathrm{M}$, with $50 \%$ used as the criterion for significant inhibition at this concentration. Negative values represent slight induction. SN79 did not significantly inhibit or induce the major cytochrome P450 enzymes tested. 


\subsection{In vivo model: Male, Swiss Webster mice}

This strain of mice was used for the studies in this dissertation because they are capable of exhibiting the behavioral and neurotoxic effects of $\mathrm{METH}$, and have been widely used to study $\sigma$ and non- $\sigma$ compounds (Itzhak and Ali, 1996; Ali and Itzhak, 1998; Callahan and Ricaurte, 1998; Itzhak et al., 1998; Itzhak et al., 2003; Nguyen et al., 2005; Matsumoto et al., 2008). Their continued use will facilitate comparisons to data already in the literature. Mice were preferred over rats for these studies because the novel compounds are produced in small amounts, and the smaller size of the mice will help in optimizing their use. Male mice were used in this study because of varying levels of progesterone in the system of female mice during estrous cycle (Kosaka et al., 1988). Progesterone is considered an endogeneous $\sigma$ ligand and can therefore interfere with the binding of the drugs and interpretation of the results (Su, 1991).

\subsection{In vitro model: NG108-15 cells}

In order to elucidate the cellular mechanisms of METH-induced toxicity at which $\sigma$ receptors may intervene, a neuronal cell culture model (neuroblastomaxglioma hybridoma, NG108-15 cells) was used. A cell culture model also provides a system where the temperature can be maintained constant and the mechanistic basis of the neuroprotective effects of $\sigma$ antagonists can be studied under more controlled conditions compared to in vivo. NG108-15 cells when differentiated display neurite outgrowth, electrical excitability and express proteins with neuronal and glial properties (Ma et al., 1998). These cells have been used extensively as a sensitive cell line to study toxic effects of various drugs and chemicals (Canete and Diogene, 2008). Additionally, NG108-15 cells have been commonly used in the literature to study the functioning of $\sigma$ receptors, thus making it a suitable model for these 
studies (McLawhon et al., 1981; Georg and Friedl, 1991; Vilner et al., 1995b; Hayashi and Su, 2003a; Peeters et al., 2004).

\subsection{Specific Aims}

The future chapters will describe the studies conducted using sigma receptor antagonists: AC927, CM156 and SN79 in in vivo and in vitro models. The aims of this dissertation are as follows:

Specific Aim 1: To determine if antagonism of $\sigma$ receptors (using AC927, CM156 and SN79) can attenuate METH-induced neurotoxicity in vivo: The following studies were performed:

1. To determine if $\sigma$ receptor antagonists (AC927, CM156 and SN79) can attenuate METH-induced neurotoxicity in vivo. Male, Swiss Webster mice were pretreated with AC927, CM156 or SN79 to determine if METH-induced dopaminergic and serotonergic neurotoxicity can be attenuated. The markers studied were: striatal dopamine and 5HT levels, striatal DAT and SERT expression levels. This study had been included in chapter 2.

2. To determine if the $\sigma$ receptor antagonists can attenuate the hyperthermic effects of

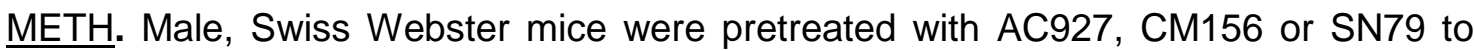
determine if METH-induced hyperthermia can be attenuated. This study has been included in Chapter 3.

3. To determine if hyperthermia is associated with neurotoxicity of METH. Correlation between the body temperature of the mice and striatal dopamine and serotonin levels was determined. This study has been included in Chapter 3. 
Specific Aim 2: To determine the mechanisms of neuroprotective effects of sigma receptor antagonists against METH-induced neurotoxicity in vitro: The following studies were performed:

1. Identification of the mechanisms of METH-induced neurotoxicity in differentiated NG108-15 cells that can be prevented by sigma receptor antagonists (AC927 and SN79). Differentiated NG108-15 cells were used as a model system to identify the mechanisms of METH-induced neurotoxicity that can be attenuated by sigma receptor antagonists. The neurotoxic end points and mediators detected were: apoptosis, necrosis, caspase-3, $-9,-8$ activation, ROS/RNS generation and dopamine release. The results from this study have been included in chapter 4 and 5 .

2. Effect of elevated temperature on METH-induced neurotoxicity in differentiated NG10815 cells: Differentiated NG108-15 cells were used to study the effect of METH treatment at $37^{\circ} \mathrm{C}$ and elevated temperature $\left(40{ }^{\circ} \mathrm{C}\right)$. The ability of SN79 to attenuate METH and elevated temperature-induced toxicity was also determined. The results from this study have been included in Chapter 5 .

\section{Specific Aim 3: To determine if antagonism of $\sigma-2$ receptors can attenuate METH-} induced neurotoxicity in vitro: A series of potential $\sigma 2$ receptor selective compounds were synthesized and screened using radioligand binding assay for their high affinity and selectivity for $\sigma 2$ receptors over $\sigma 1$ receptors and other non- $\sigma$ sites. Sigma-2 receptor antagonist, CM398 was tested to determine its ability to attenuate METH-induced apoptotic and necrotic end points. The results from this study have been included in Chapter 6 .

It is expected that this study will help us understand the role of $\sigma$ receptors especially $\sigma 2$ receptor subtype in the neurotoxic effects of $\mathrm{METH}$. The work is significant because of the 
impact it will have not only on the understanding of the functioning of $\sigma$ receptors but also on the potential development of medications to treat METH-induced neurotoxicity.

1.12 Contributions: The compounds CM156 and SN79 were synthesized by Dr. Christophe Mésangeau and Dr. Sanju Narayanan in Dr. Christopher R. McCurdy's lab at University of Mississippi. AC927 was obtained from Dr. Andrew Coop's laboratory at University of Maryland, Baltimore.

The radioligand binding studies for SN79 were performed by Dr. Jamaluddin Shaikh, Michael Seminerio and Dr. Yan-tong Xu at the University of Mississippi and West Virginia University. The radioligand binding studies for CM156 and AC927 were performed by Dr. Jamaluddin Shaikh at the University of Mississippi. The NOVAScreen for all the three compounds were performed by Calipers Life Sciences (Hanover, MD).

The in vivo pharmacokinetic studies for SN79 were performed by Dr. Harsha Vinnakota in Dr. Bonnie A. Avery's lab at University of Mississippi. 


\section{CHAPTER 2}

\section{EVALUATION OF SIGMA RECEPTOR ANTAGONISTS AGAINST METH-INDUCED NEUROTOXICITY: IN VIVO STUDIES}




\subsection{Introduction}

High or repeated METH administration results in hyperthermia and neurotoxicity (Cruickshank and Dyer, 2009). At high doses, neurotoxic cascades are activated due to excessive dopamine and 5-HT release into the cytoplasm and synapse (Baldwin et al., 1993; Kuczenski et al., 1995; Gough et al., 2002). Neuroimaging and postmortem studies in human METH users, as well as studies performed using animal models, have shown damage to dopaminergic and serotonergic neurons measured as reductions in DAT, SERT, dopamine and 5-HT levels in several brain regions (Krasnova and Cadet, 2009). Recent studies have indicated an association between neurotoxicity and several neuropsychiatric disorders including psychosis, motor and cognitive deficits (Walsh and Wagner, 1992; Cruickshank and Dyer, 2009), conferring additional urgency to the development of effective pharmacotherapies against the effects of METH.

In the present study, the role of $\sigma$ receptors in METH-induced neurotoxicity was evaluated. We focused on $\sigma$ receptors for several reasons. First, METH binds to $\sigma$ receptors at physiologically relevant concentrations (Nguyen et al., 2005). Second, $\sigma$ receptors are present on dopamine and 5-HT neurons, which are damaged by neurotoxic doses of METH, and can modulate their function (Campbell et al., 1989; Bastianetto et al., 1995; Derbez et al., 2002). Third, $\sigma$ receptors participate in cell death pathways in tumor cells (Bowen, 2000), suggesting their possible contribution in METH-induced neurotoxic cascades. Fourth, targeting $\sigma$ receptors can attenuate chronic disabilities like cognitive deficits, psychosis, and depression, which are also caused by METH's neurotoxicity (Cruickshank and Dyer, 2009).

Therefore, in this study three sigma receptor antagonists (AC927, CM156 and SN79) were tested to determine if they can attenuate METH-induced neurotoxicity in vivo. All these compounds have previously been tested against the behavioral and toxic effects of cocaine, and were found to function as antagonists at $\sigma$ receptors (Xu et al., 2010; Kaushal et al., 
2011a; Matsumoto et al., 2011). The effect of pretreatment of AC927, CM156 and SN79 was determined on the striatal dopaminergic and serotonergic neurotoxicity caused by METH. The markers used were: striatal dopamine and 5-HT levels, striatal DAT and SERT expression.

\subsection{Materials and Methods}

2.2.1. Animals: Male, Swiss Webster mice (18-28 g; Harlan, Indianapolis, IN) were used for the in vivo studies. They were housed in groups of five with a 12:12h light/dark cycle with food and water available ad libitum. Naïve mice were randomly assigned to different treatment groups. All procedures involving animals were performed as approved by the Institutional Animal Care and Use Committee at the West Virginia University.

2.2.2. Drugs: CM156 and SN79 were obtained from Dr. Christopher McCurdy's laboratory (University of Mississippi, University, MS). AC927 was provided by Dr. Andrew Coop (University of Maryland, Baltimore, MD). METH hydrochloride was obtained from Research Biochemicals International (Natick, MA).

2.2.3. METH neurotoxic schedule: As shown in Figure 2.1 male, Swiss Webster mice were randomly divided into four experimental groups: 1) Saline/Saline, 2) Saline/METH (1.25, 2.5, 5, $10 \mathrm{mg} / \mathrm{kg}$ ) 3) Antagonist (AC927: 5, 10, $20 \mathrm{mg} / \mathrm{kg}$; CM156: 5, 10, $20 \mathrm{mg} / \mathrm{kg}$ or SN79: 1, 3, $10 \mathrm{mg} / \mathrm{kg}$ )/Saline, 4) Antagonist (AC927: 5, 10, 20 mg/kg, i.p.; CM156: 5, 10, 20 mg/kg, i.p. or SN79: 1, 3, $10 \mathrm{mg} / \mathrm{kg}$, i.p.)/METH (5, $10 \mathrm{mg} / \mathrm{kg}$, I.p.). These doses of AC927, CM156 and SN79 were selected as these were effective in attenuating the behavioral and toxic effects of cocaine, another sigma receptor agonist (Xu et al., 2010; Kaushal et al., 2011a; Matsumoto et al., 2011). The first drug was administered 15 min prior to the second drug. Each group of mice received their treatment a total of four times at two hour intervals. One hour after each treatment, the body temperature of the mice was recorded. To allow sufficient time for the METH-induced degeneration of nerve terminals to occur, the animals were sacrificed and their 
brains removed one week following treatment (Cappon et al., 2000). The detailed procedure for each of the end points is provided below.

Figure 2.1 Neurotoxic schedule of METH

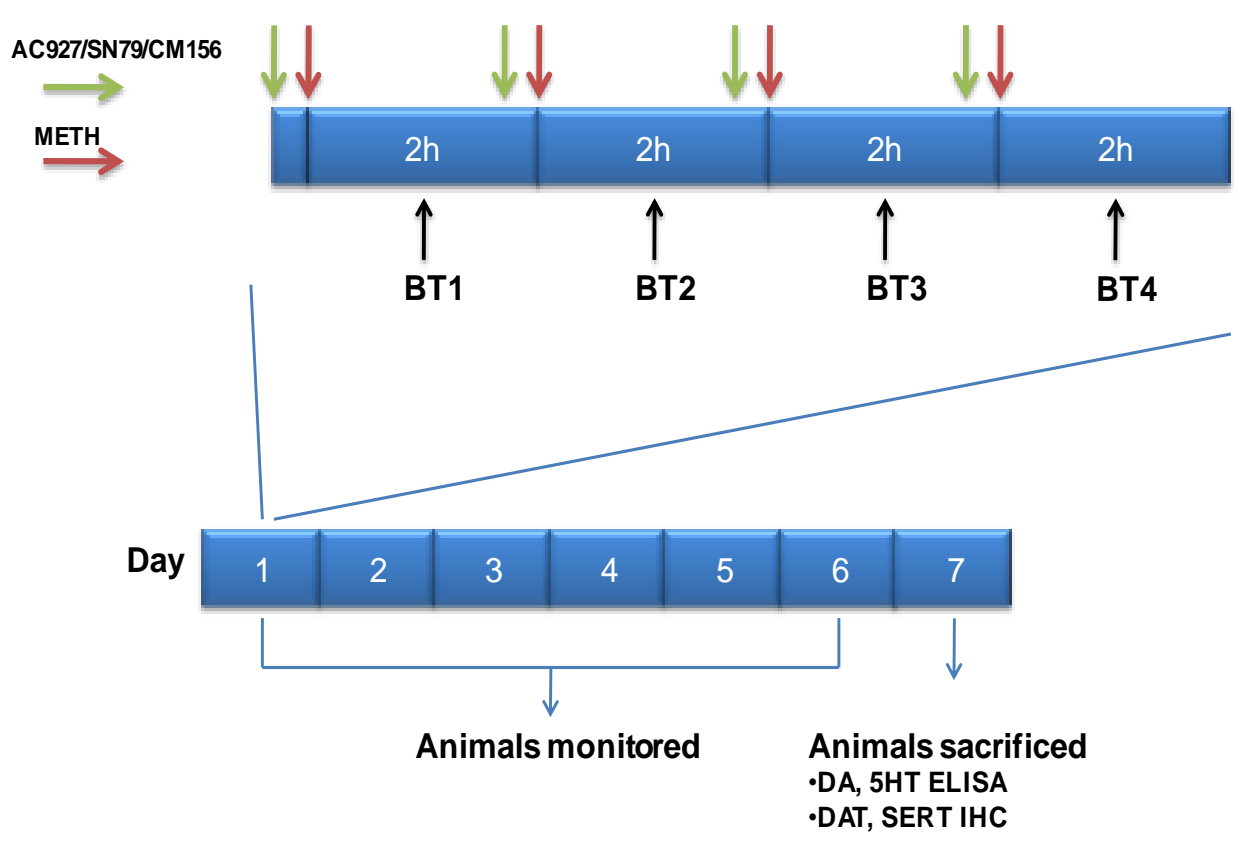

2.2.3.1. Dopamine assay: The mice ( $n=5-9 /$ group) were randomly assigned to one of the following treatments: (1) Saline + Saline; (2) Saline $+\mathrm{METH}(1.25,2.5$, or $5 \mathrm{mg} / \mathrm{kg}$, i.p.); (3) $\operatorname{AC927~(5,~10,~} 20 \mathrm{mg} / \mathrm{kg}$, i.p.)/CM156 (5, 10, or $20 \mathrm{mg} / \mathrm{kg}$, i.p.)/SN79 (1, 3, $10 \mathrm{mg} / \mathrm{kg}$, i.p.) + Saline; (4) AC927 (5, 10, $20 \mathrm{mg} / \mathrm{kg}$, i.p.)/CM156 (5, 10, or $20 \mathrm{mg} / \mathrm{kg}$, i.p.)/SN79 (1, 3, 10 $\mathrm{mg} / \mathrm{kg}$, i.p.) $+\mathrm{METH}(5 \mathrm{mg} / \mathrm{kg}$, i.p.). The striatum and cerebellum were dissected from each treated mice and then frozen in liquid nitrogen. The tissues were stored at $-80{ }^{\circ} \mathrm{C}$ for later analysis of dopamine content. One week after the treatment schedule, the mice were 
sacrificed and the striatum and cerebellum were dissected from each treated mice and then frozen in liquid nitrogen. The tissues were stored at $-80{ }^{\circ} \mathrm{C}$ for later analysis of dopamine content. Using a dopamine research enzyme immunoassay kit and protocols provided by the manufacturer (Rocky Mountain Diagnostics, Colorado Springs, CO), mouse brain striatal and cerebellar dopamine were quantified. Brain tissues were homogenized in $0.01 \mathrm{~N} \mathrm{HCl}$ and dopamine was extracted and then acylated to $\mathrm{N}$-acyldopamine using the buffer and reagents provided by the ELISA kit. Acylated dopamine from the tissue samples was incubated with solid phase bound dopamine, dopamine antiserum, and antiserum buffer to compete for a fixed number of antiserum binding sites. Free antigen and free antigen-antiserum complexes were removed via the wash buffer. The antibody bound to the solid phase dopamine was detected using an anti-rabbit IgG-peroxidase conjugate with TMB $\left(3,3^{\prime}, 5,5^{\prime \prime}\right.$ tetramethylbenzidine) as the substrate. The amount of antibody bound to the solid phase dopamine was measured by monitoring the reaction at $450 \mathrm{~nm}$. The solid phase dopamine measured is inversely proportional to the dopamine concentration of the tissue sample and is quantified relative to a standard curve of known concentrations.

2.2.3.2. 5-HT assays: The mice ( $n=5-10$ /group) were randomly assigned to one of the following treatments: (1) Saline + Saline; (2) Saline + METH (1.25, 2.5, 5 or 10 mg/kg, i.p.); (3) $\operatorname{AC9} 27$ (5, 10, 20 mg/kg, i.p.)/CM156 (5, 10, or 20 mg/kg, i.p.)/SN79 (1, 3, 10 mg/kg, i.p.) + Saline; (4) AC927 (5, 10, 20 mg/kg, i.p.)/CM156 (5, 10, or 20 mg/kg, i.p.)/SN79 (1, 3, 10 $\mathrm{mg} / \mathrm{kg}$, i.p.) $+\operatorname{METH}(5,10 \mathrm{mg} / \mathrm{kg}$, i.p.). One week following the treatments, striatum and cerebellum were dissected from each treated mice and then frozen in liquid nitrogen. The tissues were stored at $-80{ }^{\circ} \mathrm{C}$ for later analysis of $5-\mathrm{HT}$ content. The protocol was the same as described above for dopamine, with the exception that brain tissues were homogenized in 0.2 M perchloric acid, followed by centrifugation at $3,000 \mathrm{rpm}$ for $10 \mathrm{~min}$ at $4{ }^{\circ} \mathrm{C}$. The supernatants 
were collected and evaluated for 5-HT levels using 5-HT research enzyme immunoassay kits (Rocky Mountain Diagnostics, Colorado Springs, CO).

2.2.3.3. DAT Immunohistochemistry: Striatal sections were assessed for DAT expression. The mice ( $n=4 /$ group) were randomly assigned to one of the following treatment groups: (1) Saline + Saline; (2) Saline + METH (5 mg/kg, i.p.); (3) AC927 (10 mg/kg, i.p.)/CM156 (10 mg/kg, i.p.)/SN79 (3 mg/kg, i.p.) + METH (5 mg/kg, i.p.); (4) AC927 (10 $\mathrm{mg} / \mathrm{kg}$, i.p.)/CM156 (10 mg/kg, i.p.)/SN79 (3 mg/kg, i.p.) + Saline. Striatal sections were assessed for DAT expression. One week following treatment, the mice were perfused transcardially with $0.1 \mathrm{M}$ phosphate buffered saline $(\mathrm{pH} 7.4)$, followed by $4 \%$ paraformaldehyde. The brains were further fixed overnight in $4 \%$ paraformaldehyde. Coronal sections $(50 \mu \mathrm{m})$ of the fixed tissue were made throughout the rostral-caudal extent of the striatum using a cryostat, and processed in a free-floating state in $0.1 \mathrm{M}$ Tris- $\mathrm{HCl}$ buffered saline (TBS, $\mathrm{pH}$ 7.5). The sections were treated with $0.3 \%$ in $\mathrm{H}_{2} \mathrm{O}_{2}$ in TBS for 30 min at room temperature. The sections were then treated with TBS containing $0.2 \%$ Triton $\mathrm{X}-100$ and $1.5 \%$ normal goat serum for $30 \mathrm{~min}$ at room temperature. Incubation of the sections with anti-rat DAT antibody (Chemicon International, Temecula, CA; MAB369, dilution 1:10,000) were then performed for $36 \mathrm{~h}$ at $4^{\circ} \mathrm{C}$. The labeled sections were washed twice in TBS and processed using Vectastain Elite ABC (Vector Laboratories, Burlingame, CA). Sections were incubated with biotinylated secondary anti-rat antisera (diluted 1:200) in TBS-NBS for 60 min. This was followed by incubation of the sections with avidin-biotinylated peroxidase substrate in TBS for 60 min. The staining was visualized by reacting 3,3'-diaminobendine containing $0.01 \% \mathrm{H}_{2} \mathrm{O}_{2}$ for $5 \mathrm{~min}$.

The stained sections were mounted onto gelatin-coated slides and dried. The sections were dehydrated, cleared, and coverslipped. The images were captured digitally using a Leica DMIL microscope (Leica Microsystems, Bannockburn, IL) and optical density 
readings quantified in anterior regions of the striatum using ImageJ software (National Institutes of Health, Bethesda, MD). To obtain the data point for a given animal, at least two sections per mouse brain were processed and the optical density readings from both the striatal regions of each section averaged.

2.2.3.4. SERT Immunohistochemistry: To confirm that depletion in 5-HT levels is due to METH-induced damage to serotonin nerve terminals, the striatal sections were assessed for SERT expression. This experiment was performed after relocation of the lab to a different building, with a slightly higher ambient temperature (SERT expression: $23-23.5{ }^{\circ} \mathrm{C}$ ) than the earlier lab (5-HT levels: $\left.21-22^{\circ} \mathrm{C}\right)$. Since serotonin neurotoxicity is sensitive to changes in ambient room temperature (Malberg and Seiden, 1998), a dose response validation for serotonin neurotoxicity was conducted in the first part of the study. Moreover, higher mortality was observed in the $10 \mathrm{mg} / \mathrm{kg}$ METH group, therefore in the second part of the studyCM156 was evaluated against the $5 \mathrm{mg} / \mathrm{kg}$ dose of METH. The mice ( $n=4 / \mathrm{group}$ ) were randomly assigned to one of the following treatment groups: (1) Saline + Saline; (2) Saline + METH (5, 10 mg/kg, i.p.); (3) AC927 (10 mg/kg, i.p.)/CM156 (20 mg/kg, i.p.)/SN79 (3 mg/kg, i.p.) + METH (5, 10 mg/kg, i.p.); (4) AC927 (10 mg/kg, i.p.)/CM156 (20 mg/kg, i.p.)/SN79 (3 mg/kg, i.p.) + Saline. The protocol was the same as for DAT immunohistochemistry with the exception of incubating with rabbit anti-mouse SERT antibody (Millipore, Temecula, CA; AB9726, dilution 1:5,000) for $36 \mathrm{~h}$ at $4 \stackrel{\circ}{\mathrm{C}}$. The labeled sections were washed thrice in TBS and processed with Histostain-Plus kit (DAB, Broad Spectrum) (Invitrogen, Camarillo, CA). Briefly, the labeled sections were incubated in $100 \mu \mathrm{l}$ of DAB substrate for $4 \mathrm{~min}$. The sections were then washed in $5 \mathrm{ml}$ of distilled water. The stained sections were mounted on the slides and analysed in the same way as for DAT immunohistochemistry. 
2.2.4. Statistical analysis: The data from the dopamine and 5-HT assays, and DAT and SERT immunohistochemical studies were evaluated using one-way analysis of variance (ANOVA). Post-hoc analyses were performed with Dunnett's test for comparisons to controls or Tukey's tests for pairwise comparisons. For all statistical analyses, $p<0.05$ was considered statistically significant.

\subsection{Results}

2.3.1. Dopamine assays: One-way ANOVA showed that METH produced a dose dependent reduction of dopamine levels in the striatum (Figure 2.2A., $F(3,27)=7.26, p<0.0005$ ). Posthoc Dunnett's tests revealed that the striatal changes produced by the following doses of METH differed significantly from the saline control group: $2.5 \mathrm{mg} / \mathrm{kg}(q=2.55, p<0.05), 5$ $\mathrm{mg} / \mathrm{kg}(q=4.61, p<0.01)$. However, no significant changes in dopamine concentration following doses of METH, were observed in the cerebellum $(F(3,27)=0.20$, n.s. $)$.

Administration of AC927 in the absence of METH had no significant effects on dopamine levels in the striatum and cerebellum of the mouse brain (Figure 2.2B). ANOVA confirmed that there were no significant differences between the treatment groups in either the striatum $(F[3,16]=1.10$, n.s. $)$ or the cerebellum $(F 3,16]=0.14$, n.s. $)$. One-way ANOVA showed that AC927 pretreatment significantly protected against the striatal dopamine depletions produced by METH $(F(4,23)=6.26, p<0.005)$. Post-hoc Tukey's multiple comparison tests showed that METH caused a siginificant decrease in dopamine levels $(q=5.96, p<0.001)$ and AC927 (10 mg/kg) significantly attenuated the striatal $(q=5.58, p<0.01)$ dopamine depletions caused by METH.

When the selective $\sigma$ receptor antagonist CM156 was administered in the absence of $\mathrm{METH}$, one-way ANOVA showed that there were no significant changes in striatal and cerebellar dopamine levels $(F(3,16)=0.36$, n.s.; $F(3,16)=0.37$, n.s. respectively). 
Nevertheless, in the presence of METH (5 mg/kg), pretreatment with CM156 significantly protected against the neurotoxic dopamine depletions produced by METH in the striatum (Figure 2.2C, $F(4,24)=12.32, p<0.0001)$. Post-hoc Tukey's tests show that METH treatment caused a significant decrease in dopamine levels $(q=7.50, p<0.001)$ and that pretreatment with the following doses of CM156 differed significantly protected against METH-induced striatal dopamine depletions: $10 \mathrm{mg} / \mathrm{kg}(q=7.60, p<0.001)$ and $20 \mathrm{mg} / \mathrm{kg}(q=7.36, p<$ 0.001).

When SN79 was administered in the absence of METH, one-way ANOVA showed that there were no significant changes in striatal and cerebellar dopamine levels (Figure 2.2D, $F(3,19)=1.53, n s ; F(3,19)=1.30, n s)$. One-way ANOVA showed that SN79 pretreatment significantly attenuated METH-induced dopamine depletion $(F(4,24)=31.61, p<0.0001)$. Post-hoc Tukey's test show that METH treatment caused a significant decrease in dopamine levels when compared with saline treatment $(q=10.68, p<0.001)$ and that SN79 pretreatment is able to significantly prevent METH induced decrease in dopamine levels (SN79 dose: $1 \mathrm{mg} / \mathrm{kg}, q=11.70, p<0.001 ; 3 \mathrm{mg} / \mathrm{kg}, q=12.24, p<0.001 ; 10 \mathrm{mg} / \mathrm{kg} q=$ 14.28, $p<0.001)$. 
A
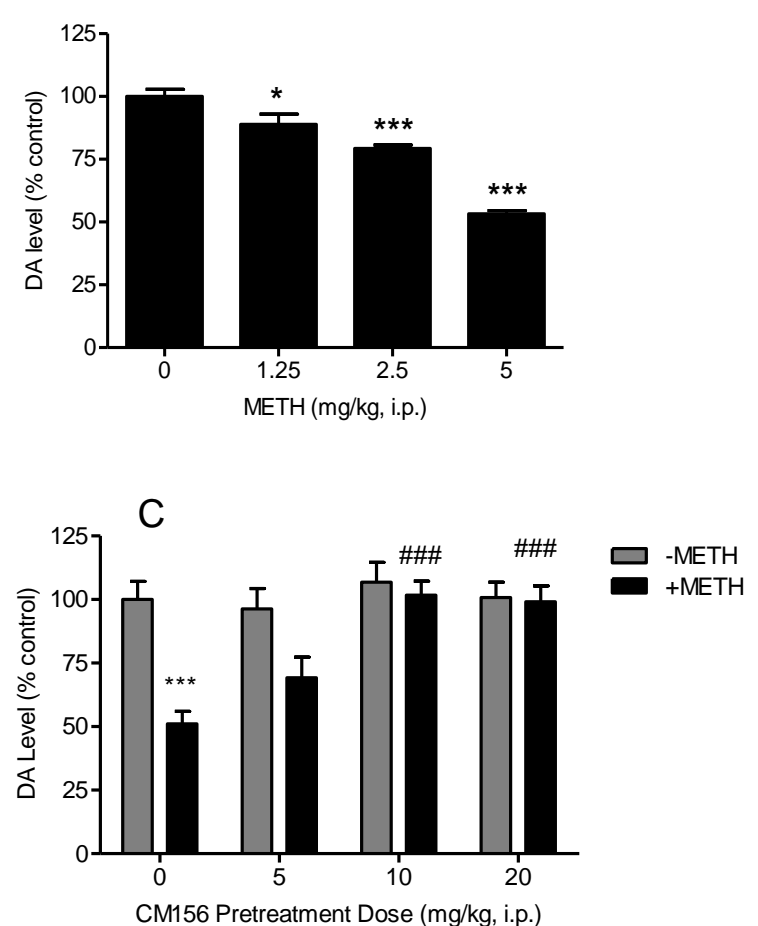

B
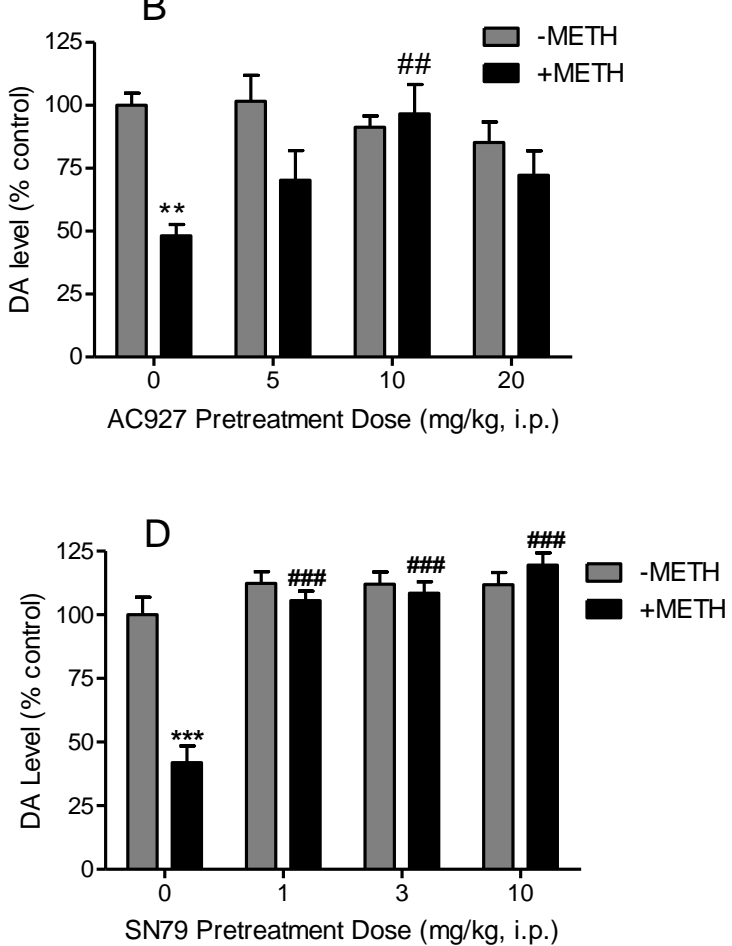

Figure 2.2 Dopamine assays: A. Dose response of METH. B, C and D. Effect of AC927, CM156 and SN79 pretreatment on METH-induced striatal dopamine depletion. (A) Dose response effects of METH on dopamine (DA) levels in the striatum. Male, Swiss Webster mice ( $n=5-9$ per group) were injected (i.p.) with METH (1.25-5.0 mg/kg, i.p.) or saline $(0 \mathrm{mg} / \mathrm{kg}$, i.p.) at $2 \mathrm{~h}$ intervals for a total of four times. DA levels in the striatum were measured one week later. (B, C, D) Effects of CM156 on METHinduced depletion of dopamine (DA) levels in striatum of mouse brain tissue. Male, Swiss Webster mice ( $n=5$ per group) were pretreated with saline or $\operatorname{AC927~(5,10,20~mg/kg,~i.p.)~or~CM156~(5,~10,~} 20$ $\mathrm{mg} / \mathrm{kg}$, i.p.) or SN79 (1, 3, $10 \mathrm{mg} / \mathrm{kg}$, i.p.). Mice were then treated with saline (-METH $0 \mathrm{mg} / \mathrm{kg}$, i.p.) or METH (+METH $5 \mathrm{mg} / \mathrm{kg}$, i.p.) after 15min. This treatment regimen was repeated at $2 \mathrm{~h}$ intervals for a total of four times. Tissue samples from mouse striatum were collected and DA concentration was measured one week later. Data was reported as mean \pm SEM. ${ }^{*} p<0.05,{ }^{* *} p<0.01,{ }^{* *} p<0.001$ vs. saline, $\# \# p<0.01, \# \# p<0.001$ vs. METH. 
2.3.2. 5-HT assays: Figure $2.3 \mathrm{~A}$ illustrates striatal $5-\mathrm{HT}$ levels following administration of METH. A one-way ANOVA showed a significant reduction in 5-HT levels in the mouse striatum $(F(4,35)=2.93, p<0.05)$. Post-hoc Dunnett's tests confirmed that 5 -HT levels were significantly reduced relative to the saline control following injection of $10 \mathrm{mg} / \mathrm{kg}$, i.p. of METH $(q=3.38, p<0.01)$. However, in the cerebellum, METH did not produce significant $5-\mathrm{HT}$ depletions $(F(4,35)=2.33$, n.s. $)$.

Figure 2.3B shows the effects of the $\sigma$ receptor antagonist AC927 $(0-20 \mathrm{mg} / \mathrm{kg}$, i.p.) on METH-induced 5-HT depletions in the striatum of mice. To determine the effects of AC927 against METH-induced 5-HT depletions, a one-way ANOVA followed by a post-hoc Tukey's multiple comparison was run. Pretreatment with AC927 (5, 10 or $20 \mathrm{mg} / \mathrm{kg}$, i.p.) significantly attenuated the ability of METH to produce its neurotoxic effects in the striatum $(F(7,32)=4.49$, $p<0.005)$. Post-hoc Tukey's multiple comparisons tests confirmed that pretreatment with the $10 \mathrm{mg} / \mathrm{kg}$ dose of AC927 significantly attenuated the striatal $(q=6.17, p<0.01) 5-\mathrm{HT}$ depletions caused by METH.

As the one-way ANOVA showed, administration of CM156 alone produced no significant changes in striatal and cerebellar $5-\mathrm{HT}$ levels $(F(3,21)=2.37$, n.s.; and $F(3,21)=0.49$, n.s., respectively). However, similar to that seen with dopamine, a one-way ANOVA showed that pretreatment with $\mathrm{CM} 156$ protected against METH-induced 5-HT depletions in the striatum (Figure 2.3C; $F(4,34)=11.14, p<0.0001)$. Post-hoc Tukey's tests confirmed that METH treatment caused a significant depletion in striatal $5-\mathrm{HT}$ levels $(q=8.93, p<0.01)$ and that pretreatment with CM156 (20 mg/kg) significantly attenuated METH (10 mg/kg, i.p.)-induced striatal 5 -HT depletions $(q=4.92, p<0.05)$ when compared to pretreatment with saline.

One-way ANOVA showed that administration of SN79 alone produced no significant changes in $5-\mathrm{HT}$ levels in cerebellum and striatum $(2.3 \mathrm{D}, F(3,19)=0.24$, ns and $F(3,38)=$ 0.72, ns respectively). When SN79 is given as a pretreatment prior to METH treatment, two- 
way ANOVA showed a significant effect of METH treatment $(F(1,71)=9.60, p<0.005)$, SN79 pretreatment $(F(3,71)=5.26, p<0.005)$ and SN79 pretreatment $\times$ METH treatment interaction $(F(3,71)=3.29, p<0.05)$. Post-hoc Tukey's test showed that METH treatment caused a significant decrease in striatal 5 -HT levels $(q=5.86, p<0.01)$ and that SN79 pretreatment is able to significantly prevent the METH-induced decrease in 5-HT levels (SN79 dose: $1 \mathrm{mg} / \mathrm{kg}$, $q=4.95, p<05 ; 3 \mathrm{mg} / \mathrm{kg}, q=5.29, p<0.01$ and $10 \mathrm{mg} / \mathrm{kg}, q=6.88, p<0.001)$. 

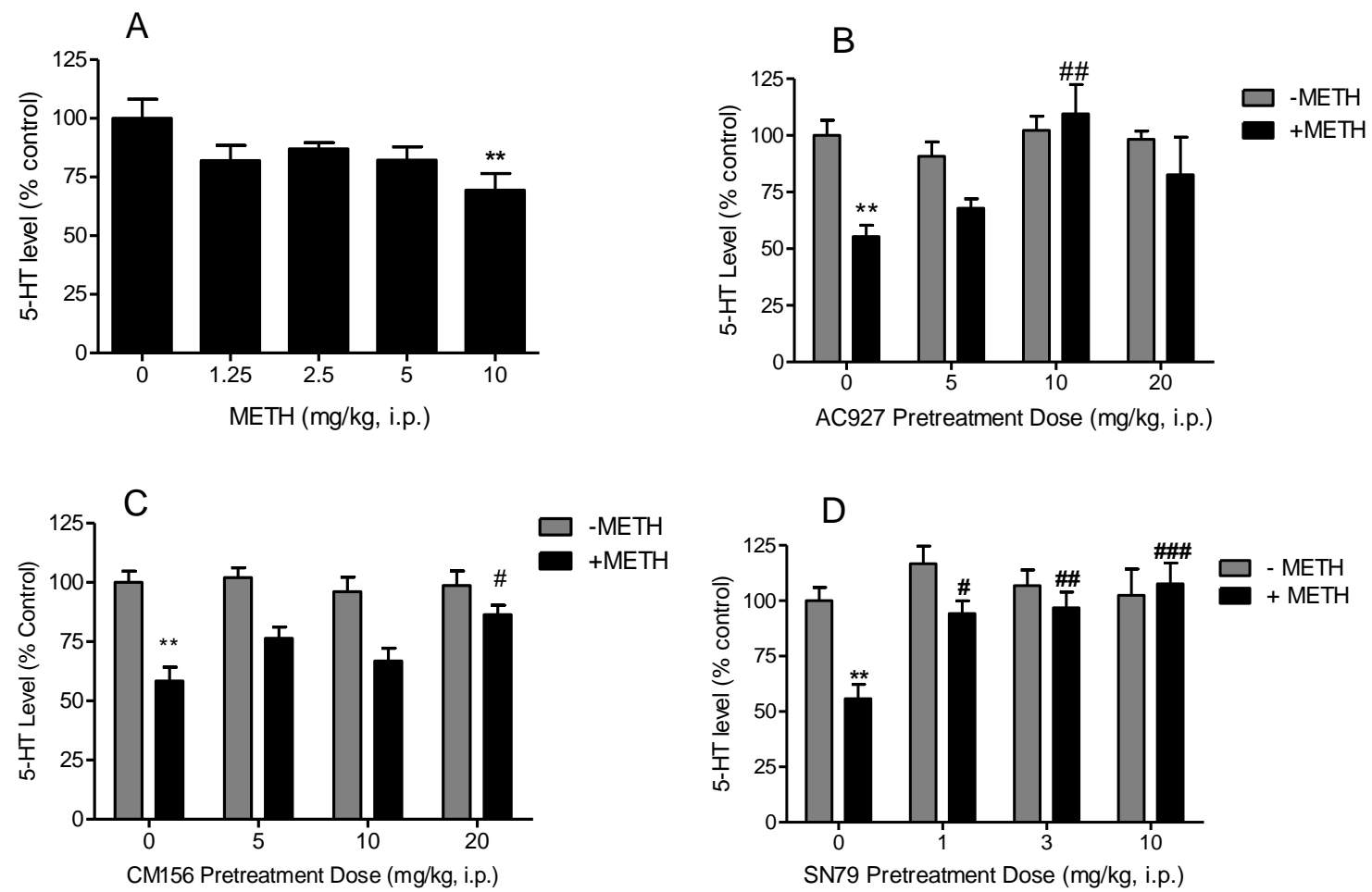

Figure 2.3 5-HT assays: A. Dose response of METH. B,C and D. Effect of AC927, CM156 and SN79 pretreatment on METH-induced striatal 5-HT depletion. (A) Dose response effects of METH on 5-HT levels in the striatum. Male, Swiss Webster mice ( $n=5-10$ per group) were injected with saline or METH (1.25-10.0 mg/kg, i.p.) or saline ( $0 \mathrm{mg} / \mathrm{kg}$, i.p.) at $2 \mathrm{~h}$ intervals for a total of four times. Striatal tissue samples were collected one week later and measured for 5-HT concentration. (B, C, D) Effect of AC927, CM156 and SN79 pretreatment on METH-induced alteration of 5-HT levels in the striatum of mouse brain. Male, Swiss Webster mice ( $n=5-10$ per group) were pretreated with saline or AC927 (5, $10,20 \mathrm{mg} / \mathrm{kg}$, i.p.) or CM156 (5, 10, $20 \mathrm{mg} / \mathrm{kg}$, i.p.) or SN79 (1, 3, $10 \mathrm{mg} / \mathrm{kg}$, i.p.), and $15 \mathrm{~min}$ later, the mice were treated with saline (-METH $0 \mathrm{mg} / \mathrm{kg}$, i.p.) or METH (+METH $10 \mathrm{mg} / \mathrm{kg}$, i.p.). These treatment combinations were repeated at $2 \mathrm{~h}$ intervals a total of four times. One week later, mouse striatum were collected and 5-HT concentration was measured. Data was reported as mean \pm SEM. ${ }^{* *} p<0.01$ vs. saline, $\# p<0.05, \# \#<0.01, \# \# p<0.001$ vs. METH. 
2.2.5. DAT immunohistochemistry: Figure 2.4A illustrates the effects of METH and AC927 on DAT immunoreactivity in the mouse striatum. ANOVA revealed a significant difference between the treatment groups $(F(3,12)=43.76, p<0.0001)$. Post-hoc Tukey's multiple comparison tests confirmed that METH caused a significant reduction in DAT immunoreactivity $(q=14.26, p<0.001)$. Pretreatment with AC927 significantly attenuated the METH-induced neurotoxicity $(q=13.63, p<0.001)$, whereas treatment with AC927 alone had no significant effects on DAT expression $(q=3.56$, n.s.).

Immunohistochemical analysis of striatal DAT expression confirmed that the METHinduced reductions in striatal dopamine levels were linked to degeneration of dopaminergic nerve terminals. Figure $2.4 \mathrm{~B}$ depicts the effects of METH and CM156 on DAT immunoreactivity in the mouse striatum, with a significant difference between the treatment groups $(F(3,34)=14.89, p<0.0001)$. Post-hoc Tukey's multiple comparisons tests confirmed that METH caused a significant reduction in DAT immunoreactivity relative to treatment with saline alone $(q=7.70, p<0.001)$. Pretreatment with $\mathrm{CM} 156(10 \mathrm{mg} / \mathrm{kg})$ significantly attenuated METH-induced neurotoxicity $(q=7.90, p<0.001)$, whereas treatment with CM156 alone had no significant effects on DAT expression ( $q=0.75$, n.s.).

Figure 2.4C illustrates the effects of METH and SN79 on DAT immunoreactivity in the mouse striatum. ANOVA revealed a significant difference between the treatment groups $(F(3,71)=162.90, p<0.0001)$. Post-hoc Tukey's multiple comparison tests confirmed that METH caused a significant reduction in DAT immunoreactivity $(q=28.66, p<0.001)$. Pretreatment with SN79 significantly attenuated the METH-induced neurotoxicity $(q=24.66, p$ $<0.001$ ), whereas treatment with SN79 alone had no significant effects on DAT expression ( $q$ $=1.81$, n.s.). 

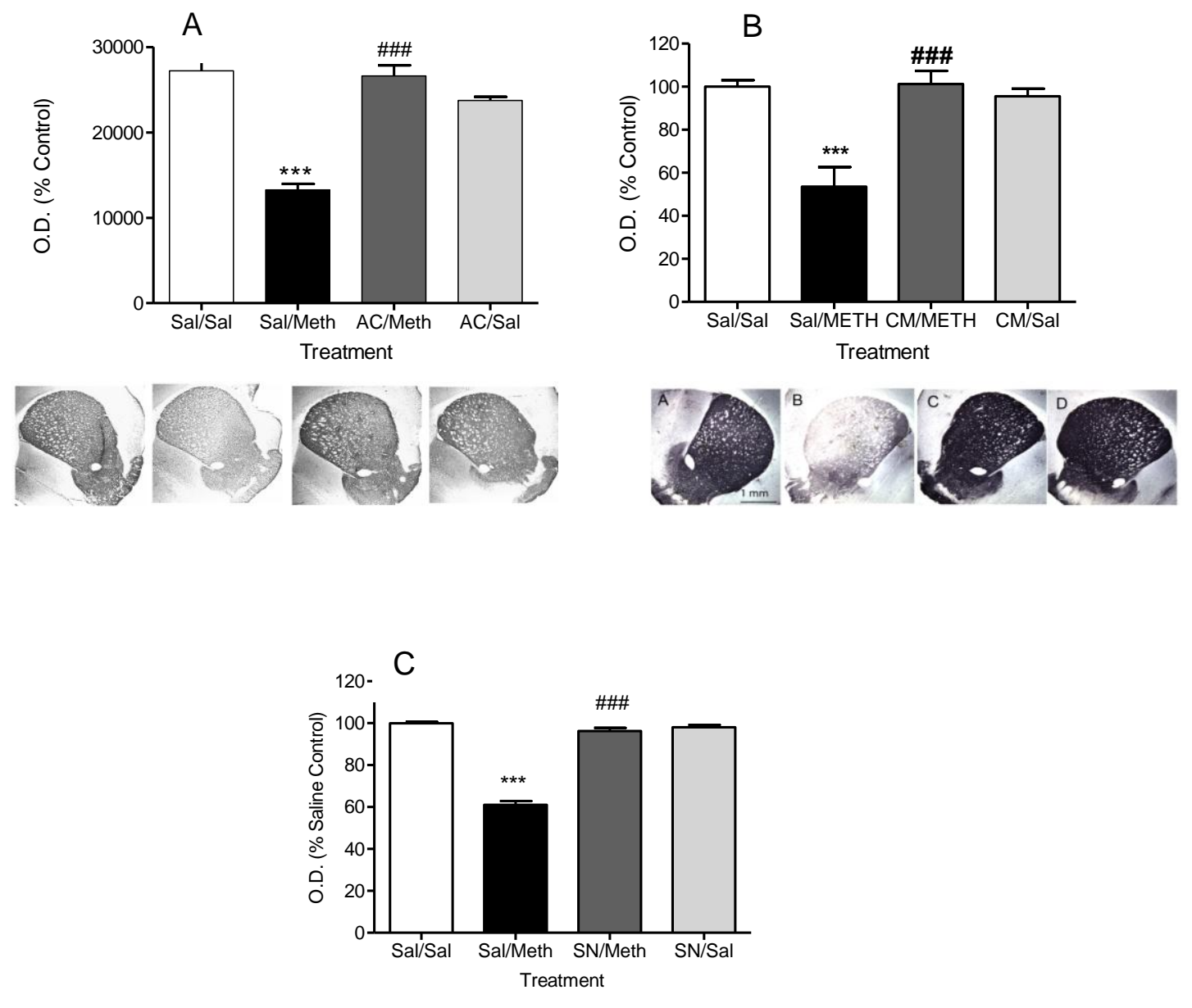

Figure 2.4 DAT Immunohistochemistry: Effect of (A) AC927, (B) CM156 and (C) SN79 pretreatment on METH-induced decrease in striatal DAT levels. Male, Swiss Webster mice $(n=4$ per group) were pretreated with saline (SAL) or AC927 (AC, $10 \mathrm{mg} / \mathrm{kg}$, i.p.) or CM156 (CM, $10 \mathrm{mg} / \mathrm{kg}$, i.p.) or SN79 (SN, $3 \mathrm{mg} / \mathrm{kg}$, i.p.). After $15 \mathrm{~min}$, the mice were then treated with saline (SAL) or METH (5 $\mathrm{mg} / \mathrm{kg}$, i.p.). This treatment schedule was repeated 4 times at $2 \mathrm{~h}$ intervals. One week later, the brain was removed and stained for DAT immunoreactivity. A representative section from each treatment group is shown, along with average optical density readings (mean $\pm \mathrm{SEM}$ ). ${ }^{* *} p<0.001$ vs. saline, $\# \#$ \# 0001 vs. METH. 
2.2.6. SERT immunohistochemistry: Immunohistochemical analysis revealed that METH induced reductions in striatal SERT expression. One-way ANOVA showed that METH caused a significant decrease in SERT expression in the striatum of the mice (Figure $2.5 \mathrm{~A} ; F(2,20)=$ 56.67, $p<0.0001)$. Post-hoc Dunnett's tests showed that both 5 and $10 \mathrm{mg} / \mathrm{kg}$ doses of METH significantly reduced striatal SERT expression $(q=9.27, p<0.01$ and $q=8.41, p<$ 0.01 , respectively).

The effects of METH and AC927 on SERT immunoreactivity in the mouse striatum were explored in order to confirm that 5-HT depletions were a result of nerve terminal damage (Figure 2.5B). Significant difference between the treatment groups $(F(5,47)=50.85, p<$ 0.0001) were revealed using a one-way ANOVA. Post-hoc Tukey's multiple comparisons tests confirmed that METH (5 and $10 \mathrm{mg} / \mathrm{kg}$ ) caused a significant reduction in SERT immunoreactivity relative to treatment with saline alone $(q=15.90, p<0.001$ and $q=14.43, p$ $<0.001$ respectively). Pretreatment with AC927 (10 mg/kg) significantly attenuated METH (5 and $10 \mathrm{mg} / \mathrm{kg}$ )-induced neurotoxicity $(q=12.98, p<0.001$ and $q=11.85, p<0.001$ respectively), whereas treatment with AC927 alone had no significant effects on SERT expression $(q=0.87$, n.s.).

Immunohistochemical analysis of striatal SERT expression confirmed that the METHinduced reductions in striatal 5-HT levels were linked to degeneration of serotonergic nerve terminals. Figure 2.5C depicts the effects of METH and CM156 on SERT immunoreactivity in the mouse striatum, with a significant difference between the treatment groups $(F(5,44)=$ 45.42, $p<0.0001$ ). Post-hoc Tukey's multiple comparisons tests confirmed that METH (5 and $10 \mathrm{mg} / \mathrm{kg}$ ) caused a significant reduction in SERT immunoreactivity relative to treatment with saline alone $(q=15.07, p<0.001$ and $q=13.67, p<0.001$ respectively). Pretreatment with CM156 $(20 \mathrm{mg} / \mathrm{kg})$ significantly attenuated METH (5 and $10 \mathrm{mg} / \mathrm{kg})$-induced neurotoxicity $(q=$ 
13.17, $p<0.001$ and $q=8.10, p<0.001)$, whereas treatment with CM156 alone had no significant effects on SERT expression ( $q=0.4$, n.s.).

Figure 2.5D illustrates the effects of METH and SN79 on SERT immunoreactivity in the mouse striatum. ANOVA revealed a significant difference between the treatment groups $(F(3,54)=53.73, p<0.0001)$. Post-hoc Tukey's multiple comparison tests confirmed that METH caused a significant reduction in SERT immunoreactivity $(q=15.07, p<0.001)$. Pretreatment with SN79 significantly attenuated the METH-induced neurotoxicity $(q=14.81, p$ $<0.001$ ), whereas treatment with SN79 alone had no significant effects on SERT expression $(q=2.91$, n.s. $)$ 

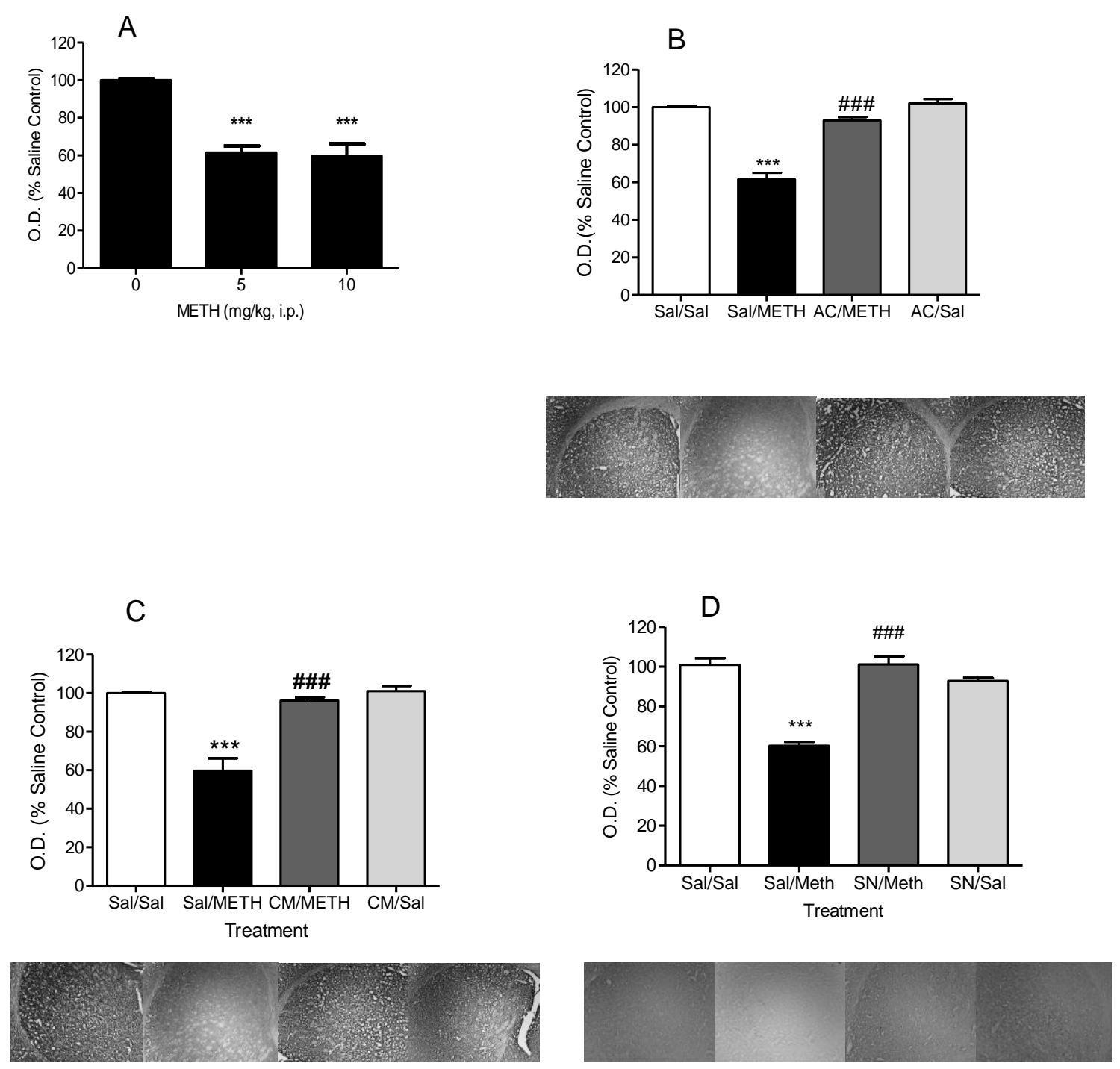

Figure 2.5 SERT Immunohistochemistry: Effect of (A) AC927, (B) CM156 and (C) SN79 pretreatment on METH-induced decrease in striatal SERT levels. Male, Swiss Webster mice $(n=4$ per group) were injected with METH (5, $10 \mathrm{mg} / \mathrm{kg}$, i.p.) or saline at $2 \mathrm{~h}$ intervals for a total of four times. One week later, the brain was removed and stained for SERT immunoreactivity. (B, C, D) Male, Swiss Webster mice ( $n=4$ per group) were pretreated with saline (SAL) or AC927 (AC, $10 \mathrm{mg} / \mathrm{kg}$, i.p.) or CM156 (CM, $20 \mathrm{mg} / \mathrm{kg}$, i.p.) or SN79 (SN, $3 \mathrm{mg} / \mathrm{kg}$, i.p.). After $15 \mathrm{~min}$, the mice were then treated with saline (SAL) or METH (5 mg/kg, i.p.). This treatment schedule was repeated 4 times at $2 \mathrm{~h}$ intervals. One week later, the brain was removed and stained for SERT immunoreactivity. A representative section from each treatment group is shown, along with average optical density readings (mean \pm SEM). ${ }^{* * *} p<0.001$ vs. saline, $\# \# \#<0001$ vs. METH. 


\subsection{Discussion}

The current study demonstrates that pretreatment with AC927, CM156 and SN79 can mitigate METH-induced decreases in striatal dopamine and 5-HT levels and DAT and SERT expression levels. These protective effects likely involve modulation through both $\sigma_{1}$ and $\sigma_{2}$ receptors. The implications of the results are discussed below.

Consistent with the literature, high subchronic dose administration of METH leads to dopaminergic and serotonergic neurotoxicity (Krasnova and Cadet, 2009). The striatal and cerebellar brain regions were evaluated for the neurotoxic effects of METH. Since METH is retained for a longer time in the striatum as compared to the control cerebellum brain region, this explains why no significant neurotoxicity was seen in the cerebellum (Fowler et al., 2007). The damage to 5-HT neurons was observed at comparatively higher doses than dopamine neurons, most likely because METH has higher affinity for DAT than SERT (Han and Gu, 2006). In addition, METH causes greater release of dopamine than 5-HT in the striatum (Gough et al., 2002), providing an opportunity for increased oxidative damage to dopaminergic neurons. For the striatal 5-HT neurotoxicity studies, SERT immnunohistochemistry and 5-HT depletion experiments were performed in different buildings with slightly different ambient temperatures $\left(5-\mathrm{HT}: 21-22^{\circ} \mathrm{C}\right.$, SERT: $\left.23-23.5{ }^{\circ} \mathrm{C}\right)$. Since $5-\mathrm{HT}$ neurotoxicity is sensitive to changes in ambient room temperature (Malberg and Seiden, 1997; Malberg and Seiden, 1998), this may explain the difference in dose response between the two experiments

In this study, AC927, CM156 and SN79 pretreatment protected against two markers of $\mathrm{METH}$-induced striatal dopamine and serotonin nerve terminal degeneration (dopamine and 5-HT depletion and reductions in DAT and SERT expression levels), thus providing evidence of neuroprotection.

Although the mechanisms of METH-induced neurotoxicity are not very well understood, there are some evidences in the literature suggesting the involvement of the following 
cascades of events: excessive release of monoamines like dopamine and 5-HT, autooxidation of monoamines leading to reactive oxygen species generation, ER stress and activation of mitochondrial death cascades as well as glutamatergic/NMDA-mediated excitotoxic mechanisms (Kaushal and Matsumoto, 2011). AC927, CM156 and SN79 can provide neuroprotection by acting through $\sigma$ receptors and competitively or non-competitively intervening at the previously described METH's downstream mechanisms (Kaushal and Matsumoto, 2011). First, $\sigma$ receptors are located on dopamine and 5-HT neurons, and can modulate the release of these neurotransmitters (Campbell et al., 1989; Bastianetto et al., 1995; Derbez et al., 2002). Second, $\sigma$ receptors have been implicated in protective effects against ROS-related dysfunctions such as brain ischemia (Schetz et al., 2007). Third, presence of $\sigma$ receptors at the ER and mitochondria and its function as a chaperone between these organelles can help regulate the ER stress and mitochondrial death cascades (Tsai et al., 2009; Su et al., 2010). Fourth, $\sigma$ receptors can modulate NMDA receptor function, and have been shown to protect against excitotoxic mechanisms in ischemic stroke models, midbrain and cortical dopaminergic neurons, and retinal ganglion cells (DeCoster et al., 1995; Shimazu et al., 2000; Shen et al., 2008). Taking all these observations from the literature and the results obtained from this study into consideration, the neuroprotective effects of $\sigma$ receptor antagonists may be due to their ability to modulate various steps in METH's neurotoxic cascade.

$\sigma$ Receptors, due to their properties of intracellular translocation, protein-protein interaction and chaperone activity can help normalize a disordered system (Tsai et al., 2009). Therefore, in addition to mitigating $\mathrm{METH}$-induced neurotoxicity, targeting $\sigma$ receptors has also been reported to effectively attenuate neurotoxicity in several other models including $\beta$-amyloid, carbon monoxide, and excitotoxicity (Marrazzo et al., 2005; Meunier et al., 2006; Shen et al., 2008). Additionally, $\sigma$ receptors may play a role in animal models of neuropsychiatric 
complications like depression, psychosis, cognitive and motor deficits (Guitart et al., 2004; Mishina et al., 2005), which are also observed in METH users and have been associated with the neurotoxic effects of METH (Cruickshank and Dyer, 2009).

In conclusion, pretreatment with AC927, CM156 and SN79 significantly protects against METH's dopamine and 5-HT neurotoxicity. Together with other studies, the data suggest an important role of $\sigma$ receptors in various $\mathrm{METH}$-induced complications, and suggest a mechanistic-based strategy for mitigating these adverse effects. Future studies will be conducted to provide a more complete understanding of the underlying mechanisms through which $\sigma$ ligands convey neuroprotective actions.

2.4 Contributions: Nidhi Kaushal conducted the Dopamine ELISA studies for SN79; 5-HT ELISA studies for CM156 and SN79; DAT immunohistochemistry studies for SN79 and SERT immunohistochemistry studies for AC927, CM156 and SN79.

Dr. Jamaluddin Shaikh performed the DAT immunohistochemistry studies for AC927 and CM156; Dopamine ELISA studies for AC927 and CM156; and 5-HT ELISA studies for AC927. 


\section{CHAPTER 3}

\section{EVALUATION OF AC927, CM156 AND SN79 AGAINST METH- INDUCED HYPERTHERMIA}




\subsection{Introduction}

Methamphetamine is a highly abused drug which produces neurotoxic effects and psychiatric complications (Davidson et al., 2001; Cadet et al., 2003). High or repeated METH administration also causes an elevation in body temperature (Fukumura et al., 1998; Numachi et al., 2007). Previous clinical reports and animal studies suggest the lethality produced by METH is closely related with hyperthermia, which may be the primary cause of death (Bowyer et al., 1994; Davidson et al., 2001).Earlier studies have shown that hyperthermia potentiates METH-induced dopamine and 5-HT depletions and exacerbates oxidative stress in the brain (Bowyer et al., 1994; Hirata et al., 1995; Fukumura et al., 1998), whereas hypothermia protects against these effects (Bowyer et al., 1994). Therefore, the hyperthermic effect of METH is an essential factor for the neurotoxic effects of METH. It is critical to verify if the neuroprotective effects of these $\sigma$ receptor antagonists is dependent on their ability to decrease the hyperthermic effects of METH.

Recent evidence has shown that METH produces some of its physiological and behavioral effects through $\sigma$ receptors (Nguyen et al., 2005). $\sigma$ Receptors can be found on monoaminergic neurons (Booth and Baldessarini, 1991; Bastianetto et al., 1995) and modulate the release of neurotransmitters such as dopamine and serotontin, which have been linked to changes in body temperature (Lee et al., 1985; Gonzalez et al., 1986; Lipton and Clark, 1986; Schwartz et al., 1995; Salmi and Ahlenius, 1998). In addition, $\sigma$ receptor ligands can modulate thermoregulation (Rawls et al., 2002), likely mediated through an association between thermosensitive neurons and $\sigma$ receptors in the hypothalamus (Bouchard and Quirion, 1997). 
The present study investigated whether METH-induced hyperthermia could be prevented using the $\sigma$ receptor antagonists AC927, CM156 and SN79. Two wellknown markers of neurotoxicity were also evaluated; striatal dopamine and serotonin levels, results of which have been shown in Chapter 2. Striatal tissue was used in the present investigation because it contains the terminals of monoaminergic neurons and is the region primarily affected by METH-induced neurotoxicity (Brunswick et al., 1992; Kovachich et al., 1989; Ricaurte et al., 1980; Seiden et al., 1988). Using correlation analysis, it was also determined if the body temperatures of mice in each of the treatment groups can be correlated with striatal dopamine and serotonin levels.

\subsection{Methods}

3.2.1. Animals: Male, Swiss Webster mice (18-28 g; Harlan, Indianapolis, IN) were used for the in vivo studies. They were housed in groups of five with a 12:12h light/dark cycle with food and water available ad libitum. Naïve mice were randomly assigned to different treatment groups. All procedures involving animals were performed as approved by the Institutional Animal Care and Use Committee at the West Virginia University.

3.2.2. Drugs: CM156 and SN79 were obtained from Dr. Christopher McCurdy's laboratory (University of Mississippi, University, MS). AC927 was provided by Dr. Andrew Coop (University of Maryland, Baltimore, MD). METH hydrochloride was obtained from Research Biochemicals International (Natick, MA).

3.2.3 Experimental schedule: As shown in Figure 3.1 male, Swiss Webster mice $(n=5$ 10/group) were randomly divided into four experimental groups: 1) Saline/Saline, 2) Saline/METH (1.25, 2.5, 5, $10 \mathrm{mg} / \mathrm{kg}$ ) 3) Antagonist (AC927: 5, 10, 20 mg/kg; CM156: 5, 10, 
$20 \mathrm{mg} / \mathrm{kg}$ or SN79: 1, 3, $10 \mathrm{mg} / \mathrm{kg}$ )/Saline, 4) Antagonist (AC927: 5, 10, $20 \mathrm{mg} / \mathrm{kg}$, i.p.; CM156: 5, 10, $20 \mathrm{mg} / \mathrm{kg}$, i.p. or SN79: 1, 3, $10 \mathrm{mg} / \mathrm{kg}$, i.p.)/METH (5, $10 \mathrm{mg} / \mathrm{kg}$, I.p.). The first drug was administered 15 min prior to the second drug. Each group of mice received their treatment a total of four times at two hour intervals. Core body temperature was measured $1 \mathrm{~h}$ following each of the four treatment injections with a Thermalert TH-S monitor (Physitemp Instruments Inc., Clifton, NJ). During the temperature measurements, mice were gently held at the base of the tail and a probe (RET-3) was inserted approximately $2.5 \mathrm{~cm}$ past the rectum into the colon for 8-10 s until a rectal temperature was maintained for 3-4 seconds. All procedures involving animals were performed as approved by the Institutional Animal Care and Use Committee at the University of Mississippi and West Virginia University.

3.2.4 Statistical analysis: The body temperature readings were evaluated using one-way analysis of variance (ANOVA). Post-hoc analyses were performed with Dunnett's test for comparisons to controls and Tukey's tests for pairwise comparisons. The body temperature of the mice from each group was correlated with the striatal dopamine and 5-HT levels obtained a week later. Results from studies in Chapter 2 measuring striatal dopamine and 5-HT levels have been used for the correlation studies. For all statistical analyses, $p<0.05$ was considered statistically significant. 
Figure 3.1 Neurotoxic schedule of METH

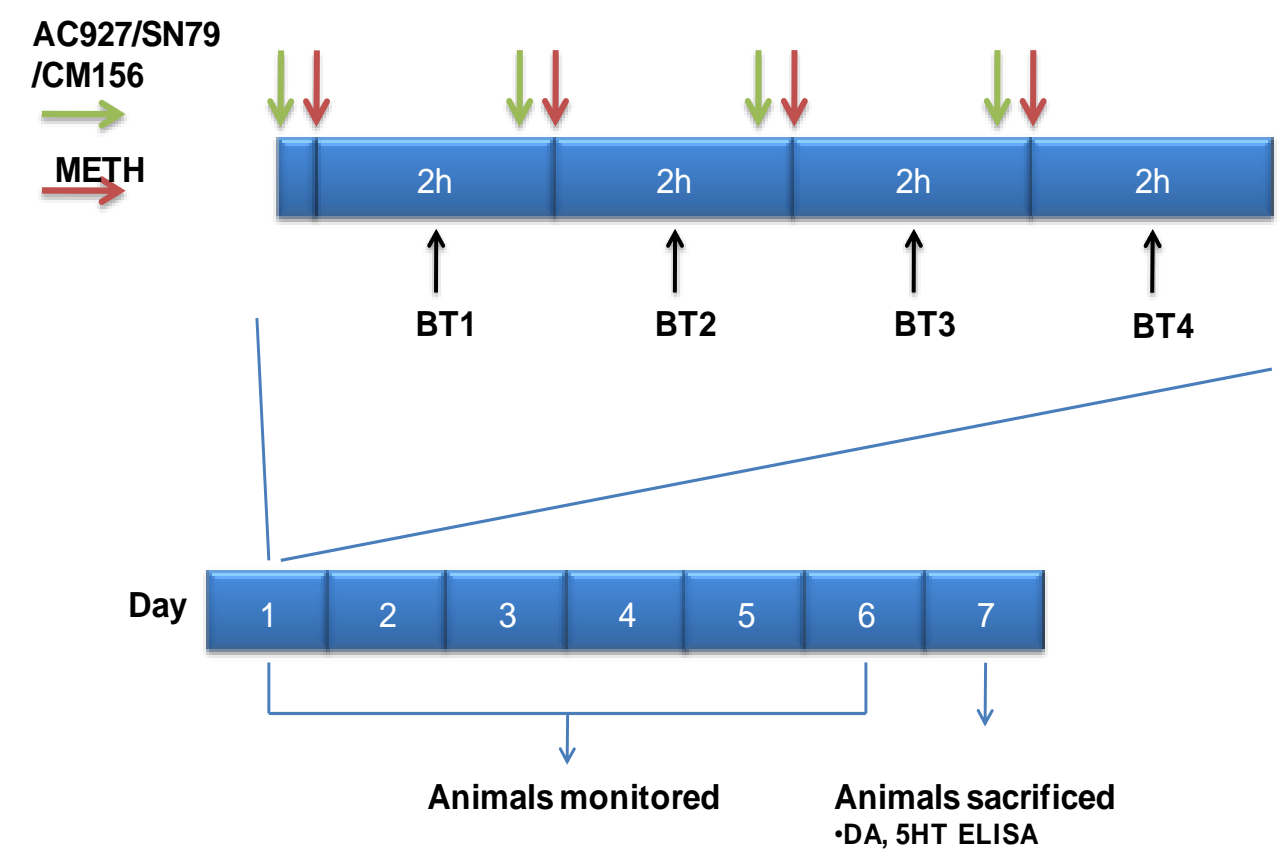




\subsection{Results}

3.3.1 Body temperature: The hyperthermic effects of METH are represented in Figure 3.2. One-way ANOVA demonstrated that METH produces a dose dependent increase in core body temperature after the first injection $(F(4,81)=7.29, p<0.0001)$, second injection $(F(4,81)=12.70, p<0.0001)$, third injection $(F(4,81)=29.21, p<0.0001)$, and fourth injection $(F(4,81)=52.72, p<0.0001)$. Post-hoc Dunnett's tests confirmed that compared to saline, the following doses of METH significantly increased body temperature under the specified conditions: after the first injection with METH $2.5 \mathrm{mg} / \mathrm{kg}(q=2.53, p<0.05), 5 \mathrm{mg} / \mathrm{kg}(q=$ 3.62, $p<0.01)$, and $10 \mathrm{mg} / \mathrm{kg}(q=4.99, p<0.01)$; after the second injection with METH 1.25 $\mathrm{mg} / \mathrm{kg}(q=4.46, p<0.01), 2.5 \mathrm{mg} / \mathrm{kg}(q=4.05, p<0.01), 5 \mathrm{mg} / \mathrm{kg}(q=6.01, p<0.01)$, and $10 \mathrm{mg} / \mathrm{kg}(q=5.52, p<0.01)$; after the third injection with METH $1.25 \mathrm{mg} / \mathrm{kg}(q=4.53, p<$ $0.01), 2.5 \mathrm{mg} / \mathrm{kg}(q=4.91, p<0.01), 5 \mathrm{mg} / \mathrm{kg}(q=9.01, p<0.01)$, and $10 \mathrm{mg} / \mathrm{kg}(q=8.95, p$ $<0.01)$; and after the fourth injection with METH $1.25 \mathrm{mg} / \mathrm{kg}(q=3.91, p<0.01), 2.5 \mathrm{mg} / \mathrm{kg}(q$ $=5.30, p<0.01), 5 \mathrm{mg} / \mathrm{kg}(q=9.46, p<0.01)$ and $10 \mathrm{mg} / \mathrm{kg}(q=13.57, p<0.01)$.

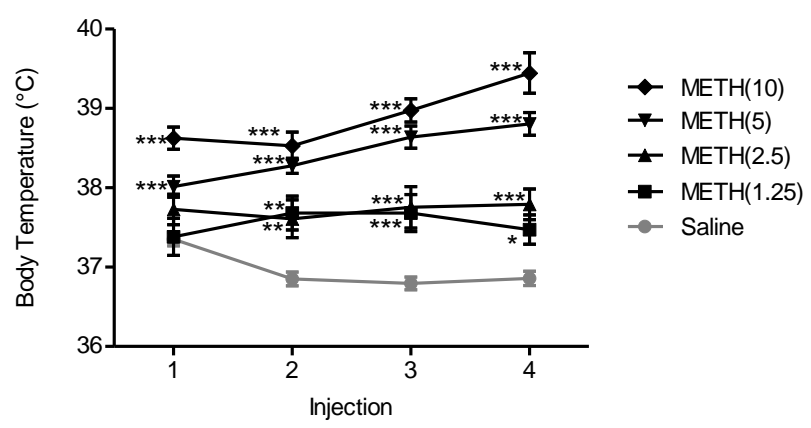

Figure 3.2 Dose response of METH-induced hyperthermia Dose response effects of METH on core body temperature. Male, Swiss Webster mice ( $n=5-10$ per group) were injected with saline or METH $(1.25-10 \mathrm{mg} / \mathrm{kg}$, i.p.) at $2 \mathrm{~h}$ intervals for a total of four times. Core body temperature was measured via rectal thermometer $1 \mathrm{~h}$ after each injection and data was reported as mean \pm SEM. ${ }^{*} p<0.05,{ }^{* *} p<$ $0.01,{ }^{* * *} p<0.001$ vs. saline. 
AC927, on the other hand, did not significantly change core body temperature after the first injection (Figure 3.3A, $F(3,19)=1.29, n s)$, second injection $(F(3,19)=1.02$, $n s$ ), third injection $(F(3,19)=1.25, n s)$ and fourth injection $(F(3,19)=1.44, n s)$. However, pretreatment with AC927 significantly attenuated the ability of METH to produce its hyperthermic effects (Figure 3.3B; after 2nd injection, $F(4,20)=5.86, p<0.005$ and 3rd injection, $F(4,20)=9.12, p$ $<0.0005)$.
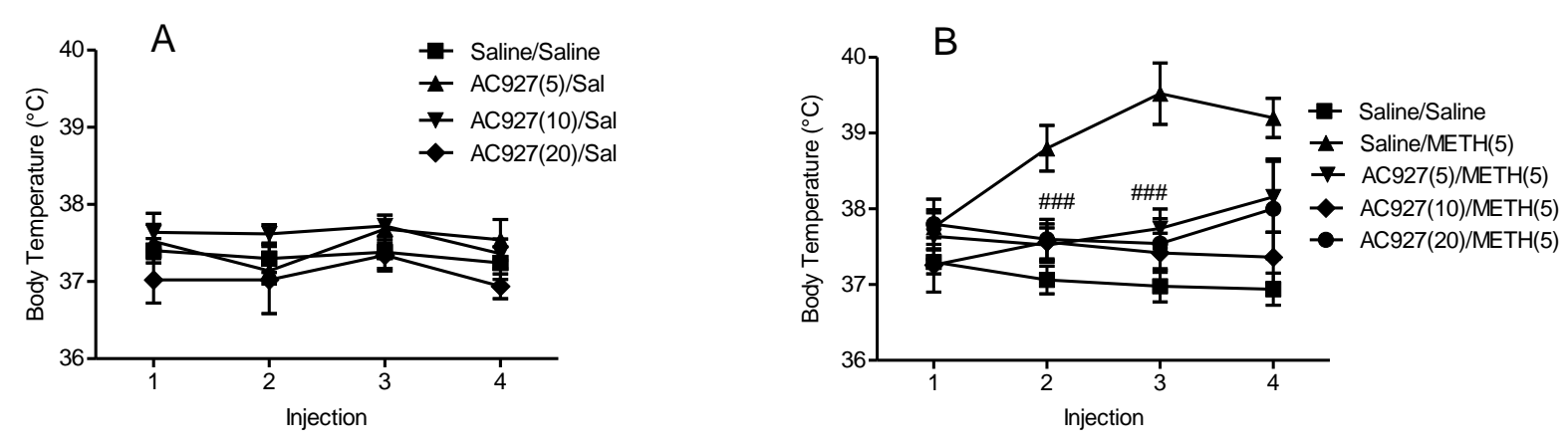

Figure 3.3 Effect of AC927 on basal body temperature, and METH-induced hyperthermia in mice. Effect of (A) AC927 (5, 10, 20 mg/kg, i.p.) alone on core body temperature, (B) Saline or AC927 (5, 10, $20 \mathrm{mg} / \mathrm{kg}$, i.p.) pretreatment on METH (5 mg/kg, i.p.)-induced hyperthermia. Male, Swiss Webster mice ( $n=5-10$ per group) were pretreated with saline or $\operatorname{AC9} 27(5,10,20 \mathrm{mg} / \mathrm{kg}$, i.p.), and after $15 \mathrm{~min}$, the mice were treated with saline or METH (5 mg/kg, i.p.). Core body temperature was measured $1 \mathrm{~h}$ after each injection combination. This regimen was repeated four times at $2 \mathrm{~h}$ intervals. Data was reported as mean \pm SEM. \#\#\#p<0.001 vs. METH. 
The effects of CM156 alone on body temperature are depicted in Figure 3.4A. One-way ANOVA showed that CM156 alone had no significant effects on body temperature after the first $(F(3,36)=0.05$, n.s. $)$, second $(F(3,36)=1.81$, n.s. $)$, third $(F(3,36)=1.37$, n.s. $)$, or fourth $(F(3,36)=1.68$, n.s. $)$ injection. Pretreatment with CM156 attenuated METH $(5 \mathrm{mg} / \mathrm{kg}$, i.p.)induced hyperthermia after all but the first injection (Figure 3.4B): first $(F(3,51)=0.99$, n.s.); second $(F(3,51)=7.56, p<0.0005)$; third $(F(3,51)=10.44, p<0.0001)$; fourth $(F(3,51)=$ 15.79, $p<0.0001)$. Post-hoc Dunnett's tests showed that the following changes were significant from the second injection onwards: after the second injection, CM156 (20 mg/kg, i.p.), when compared to saline-pretreatment, significantly mitigated the hyperthermia effects of $\operatorname{METH}(q=4.47, p<0.01)$; after third injection, $\operatorname{CM156~(5,10~and~} 20 \mathrm{mg} / \mathrm{kg}$, i.p.) attenuated the hyperthermic effects of METH $(q=2.51, p<0.05 ; q=3.71, p<0.01$ and $q=5.09, p<$ 0.01 respectively); after the fourth injection, CM156 (10 and $20 \mathrm{mg} / \mathrm{kg}$, i.p.) attenuated the hyperthermic effects of METH ( $q=3.82, p<0.01$ and $q=6.59, p<0.01$ respectively).

Figure 3.4C shows the effects of pretreatment with the $\square$ receptor antagonist CM156 against the hyperthermia produced by a high (10 mg/kg, i.p.) dose of METH. One-way ANOVA showed a significant attenuation of METH-induced hyperthermia after the fourth injection (first: $F(3,21)=1.20$, n.s.; second: $F(3,21)=1.29$, n.s.; third: $F(3,21)=2.57$, n.s.; fourth: $F(3,21)=21.18, p<0.0001)$. Post-hoc Tukey's tests revealed that pretreatment with CM156 (10 and $20 \mathrm{mg} / \mathrm{kg}$, i.p.) attenuated the hyperthermic effects of METH after the fourth injection ( $q=3.68, p<0.01 ; q=7.86, p<0.01$ respectively). 


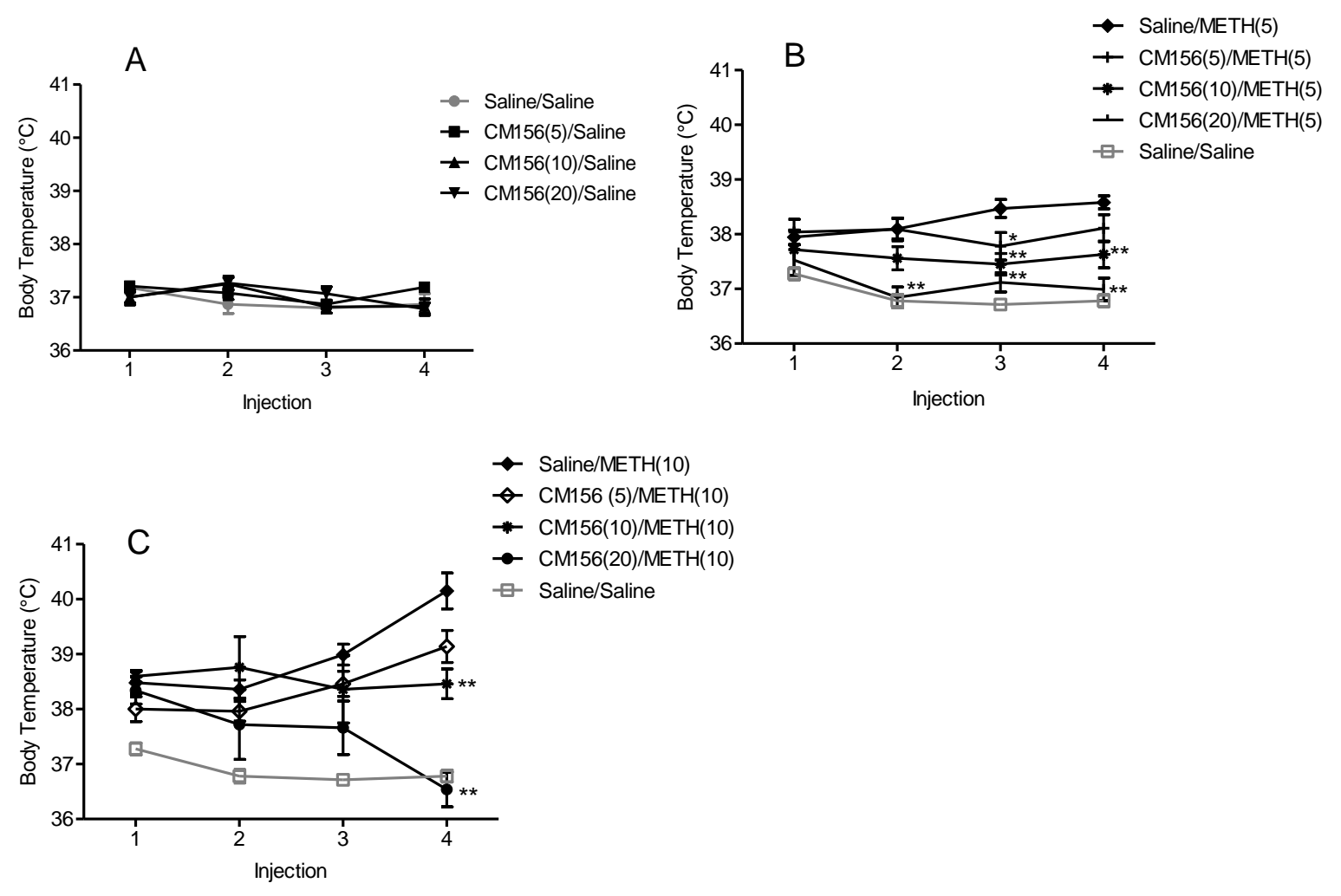

Figure 3.4 Effect of CM156 on basal body temperature and METH (5 and $10 \mathrm{mg} / \mathrm{kg}$ )-induced hyperthermia in mice Effects of CM156 on (A) basal body temperature, (B) METH (5 mg/kg, i.p.) or (C) METH (10 mg/kg, i.p.) induced hyperthermia. Male, Swiss Webster mice ( $n=5-10$ per group) were pretreated with saline or CM156 (5, 10, $20 \mathrm{mg} / \mathrm{kg}$, i.p.), and after $15 \mathrm{~min}$, the mice were treated with saline or METH (5, $10 \mathrm{mg} / \mathrm{kg}$, i.p.). Core body temperature was measured $1 \mathrm{~h}$ after each injection combination. This regimen was repeated four times at $2 \mathrm{~h}$ intervals. Data was reported as mean \pm SEM. ${ }^{*} p<0.05,{ }^{* *} p<0.05$ vs. METH. 
One-way ANOVA showed that SN79 treatment significantly reduced body temperature (Figure $3.5 \mathrm{~A})$ when compared with saline treated mice after the first injection $(F(3,59)=$ 21.77, $p<0.0001)$, second injection $(F(3,59)=20.12, p<0.0001)$, third injection $(F(3,59)=$ 11.34, $p<0.0001)$ and fourth injection $(F(3,59)=18.01, p<0.0001)$. Post-hoc Dunnetts test revealed that SN79 $(10 \mathrm{mg} / \mathrm{kg})$ significantly decreased the basal body temperature after first injection $(q=6.54, p<0.001)$, second injection $(q=5.98, p<0.001)$, third injection $(q=4.36$, $p<0.001)$ and fourth injection $(q=5.58, p<0.001)$.

One-way ANOVA showed that SN79 pretreatment is able to significantly attenuate the hyperthermic effects of METH (Figure 3.5B and C) after the first injection $(F(11,123)=24.04$, $p<0.0001)$, second injection $(F(11,123)=15.40, p<0.0001)$, third injection $(F(11,123)=$ 18.25) and fourth injection $(F(11,123)=18.21)$. Post-hoc Tukey's test revealed that the following doses of SN79 attenuated the hyperthermic effects of METH $(5 \mathrm{mg} / \mathrm{kg})$ after the first injection (3 mg/kg: $q=4.84, p<0.05 ; 10 \mathrm{mg} / \mathrm{kg}: q=9.26, p<0.001)$, second injection (3 $\mathrm{mg} / \mathrm{kg}: q=5.51, p<0.01 ; 10 \mathrm{mg} / \mathrm{kg}: q=6.86, p<0.001)$, third injection $(1 \mathrm{mg} / \mathrm{kg}: q=4.80, p$ $<0.05 ; 3 \mathrm{mg} / \mathrm{kg}: q=8.41, p<0.001 ; 10 \mathrm{mg} / \mathrm{kg}: q=7.76, p<0.001)$ and fourth injection (1 $\mathrm{mg} / \mathrm{kg}: q=5.85, p<0.01 ; 3 \mathrm{mg} / \mathrm{kg}: q=7.85, p<0.001 ; 10 \mathrm{mg} / \mathrm{kg}: q=9.63, p<0.001)$. Post hoc Tukey's test also revealed that the following doses of SN79 attenuated the hyperthermic effects of METH (10 mg/kg) after the first injection $(3 \mathrm{mg} / \mathrm{kg}: q=5.71, p<0.01 ; 10 \mathrm{mg} / \mathrm{kg}: q=$ 13.34, $p<0.001)$, second injection $(1 \mathrm{mg} / \mathrm{kg}: q=5.91, p<0.01 ; 3 \mathrm{mg} / \mathrm{kg}: q=9.59, p<0.001$; $10 \mathrm{mg} / \mathrm{kg}: q=10.39, p<0.001)$, third injection $(1 \mathrm{mg} / \mathrm{kg}: q=5.18, p<0.05 ; 3 \mathrm{mg} / \mathrm{kg}: q=7.39$, $p<0.001 ; 10 \mathrm{mg} / \mathrm{kg}: q=10.20, p<0.001)$ and fourth injection $(3 \mathrm{mg} / \mathrm{kg}: q=6.94, p<0.001$; $10 \mathrm{mg} / \mathrm{kg}: q=9.84, p<0.001)$. 

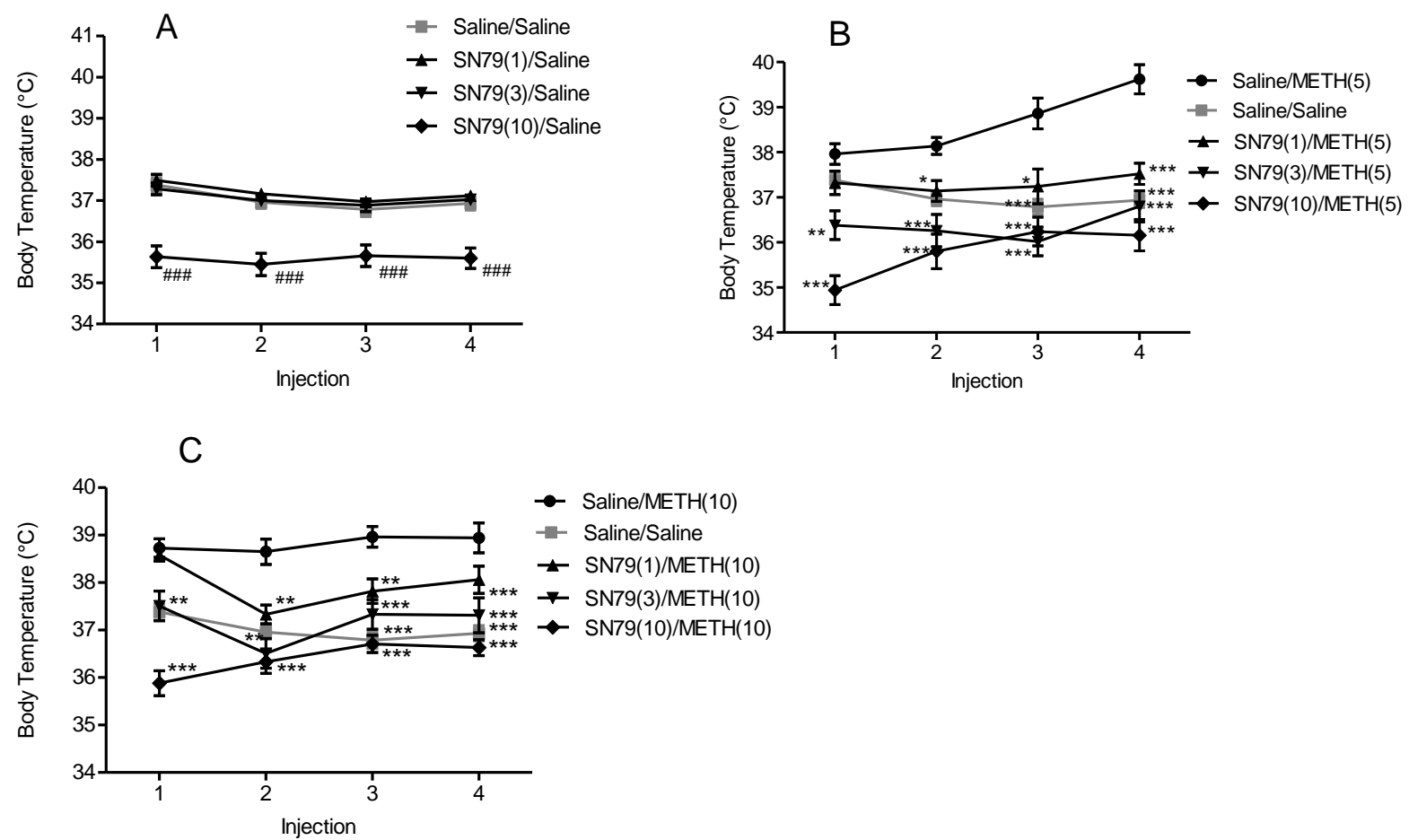

Figure 3.5 Effect of SN79 treatment on basal body temperature and METH (5 and $10 \mathrm{mg} / \mathrm{kg}$ )induced hyperthermia in mice. Effects of SN79 on (A) basal body temperature, (B) METH (5 mg/kg, i.p.) or (C) METH (10 mg/kg, i.p.) induced hyperthermia. Male, Swiss Webster mice $(n=5-10$ per group) were pretreated with saline or $\operatorname{SN} 79$ (1, 3, $10 \mathrm{mg} / \mathrm{kg}$, i.p.), and after $15 \mathrm{~min}$, the mice were treated with saline or METH $(5,10 \mathrm{mg} / \mathrm{kg}$, i.p.). Core body temperature was measured $1 \mathrm{~h}$ after each injection combination. This regimen was repeated four times at $2 \mathrm{~h}$ intervals. Data was reported as mean \pm SEM. \#\#\#p 0.001 vs. Saline; ${ }^{*} p<0.05,{ }^{* *} p<0.05,{ }^{* * *} p<0.001$ vs. METH. 
3.3.2 Correlation: Table 3.1-3.3 summarizes the mean \pm S.E.M. for each of the groups, with the statistical results shown at the bottom. The numbers in the parentheses of the treatment group column represent doses (in mg/kg, i.p.) of AC927, CM156, SN79 or METH. The correlation plot for each experiment is shown above the table. 
Figure 3.6 and Table 3.1 Correlation of body temperature and striatal (A) dopamine (DA) and (B) 5-HT levels of mice pretreated with saline or AC927(5-20 mg/kg) prior to saline or METH $(5 \mathrm{mg} / \mathrm{kg})$

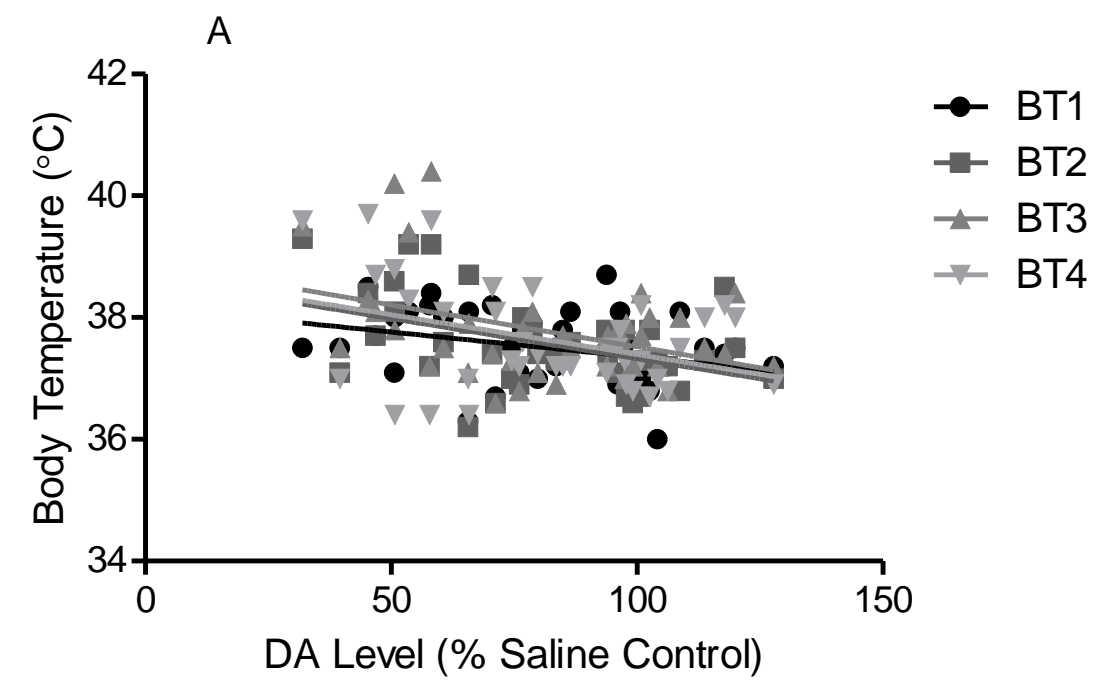

\begin{tabular}{|llllll|}
\hline Treatment Group & $\begin{array}{l}\text { DA } \\
\text { Control) }\end{array}$ & BT1 & BT2 & BT3 & BT4 \\
\hline Sal/Sal & $100 \pm 4.83$ & $37.4 \pm 0.16$ & $37.3 \pm 0.18$ & $37.38 \pm 0.21$ & $37.24 \pm 0.21$ \\
\hline Sal/Meth(5) & $48.21 \pm 4.45$ & $37.76 \pm 0.23$ & $38.8 \pm 0.30$ & $39.52 \pm 0.40$ & $39 \pm 0.26$ \\
\hline AC927(5)/Meth(5) & $67.19 \pm 11.28$ & $37.64 \pm 0.31$ & $37.52 \pm 0.23$ & $37.74 \pm 0.26$ & $38.16 \pm 0.47$ \\
\hline AC927(10)/Meth(5) & $96.64 \pm 11.69$ & $37.26 \pm 0.36$ & $37.56 \pm 0.24$ & $37.42 \pm 0.26$ & $37.36 \pm 0.33$ \\
\hline AC927(20)/Meth(5) & $69.08 \pm 9.24$ & $37.85 \pm 0.42$ & $37.53 \pm 0.33$ & $37.28 \pm 0.26$ & $37.43 \pm 0.42$ \\
\hline AC927(5)/Sal & $97.16 \pm 0.82$ & $37.52 \pm 0.22$ & $37.14 \pm 0.17$ & $37.68 \pm 0.18$ & $37.54 \pm 0.26$ \\
\hline AC927(10)/Sal & $91.27 \pm 4.46$ & $37.64 \pm 0.25$ & $37.66 \pm 0.11$ & $37.72 \pm 0.09$ & $37.36 \pm 0.19$ \\
\hline AC927(20)/Sal & $81.47 \pm 7.78$ & $37.02 \pm 0.30$ & $37.02 \pm 0.44$ & $37.34 \pm 0.20$ & $36.94 \pm 0.16$ \\
\hline $\boldsymbol{P}$ & & $<0.05$ & $<0.01$ & $<0.05$ & $<0.05$ \\
\hline Pearson $\mathbf{r}$ & & -0.3219 & -0.4313 & -0.3899 & -0.3672 \\
\hline $\mathbf{r}^{\mathbf{2}}$ & & 0.1036 & 0.186 & 0.152 & 0.1348 \\
\hline
\end{tabular}

The values from individual mice were used to calculate the correlation between core body temperature at each of the four time points and striatal dopamine levels measured one week later. The table summarizes the mean \pm S.E.M. for each of the groups, with the statistical results shown at the bottom. The numbers in the parentheses of the treatment group column represent doses (in $\mathrm{mg} / \mathrm{kg}$, i.p.) of AC927 or methamphetamine (METH). 


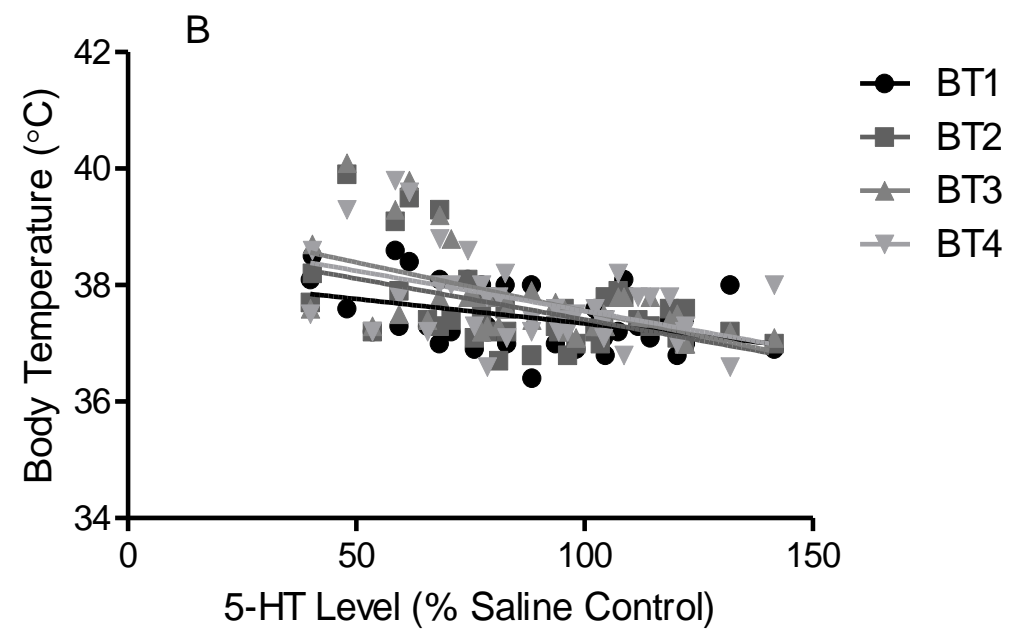

\begin{tabular}{|llllll|}
\hline Treatment Group & $\begin{array}{l}\text { 5-HT (\% Saline } \\
\text { Control) }\end{array}$ & BT1 & BT2 & BT3 & BT4 \\
\hline Sal/Sal & $100 \pm 6.71$ & $37.1 \pm 0.07$ & $37.18 \pm 0.16$ & $37.3 \pm 0.11$ & $37.38 \pm 0.12$ \\
\hline Sal/METH(5) & $55.35 \pm 4.99$ & $38.24 \pm 0.18$ & $39.2 \pm 0.28$ & $39.42 \pm 0.24$ & $39.22 \pm 0.23$ \\
\hline AC927(5)/METH(5) & $67.85 \pm 4.16$ & $37.52 \pm 0.22$ & $37.5 \pm 0.16$ & $37.5 \pm 0.13$ & $37.8 \pm 0.27$ \\
\hline AC927(10)/METH(5) & $109.55 \pm 12.86$ & $37.32 \pm 0.20$ & $37.3 \pm 0.16$ & $37.4 \pm 0.14$ & $37.28 \pm 0.23$ \\
\hline AC927(20)/METH(5) & $82.71 \pm 16.50$ & $37.5 \pm 0.23$ & $37.5 \pm 0.14$ & $37.82 \pm 0.28$ & $37.9 \pm 0.12$ \\
\hline AC927(5)/Sal & $90.77 \pm 6.37$ & $37.34 \pm 0.18$ & $37.2 \pm 0.19$ & $37.62 \pm 0.13$ & $37.34 \pm 0.26$ \\
\hline AC927(10)/Sal & $102.24 \pm 6.23$ & $37.34 \pm 0.10$ & $37.4 \pm 0.08$ & $37.46 \pm 0.06$ & $37.54 \pm 0.13$ \\
\hline AC927(20)/Sal & $98.30 \pm 3.67$ & $37.16 \pm 0.29$ & $37.3 \pm 0.22$ & $37.48 \pm 0.12$ & $37.28 \pm 0.14$ \\
\hline $\boldsymbol{P}$ & & $<0.01$ & $<0.005$ & $<0.0005$ & $<0.005$ \\
\hline Pearson $\mathbf{r}$ & & -0.4042 & -0.481 & -0.5693 & -0.4707 \\
\hline $\mathbf{r}^{2}$ & & 0.1634 & 0.2314 & 0.3241 & 0.2216 \\
\hline
\end{tabular}

The values from individual mice were used to calculate the correlation between core body temperature at each of the four time points and striatal serotonin levels measured one week later. The table summarizes the mean \pm S.E.M. for each of the groups, with the statistical results shown at the bottom. The numbers in the parentheses of the treatment group column represent doses (in $\mathrm{mg} / \mathrm{kg}$, i.p.) of AC927 or methamphetamine (METH). 
Figure 3.7 and Table 3.2 Correlation of body temperature and striatal (A) dopamine (DA) and (B) 5-HT levels of mice pretreated with saline or CM156 $(5-20 \mathrm{mg} / \mathrm{kg})$ prior to saline or METH (5 and $10 \mathrm{mg} / \mathrm{kg}$ )

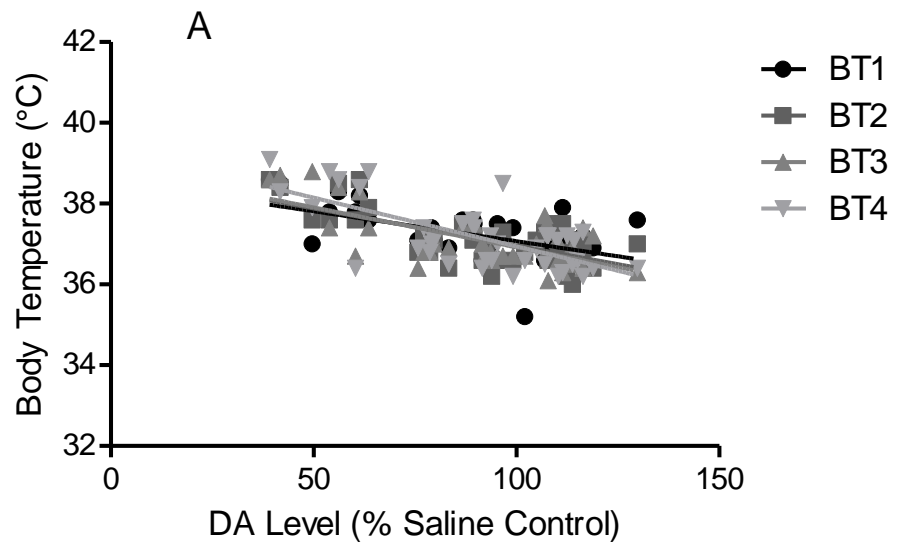

\begin{tabular}{|llllll|}
\hline Treatment Group & $\begin{array}{l}\text { DA (\% Saline } \\
\text { Control) }\end{array}$ & BT1 & BT2 & BT3 & BT4 \\
\hline Sal/Sal & $100 \pm 7.15$ & $37.06 \pm 0.10$ & $36.62 \pm 0.20$ & $36.72 \pm 0.09$ & $36.7 \pm 0.25$ \\
\hline Sal/Meth(5) & $51.06 \pm 4.96$ & $37.98 \pm 0.30$ & $38.22 \pm 0.20$ & $38.36 \pm 0.25$ & $38.5 \pm 0.21$ \\
\hline CM156(5)/Meth(5) & $69.20 \pm 8.17$ & $37.58 \pm 0.28$ & $37.64 \pm 0.23$ & $37.28 \pm 0.31$ & $37.86 \pm 0.49$ \\
\hline CM156(10)/Meth(5) & $101.71 \pm 5.52$ & $37.08 \pm 0.48$ & $37.12 \pm 0.12$ & $37.08 \pm 0.25$ & $37.04 \pm 0.25$ \\
\hline CM156(20)/Meth(5) & $99.07 \pm 6.33$ & $36.76 \pm 0.07$ & $36.44 \pm 0.07$ & $36.76 \pm 0.19$ & $36.62 \pm 0.15$ \\
\hline CM156(5)/Sal & $96.34 \pm 7.94$ & $37.04 \pm 0.05$ & $36.88 \pm 0.21$ & $36.8 \pm 0.12$ & $36.98 \pm 0.07$ \\
\hline CM156(10)/Sal & $106.87 \pm 7.80$ & $37.1 \pm 0.21$ & $37.08 \pm 0.12$ & $36.76 \pm 0.18$ & $36.66 \pm 0.22$ \\
\hline CM156(20)/Sal & $100.74 \pm 6.07$ & $37.06 \pm 0.14$ & $37.06 \pm 0.13$ & $37.08 \pm 0.23$ & $36.98 \pm 0.12$ \\
\hline $\boldsymbol{P}$ & & $<0.0005$ & $<0.0001$ & $<0.0001$ & $<0.0001$ \\
\hline Pearson $\mathbf{r}$ & & -0.5581 & -0.6725 & -0.6793 & -0.6923 \\
\hline $\mathbf{r}^{2}$ & & 0.3114 & 0.4523 & 0.4614 & 0.4793 \\
\hline
\end{tabular}

The values from individual mice were used to calculate the correlation between core body temperature at each of the four time points and striatal dopamine levels measured one week later. The table summarizes the mean \pm S.E.M. for each of the groups, with the statistical results shown at the bottom. The numbers in the parentheses of the treatment group column represent doses (in $\mathrm{mg} / \mathrm{kg}$, i.p.) of CM156 or methamphetamine (METH). 
B

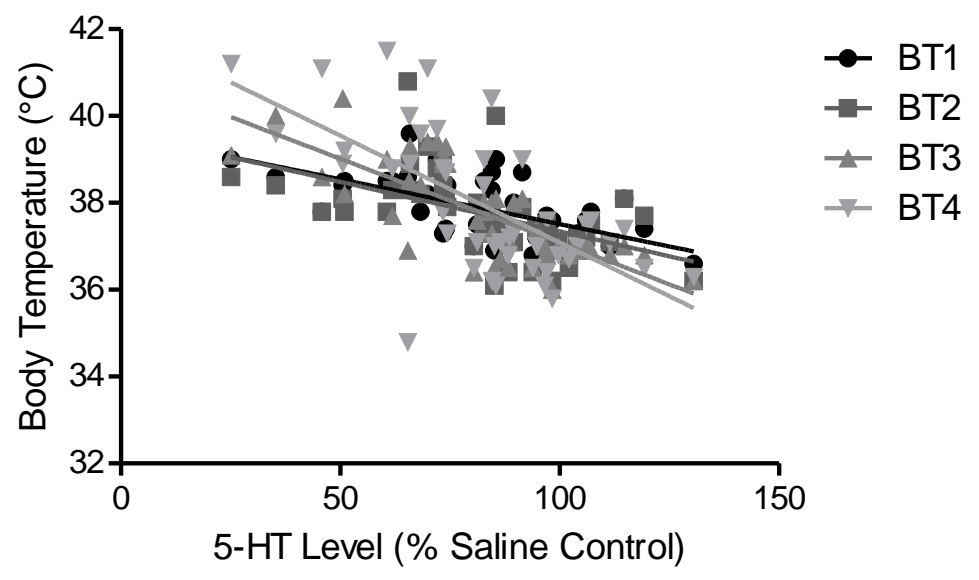

\begin{tabular}{|c|c|c|c|c|c|}
\hline Treatment Group & $\begin{array}{l}\text { 5-HT (\% } \\
\text { Saline } \\
\text { Control) }\end{array}$ & BT1 & BT2 & BT3 & BT4 \\
\hline Sal/Sal & $100 \pm 8.16$ & $36.84 \pm 0.10$ & $36.32 \pm 0.07$ & $36.5 \pm 0.09$ & $36.66 \pm 0.12$ \\
\hline Sal/Meth(10) & $58.35 \pm 5.91$ & $38.48 \pm 0.20$ & $38.36 \pm 0.17$ & $38.99 \pm 0.19$ & $40.15 \pm 0.33$ \\
\hline CM156(5)/Meth(10) & $76.44 \pm 4.76$ & $38 \pm 0.23$ & $37.96 \pm 0.18$ & $38.46 \pm 0.23$ & $39.14 \pm 0.29$ \\
\hline CM156(10)/Meth(10) & $66.80 \pm 5.42$ & $38.6 \pm 0.10$ & $38.76 \pm 0.56$ & $38.36 \pm 0.61$ & $37.86 \pm 0.79$ \\
\hline CM156(20)/Meth(10) & $86.45 \pm 3.88$ & $38.34 \pm 0.25$ & $37.72 \pm 0.63$ & $37.66 \pm 0.49$ & $36.54 \pm 0.32$ \\
\hline CM156(5)/Sal & $102.04 \pm 4.10$ & $37.38 \pm 0.14$ & $37.28 \pm 0.06$ & $36.94 \pm 0.07$ & $37.4 \pm 0.10$ \\
\hline CM156(10)/Sal & $96.09 \pm 6.11$ & $37.38 \pm 0.19$ & $37.42 \pm 0.19$ & $36.88 \pm 0.17$ & $37 \pm 0.14$ \\
\hline CM156(20)/Sal & $98.74 \pm 6.07$ & $37.34 \pm 0.13$ & $37.48 \pm 0.17$ & $37.06 \pm 0.14$ & $36.58 \pm 0.17$ \\
\hline$P$ & & $<0.0001$ & $<0.0005$ & $<0.0001$ & $<0.0001$ \\
\hline Pearson $r$ & & -0.5978 & -0.5170 & -0.7484 & -0.6552 \\
\hline$r^{2}$ & & 0.3573 & 0.2673 & 0.5601 & 0.4293 \\
\hline
\end{tabular}

The values from individual mice were used to calculate the correlation between core body temperature at each of the four time points and striatal serotonin levels measured one week later. The table summarizes the mean \pm S.E.M. for each of the groups, with the statistical results shown at the bottom. The numbers in the parentheses of the treatment group column represent doses (in $\mathrm{mg} / \mathrm{kg}$, i.p.) of CM156 or methamphetamine (METH). 
Figure 3.8 and Table 3.3 Correlation of body temperature and striatal (A) dopamine (DA) and (B) 5-HT levels of mice pretreated with saline or SN79 $(1-10 \mathrm{mg} / \mathrm{kg})$ prior to saline or METH (5 and $10 \mathrm{mg} / \mathrm{kg}$ )

A

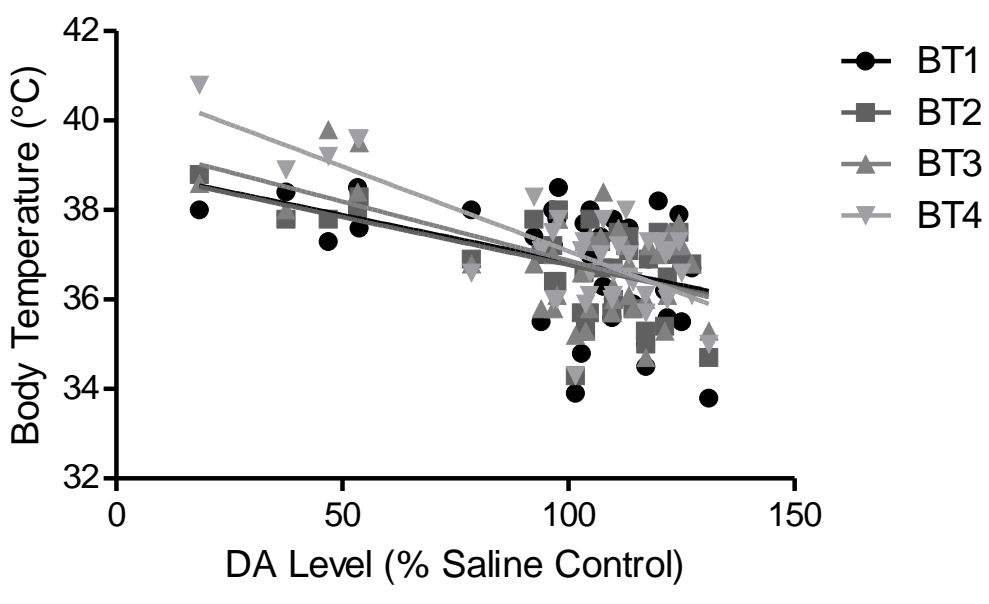

\begin{tabular}{|llllll|}
\hline Treatment Group & $\begin{array}{l}\text { DA (\% Saline } \\
\text { Control) }\end{array}$ & BT1 & BT2 & BT3 & BT4 \\
\hline Sal/Sal & $100 \pm 6.9$ & $37.86 \pm 0.24$ & $37.24 \pm 0.29$ & $37.06 \pm 0.29$ & $36.8 \pm 0.30$ \\
\hline SN79(1)/Saline & $112.39 \pm 4.55$ & $37.76 \pm 0.17$ & $37.16 \pm 0.14$ & $36.92 \pm 0.19$ & $36.9 \pm 0.26$ \\
\hline SN79(3)/Saline & $112.04 \pm 4.75$ & $37.06 \pm 0.33$ & $36.78 \pm 0.31$ & $36.78 \pm 0.41$ & $36.8 \pm 0.26$ \\
\hline SN79(10)/Saline & $111.87 \pm 4.7$ & $35.2 \pm 0.48$ & $35.42 \pm 0.41$ & $35.54 \pm 0.35$ & $35.6 \pm 0.33$ \\
\hline Saline/Meth(5) & $41.95 \pm 6.59$ & $37.96 \pm 0.23$ & $38.14 \pm 0.19$ & $38.86 \pm 0.34$ & $39.62 \pm 0.32$ \\
\hline SN79(1)/Meth(5) & $105.58 \pm 3.70$ & $37.32 \pm 0.26$ & $37.14 \pm 0.23$ & $37.24 \pm 0.39$ & $37.52 \pm 0.24$ \\
\hline SN79(3)/Meth(5) & $108.48 \pm 4.53$ & $36.38 \pm 0.36$ & $36.26 \pm 0.36$ & $36.02 \pm 0.32$ & $36.8 \pm 0.35$ \\
\hline SN79(10)/Meth(5) & $119.58 \pm 4.76$ & $34.94 \pm 0.32$ & $35.8 \pm 0.38$ & $36.24 \pm 0.32$ & $36.16 \pm 0.35$ \\
\hline $\boldsymbol{P}$ & & $<0.01$ & $<0.0005$ & $<0.0001$ & $<0.0001$ \\
\hline Pearson $\mathbf{r}$ & & -0.4164 & -0.5291 & -0.5819 & -0.7555 \\
\hline $\mathbf{r}^{2}$ & & 0.1734 & 0.28 & 0.3386 & 0.5708 \\
\hline
\end{tabular}

The values from individual mice were used to calculate the correlation between core body temperature at each of the four time points and striatal dopamine levels measured one week later. The table summarizes the mean \pm S.E.M. for each of the groups, with the statistical results shown at the bottom. The numbers in the parentheses of the treatment group column represent doses (in $\mathrm{mg} / \mathrm{kg}$, i.p.) of SN79 or methamphetamine (METH). 
B

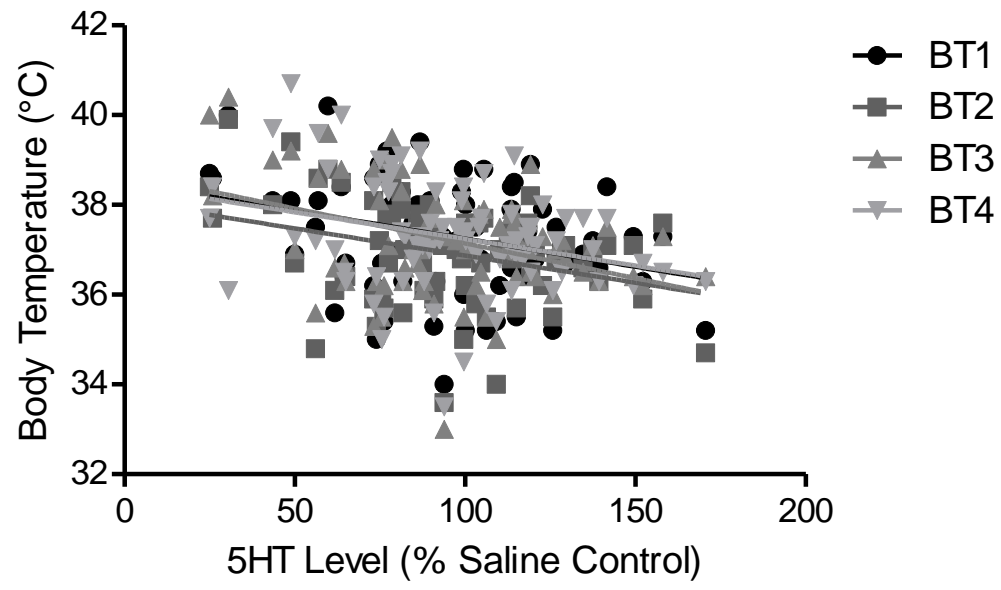

\begin{tabular}{|llllll|}
\hline Treatment Group & $\begin{array}{l}\text { 5-HT (\% Saline } \\
\text { Control) }\end{array}$ & BT1 & BT2 & BT3 & BT4 \\
\hline Sal/Sal & $100 \pm 6.86$ & $37.14 \pm 0.19$ & $36.82 \pm 0.15$ & $36.65 \pm 0.20$ & $37 \pm 0.19$ \\
\hline SN79(1)/Saline & $115.59 \pm 7.95$ & $37.32 \pm 0.20$ & $37.12 \pm 0.20$ & $36.99 \pm 0.16$ & $37.24 \pm 0.12$ \\
\hline SN79(3)/Saline & $107.58 \pm 6.70$ & $37.4 \pm 0.15$ & $37.11 \pm 0.13$ & $36.94 \pm 0.14$ & $37.14 \pm 0.13$ \\
\hline SN79(10)/Saline & $99.51 \pm 11.80$ & $35.85 \pm 0.31$ & $35.46 \pm 0.36$ & $35.72 \pm 0.36$ & $35.6 \pm 0.34$ \\
\hline Saline/Meth(10) & $55.76 \pm 6.14$ & $38.78 \pm 0.22$ & $38.45 \pm 0.20$ & $39.17 \pm 0.18$ & $38.83 \pm 0.34$ \\
\hline SN79(1)/Meth(10) & $93.18 \pm 5.63$ & $38.56 \pm 0.14$ & $37.37 \pm 0.22$ & $37.9 \pm 0.27$ & $38.16 \pm 0.31$ \\
\hline SN79(3)/Meth(10) & $95.81 \pm 6.91$ & $37.31 \pm 0.27$ & $36.43 \pm 0.34$ & $37.27 \pm 0.34$ & $37.53 \pm 0.33$ \\
\hline SN79(10)/Meth(10) & $108.08 \pm 8.83$ & $35.88 \pm 0.26$ & $36.33 \pm 0.24$ & $36.71 \pm 0.18$ & $36.63 \pm 0.17$ \\
\hline $\boldsymbol{P}$ & & $<0.01$ & $<0.005$ & $<0.001$ & $<0.05$ \\
\hline Pearson $\mathbf{r}$ & & -0.3025 & -0.3208 & -0.3735 & -0.2875 \\
\hline $\mathbf{r}^{\mathbf{2}}$ & & 0.09152 & 0.1029 & 0.1395 & 0.08267 \\
\hline
\end{tabular}

The values from individual mice were used to calculate the correlation between core body temperature at each of the four time points and striatal serotonin levels measured one week later. The table summarizes the mean \pm S.E.M. for each of the groups, with the statistical results shown at the bottom. The numbers in the parentheses of the treatment group column represent doses (in $\mathrm{mg} / \mathrm{kg}$, i.p.) of SN79 or methamphetamine (METH). 


\subsection{Discussion}

$\sigma$ Receptor antagonists, AC927, CM156 and SN79 can attenuate the hyperthermic effects of METH. Mechanistically, dopaminergic and serotonergic systems are implicated in METHinduced body temperature alterations (Numachi et al., 2007). In addition, the production of ROS and release of cytokines like IL1 $\beta$ have been implicated in the generation of METH's hyperthermia (Bowyer et al., 1994; Imam et al., 1999; Riedel and Maulik, 1999; Yamashita et al., 2000; Fukami et al., 2004).. Moreover, $\sigma$ Receptor ligands, with their ability to modulate these neurotransmitter systems, cytokines, as well as ROS, can attenuate elevations in body temperature (Campbell et al., 1989; Bastianetto et al., 1995; Derbez et al., 2002; Schetz et al., 2007; Matsumoto et al., 2008). Additionally, $\sigma$ receptors are located in the hypothalamic brain region and have previously been shown to modulate body temperature (Gundlach et al., 1986; Rawls et al., 2002). A combination of all these factors may explain how AC927, CM156 and SN79 can prevent METH-induced hyperthermia.

When body temperature of the mice was correlated with the striatal dopamine and $5-\mathrm{HT}$ levels a week later, a significant correlation was observed. This indicates that the METHinduced neurotoxicity is related to the body temperature of the mice during treatment. In addition, the ability of AC927, CM156 and SN79 to attenuate the depletions in dopamine and 5-HT levels may be related to their ability to decrease the hyperthermic effects of METH. However, correlation does not always mean causation. As discussed earlier, sigma receptors may be able to attenuate the hyperthermic effects of METH through various mechanisms; they may also be able to prevent METH-induced neurotoxicity at a cellular level independent of temperature influence. However, the separation of these effects in an in vivo system may not be possible or very difficult to interpret.

Certain animal studies can be performed to determine if the $\sigma$ antagonists can attenuate the neurotoxicity independent of decreases in body temperature. It involves maintaining the 
mice at elevated ambient temperatures (under a $37^{\circ} \mathrm{C}$ heating lamp) and then conducting the experiment. This would prevent the decrease in body temperature observed by pretreatment with $\sigma$ receptor antagonists. However, the limitation of this study is that the positive control METH treated mice all die (Miller and O'Callaghan, 1994; Miller and O'Callaghan, 2003; Seminerio et al., 2011). Nevertheless, this study was conducted with AC927 which significantly decreased the METH-induced mortality. However, the neurotoxicity data was difficult to interpret because of the lack of a positive control (Seminerio et al., 2011).

In order to clearly differentiate between the ability of $\sigma$ receptor antagonists to attenuate the neurotoxic effects of METH independent of temperature modulation, an experimental model is needed where temperature component can be controlled and separated the effects of METH alone. Therefore, in the next chapter, a neuronal cell culture model was used to begin identifying the mechanisms of METH's neurotoxicity and the pathways where $\sigma$ receptors may mediate neuroprotection.

3.5 Contributions: Nidhi Kaushal conducted the body temperature experiments for CM156 (serotonin depletion experiment) and SN79 (dopamine and 5-HT depletion experiment).

Dr. Jamaluddin Shaikh performed the body temperature experiments for AC927 (dopamine and 5-HT depletion experiments) and CM156 (dopamine depletion experiment). 


\section{CHAPTER 4}

\section{EVALUATION OF AC927 AGAINST METH-INDUCED NEUROTOXICITY: IN VITRO STUDIES}




\subsection{Introduction}

Methamphetamine (METH) is a highly abused psychostimulant drug that results in neurotoxicity at high or repeated drug administration (Krasnova and Cadet, 2009). This neurotoxicity is seen as dopamine nerve terminal degeneration and apoptosis in several brain regions (Krasnova and Cadet, 2009), the mechanism of which is not completely understood. However, some of the neurotoxic cascades involved are excessive release of dopamine, oxidative/nitrosative stress, endoplasmic reticulum (ER) stress, and activation of mitochondrial death cascades (Cadet and Brannock, 1998; Krasnova and Cadet, 2009).

Among its various targets, METH interacts with sigma $(\sigma)$ receptors at physiologically relevant micromolar concentrations (Nguyen et al., 2005; Han and Gu, 2006). Two subtypes of $\sigma$ receptors, $\sigma_{1}$ and $\sigma_{2}$, are expressed in almost all types of mammalian cells (Guitart et al., 2004). $\sigma_{1}$ Receptors are highly conserved 223 amino acid membrane bound proteins (Kekuda et al., 1996). They function as chaperones at the mitochondrial-ER membrane and regulate $\mathrm{Ca}^{2+}$ signaling via inositol trisphosphate $\left(\mathrm{IP}_{3}\right)$ receptors (Hayashi and Su, 2007). Additionally, $\sigma_{1}$ receptors can undergo protein-protein interactions with several other cellular proteins such as binding immunoglobulin protein $(\mathrm{BiP})$, ankyrin- $\mathrm{B}, \mathrm{IP}_{3}$ receptors, and dopamine $\mathrm{D}_{1}$ receptors (Hayashi and Su, 2001; Hayashi and Su, 2007; Navarro et al., 2010; Su et al., 2010). $\sigma_{1}$ Receptors are also capable of translocation to different subcellular compartments upon stimulation through ligand binding and changes in intracellular conditions (Hayashi and Su, 2003a). In contrast, $\sigma_{2}$ receptors are less well characterized. However, they are elevated in immortalized cell lines and tumor cells (Vilner et al., 1995b), where they have been implicated in the control of cell cycle functions (Wheeler et al., 2000), alterations in cellular $\mathrm{Ca}^{2+}$ levels (Vilner and Bowen, 2000), and cell death signaling involving sphingolipid products (Crawford et al., 2002). 
Previous in vivo studies have shown that pretreatment with AC927 (Nphenethylpiperidine oxalate), a $\sigma$ receptor ligand, attenuates the neurotoxic effects of METH in male, Swiss Webster mice (Matsumoto et al., 2008; Seminerio et al., 2011). The ability of AC927 to mitigate neurotoxic cascades is consistent with the location of $\sigma$ receptors in various subcellular organelles like ER, mitochondria, lysosomes, cell membrane, and nucleus (McCann et al., 1994; Zeng et al., 2007) as well as the functional roles of $\sigma$ receptors in cells as described above. Nevertheless, the role of $\sigma \square$ receptors in neurotoxicity resulting from drugs of abuse like METH remains unclear due to various limitations, including the lack of a suitable in vitro model system. Previous studies to understand the mechanisms of METHinduced toxicity employed either primary neuronal cultures or immortalized cell lines of neuronal origin (Cadet et al., 1997; Choi et al., 2002; Deng et al., 2002; Kanthasamy et al., 2006; Wu et al., 2007). In order to induce cell death/damage, millimolar concentrations of METH were required, which are rarely achieved in vivo (Segal and Kuczenski, 2006; Melega et al., 2008). Therefore, a model system suitable for identifying potential mechanisms leading to neurotoxicity is needed.

In order to elucidate the cellular mechanisms of METH-induced neurotoxicity at which AC927 may intervene via $\sigma$ receptors, a neuronal/glial cell culture model (neuroblastoma $\times$ glioma hybridoma, NG108-15 cells) was used in the present study. NG108-15 cells when differentiated display neurite outgrowth, electrical excitability, and express proteins with neuronal and glial properties (Ma et al., 1998). These cells have been used extensively as a sensitive cell line to study the toxic effects of various drugs and chemicals (Canete and Diogene, 2008). Additionally, NG108-15 cells have been commonly used in the literature to study the functions of $\sigma$ receptors (Hayashi and Su, 2003a). In the current study, the end points measured were reactive oxygen and nitrogen species (ROS/RNS) generation, 
dopamine release, apoptosis, and necrosis. Finally, AC927 was tested against these cytotoxic endpoints and mediators to gain insight into the mechanisms of $\sigma$-mediated neuroprotection.

\subsection{Materials and Methods}

\subsubsection{Cell line and culture}

4.2.1.1. Cell growth: The neuroblastoma x glioma, hybridoma cell line NG108-15 (Hamprecht et al., 1985) were obtained from ATCC (Rockville, MD). Cells were maintained in $25 \mathrm{~cm}^{2}$ (T25) or $75 \mathrm{~cm}^{2}$ (T75) culture flasks (Corning-Costar, Lowell, MA) in hi-glucose (4.5 g/L) DMEM (Dulbecco's modified Eagle's medium) supplemented with 10\% FBS (fetal bovine serum), penicillin, streptomycin, and HAT (hypoxanthine-aminopterin-thymidine) at $37^{\circ} \mathrm{C}$ in a humidified incubator in $5 \% \mathrm{CO}_{2}$.

4.2.1.2. Cell differentiation: Culture medium was replaced with differentiation medium (DMEM with $0.5 \%$ FBS, penicillin, streptomycin, HAT and $1 \%$ DMSO) and the cells allowed to grow for a further 3-4 days.

4.2.2 Reactive oxygen/nitrogen species: Cells grown in complete or differentiation medium were used for assay when $60-70 \%$ confluent. The culture medium was replaced phenol red free medium containing $0.5 \%$ FBS and $5 \mu \mathrm{M}$ fluorigenic, oxidizable, dye $\mathrm{CM}-\mathrm{H}_{2}$ DCFDA (5(and-6)-chloromethyl-2',7'-dichlorodihydrofluorescein diacetate) and returned to the incubator at $37^{\circ} \mathrm{C}$ for $45-60 \mathrm{~min}$. Cells were treated with appropriate concentrations of METH or AC927. Exogenously added $100 \mu \mathrm{M} \mathrm{H}_{2} \mathrm{O}_{2}$ and $\mathrm{Na}_{2} \mathrm{Cr}_{2} \mathrm{O}_{7}$ served as a positive control in this assay. All compounds were added in replicates of 4 or 8 and the plates are returned to the incubator. In the assay, AC927 (0-300 $\mu \mathrm{M}), \mathrm{N}$-acetylcysteine (NAC, $10 \mathrm{mM})$, catalase (10000 units per $\mathrm{ml}$ ), L-NMMA $(200 \mu \mathrm{M})$ were added 15 min prior to the addition of METH $(0.1-3000 \mu \mathrm{M}), \mathrm{H}_{2} \mathrm{O}_{2}(100$ $\mu \mathrm{M})$ or $\mathrm{Na}_{2} \mathrm{Cr}_{2} \mathrm{O}_{7}(100 \mu \mathrm{M})$. At specified time points, plates were read in a Fluostar Optima 
fluorescence plate reader fitted with a 485/520 nm excitation/emission filter set (BMG Labtech GmbH, Offenberg, Germany).

4.2.3 Dopamine release: NG108-15 cells grown and differentiated in T75 flasks were harvested by replacing the medium with $\mathrm{Ca}^{++}, \mathrm{Mg}^{++}$free DPBS (Dulbecco's PhosphateBuffered Saline), centrifuged, re-suspended in differentiation medium with reduced glucose $(1.5 \mathrm{~g} / \mathrm{l})$ at $3 \times 10^{5}$ cells per $\mathrm{ml}$ and seeded in 24-well CellBind tissue culture plates (CorningCostar, Lowell, MA) at $0.5 \mathrm{ml}$ per well. After $4 \mathrm{hr}$, various concentrations of METH (0.3-300 $\mu \mathrm{M})$ were added to sets of wells. $\mathrm{KCl}(50 \mathrm{mM})$ was used as a positive control for maximum dopamine release. In one set of wells, AC927 was added 15 min prior to the addition of METH or $\mathrm{KCl}$. After $5 \mathrm{~min}$ of exposure to $\mathrm{KCl}$ or $\mathrm{METH}$, supernatants were harvested $(450 \mu \mathrm{l})$, centrifuged to remove cells, acidified with the addition of $1 / 10$ volume of buffer $(0.1 \mathrm{~N} \mathrm{HCl}, 10$ $\mathrm{mM}$ EDTA and $40 \mathrm{mM} \mathrm{Na} \mathrm{S}_{2} \mathrm{O}_{5}$ ) and samples were stored at $-20{ }^{\circ} \mathrm{C}$. Dopamine was quantitated in an enzyme-linked immunosorbent assay (ELISA) employing a kit from Rocky Mountain Diagnostics (Denver, CO) and manufacturer's protocols. Briefly, dopamine was extracted from the culture supernatants by binding to an affinity gel matrix, acetylated, eluted and then measured in a competitive inhibition ELISA, using a standard curve of known concentrations of dopamine.

4.2.4 Hoechst and propidium iodide staining: NG108-15 cells were grown and differentiated in 96-well culture plates and exposed to various concentrations of METH (0-10 mM), AC927 (0.3-30 $\mu \mathrm{M}), \operatorname{AC9} 27(0.3-30 \mu \mathrm{M})+\operatorname{METH}(0-1 \mathrm{mM})$ for $24 \mathrm{hrs}$ at $37^{\circ} \mathrm{C}$. Hoechst stain (20 $\mu \mathrm{g} / \mathrm{ml}$ final concentration) and propidium iodide stain (20 $\mu \mathrm{g} / \mathrm{ml}$ final concentration) were added to each well and incubated at room temperature for $10 \mathrm{~min}$. Three images are taken/well using an UV light microscope. Cells with brightly stained and fragmented nuclei were counted as apoptotic and cells that were red were counted as necrotic. The percentage of apoptotic and necrotic cells were counted with the help of Image $J$ cell counter $(\mathrm{NIH})$. 
4.2.5 Statistical analysis: Statistical analysis of data was performed using ANOVA with appropriate post-hoc tests employing GraphPad Prism 4 (GraphPad Software, San Diego, CA).

\subsection{Results}

4.3.1. Reactive oxygen/nitrogen species: As shown in Figure 4.1, CM- $\mathrm{H}_{2}$ DCFDA detected exogenously added $\mathrm{H}_{2} \mathrm{O}_{2}$ within 10 min (168.91 $\pm 6.95 \%$ of untreated control) and up to 60 $\min (176.69 \pm 7.1 \%$ of control). Low levels of ROS were also induced in NG108-15 cells by $\mathrm{Na}_{2} \mathrm{Cr}_{2} \mathrm{O}_{7}$ starting at $10 \mathrm{~min}$; ROS in this sample increased dramatically $4 \mathrm{hr}$ after treatment (140.1 $\pm 8.6 \%$ of control) and continued to increase up to $24 \mathrm{hr}$ reaching $223.70 \pm 21.92 \%$ of that in untreated control cells. These controls established that the assay contained sufficient and stable reagents to continuously detect oxidizing radicals from within 10 min of initiation and up to $24 \mathrm{hr}$. All tested concentrations of METH except the lowest $(0.1 \mu \mathrm{M})$ induced the production of ROS capable of oxidizing $\mathrm{CM}-\mathrm{H}_{2}$ DCFDA significantly above background levels within 10 min of exposure, with $3 \mu \mathrm{M}$ inducing the highest levels $(201.97 \pm 9.97 \%$ of control). The difference between METH-induced ROS and basal ROS in NG108-15 cells diminished beyond $60 \mathrm{~min}$, while ROS continued to accumulate in cells treated with $\mathrm{Na}_{2} \mathrm{Cr}_{2} \mathrm{O}_{7}$ up to $24 \mathrm{hr}$. Statistical analysis of the data obtained from 10 to $60 \mathrm{~min}$ employing two-way repeated measures ANOVA showed a significant effect of METH concentration $(F(10,1364)=54.41, p$ $<0.0001)$, time $(F(3,1364)=21.14, p<0.0001)$ and METH treatment $\times$ time interaction $(F(30,1364)=1.84, p<0.005)$. Bonferroni's post-hoc tests further established that the following concentrations of METH and positive control are capable of reproducibly inducing the strongest and sustained ROS responses: $0.3 \mu \mathrm{M}(10 \mathrm{~min}: t=4.7, p<0.001 ; 20 \mathrm{~min}: t=$ 3.46, $p<0.01 ; 30 \min : t=2.95, p<0.05$ and $60 \min : t=2.63, p<0.05), 1 \mu \mathrm{M}(10 \min : t=$ 
6.88, $p<0.001 ; 20 \min : t=5.46, p<0.001 ; 30 \min : t=4.58, p<0.001$ and $60 \min : t=3.82, p$ $<0.001), 3 \mu \mathrm{M}(10 \min : t=11.46, p<0.001 ; 20 \min : t=8.69, p<0.001 ; 30 \min : t=7.60, p<$ 0.001 and 60 min: $t=5.33, p<0.001), 10 \mu \mathrm{M}(10 \min : t=3.50, p<0.01), 30 \mu \mathrm{M}(t=3.81, p<$ 0.001), $100 \mu \mathrm{M}$ (10 $\min : t=6.30, p<0.001 ; 20 \min : t=3.41, p<0.01$ and $30 \min : t=3.06, p$ $<0.01), 300 \mu \mathrm{M}(10 \min : t=8.58, p<0.001 ; 20 \mathrm{~min}: t=5.23, p<0.001 ; 30 \min : t=5.78, p<$ 0.001 and 60 min: $t=3.71, p<0.001), \mathrm{H}_{2} \mathrm{O}_{2}(10 \mathrm{~min}: t=7.74, p<0.001 ; 20 \min : t=7.46, p<$ $0.001 ; 30 \min : t=7.27, p<0.001$ and $60 \min : t=8.63, p<0.001)$ and $\operatorname{Cr}(10 \min : \mathrm{t}=3.42, p$ $<0.01 ; 20 \min : t=2.62, p<0.05 ; 30 \mathrm{~min}: t=3.20, p<0.01$ and $60 \mathrm{~min}: t=3.63, p<0.01$ ). 


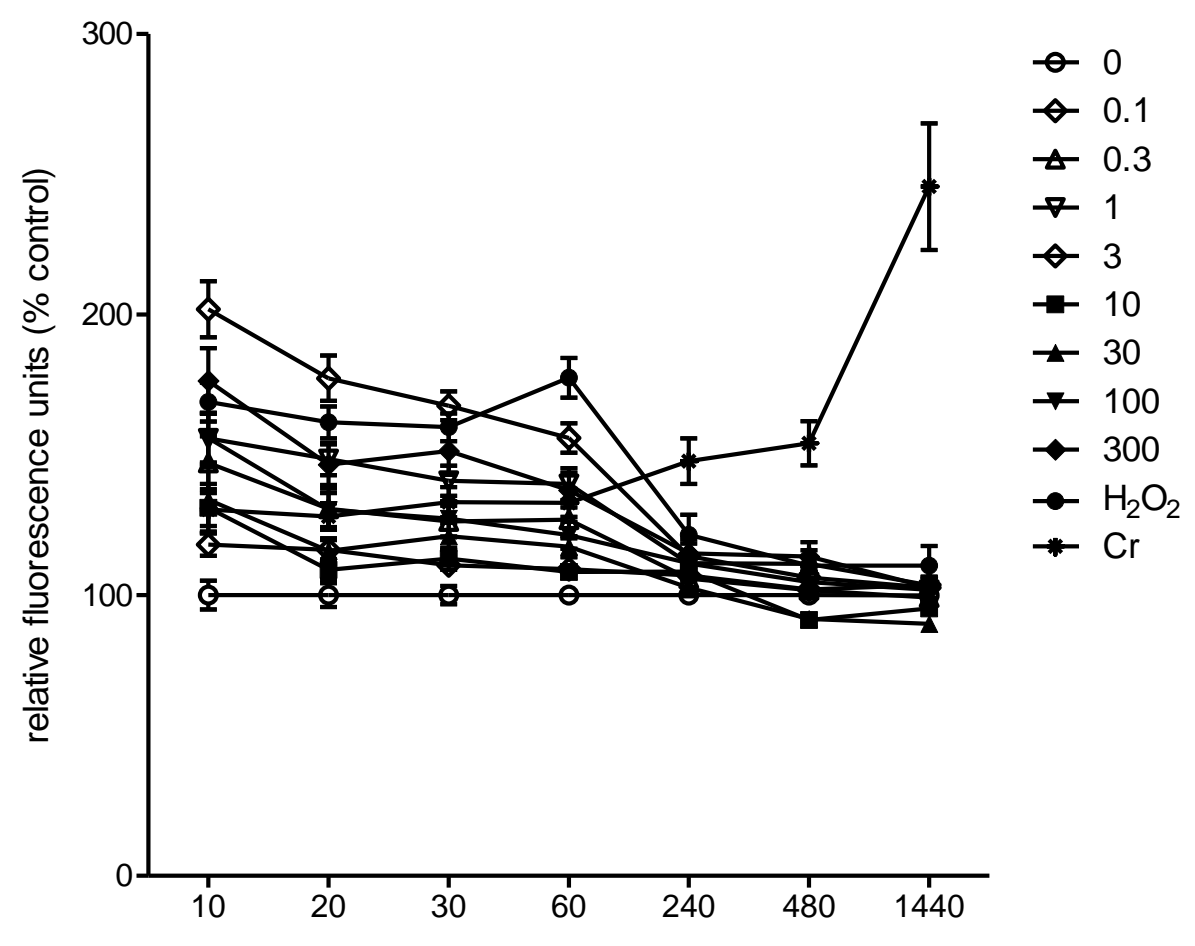

Time following methamphetamine ( $\mathrm{min})$

Figure 4.1 Dose response and time course of METH-induced ROS/RNS generation. The production of ROS capable of oxidizing $\mathrm{CM}-\mathrm{H}_{2}$ DCFDA was conducted as described in the materials and methods in NG108-15 cells following exposure to $100 \mu \mathrm{M} \mathrm{H}_{2} \mathrm{O}_{2}, 100 \mu \mathrm{M} \mathrm{Na} \mathrm{Cr}_{2} \mathrm{O}_{7}$ (Cr), or 0 to $300 \mu \mathrm{M}$ METH. Relative fluorescence units from five separate experiments obtained at each indicated time point are shown; data were normalized to the mean rfu for untreated cells to obtain percent control values $(n=8 /$ experiment $) \pm$ SEM. 
As shown in Figure 4.2A, ROS detectable by $\mathrm{CM}-\mathrm{H}_{2}$ DCFDA induced in NG108-15 cells by METH was completely inhibited in the presence of the common antioxidant and radical scavenger NAC as seen within 20 min of addition of the drug, confirming that the assay was indeed detecting ROS. Two-way ANOVA showed significant effect of NAC treatment $(F(1,80)=962.7, p<0.0001)$, METH and $\mathrm{H}_{2} \mathrm{O}_{2}$ treatment $(F(5,80)=10.64, p<$ $0.0001)$ and NAC treatment $\times \mathrm{METH}$ and $\mathrm{H}_{2} \mathrm{O}_{2}$ treatment interaction $(F(5,80)=8.83, p<$ 0.0001). Bonferroni's post-hoc tests showed that NAC significantly decreased ROS for all tested concentrations of METH $(0.1 \mu \mathrm{M}: t=11.66, p<0.001 ; 0.3 \mu \mathrm{M}: t=12.86, p<0.001 ; 1$ $\mu \mathrm{M}: t=12.91, p<0.001$ and $3 \mu \mathrm{M}: t=13.29, p<0.001)$ and $\mathrm{H}_{2} \mathrm{O}_{2}(t=18.39, p<0.001)$. Significant inhibition of radical generation persisted up to $4 \mathrm{hr}$ after addition of METH, at which time the experiment was terminated. Interestingly, NAC also reduced the ROS detectable in untreated control cells $(t=7.97, p<0.001)$ at $20 \mathrm{~min}$, indicating that differentiated NG108-15 cells produce significant amounts of basal ROS.

The presence of catalase in the assay medium inhibited ROS induced by METH within 20 min of addition of the drug (Figure 4.2B). Two-way ANOVA confirmed significant effect of catalase treatment $(F(1,80)=42.85, p<0.0001)$, METH and $\mathrm{H}_{2} \mathrm{O}_{2}$ treatment $(F(5,80)=3.79, p$ $<0.005)$ and catalase treatment $\times$ METH and $\mathrm{H}_{2} \mathrm{O}_{2}$ treatment $(F(5,80)=3.71, p<0.005)$. Bonferroni's post-hoc tests confirmed significant differences for $1 \mu \mathrm{M}$ and $3 \mu \mathrm{M} \mathrm{METH}$ concentration $(t=3.17, p<0.05$ and $t=3.20, p<0.05)$ and $\mathrm{H}_{2} \mathrm{O}_{2}$ treatment $(t=6.03, p<$ 0.001), suggesting that $\mathrm{H}_{2} \mathrm{O}_{2}$ was a small but significant product of reactive species induced by these concentrations of the drug.

Finally, the increase in ROS in NG108-15 cells induced by METH was also significantly inhibited in the presence of L-NMMA (Figure 4.2C). Two-way ANOVA showed a significant effect of L-NMMA treatment $(F(1,60)=26.89, p<0.0001)$, METH and $\mathrm{H}_{2} \mathrm{O}_{2}$ treatment $(F(5,60)=57.36, p<0.0001)$ and L-NMMA treatment $\times$ METH and $\mathrm{H}_{2} \mathrm{O}_{2}$ treatment 
$(F(5,60)=5.85, p<0.0005)$. Bonferroni's post-hoc tests confirmed that L-NMMA inhibited the ROS/RNS generated by 1 and $3 \mu \mathrm{M} \mathrm{METH}(t=4.47, p<0.001$ and $t=5.09, p<0.001$ respectively), suggesting that the generation of some of the reactive species detected by CM$\mathrm{H}_{2}$ DCFDA in these test groups must proceed through intermediates requiring the synthesis of nitric oxide radicals. 

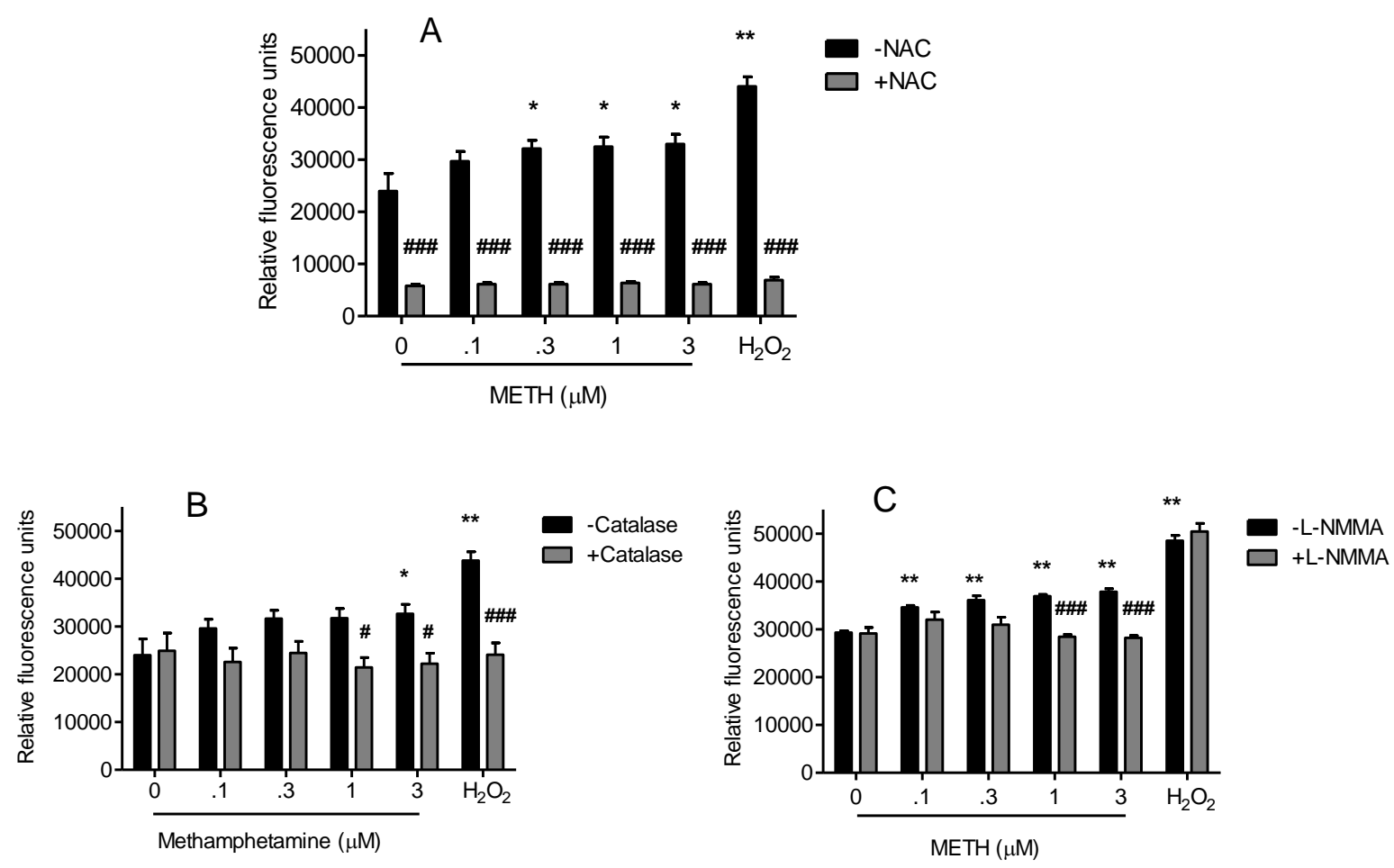

Figure 4.2 Effect of antioxidants (A) NAC, (B) catalase, (C) L-NMMA on METH-induced ROS/RNS generation. Inhibition of ROS production in NG108-15 cells by N-acetylcysteine (NAC), catalase and L$\mathrm{N}^{\mathrm{G}}$-monomethyl arginine (L-NMMA). Inhibition of ROS following exposure to 0 to $3 \mu \mathrm{M}$ methamphetamine (METH) or $100 \mu \mathrm{M} \mathrm{H}_{2} \mathrm{O}_{2}$ was determined in the absence (solid bars) or presence (gray bars) of $10 \mathrm{mM} \mathrm{NAC} \mathrm{(A),} \mathrm{10,000} \mathrm{units} \mathrm{catalase} \mathrm{(B)} \mathrm{or} 20 \mathrm{mM} \mathrm{L-NMMA} \mathrm{(C)} 20$ min following exposure to METH. Data represent averages of relative fluorescence units from two separate experiments $\left(n=4\right.$ /experiment) \pm SEM. Significant differences are noted, ${ }^{*} p<0.05,{ }^{* *} p<0.01$ (control vs. METH treated) and \#p<0.05, \#\#\#<0.001 (METH alone vs. METH with ROS inhibitor). 
As shown in Figure 4.3, CM- $\mathrm{H}_{2}$ DCFDA detected exogenously added $\mathrm{H}_{2} \mathrm{O}_{2}$ within 10 $\min \left(146.69 \pm 4.97 \%\right.$ of control) and ROS generated by $\mathrm{Na}_{2} \mathrm{Cr}_{2} \mathrm{O}_{7}$ in $\mathrm{NG108-15}$ cells, which peaked at $24 \mathrm{hr}(242.06 \pm 11.56 \%$ of control). In contrast, all tested concentrations of AC927 from 0 to $300 \mu \mathrm{M}$ failed to induce ROS significantly higher than that in untreated control cells. Statistical analyses of the data employing two-way repeated measures ANOVA showed a significant effect of AC927 and positive control treatment $(F(9,900)=75.37, p<0.0001)$, time $(F(6,900)=28.36, p<0.0001)$ and AC927 and positive control treatment $\times$ time interaction $(F(54,900)=60.50, p<0.0001)$. Bonferroni's post-hoc tests revealed that none of the tested concentrations of AC927 were able to induce elevation of ROS above background levels, while ROS was detected in cells treated with $\mathrm{H}_{2} \mathrm{O}_{2}(10 \min : t=11.26, p<0.001 ; 20$ min: $t=$ 14.14, $p<0.001 ; 30 \min : t=14.50, p<0.001 ; 60 \mathrm{~min}: t=11.47, p<0.001 ; 240 \min : t=3.03$, $p<0.05$ and $480 \min : t=3.00, p<0.05)$ and $\mathrm{Na}_{2} \mathrm{Cr}_{2} \mathrm{O}_{7}(240 \min : t=7.01, p<0.001 ; 480 \min$ : $t=16.52, p<0.001$ and $1440 \mathrm{~min}: t=34.24, p<0.001)$. Interestingly, AC927 at $0.3 \mu \mathrm{M}$ led to a reduction in basal ROS in NG108-15 cells, the reduction becoming statistically significant at $240 \min (t=3.78, p<0.01), 480 \min (t=2.87, p<0.05)$ and up to $1440 \min (t=4.38, p<$ $0.001)$ 


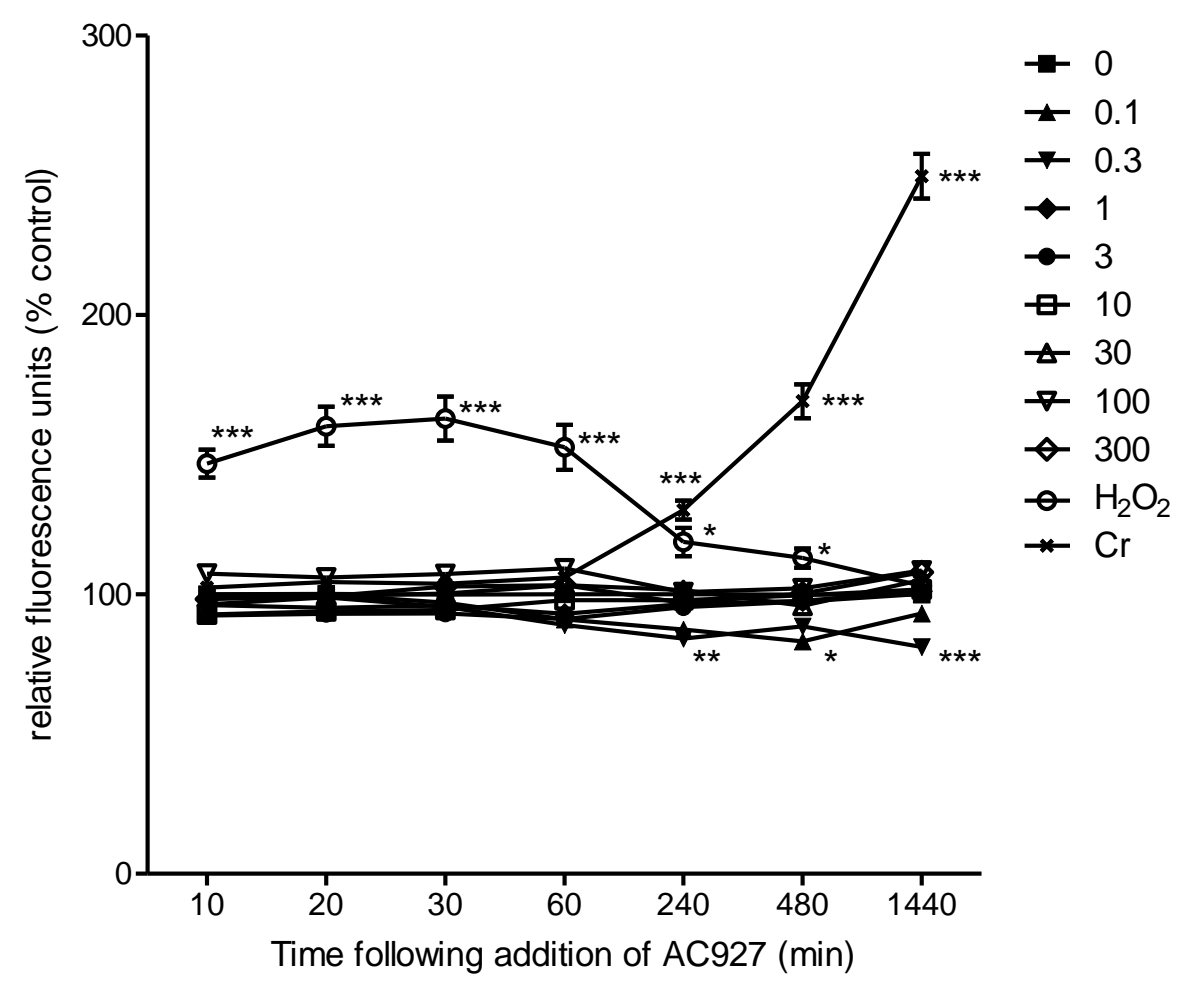

Figure 4.3 Dose response and time course of AC927-induced ROS/RNS generation. The production of ROS capable of oxidizing $\mathrm{CM}-\mathrm{H}_{2}$ DCFDA was conducted as described in the materials and methods in NG108-15 cells following exposure to $100 \mu \mathrm{M} \mathrm{H}_{2} \mathrm{O}_{2}, 100 \mu \mathrm{M} \mathrm{Na} \mathrm{Cr}_{2} \mathrm{O}_{7}$ (Cr), or 0 to $300 \mu \mathrm{M}$ AC927. Relative fluorescence units from two separate experiments obtained at each indicated time point are shown; data were normalized to the mean rfu for untreated cells to obtain percent control values ( $\mathrm{n}=8$ /experiment) \pm SEM. ${ }^{*} p<0.05,{ }^{* *} p<0.01,{ }^{* * *} p<0.001$ vs. control treatment. 
As shown in Figure 4.4, $0.3 \mu \mathrm{M}$ AC927 attenuated the production of reactive radicals induced by METH, reducing them to levels observed in untreated control cells for all tested concentrations of METH except the highest $(300 \mu \mathrm{M})$; data shown here were obtained 20 min following stimulation with METH. Two-way ANOVA showed a significant effect of AC927 pretreatment $(F(1,138)=98.44, p<0.0001)$, METH or positive control treatment $(F(10,138)=$ 15.63, $p<0.0001)$ and AC927 pretreatment $\times$ METH or positive control treatment interaction $(F(10,138)=2.39, p<0.05)$. Bonferroni's post-hoc tests showed that the AC927 attenuated ROS/RNS generated by following METH concentrations: $0.1 \mu \mathrm{M}(t=3.28, p<0.05), 0.3 \mu \mathrm{M}(t$ $=3.16, p<0.05), 1 \mu \mathrm{M}(t=3.52, p<0.01), 3 \mu \mathrm{M}(t=7.16, p<0.001), 10 \mu \mathrm{M}(t=3.99, p<$ $0.01), 30 \mu \mathrm{M}(t=3.14, p<0.05), 100 \mu \mathrm{M}(t=3.39, p<0.05)$ and $300 \mu \mathrm{M}(t=3.84, p<0.01)$. As expected, AC927 did not inhibit the oxidation of the dye by exogenously added $\mathrm{H}_{2} \mathrm{O}_{2}(t=$ $1.39, \mathrm{~ns})$. It also failed to significantly inhibit the small amount of ROS generated by $\mathrm{Na}_{2} \mathrm{Cr}_{2} \mathrm{O}_{7}$ at this time point $(t=0.99, n s)$. However, at later time points, AC927 inhibited ROS induction by $\mathrm{Na}_{2} \mathrm{Cr}_{2} \mathrm{O}_{7}$ as seen at $4 \mathrm{hr}(t=4.05, p<0.001)$ and $24 \mathrm{hr}(t=7.73, p<0.001)$. 


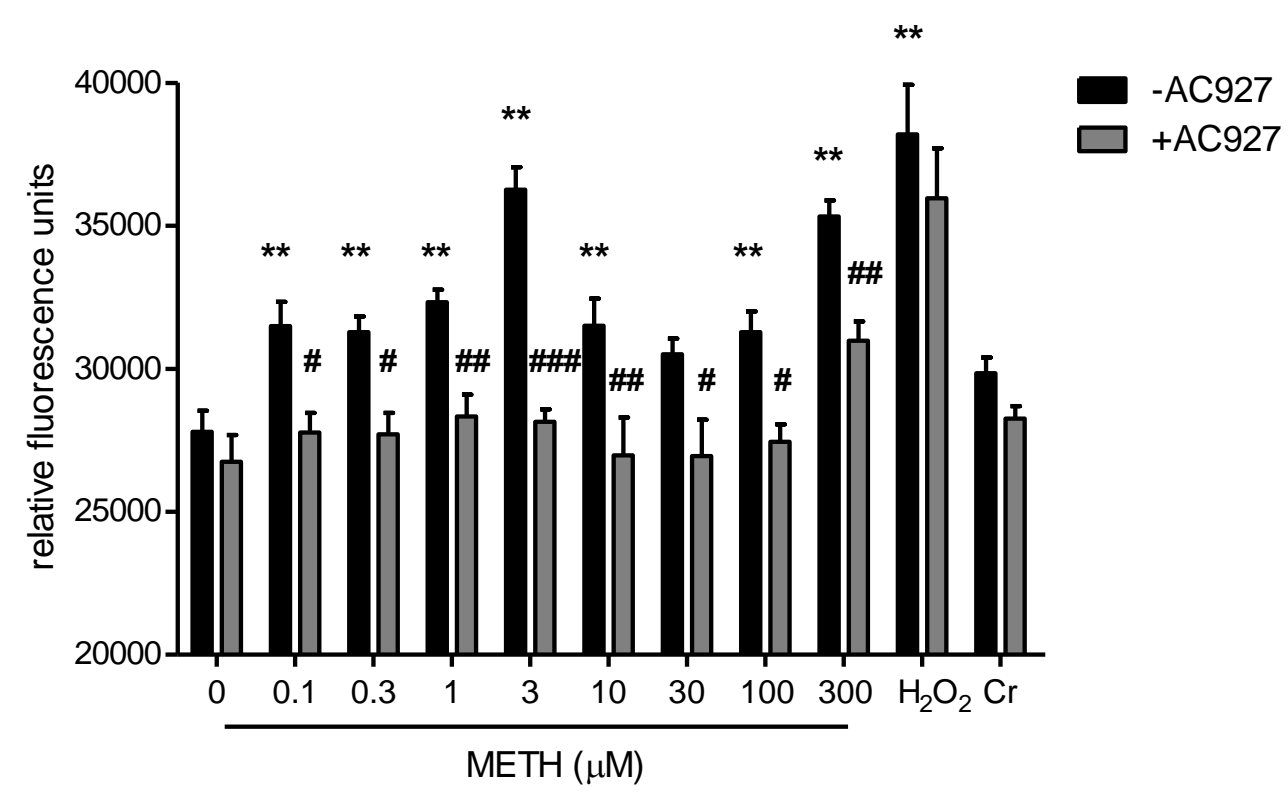

Figure 4.4 Effect of AC927 pretreatment on METH-induced ROS/RNS generation. Inhibition of methamphetamine (METH)-induced ROS generation in NG108-15 cells by AC927. The production of ROS capable of oxidizing CM- $\mathrm{H}_{2}$ DCFDA was assessed in differentiated NG108-15 cells in the presence of 0 to $300 \mu \mathrm{M}$ METH, $100 \mu \mathrm{M} \mathrm{H}_{2} \mathrm{O}_{2}$ or $100 \mu \mathrm{M} \mathrm{Na}_{2} \mathrm{Cr}_{2} \mathrm{O}_{7}(\mathrm{Cr}$ ) in the absence (solid bars) or presence (gray bars) of $0.3 \mu \mathrm{M}$ AC927 as described in the methods. Data represent averages of relative fluorescence units from two different experiments ( $n=8 /$ experiment) obtained 20 min after addition of drug \pm SEM. Significant differences are noted as ${ }^{* *} p<0.01$ (control vs. METH treated) and $\# p<0.05, \# \#<0.01, \# \# \#<0.001$ (METH alone vs. METH with AC927). 
4.3.2. Dopamine release assay: As shown in Figure 4.5, in untreated cells, $0.0-41.85$ pg of dopamine was detected. In contrast, when cells were treated with $\mathrm{KCl}, 268.30-389.62 \mathrm{pg}$ of dopamine was detected in the culture supernatant 5 min following exposure.

Dopamine secretion was induced by all four concentrations of METH ranging from 0.3 to $300 \mu \mathrm{M}$, with $3 \mu \mathrm{M}$ METH inducing maximum secretion with $204.75-413.12$ pg per $1.5 \times 10^{5}$ cells, compared to that in untreated control cells. One-way ANOVA showed a significant effect of METH treatment $(F(5,23)=8.87, p<0.001)$. Post-hoc Dunnett's tests show that the 0.3 and $3 \mu \mathrm{M}$ of METH caused a significant increase in dopamine release $(q=2.77, p<0.05$ and $q=$ $5.32, p<0.01) \mathrm{KCl}(50 \mu \mathrm{M})$ also caused a significant increase in dopamine release $(q=5.78$, $p<0.01)$

In cells exposed to $0.3 \mu \mathrm{M}$ AC927 for $5 \mathrm{~min}$, dopamine levels were not significantly different from those in untreated controls $(F(5,18)=0.20$, ns). Two-way ANOVA showed a significant effect of $\mathrm{METH}$ and $\mathrm{KCl}$ treatment $(F(5,30)=19.39, p<0.0001)$, AC927 pretreatment $(F(1,30)=32.21, p<0.0001)$ and AC927 pretreatment $\times$ METH and $\mathrm{KCl}$ treatment interaction $(F(5,30)=4.86, p<0.005)$. Bonferroni's post-hoc tests confirm that AC927 pretreatment attenuates dopamine release caused by 0.3 and $3 \mu \mathrm{M} \mathrm{METH}(t=3.19, p$ $<0.05$ and $t=5.58, p<0.001$ respectively). Pretreatment of cells with AC927 did not however, block the release of dopamine in cells treated with $\mathrm{KCl}(t=0.23, p<0.05)$. 


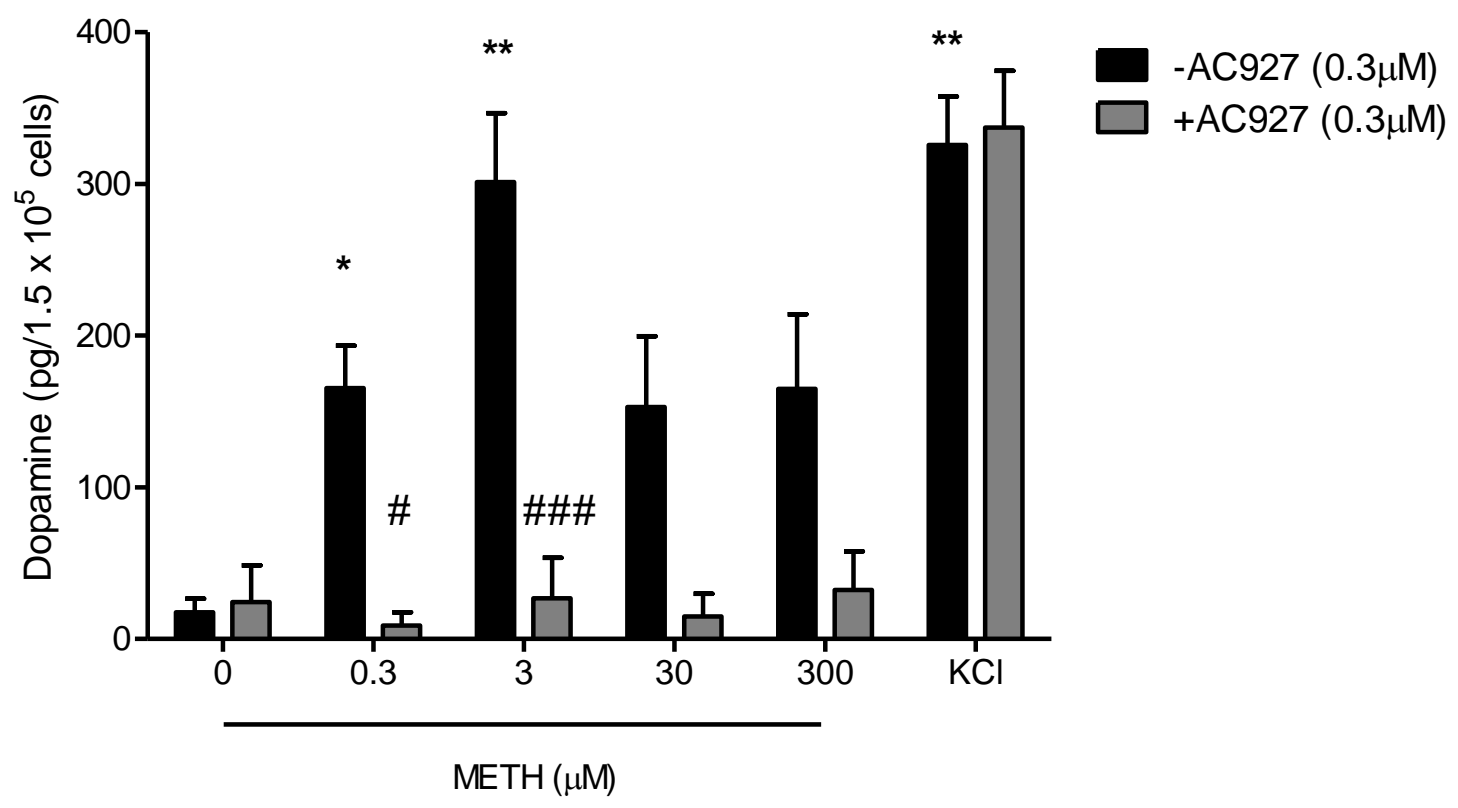

Figure 4.5 Effect of AC927 pretreatment on METH-induced dopamine release. Release of dopamine in response to methamphetamine (METH) from NG108-15 cells. Supernatants harvested from NG108-15 cells cultured in the presence or absence of METH and/or AC927 (x-axis) and quantitated as described in the materials and methods are represented as pg dopamine per $1.5 \times 10^{5}$ cells in $500 \mu \mathrm{l}$ of medium. Data represent means from four (METH or $\mathrm{KCl}$ alone) or three (METH with AC927) independent experiments \pm SEM. Significant differences are noted as follows, ${ }^{*} p<0.05,{ }^{* \star} p<$ 0.01 (control vs. METH or $\mathrm{KCl}$ treated) and $\# p<0.05$, \#\#\#p<0.001 (METH alone vs. METH with AC927). 
4.3.3. Hoechst and propidium iodide staining: The apoptotic effects of various concentrations of METH (0-1 mM) on NG108-15 cells over a period of $24 \mathrm{hr}$ are shown in Figure 4.6A. One-way ANOVA showed that METH caused a significant and concentration dependent increase in the percentage of apoptotic cells $(F(7,187)=37.21, p<0.0001)$. Posthoc analysis employing Dunnett's tests showed that the following concentrations of METH caused significant increases in apoptosis when compared with controls: $3 \mu \mathrm{M}(q=2.87, p<$ 0.05), $10 \mu \mathrm{M}(q=3.74, p<0.01), 100 \mu \mathrm{M}(q=5.99, p<0.001), 300 \mu \mathrm{M}(q=7.73, p<0.001)$, and $1000 \mu \mathrm{M}(q=13.68, p<0.001)$.

AC927 pretreatment significantly attenuated the apoptotic effects of METH. Two-way ANOVA showed a significant effect of METH treatment $(F(6,392)=37.82, p<0.0001)$, AC927 pretreatment $(F(3,392)=55.94, p<0.0001)$ and METH treatment $\times$ AC927 pretreatment interaction $(F(18,392)=5.41, p<0.0001)$. Post-hoc Bonferroni's tests showed that AC927 $(0.3,3$ and $30 \mu \mathrm{M})$ attenuated the apoptotic effects of METH. AC927 (0.3 $\mu \mathrm{M})$ attenuated the apoptotic effects of the following concentrations of METH: $3 \mu \mathrm{M}(t=3.34, p<0.01), 10 \mu \mathrm{M}(t=$ $3.70, p<0.01), 100 \mu \mathrm{M}(t=5.05, p<0.001), 300 \mu \mathrm{M}(t=5.85, p<0.001)$, and $1000 \mu \mathrm{M}(t=$ 9.80, $p<0.001)$. AC927 $(3 \mu \mathrm{M})$ prevented the apoptotic effects of the following concentrations of METH: $10 \mu \mathrm{M}(t=3.52, p<0.01), 100 \mu \mathrm{M}(t=3.45, p<0.01), 300 \mu \mathrm{M}(t=5.67, p<0.001)$, and $1000 \mu \mathrm{M}(t=8.84, p<0.001)$. AC927 $(30 \mu \mathrm{M})$ attenuated the apoptotic effects of the following concentrations of METH: $100 \mu \mathrm{M}(t=3.20, p<0.05), 300 \mu \mathrm{M}(t=3.00, p<0.05)$, and $1000 \mu \mathrm{M}(t=7.82, p<0.001)$.

The necrotic effects of various concentrations of METH (0-1 mM) on NG108-15 cells over a period of $24 \mathrm{hr}$ are shown in Figure 4.6B. One-way ANOVA showed that METH caused a significant and concentration dependent increase in the percentage of necrotic cells $(F(7,187)=7.35, p<0.0001)$. Post-hoc analysis employing Dunnett's tests showed that the 
following concentrations of METH caused significant increases in necrosis when compared with no treatment controls: $300 \mu \mathrm{M}(q=3.82, p<0.01)$ and $1000 \mu \mathrm{M}(q=5.88, p<0.01)$.

AC927 pretreatment significantly attenuated the necrotic effects of METH. Two-way ANOVA showed a significant effect of METH treatment $(F[6,392]=8.32, p<0.0001)$ and AC927 pretreatment $(F(3,392)=17.14, p<0.0001)$. Post-hoc Bonferroni's tests showed that the following concentrations of AC927 attenuated the necrotic effects of METH (300 and 1000 $\mu \mathrm{M}): 0.3 \mu \mathrm{M}, t=4.33, p<0.001$ and $t=4.26, p<0.001 ; 3 \mu \mathrm{M}, t=3.30, p<0.01$ and $t=3.91$, $p<0.001 ; 30 \mu \mathrm{M}, t=3.29, p<0.01$ and $t=2.87, p<0.05$. 

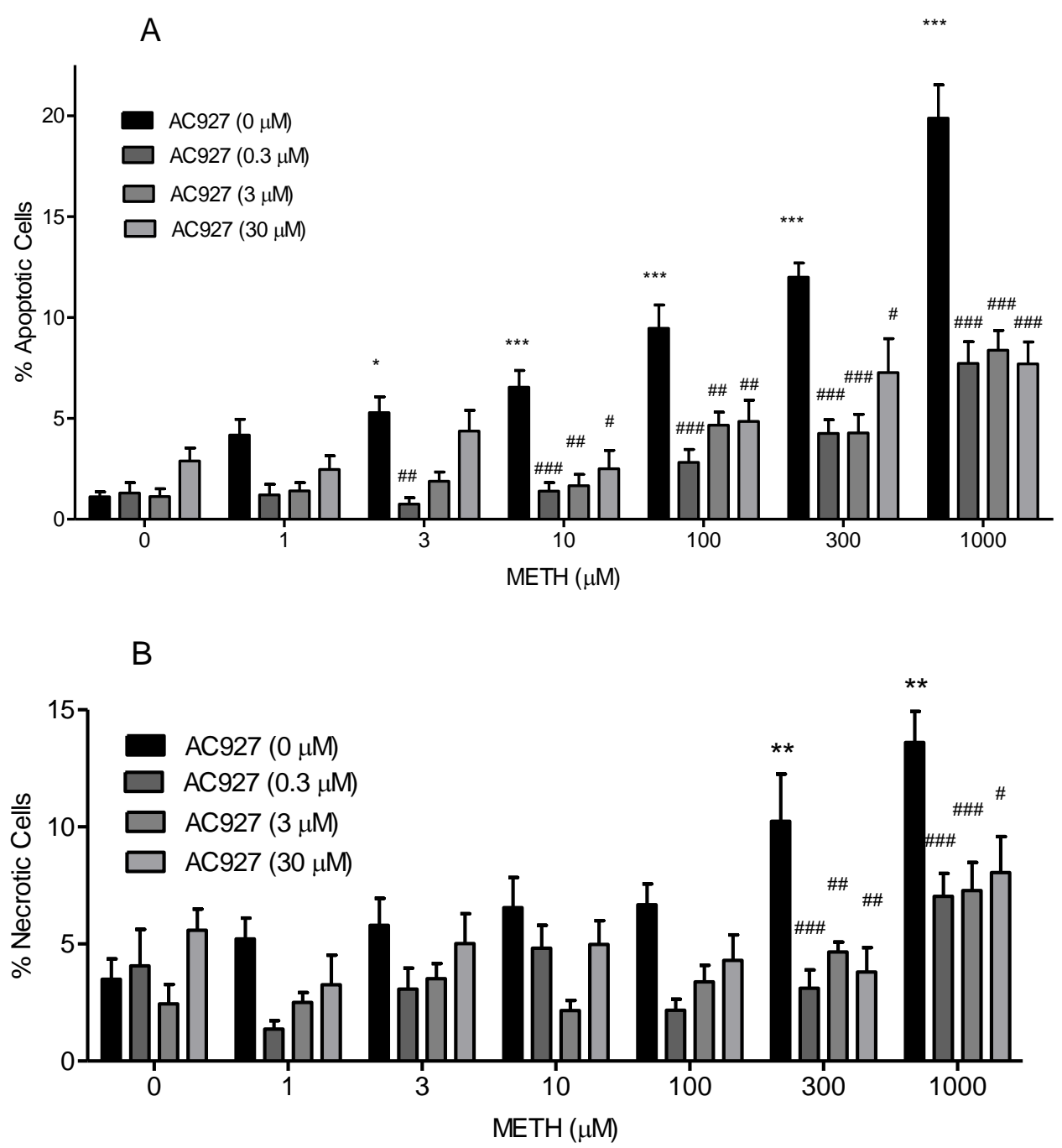

Figure 4.6 Effect of AC927 pretreatment on METH-induced (A) apoptosis and (B) necrosis. AC927 protects against methamphetamine (METH)-induced apoptosis (A) and necrosis (B). NG108-15 cells were pretreated with AC927 (0-30 $\mu \mathrm{M})$ prior to exposure to METH $(0-1 \mathrm{mM})$ for $24 \mathrm{hr}$. After $24 \mathrm{hr}$, the wells were incubated with Hoechst 33342 and propidium iodide stains $(20 \mu \mathrm{g} / \mathrm{ml}$ each) to obtain percentages of apoptotic and necrotic cells. Data represent means from two separate experiments ( $n=3$ /experiment) \pm SEM. Significant differences are indicated by ${ }^{*} p<0.05,{ }^{* *} p<0.01$, ${ }^{* * *} p<0.001$ (control vs. METH treated); $\# p<0.05, \# \# p<0.01, \# \# p<0.001$ (METH alone vs. METH with AC927). 


\subsection{Discussion}

This study showed that METH causes apoptosis in differentiated NG108-15 cells at physiologically relevant micromolar concentrations and can cause necrosis at higher concentrations. At earlier time points, ROS/RNS generation and release of dopamine were also observed. AC927, a $\sigma$ receptor ligand, attenuated the apoptotic and necrotic cell death as well as the neurotoxicity mediators. The implications of these findings are further discussed below.

One of the key mediators of METH's neurotoxicity is ROS/RNS generation, which can occur through multiple mechanisms including excessive dopamine release, microglial activation, glutamate release, and mitochondrial dysfunction (Krasnova and Cadet, 2009). Excessive generation of ROS/RNS can injure neurons and surrounding cells via direct oxidative damage to cellular components such as lipids, proteins, and DNA, or by causing ER stress and activation of mitochondrial death cascades, ultimately leading to nerve terminal degeneration or cell death (Krasnova and Cadet, 2009). This study demonstrated that METH generates ROS/RNS in the NG108-15 model system. All tested concentrations of METH ranging from 0.1 to $300 \mu \mathrm{M}$ induced the production of ROS/RNS within 10 min of exposure. High and stable ROS/RNS levels were detected at $20 \mathrm{~min}$ and up to $60 \mathrm{~min}$ after exposure of NG108-15 cells to METH. After the first hour, the levels of ROS/RNS decreased, indicating that the cells may shift to the production of radicals not detected by $\mathrm{CM}-\mathrm{H}_{2} \mathrm{DCFDA}$. Alternately, in METH-treated cells, endogenous peroxidases as well as antioxidants such as glutathione may be rapidly recruited after the first hour to scavenge $\mathrm{H}_{2} \mathrm{O}_{2}$ and $\mathrm{ONOO}^{-}$ radicals.

At the early time point $(20 \mathrm{~min})$ that gave consistent and robust ROS/RNS signals following METH administration, the antioxidant NAC reduced the signal indicating that the fluorescent probe $\mathrm{CM}-\mathrm{H}_{2}$ DCFDA was detecting ROS/RNS. In addition, catalase and L-NMMA 
also decreased the METH-induced signal indicating that $\mathrm{H}_{2} \mathrm{O}_{2}$ and $\mathrm{NO}$ species were being generated. This result is consistent with the ability of METH to generate $\mathrm{H}_{2} \mathrm{O}_{2}$ and $\mathrm{NO}$ species from various sources including dopamine oxidation and glutamate-induced NOS activation (Krasnova and Cadet, 2009). It is also interesting to note that the dose response of METHinduced reactive species generation did not follow a classical sigmoidal pattern, displaying highest radical generation at the $3 \mu \mathrm{M}$ concentration. This pattern of results is most likely due to multiple mechanisms and sources of METH's ROS/RNS generation (Krasnova and Cadet, 2009).

AC927 pretreatment attenuated the ROS/RNS generated by METH. This effect of AC927 does not seem to be a general antioxidant effect because AC927 did not prevent the $\mathrm{H}_{2} \mathrm{O}_{2}$-mediated ROS signal or reduce the basal cellular ROS/RNS signal. However, at the $4 \mathrm{hr}$ time point onwards, AC927 $(0.3 \mu \mathrm{M})$ attenuated the basal cellular ROS/RNS levels as well as the ROS signal produced by $\mathrm{Na}_{2} \mathrm{Cr}_{2} \mathrm{O}_{7} \cdot \mathrm{Na}_{2} \mathrm{Cr}_{2} \mathrm{O}_{7}$ generates $\cdot \mathrm{O}_{2}^{-}, \mathrm{H}_{2} \mathrm{O}_{2}$ and $\mathrm{OH}^{-}$in the cell (Azad et al., 2008). In combination with $\mathrm{NO}, \mathrm{O}_{2}{ }^{-}$can produce $\cdot \mathrm{ONOO}^{-}$in the cell. The ability of AC927 to attenuate the ROS signal produced by $\mathrm{Na}_{2} \mathrm{Cr}_{2} \mathrm{O}_{7}$ and not $\mathrm{H}_{2} \mathrm{O}_{2}$ is most likely due to increased levels of cellular antioxidant/antioxidant enzymes like superoxide dismutase which can reduce superoxide levels in the cell, or decreased levels of enzymes like NOS which can generate $\mathrm{NO}$ leading to the production of ' $\mathrm{ONOO}^{-}$. Since this effect of AC927 is observed after $4 \mathrm{hr}$ and not before, it suggests the induction of cellular antioxidants or a decrease in prooxidant/nitrosative stress enzymes, rather than the effect of generalized intrinsic antioxidant activity.

Corroborating with this interpretation, several studies in the literature demonstrate the ability of $\sigma$ receptors to modulate cellular ROS/RNS generation and antioxidant systems. Previous studies in tumor cells have shown that $\sigma_{2}$ receptor activation causes ROS generation (Ostenfeld et al., 2005). $\sigma_{1}$ Receptors are also involved in oxidative stress-mediated toxicities 
like ischemic stroke and have been shown to provide protective effects (Schetz et al., 2007). $\sigma$ Receptors also play a regulatory role in the redox state of the cell, and can modulate cellular NOS enzyme activity (Vagnerova et al., 2006; Tsai et al., 2009; Yang et al., 2010). In addition to modulating the cellular redox system, $\sigma$ receptors can also regulate other systems that are involved in ROS/RNS generation by METH. First, $\sigma$ receptors can regulate glutamate release through NMDA receptors which in turn causes nNOS activation and nitrosative stress (DeCoster et al., 1995). Second, $\sigma$ receptors can modulate microglial activation through $\mathrm{Ca}^{2+}$ dependent mechanisms, which can contribute to the release of inflammatory cytokines and ROS/RNS generation (Hall et al., 2009). Third, $\sigma$ receptors can regulate the release of dopamine which in turn undergoes autooxidation and is a major cause of METH's ROS generation (Gonzalez-Alvear and Werling, 1994; Derbez et al., 2002).

Although additional studies are needed to identify the specific mechanism(s) through which AC927 reduces the generation of METH-induced ROS/RNS, the studies conducted herein suggest that the modulation of dopamine release may be an important contributor. AC927 attenuates METH-induced dopamine release from the NG108-15 cells, with peak release observed at the $3 \mu \mathrm{M}$ concentration of $\mathrm{METH}$ which is consistent with the peak observed in the ROS assay. Moreover, AC927 pretreatment prevented the dopamine release caused by $\mathrm{METH}$, but not the non-specific dopamine release caused by $\mathrm{K}^{+}$-mediated hyperpolarization. This is consistent with the role of $\sigma$ receptors in regulating DAT function and dopamine release in several in vivo and in vitro studies, including the involvement of $\mathrm{Ca}^{2+}$ dependent and protein kinase C-mediated mechanisms (Booth and Baldessarini, 1991; Derbez et al., 2002).

METH also caused apoptosis and necrosis in NG108-15 cells. Oxidative and nitrosative stress in the cell can lead to the activation of pro death pathways like mitochondrial release of cytochrome c, and/or caspase 3 activation which ultimately leads to apoptotic or 
necrotic cell death (Higuchi et al., 1998). AC927 significantly attenuated both the apoptotic and necrotic cell death which is consistent with the role of $\sigma$ receptors in cell death mechanisms (Bowen, 2000; Marrazzo et al., 2011). Furthermore, the protective effects of AC927 observed in NG108-15 cells is complementary and consistent with the neuroprotection observed in earlier in vivo studies (Matsumoto et al., 2008; Seminerio et al., 2011). Moreover, in tumor cells, AC927 has been shown to prevent apoptosis caused by $\sigma_{2}$ receptor agonists, further underscoring an important role of $\sigma$ receptors in cell death mechanisms (Marrazzo et al., 2011).

Apart from $\sigma$ receptors, $D_{1}$ receptor antagonism can also protect against the apoptotic effects of METH (Jayanthi et al., 2005). Recent studies have shown that $\sigma_{1}$ and $D_{1}$ receptors heteromerize in cells, which has implications for the downstream effects of psychostimulants including the activation of adenyl cyclase and MAPK pathways (Navarro et al., 2010). Therefore, AC927 may potentially modulate the $\sigma_{1}$ and $D_{1}$ interaction and mitigate the toxic effects of METH.

In summary, the data in this chapter demonstrates that METH can cause apoptosis and necrosis in an in vitro system representative of a differentiated neuronal cell, which mechanistically involves dopamine release and induction of reactive oxygen/nitrogen radicals. Additionally, a synthetic $\sigma$ ligand, AC927, can attenuate the cytotoxic effects of METH and contributing neurotoxic mechanisms. Future studies will be directed towards the elucidation of the downstream neurotoxic pathways activated after ROS/RNS generation in differentiated NG108-15 cells. Also, the individual contributions of the two subtypes of $\sigma$ receptors will have to be discerned, as better tools are developed.

4.5 Contributions: Nidhi Kaushal conducted the apoptosis and necrosis assays. Dr. Meenal Elliott performed the dopamine release assay and the ROS assay. 


\section{CHAPTER 5}

EVALUATION OF SN79 AGAINST METH AND ELEVATED TEMPERATURE-INDUCED NEUROTOXICITY: IN VITRO STUDIES 


\subsection{Introduction}

METH is known to cause cell death in various brain regions as well as in vitro cell culture system (Krasnova and Cadet, 2009). Previous in vivo studies have shown that pretreatment of $\sigma$ receptor antagonists attenuated the neurotoxic effects of METH in male, Swiss Webster mice (Matsumoto et al., 2007; Kaushal et al., 2011b; Seminerio et al., 2011). Nevertheless, the role of $\sigma$-receptors in neurotoxicity resulting from drugs of abuse like METH remained unclear due to various limitations, including the lack of a suitable in vitro model system. In chapter 4, differentiated NG108-15 cells were used to identify some of the most well studied mechanisms of METH-induced neurotoxicity: ROS/RNS generation and dopamine release. Notably, the concentrations of METH used to cause apoptosis and the activation of these neurotoxicity mediators were within the physiologically relevant micromolar concentrations.

AC927, a sigma receptor antagonist attenuated METH-induced neurotoxicity (apoptosis and necrosis), and its mediators like ROS/RNS generation and dopamine release. In that study, AC927 was the only compound to be tested. In order to confirm that the protective effects observed were mediated through sigma receptors, another sigma receptor antagonist needed to be tested. SN79, with its long half-life and low propensity for toxicity is a better drug candidate than AC927. In this study, SN79 was therefore tested against METH-induced cell death (apoptosis and necrosis) and its mediators like ROS/RNS generation to confirm the pattern of results obtained with AC927. If a sigma receptor antagonist attenuates the neurotoxic effects of $\mathrm{METH}$, the agonist is expected to enhance the toxicity. With this hypothesis, DTG (a sigma receptor agonist) was tested against METH-induced cell death and shifts in dose response curve of $\mathrm{METH}$-induced cell death were evaluated. In addition to testing SN79 against METH-induced cell death and ROS/RNS generation; in this study additional mechanisms of METH-induced apoptotic cell death in differentiated NG108-15 cells were identified. The mechanisms looked into were caspase dependence or independence 
(caspase-3 activation), as well as activation of intrinsic (caspase-9 activation) or extrinsic apoptotic pathway (caspase-8 activation).

In addition to identifying the sigma receptor sensitive mechanisms of METH-induced neurotoxicity, it is also important to evaluate the contribution of elevated temperature as observed during METH administration during in vivo studies. Although the exact mechanism of hyperthermic effects of METH is not clear, release of inflammatory cytokines like IL-1 $1 \beta$ from microglial cells, ROS/RNS generation are thought to be contributing factors (Bowyer et al., 1994; Imam et al., 1999; Riedel and Maulik, 1999; Yamashita et al., 2000; Fukami et al., 2004). This increase in body temperature in turn can potentially exacerbate the neurotoxic effects of METH by altering blood brain barrier permeability, increasing DAT function and ROS/RNS production (Fleckenstein et al., 1997; Xie et al., 2000; Kiyatkin et al., 2007; Numachi et al., 2007; Sharma et al., 2007).

However, it is very difficult to identify the individual contribution of METH and hyperthermia, and their interaction at the cellular level in the brain in a complex in vivo system. This also translates to the difficulty in identifying the mechanism of action of neuroprotective pharmacological strategies in vivo. Therefore, in this study a differentiated NG108-15 model system was maintained at 37 and $40{ }^{\circ} \mathrm{C}$ and then treated with METH to provide information about the contribution of hyperthermia and METH separately and also their interaction towards cell death (apoptosis and necrosis). In addition, sigma receptor antagonist, SN79 was given as a pretreatment to understand which of these components can be modulated.

\subsection{Materials and Methods}

\subsubsection{Cell line and culture}

5.2.1.1. Cell growth: The neuroblastoma x glioma, hybridoma cell line NG108-15 (Hamprecht et al., 1985) were obtained from ATCC (Rockville, MD). Cells were maintained in 
$25 \mathrm{~cm}^{2}$ (T25) or $75 \mathrm{~cm}^{2}$ (T75) culture flasks (Corning-Costar, Lowell, MA) in hi-glucose (4.5 g/L) DMEM (Dulbecco's modified Eagle's medium) supplemented with 10\% FBS (fetal bovine serum), penicillin, streptomycin, and HAT (hypoxanthine-aminopterin-thymidine) at $37^{\circ} \mathrm{C}$ in a humidified incubator in $5 \% \mathrm{CO}_{2}$.

5.2.1.2. Cell differentiation: Culture medium was replaced with differentiation medium (DMEM with $0.5 \%$ FBS, penicillin, streptomycin, HAT and 1\% DMSO) and the cells allowed to grow for a further 3-4 days.

5.2.2 Hoechst and propidium iodide staining: NG108-15 cells were grown and differentiated in 96-well culture plates and four types of experiments were conducted: 1) SN79 and METH: Cells were exposed to various concentrations of METH (0-1 mM), SN79 (1-100 nM), SN79 (1-100 nM)+METH (0-1 mM) for $24 \mathrm{hrs}$ at $37^{\circ} \mathrm{C}$. 2) DTG and METH: Cells were exposed to various concentrations of METH $(0-1 \mathrm{mM})$, DTG $(0.1 \mathrm{nM}-10 \mu \mathrm{M})$, DTG $(0.1 \mathrm{nM}-10$ $\mu \mathrm{M})+\mathrm{METH}(0-1 \mathrm{mM})$ for $24 \mathrm{hrs}$ at $37^{\circ} \mathrm{C}$. 3) METH treatment at 37 or $40^{\circ} \mathrm{C}$ : Cells were exposed to various concentrations of METH (0-1 mM) at either 37 or $\left.40{ }^{\circ} \mathrm{C} .4\right)$ SN79 and METH: Cells were exposed to various concentrations of METH (0-1 mM), SN79 (1-100 nM), SN79 $(1-100 \mathrm{nM})+\mathrm{METH}(0-1 \mathrm{mM})$ for $24 \mathrm{hrs}$ at $40{ }^{\circ} \mathrm{C}$. Hoechst stain $(20 \mu \mathrm{g} / \mathrm{ml}$ final concentration) and propidium iodide stain $(20 \mu \mathrm{g} / \mathrm{ml}$ final concentration) were added to each well and incubated at room temperature for $10 \mathrm{~min}$. Three images are taken/well using an UV light microscope. Cells with brightly stained and fragmented nuclei were counted as apoptotic and cells that were red were counted as necrotic. The percentage of apoptotic and necrotic cells were counted with the help of Image $\mathrm{J}$ cell counter $(\mathrm{NIH})$. The sum of percentage of apoptotic and necrotic cells was referred to as "total cell death".

5.2.3 MTT assay: NG108-15 cells grown and differentiated in 96-well culture plates were exposed to various concentrations of METH (0-10 mM), SN79 (0.1 -300 nM) or SN79 (0.1 $300 \mathrm{nM})+\mathrm{METH}(1 \mathrm{mM})$ for $24 \mathrm{hrs}$. After incubation at $37^{\circ} \mathrm{C}$ for the specified times, $10 \mu \mathrm{l}$ 
MTT (3-(4,5-Dimethylthiazol-2-yl)-2,5-diphenyltetrazolium bromide) freshly prepared in PBS was added to the wells at a final concentration of $50 \mu \mathrm{g} / \mathrm{ml}$ and the plates were incubated at $37^{\circ} \mathrm{C}$ for a further $4 \mathrm{hr} .100 \mu \mathrm{l}$ of solubilization solution $(10 \% \mathrm{SDS}$ in $0.1 \mathrm{~N} \mathrm{HCl})$ was then added to each well and the plates incubated overnight. Absorbance was read at $570 \mathrm{~nm}$ with a reference wavelength of $690 \mathrm{~nm}$. Percent cell viability was computed by dividing average absorbance values for experimental wells to average absorbance values for cells in untreated control wells.

5.2.4 Trypan blue exclusion assay: Cells were grown and differentiated in 6-well plates. On the day of the experiment, the differentiation media was changed to phenol red free differentiation media with various concentrations of METH (0-3 mM), SN79 (1 -30 nM) or SN79 $(1-30 \mathrm{nM})+\mathrm{METH}(1 \mathrm{mM})$ for $24 \mathrm{hrs}$. The media was removed and the cells detached using Trypsin-EDTA and then mixed with media. $10 \mu \mathrm{l}$ of trypan blue dye and $10 \mu \mathrm{l}$ of cell mixture were mixed and the number of total, live and dead cells was counted using a Countess Automated Cell Counter (Invitrogen, Carlsbad, CA).

5.2.5 Caspase-3, -9 and -8 assay: NG108-15 cells were grown and differentiated in 96-well culture plates and time course and inhibition studies were conducted: 1) Time course: Cells were exposed to various concentrations of METH (0-1 mM) for 1.5, 3, 6, 9, 12,18 and 24 hrs. 2) Inhibition: The cells were treated with either METH (0-1 mM), SN79 (1-100 nM) or SN79 (1$100 \mathrm{nM})+\mathrm{METH}(0-1 \mathrm{mM})$ for the time point at which a peak response was observed for caspase-3, -9 or -8 activation. At appropriate time points for the time course or inhibition studies, reagents from the Caspase-Glo luminescence assay kit for caspase $3 / 7,-9,-8$ (Invitrogen, Carlsbad, CA) were added to the wells and incubated for $2 \mathrm{hrs}$. The plate was read using a luminescence plate reader. The no cell blank readings were subtracted from all the treatment readings. The results were expressed as \% untreated control cells at that time point. 
5.2.6 Reactive oxygen/nitrogen species: Cells grown and differentiated in 96 well plate $\left(10^{4}\right.$ cells per well). The culture medium was replaced phenol red free medium containing $0.5 \%$ FBS and $5 \mu \mathrm{M}$ fluorigenic, oxidizable, dye $\mathrm{CM}^{-} \mathrm{H}_{2}$ DCFDA (5-(and-6)-chloromethyl-2',7'dichlorodihydrofluorescein diacetate) and returned to the incubator at $37^{\circ} \mathrm{C}$ for $45-60 \mathrm{~min}$. Cells were treated with appropriate concentrations of METH or SN79. Exogenously added 100 $\mu \mathrm{M} \mathrm{H} \mathrm{H}_{2} \mathrm{O}_{2}$ and $\mathrm{Na}_{2} \mathrm{Cr}_{2} \mathrm{O}_{7}$ served as a positive control in this assay. All compounds were added in replicates of 4 or 8 and the plates are returned to the incubator. In the assay, SN79 (1-100 $\mathrm{nM}), \mathrm{N}$-acetylcysteine (NAC, $10 \mathrm{mM}$ ), catalase (10000 units per ml), L-NMMA (200 $\mu \mathrm{M})$ were added 15 min prior to the addition of METH $(0.1-3000 \mu \mathrm{M}), \mathrm{H}_{2} \mathrm{O}_{2}(100 \mu \mathrm{M})$ or $\mathrm{Na}_{2} \mathrm{Cr}_{2} \mathrm{O}_{7}(100$ $\mu \mathrm{M})$. At specified time points, plates were read in a Fluostar Optima fluorescence plate reader fitted with a 485/520 $\mathrm{nm}$ excitation/emission filter set (BMG Labtech $\mathrm{GmbH}$, Offenberg, Germany).

5.2.7 Statistical analysis: Statistical analysis of data was performed using ANOVA with appropriate post-hoc tests employing GraphPad Prism 4 (GraphPad Software, San Diego, $\mathrm{CA})$.

\subsection{Results}

\subsubsection{Apoptosis/Necrosis:}

\subsubsection{SN79 and METH:}

Apoptosis: One-way ANOVA showed that METH treatment caused a significant increase in the percentage of apoptotic cells $(F(7,192)=22.14, p<0.0001)$. Post-hoc Dunnett's tests confirmed that the following concentrations of METH caused a significant increase in the percentage of apoptotic cells: $10 \mu \mathrm{M}(q=3.79, p<0.01), 30 \mu \mathrm{M}(q=5.09, p<$ $0.001), 100 \mu \mathrm{M}(q=7.15, p<0.01), 300 \mu \mathrm{M}(q=7.72, p<0.01)$ and $1000 \mu \mathrm{M}(q=9.77, p<$ 0.01). SN79 pretreatment significantly attenuated the apoptotic effects of METH (Figure 5.1A). 
Two-way ANOVA showed a significant effect of METH treatment $(F(7,538)=14.63, p<$ $0.0001)$, SN79 pretreatment $(F(3,538)=100.90, p<0.0001)$, and SN79 pretreatment $\times$ METH treatment $(F(21,538)=6.47, p<0.0001)$. Bonferroni's post-hoc tests showed that SN79 $(1,10$ and $100 \mathrm{nM}$ ) pretreatment is able to attenuate the apoptotic effects of the following concentrations of METH: $3 \mu \mathrm{M}(t=2.80, p<0.05$ and $t=3.07, p<0.05), 10 \mu \mathrm{M}(t=4.36, p<$ $0.001 ; t=4.59, p<0.001$ and $t=4.61, p<0.001$ respectively $), 30 \mu \mathrm{M}(t=5.78, p<0.001 ; t=$ 5.32, $p<0.001$ and $t=5.59, p<0.001$ respectively $), 100 \mu \mathrm{M}(t=6.40, p<0.001 ; t=6.70, p<$ 0.001 and $t=8.21, p<0.001$ respectively), $300 \mu \mathrm{M}(t=5.48, p<0.001 ; t=7.30, p<0.001$ and $t=7.64, p<0.001$ respectively $)$ and $1000 \mu \mathrm{M}(t=11.00, p<0.001 ; t=9.52, p<0.001$ and $t=10.52, p<0.001$ respectively).

Necrosis: One-way ANOVA showed that METH treatment caused a significant increase in the percentage of necrotic cells $(F(7,192)=8.28, p<0.0001)$. Post-hoc Dunnett's tests confirmed that 300 and $1000 \mu \mathrm{M}$ METH caused a significant increase in the percentage of necrotic cells ( $q=4.45, p<0.01$ and $q=6.31, p<0.01$ respectively). SN79 pretreatment significantly attenuated the necrotic effects of METH (Figure 5.1B). Two-way ANOVA showed a significant effect of SN79 pretreatment $(F(3,538)=14.71, p<0.0001)$, METH treatment $(F(7,538)=6.98, p<0.0001)$ and SN79 pretreatment $\times$ METH treatment interaction $(F(21,538)=1.82, p<0.05)$. Post-hoc Bonferroni's test confirmed that the following concentrations of SN79 attenuate the necrotic effects of $300 \mu \mathrm{M}(1 \mathrm{nM}: t=3.12, p<0.05 ; 10$ $\mathrm{nM}: t=3.57, p<0.01 ; 100 \mathrm{nM}: t=2.98, p<0.05)$ and $1000 \mu \mathrm{M} \mathrm{METH}(1 \mathrm{nM}: t=4.31, p<$ $0.001 ; 10 \mathrm{nM}: t=2.85, p<0.05 ; 100 \mathrm{nM}: t=5.89, p<0.001)$.

Total cell death: One-way ANOVA showed that METH treatment caused a significant increase in the percentage of total cell death $(F(7,192)=29.26, p<0.0001)$. Post-hoc Dunnett's tests confirmed that the following concentrations of METH caused a significant increase in the percentage of total cell death: $10 \mu \mathrm{M}(q=3.63, p<0.01), 30 \mu \mathrm{M}(q=5.55, p<$ 
$0.01), 100 \mu \mathrm{M}(q=6.68, p<0.01), 300 \mu \mathrm{M}(q=8.84, p<0.01)$ and $1000 \mu \mathrm{M}(q=11.71, p<$ 0.01). SN79 pretreatment significantly attenuated METH-induced cell death (Figure 5.1C). Two-way ANOVA showed a significant effect of SN79 pretreatment $(F(3,539)=73.49, p<$ 0.0001), METH treatment $(F(7,539)=15.85, p<0.0001)$ and SN79 pretreatment $\times$ METH treatment interaction $(F(21,539)=5.41, p<0.0001)$. Post-hoc Bonferroni's test confirmed that the following concentrations of SN79 attenuate cell death caused by $10 \mu \mathrm{M}(1 \mathrm{nM}: t=3.52, p$ $<0.05 ; 10 \mathrm{nM}: t=3.67, p<0.01 ; 100 \mathrm{nM}: t=3.60, p<0.01), 30 \mu \mathrm{M}(1 \mathrm{nM}: t=4.79, p<$ $0.0001 ; 10 \mathrm{nM}: t=5.08, p<0.0001 ; 100 \mathrm{nM}: t=4.90, p<0.0001), 100 \mu \mathrm{M}(1 \mathrm{nM}: t=4.52, p<$ $0.001 ; 10 \mathrm{nM}: t=5.06, p<0.0001 ; 100 \mathrm{nM}: t=6.65, p<0.0001), 300 \mu \mathrm{M}(1 \mathrm{nM}: t=5.47, p<$ $0.0001 ; 10 \mathrm{nM}: t=6.84, p<0.0001 ; 100 \mathrm{nM}: t=6.59, p<0.0001)$ and $1000 \mu \mathrm{M} \mathrm{METH}(1 \mathrm{nM}:$ $t=9.52, p<0.0001 ; 10 \mathrm{nM}: t=7.58, p<0.0001 ; 100 \mathrm{nM}: t=10.42, p<0.0001)$. 


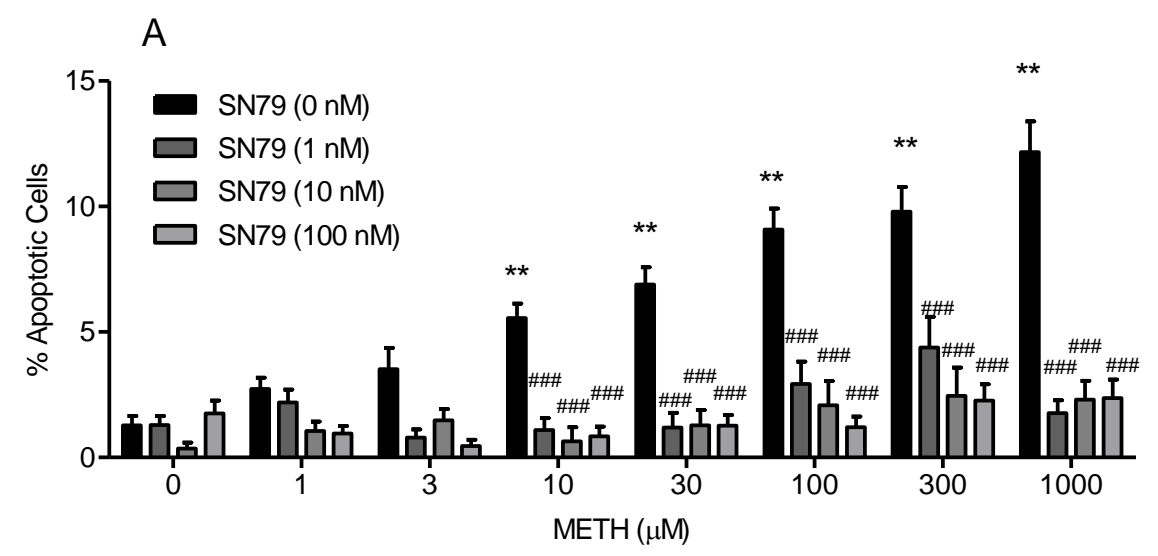

B

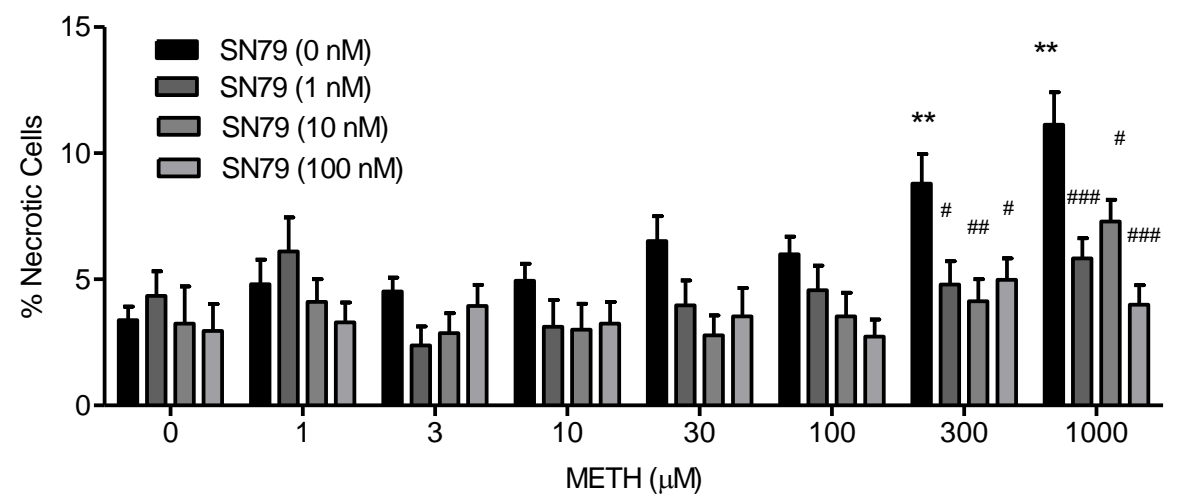

C

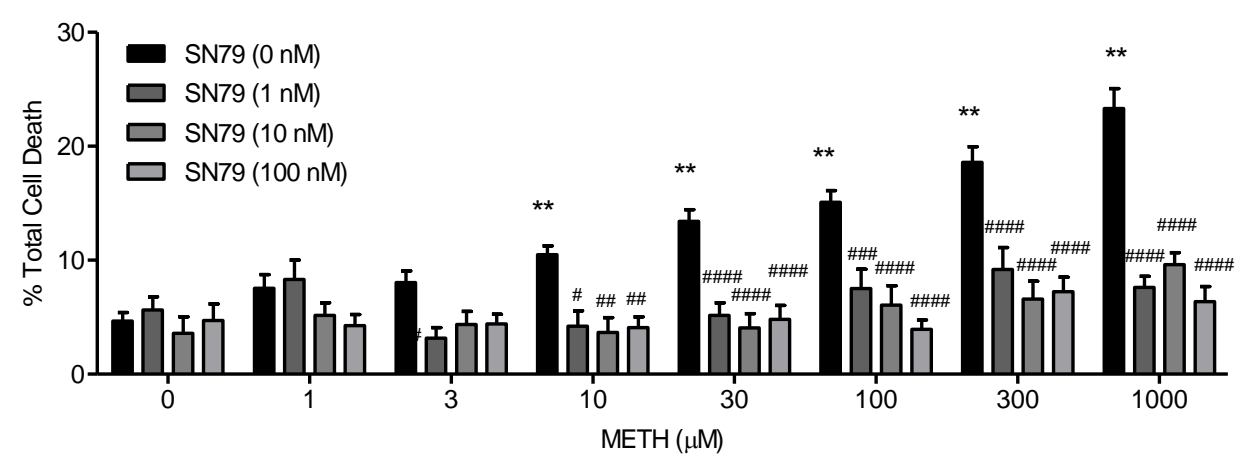

Figure 5.1 Effect of SN79 pretreatment on METH-induced (A) apoptosis, $(B)$ necrosis and (C) total cell death. SN79 protects against methamphetamine (METH)-induced apoptosis (A), necrosis $(B)$ and total cell death $(C)$. Differentiated NG108-15 cells were pretreated with SN79 (0-100 $\mathrm{nM})$ prior to exposure to METH (0-1 mM) for $24 \mathrm{hr}$. After $24 \mathrm{hr}$, the wells were incubated with Hoechst 33342 and propidium iodide stains $(20 \mu \mathrm{g} / \mathrm{ml}$ each) to obtain percentages of apoptotic and necrotic cells. Total cell death $=$ Apoptotic cell death + Necrotic cell death. Data represent means from three separate experiments $(n=3$ /experiment $) \pm$ SEM. Significant differences are indicated by ${ }^{* *} p<0.01$ (control vs. METH treated); $\# p<0.05, \# \# p<0.01, \# \# \# p<0.001$ (METH alone vs. METH with SN79). 


\subsubsection{DTG and METH:}

Apoptosis: METH treatment on its own caused a significant increase in apoptotic cell death in differentiated NG108-15 cells. One way ANOVA showed a significant effect of METH treatment $(F(6,244)=22.51, p<0.0001)$. Dunnett's post-hoc tests confirmed that the following concentrations of METH cause a significant increase in apoptosis: $10 \mu \mathrm{M}(\mathrm{q}=3.29, p<0.01)$, $100 \mu \mathrm{M}(q=6.94, p<0.01)$ and $1000 \mu \mathrm{M}(q=9.85, p<0.01)$.

Figure 5.2A shows that DTG pretreatment displayed a trend towards a shift in the dose response curve of METH-induced apoptosis towards the left; however, the effect was not significant. Two way ANOVA shows a significant effect of METH treatment $(F(6,889)=37.83$, $p<0.0001)$ and DTG pretreatment $(F(6,889)=7.49, p<0.0001)$ but METH treatment $\times$ DTG pretreatment interaction was not significant $(F(36,889)=0.68$, n.s. $)$. Bonferroni's post-hoc tests show that DTG pretreatment at $10 \mathrm{nM}$ and $1 \mu \mathrm{M}$ with METH $1 \mu \mathrm{M}$ concentration was significantly different than METH $1 \mu \mathrm{M}$ treatment alone $(t=2.92, p<0.05$ and $t=2.88, p<$ 0.05 respectively).

Necrosis: METH treatment on its own caused a significant increase in necrotic cell death in differentiated NG108-15 cells. One way ANOVA showed a significant effect of METH treatment $(F(6,249)=48.59, p<0.0001)$. Dunnett's post-hoc tests confirmed that METH 1000 $\mu \mathrm{M}$ caused a significant increase in necrosis $(q=14.25, p<0.01)$.

Figure 5.2B shows that DTG pretreatment at intermediate concentrations shifts the dose response curve of METH towards the left, and at even higher concentrations shows an upward and leftward shift in the dose response curve. Two way ANOVA showed a significant effect of METH treatment $(F(6,948)=55.75, p<0.0001)$, DTG pretreatment $(F(6,948)=$ $77.15, p<0.0001)$ and METH treatment $\times$ DTG pretreatment interaction $(F(36,6)=1.80, p<$ 0.005). Bonferroni's post-hoc tests confirm that the following concentrations of DTG in combination with METH are significantly different than METH treatment alone: DTG $10 \mathrm{nM}$ (10 
$\mu \mathrm{M}: t=3.07, p<0.05$ and $100 \mu \mathrm{M}: t=4.59, p<0.001)$, DTG $100 \mathrm{nM}(0.01 \mu \mathrm{M}: t=2.78, p<$ 0.05; $0.1 \mu \mathrm{M}: t=2.75, p<0.05 ; 1 \mu \mathrm{M}: t=5.44, p<0.001 ; 10 \mu \mathrm{M}: t=5.07, p<0.001$ and 100 $\mu \mathrm{M}: t=7.01, p<0.001)$, DTG $1 \mu \mathrm{M}(0 \mu \mathrm{M}: t=2.85, p<0.05 ; 1 \mu \mathrm{M}: t=7.39, p<0.001 ; 10 \mu \mathrm{M}:$ $t=7.92, p<0.001 ; 100 \mu \mathrm{M}: t=9.33, p<0.001$ and $1000 \mu \mathrm{M}: t=4.02, p<0.001)$, DTG 10 $\mu \mathrm{M}(0 \mu \mathrm{M}: t=6.87, p<0.001 ; 0.01 \mu \mathrm{M}: t=4.49, p<0.001 ; 0.1 \mu \mathrm{M}: t=5.18, p<0.001 ; 1 \mu \mathrm{M}:$ $t=7.07, p<0.001 ; 10 \mu \mathrm{M}: t=8.31, p<0.001 ; 100 \mu \mathrm{M}: t=10.08, p<0.001$ and $1000 \mu \mathrm{M}: t=$ $5.21, p<0.001)$.

Total cell death: METH treatment on its own caused a significant increase in cell death in differentiated NG108-15 cells. One way ANOVA showed a significant effect of METH treatment $(F(6,249)=62.50, p<0.0001)$. Dunnett's post-hoc tests confirmed that the following concentrations of METH caused a significant increase in total cell death: $1 \mu \mathrm{M}(q=3.15, p<$ $0.05), 10 \mu \mathrm{M}(q=3.54, p<0.01), 100 \mu \mathrm{M}(q=6.48, p<0.01)$ and $1000 \mu \mathrm{M}(q=16.97, p<$ 0.01). Figure $5.2 \mathrm{C}$ shows that DTG pretreatment at intermediate concentrations shifted the dose response curve of METH-induced cell death towards the left and at even higher concentrations displayed an upward and leftward shift in the dose response curve. Two way ANOVA showed a significant effect of METH treatment $(F(6,948)=88.73, p<0.0001)$, DTG pretreatment $(F(6,948)=46.62, p<0.0001)$ and METH treatment $\times$ DTG pretreatment interaction $(F(36,946)=1.69, p<0.01)$. Bonferroni's post-hoc tests confirm that the following concentrations of DTG in combination with METH are significantly different than METH treatment alone: DTG $10 \mathrm{nM}(1 \mu \mathrm{M}: t=3.02, p<0.05 ; 10 \mu \mathrm{M}: t=3.75, p<0.01$ and $100 \mu \mathrm{M}: t$ $=5.22, p<0.001)$, DTG $100 \mathrm{nM}(0.1 \mu \mathrm{M}: t=2.89, p<0.05 ; 1 \mu \mathrm{M}: t=4.23, p<0.001 ; 10 \mu \mathrm{M}: t$ $=5.52, p<0.001$ and $100 \mu \mathrm{M}: t=5.25, p<0.001)$, DTG $1 \mu \mathrm{M}(0 \mu \mathrm{M}: t=3.29, p<0.01 ; 1 \mu \mathrm{M}$ : $t=7.07, p<0.001 ; 10 \mu \mathrm{M}: t=6.14, p<0.001 ; 100 \mu \mathrm{M}: t=7.63, p<0.001$ and $1000 \mu \mathrm{M}: t=$ 3.35, $p<0.001)$, DTG $10 \mu \mathrm{M}(0 \mu \mathrm{M}: t=5.76, p<0.001 ; 0.01 \mu \mathrm{M}: t=3.30, p<0.01 ; 0.1 \mu \mathrm{M}: t$ 
$=3.44, p<0.01 ; 1 \mu \mathrm{M}: t=5.75, p<0.001 ; 10 \mu \mathrm{M}: t=7.23, p<0.001 ; 100 \mu \mathrm{M}: t=7.62, p<$ 0.001 and $1000 \mu \mathrm{M}: t=5.27, p<0.001)$.
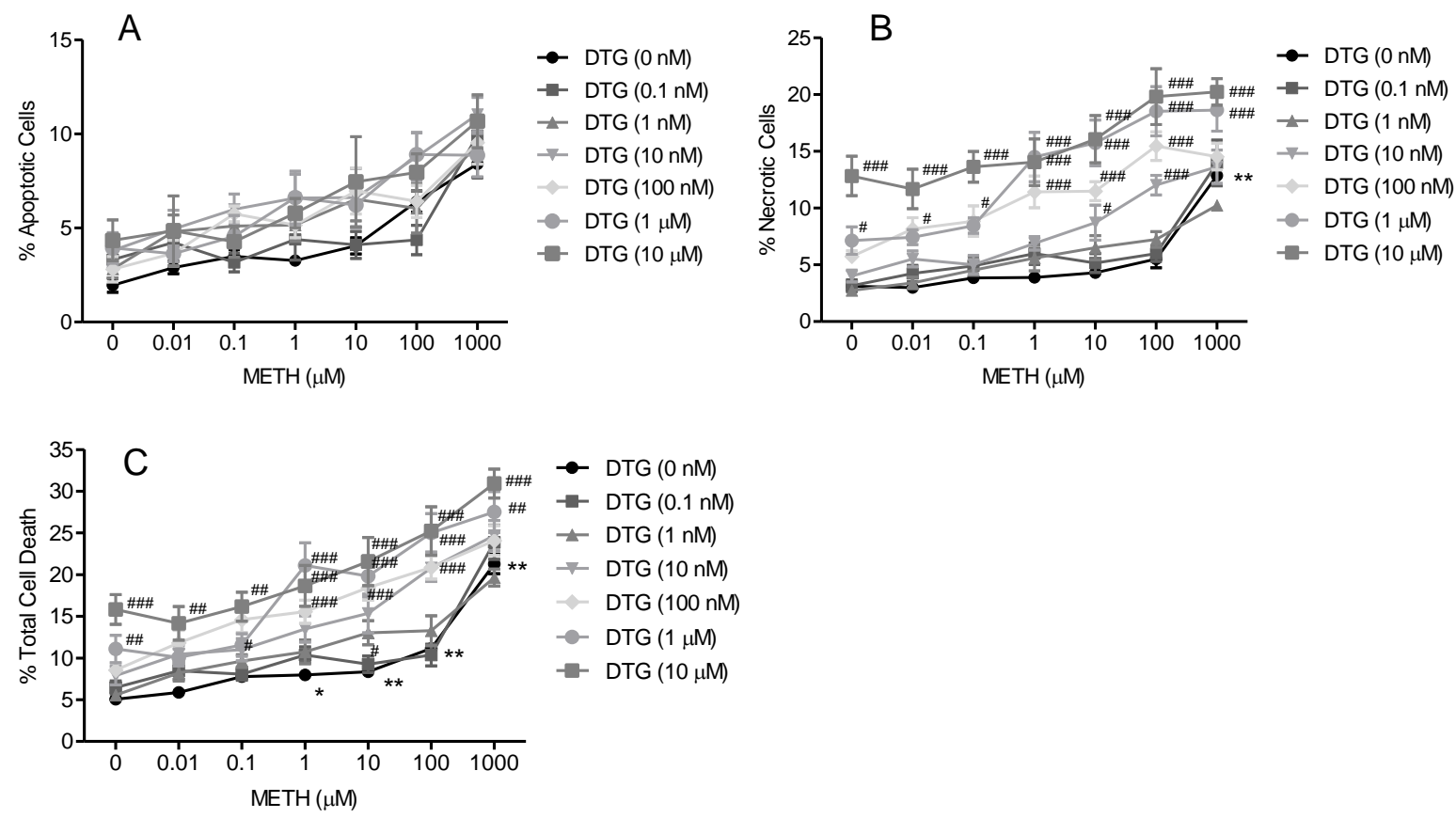

Figure 5.2 Effect of DTG pretreatment on METH-induced (A) apoptosis, (B) necrosis and (C) total cell death. NG108-15 cells were exposed to DTG $(0.1 \mathrm{nM}-10 \mu \mathrm{M})$ and/or METH (0-1000 $\mu \mathrm{M})$ for $24 \mathrm{hr}$. After $24 \mathrm{hr}$, the wells were incubated with Hoechst 33342 and propidium iodide stains $(20 \mu \mathrm{g} / \mathrm{ml}$ each) to obtain percentages of apoptotic and necrotic cells. Total cell death $=$ Apoptotic cell death $+\mathrm{Necrotic}$ cell death. Data represent means from two separate experiments $(n=3$ /experiment $) \pm$ SEM. Significant

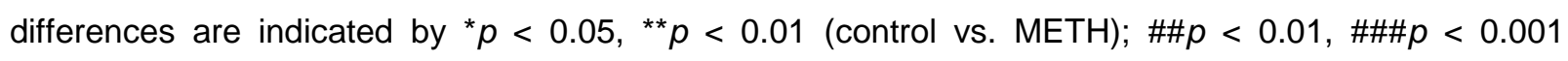
(DTG+METH vs. METH). 


\subsubsection{METH treatment at 37 and $40^{\circ} \mathrm{C}$}

Apoptosis: METH treatment caused a significant increase in apoptotic cell death in NG108-15 cells maintained at $37^{\circ} \mathrm{C}$. One way ANOVA showed a significant effect of METH treatment $(F(9,436)=33.37, p<0.0001)$. Dunnett's post-hoc tests confirmed that the following concentrations of METH caused a significant increase in apoptosis when compared to no treatment control cells: $10 \mu \mathrm{M}(q=4.77, p<0.01), 30 \mu \mathrm{M}(q=6.38, p<0.01), 100 \mu \mathrm{M}(q=$ 9.56, $p<0.01), 300 \mu \mathrm{M}(q=9.93, p<0.01)$ and $1000 \mu \mathrm{M}(q=13.30, p<0.01)$.

METH treatment at elevated temperature of $40{ }^{\circ} \mathrm{C}$ caused a significant increase in apoptotic cell death when compared to control cells maintained at the same temperature. One way ANOVA showed a significant effect of METH treatment $(F(9,217)=5.80, p<0.0001)$. Dunnett's post-hoc tests confirmed that the following concentrations of METH caused a significant increase in apoptosis when compared to control cells maintained at $40{ }^{\circ} \mathrm{C}: 10 \mu \mathrm{M}$ $(q=3.70, p<0.01), 30 \mu \mathrm{M}(q=3.42, p<0.01), 100 \mu \mathrm{M}(q=4.60, p<0.01), 300 \mu \mathrm{M}(q=$ $4.31, p<0.01)$ and $1000 \mu \mathrm{M}(q=5.16, p<0.01)$.

On comparing the METH treated NG108-15 cells at 37 and $40{ }^{\circ} \mathrm{C}$, it was observed that cells maintained at $40{ }^{\circ} \mathrm{C}$ had a higher percentage of apoptotic cells in the no treatment control as well as METH treatment when compared with the cells maintained at $37^{\circ} \mathrm{C}$ (Figure $\left.5.3 \mathrm{~A}\right)$. The dose response of $\mathrm{METH}$ at $40{ }^{\circ} \mathrm{C}$ shows a parallel and upward shift in apoptotic cell death. Two way ANOVA showed a significant effect of METH treatment $(F(9,635)=21.52, p<$ $0.0001)$ and temperature $(F(1,635)=31.49, p<0.0001)$. Bonferroni's post-hoc tests confirmed that the following concentrations of METH caused a significant increase in apoptosis when maintained at 37 and $40^{\circ} \mathrm{C}: 1 \mu \mathrm{M}(t=2.92, p<0.05), 10 \mu \mathrm{M}(t=4.47, p<$

$0.001)$ a A $00 \mu \mathrm{M}(t=2.90, p<0.05)$.

Necrosis: METH treatment caused a significant increase in necrotic cell death in NG108-15 cells maintained at $37^{\circ} \mathrm{C}$. One way ANOVA showed a significant effect of METH 
treatment $(F(9,428)=32.93, p<0.0001)$. Dunnett's post-hoc tests confirmed that the following concentrations of METH caused a significant increase in apoptosis when compared to no treatment control cells: $300 \mu \mathrm{M}(q=6.75, p<0.01)$ and $1000 \mu \mathrm{M}(q=14.02, p<0.01)$.

METH treatment at an elevated temperature of $40^{\circ} \mathrm{C}$ caused a significant increase in apoptotic cell death when compared to control cells maintained at the same temperature. The necrotic cell death was more sensitive to temperature, as lower concentrations of METH also caused significant necrosis when maintained at $40^{\circ} \mathrm{C}$. One way ANOVA showed a significant effect of METH treatment $(F(9,205)=9.63, p<0.0001)$. Dunnett's post-hoc tests confirmed that the following concentrations of METH caused a significant increase in necrosis when compared to control cells maintained at $40^{\circ} \mathrm{C}: 1 \mu \mathrm{M}(q=2.86, p<0.05), 3 \mu \mathrm{M}(q=2.89, p<$ 0.05), $10 \mu \mathrm{M}$ ( $q=3.24, p<0.05), 30 \mu \mathrm{M}(q=2.75, p<0.05), 100 \mu \mathrm{M}(q=7.10, p<0.01), 300$ $\mu \mathrm{M}(q=4.20, p<0.01)$ and $1000 \mu \mathrm{M}(q=7.33, p<0.01)$.

On comparing the METH treated NG108-15 cells at 37 and $40^{\circ} \mathrm{C}$, it was observed that cells maintained at $40{ }^{\circ} \mathrm{C}$ had a significantly higher percentage of necrotic cells in the no treatment control as well as METH treatment when compared with the cells maintained at 37 ${ }^{\circ} \mathrm{C}$ (Figure 5.3B). The dose response of METH at $40{ }^{\circ} \mathrm{C}$ shows an up and leftward shift in necrotic cell death. Two way ANOVA showed a significant effect of METH treatment $(F(9,615)$ $=19.76, p<0.0001)$, temperature $(F(1,615)=600, p<0.0001)$ and METH treatment $\times$ temperature interaction $(F(9,615)=8.81, p<0.0001)$. Bonferroni's post-hoc tests confirmed that the following concentrations of METH caused a significant increase in apoptosis when maintained at 40 versus $37^{\circ} \mathrm{C}: 0 \mu \mathrm{M}(t=3.24, p<0.05), 0.01 \mu \mathrm{M}(t=4.48, p<0.001), 0.1 \mu \mathrm{M}$ $(t=5.17, p<0.001), 1 \mu \mathrm{M}(t=8.79, p<0.001), 3 \mu \mathrm{M}(t=7.02, p<0.001), 10 \mu \mathrm{M}(t=9.45, p$ $<0.001), 30 \mu \mathrm{M}(t=6.37, p<0.001), 100 \mu \mathrm{M}(t=17.32, p<0.001), 300 \mu \mathrm{M}(t=7.80, p<$ $0.001)$ and $1000 \mu \mathrm{M}(t=14.43, p<0.001)$. 
Total cell death: METH treatment caused a significant increase in total cell death in NG108-15 cells maintained at $37^{\circ} \mathrm{C}$. One way ANOVA showed a significant effect of METH treatment $(F(9,437)=68.14, p<0.0001)$. Dunnett's post-hoc tests confirmed that the following concentrations of METH caused a significant increase in apoptosis when compared to no treatment control cells: $10 \mu \mathrm{M}(q=5.05, p<0.01), 30 \mu \mathrm{M}(q=7.59, p<0.01), 100 \mu \mathrm{M}(q=$ $9.40, p<0.01), 300 \mu \mathrm{M}(q=12.21, p<0.01)$ and $1000 \mu \mathrm{M}(q=20.21, p<0.01)$.

METH treatment at elevated temperature of $40^{\circ} \mathrm{C}$ caused a significant increase in total cell death when compared to control cells maintained at the same temperature. Similar to necrotic cell death, the total cell death was sensitive to temperature as lower concentrations of METH also caused cell death when maintained at $40{ }^{\circ} \mathrm{C}$. One way ANOVA showed a significant effect of METH treatment $(F(9,208)=13.78, p<0.0001)$. Dunnett's post-hoc tests confirmed that the following concentrations of METH caused a significant increase in necrosis when compared to control cells maintained at $40^{\circ} \mathrm{C}: 1 \mu \mathrm{M}(q=2.91, p<0.05), 3 \mu \mathrm{M}(q=$ 3.00, $p<0.05), 10 \mu \mathrm{M}(q=3.99, p<0.01), 30 \mu \mathrm{M}(q=3.58, p<0.01), 100 \mu \mathrm{M}(q=8.17, p<$ $0.01), 300 \mu \mathrm{M}(q=5.31, p<0.01)$ and $1000 \mu \mathrm{M}(q=8.57, p<0.01)$.

On comparing the METH treated NG108-15 cells at 37 and $40^{\circ} \mathrm{C}$, it was observed that cells maintained at $40{ }^{\circ} \mathrm{C}$ had a significantly higher percentage of cell death in no treatment control as well as METH treatment when compared with the cells maintained at $37^{\circ} \mathrm{C}$ (Figure 5.3C). The dose response of $\mathrm{METH}$ at $40^{\circ} \mathrm{C}$ shows an up and leftward shift in total cell death. Two way ANOVA showed a significant effect of METH treatment $(F(9,627)=36.68, p<$ $0.0001)$, temperature $(F(1,627)=652.3, p<0.0001)$ and METH treatment $\times$ temperature interaction $(F(9,627)=7.81, p<0.0001)$. Bonferroni's post-hoc tests confirmed that the following concentrations of METH caused a significant increase in total cell death when maintained at 40 versus $37^{\circ} \mathrm{C}: 0 \mu \mathrm{M}(t=4.36, p<0.001), 0.01 \mu \mathrm{M}(t=4.71, p<0.001), 0.1$ $\mu \mathrm{M}(t=5.13, p<0.001), 1 \mu \mathrm{M}(t=9.31, p<0.001), 3 \mu \mathrm{M}(t=7.49, p<0.001), 10 \mu \mathrm{M}(t=$ 
10.74, $p<0.001), 30 \mu \mathrm{M}(t=6.56, p<0.001), 100 \mu \mathrm{M}(t=17.67, p<0.001), 300 \mu \mathrm{M}(t=7.81$, $p<0.001)$ and $1000 \mu \mathrm{M}(t=14.22, p<0.001)$.

A

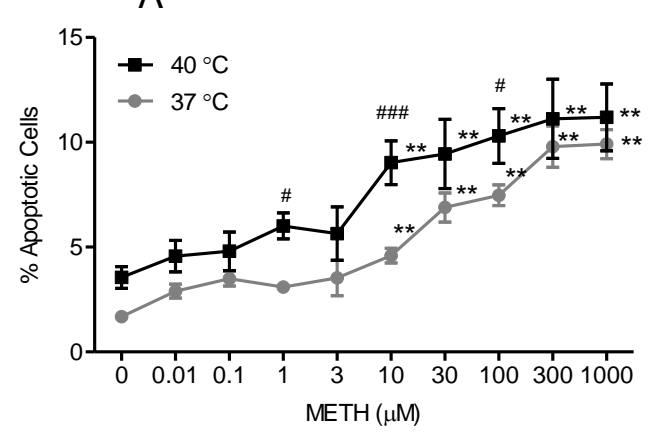

C

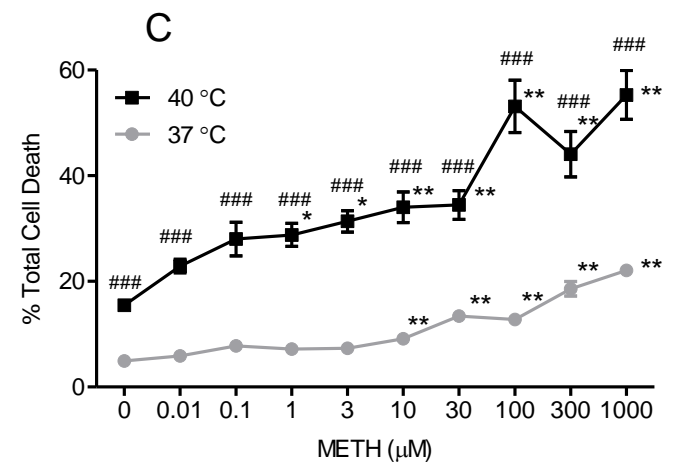

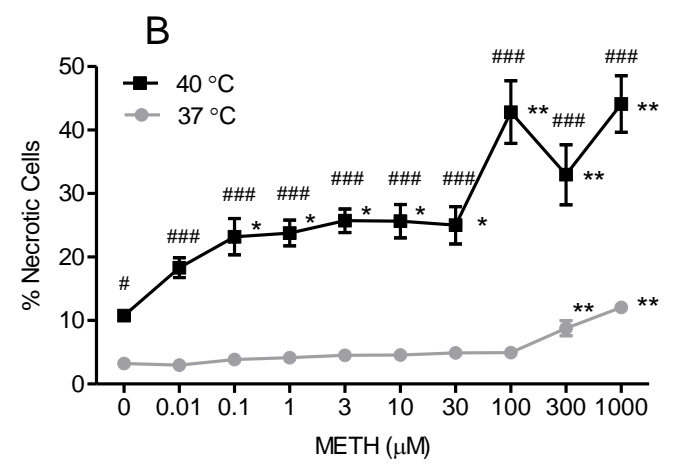

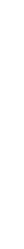

Figure 5.3 Effect of temperature (37 versus $40^{\circ} \mathrm{C}$ ) on METH-induced (A) apoptosis, (B) necrosis and (C) total cell death. NG108-15 cells were exposed to METH (0-1000 $\mu \mathrm{M})$ for $24 \mathrm{hr}$ at 37 or $40{ }^{\circ} \mathrm{C}$. After $24 \mathrm{hr}$, the wells were incubated with Hoechst 33342 and propidium iodide stains (20 $\mu \mathrm{g} / \mathrm{ml}$ each) to obtain percentages of apoptotic and necrotic cells. Total cell death = Apoptotic cell death + Necrotic cell death. Data represent means from two separate experiments $(n=3 /$ experiment $) \pm$ SEM. Significant differences are indicated by ${ }^{*} p<0.05,{ }^{* *} p<0.01$ (control vs. METH treated at a particular temperature); $\# p<0.05, \# \# p<0.001$ (treatment at $37^{\circ} \mathrm{C}$ vs. $40^{\circ} \mathrm{C}$ ). 


\subsubsection{4: SN79 and METH at $40^{\circ} \mathrm{C}$ :}

Apoptosis: SN79 treatment was able to significantly reduce the elevated apoptotic cell death caused by increased temperature $\left(40^{\circ} \mathrm{C}\right)$. One way ANOVA showed a significant effect of SN79 treatment $(F(3,120)=8.21, p<0.0001)$. Dunnett's post-hoc tests confirmed that the following concentrations of SN79 significantly attenuated the apoptotic effect of elevated temperature in control untreated cells: $1 \mathrm{nM}(q=4.14, p<0.01), 10 \mathrm{nM}(q=4.32, p<0.01)$ and $10 \mathrm{nM}(q=3.16, p<0.01)$.

SN79 also attenuated the combined apoptotic effect of elevated temperature and all the concentrations of METH (Figure 5.4A). One way ANOVA showed a significant effect of SN79 pretreatment prior to the following concentrations of METH treatment: $0.01 \mu \mathrm{M}(F(3,40)$ $=12.06, p<0.0001), 0.1 \mu \mathrm{M}(F(3,39)=3.18, p<0.05), 1 \mu \mathrm{M}(F(3,114)=20.05, p<0.0001), 3$ $\mu \mathrm{M}(F(3,65)=7.63, p<0.0005), 10 \mu \mathrm{M}(F(3,108)=30.55, p<0.0001), 30 \mu \mathrm{M}(F(3,74)=$ 23.44, $p<0.0001), 100 \mu \mathrm{M}(F(3,115)=31.41, p<0.0001), 300 \mu \mathrm{M}(F(3,73)=15.99, p<$ $0.0001)$ and $1000 \mu \mathrm{M}(F(3,110)=13.29, p<0.0001)$. Dunnett's post-hoc tests confirmed that SN79 pretreatment is able to attenuate the apoptotic effects of the following concentrations of METH: $0.01 \mu \mathrm{M}(1 \mathrm{nM}: q=3.90, p<0.01 ; 10 \mathrm{nM}: q=4.97, p<0.01 ; 100 \mathrm{nM}: q=5.28, p<$ 0.01), $0.1 \mu \mathrm{M}(100 \mathrm{nM}: q=2.96, p<0.05), 1 \mu \mathrm{M}(1 \mathrm{nM}: q=5.51, p<0.01 ; 10 \mathrm{nM}: q=6.00, p$ $<0.01 ; 100 \mathrm{nM}: q=7.00, p<0.01), 3 \mu \mathrm{M}(1 \mathrm{nM}: q=3.98, p<0.01 ; 10 \mathrm{nM}: q=4.20, p<0.01$; $100 \mathrm{nM}: q=3.28, p<0.01), 10 \mu \mathrm{M}(1 \mathrm{nM}: q=8.05, p<0.01 ; 10 \mathrm{nM}: q=8.29, p<0.01 ; 100$ $\mathrm{nM}: q=6.64, p<0.01), 30 \mu \mathrm{M}(1 \mathrm{nM}: q=7.06, p<0.01 ; 10 \mathrm{nM}: q=7.33, p<0.01 ; 100 \mathrm{nM}: q$ $=6.30, p<0.01), 100 \mu \mathrm{M}(1 \mathrm{nM}: q=8.27, p<0.01 ; 10 \mathrm{nM}: q=8.04, p<0.01 ; 100 \mathrm{nM}: q=$ 7.35, $p<0.01), 300 \mu \mathrm{M}(1 \mathrm{nM}: q=5.72, p<0.01 ; 10 \mathrm{nM}: q=6.07, p<0.01 ; 100 \mathrm{nM}: q=5.50$, $p<0.01)$ and $1000 \mu \mathrm{M}(1 \mathrm{nM}: q=5.01, p<0.01 ; 10 \mathrm{nM}: q=4.58, p<0.01 ; 100 \mathrm{nM}: q=5.64$, $p<0.01)$. 
Necrosis: SN79 treatment was able to significantly reduce the elevated necrotic cell death caused by increased temperature $\left(40^{\circ} \mathrm{C}\right)$ in control untreated cells. One way ANOVA showed a significant effect of SN79 treatment $(F(3,120)=12.57, p<0.0001)$. Dunnett's posthoc tests confirmed that the following concentrations of SN79 significantly attenuated the apoptotic effect of elevated temperature: $1 \mathrm{nM}(q=4.82, p<0.01), 10 \mathrm{nM}(q=4.95, p<0.01)$ and $10 \mathrm{nM}(q=5.04, p<0.01)$.

SN79 also attenuated the combined necrotic effect of elevated temperature and all the concentrations of METH (Figure 5.4B). One way ANOVA showed a significant effect of SN79 pretreatment prior to the following concentrations of $\mathrm{METH}$ treatment: $0.01 \mu \mathrm{M}(F(3,40)=$ 11.98, $p<0.0001), 0.1 \mu \mathrm{M}(F(3,70)=36.99, p<0.0001), 1 \mu \mathrm{M}(F(3,114)=18.84, p<0.0001)$, $3 \mu \mathrm{M}(F(3,65)=29.95, p<0.0001), 10 \mu \mathrm{M}(F(3,108)=10.09, p<0.0001), 30 \mu \mathrm{M}(F(3,74)=$ 15.68, $p<0.0001), 100 \mu \mathrm{M}(F(3,115)=24.65, p<0.0001), 300 \mu \mathrm{M}(F(3,73)=17.50, p<$ $0.0001)$ and $1000 \mu \mathrm{M}(F(3,110)=24.19, p<0.0001)$. Dunnett's post-hoc tests confirmed that SN79 pretreatment is able to attenuate the necrotic effects of the following concentrations of METH: $0.01 \mu \mathrm{M}(1 \mathrm{nM}: q=5.19, p<0.01 ; 10 \mathrm{nM}: q=5.06, p<0.01 ; 100 \mathrm{nM}: q=3.82, p<$ 0.01), $0.1 \mu \mathrm{M}(1 \mathrm{nM}: q=9.43, p<0.01 ; 10 \mathrm{nM}: q=9.61, p<0.01 ; 100 \mathrm{nM}: q=9.15, p<$ 0.01), $1 \mu \mathrm{M}(1 \mathrm{nM}: q=5.84, p<0.01 ; 10 \mathrm{nM}: q=6.65, p<0.01 ; 100 \mathrm{nM}: q=5.58, p<0.01)$, $3 \mu \mathrm{M}(1 \mathrm{nM}: q=7.22, p<0.01 ; 10 \mathrm{nM}: q=8.64, p<0.01 ; 100 \mathrm{nM}: q=6.79, p<0.01), 10 \mu \mathrm{M}$ $(1 \mathrm{nM}: q=4.30, p<0.01 ; 10 \mathrm{nM}: q=4.90, p<0.01 ; 100 \mathrm{nM}: q=4.06, p<0.01), 30 \mu \mathrm{M}(1$ $\mathrm{nM}: q=4.35, p<0.01 ; 10 \mathrm{nM}: q=5.34, p<0.01 ; 100 \mathrm{nM}: q=6.47, p<0.01), 100 \mu \mathrm{M}(1 \mathrm{nM}$ : $q=7.34, p<0.01 ; 10 \mathrm{nM}: q=6.68, p<0.01 ; 100 \mathrm{nM}: q=6.98, p<0.01), 300 \mu \mathrm{M}(1 \mathrm{nM}: q=$ 5.88, $p<0.01 ; 10 \mathrm{nM}: q=6.13, p<0.01 ; 100 \mathrm{nM}: q=6.13, p<0.01)$ and $1000 \mu \mathrm{M}(1 \mathrm{nM}: q=$ $6.46, p<0.01 ; 10 \mathrm{nM}: q=6.75, p<0.01 ; 100 \mathrm{nM}: q=7.47, p<0.01)$.

Total cell death: SN79 treatment was able to significantly reduce the elevated cell death caused by increased temperature $\left(40^{\circ} \mathrm{C}\right)$. One way ANOVA showed a significant effect 
of SN79 treatment $(F(3,120)=20.41, p<0.0001)$. Dunnett's post-hoc tests confirmed that the following concentrations of SN79 significantly attenuated the cell death of elevated temperature: $1 \mathrm{nM}(q=6.23, p<0.01), 10 \mathrm{nM}(q=6.41, p<0.01)$ and $10 \mathrm{nM}(q=6.24, p<$ $0.01)$.

SN79 also attenuated the combined effect elevated temperature and all the concentrations of METH on cell death in differentiated NG108-15 cells (Figure 5.4C). One way ANOVA showed a significant effect of SN79 pretreatment prior to the following concentrations of METH treatment: $0.01 \mu \mathrm{M}(F(3,40)=27.03, p<0.0001), 0.1 \mu \mathrm{M}(F(3,39)=20.74, p<$ 0.0001), $1 \mu \mathrm{M}(F(3,114)=28.69, p<0.0001), 3 \mu \mathrm{M}(F(3,65)=42.27, p<0.0001), 10 \mu \mathrm{M}$ $(F(3,108)=21.87, p<0.0001), 30 \mu \mathrm{M}(F(3,74)=40.99, p<0.0001), 100 \mu \mathrm{M}(F(3,115)=$ 40.66, $p<0.0001), 300 \mu \mathrm{M}(F(3,73)=36.07, p<0.0001)$ and $1000 \mu \mathrm{M}(F(3,110)=32.66, p<$ 0.0001). Dunnett's post-hoc tests confirmed that SN79 pretreatment is able to attenuate the cell death caused by the following concentrations of $\mathrm{METH}: 0.01 \mu \mathrm{M}(1 \mathrm{nM}: q=7.38, p<0.01$; $10 \mathrm{nM}: q=7.71, p<0.01 ; 100 \mathrm{nM}: q=6.50, p<0.01), 0.1 \mu \mathrm{M}(1 \mathrm{nM}: q=6.43, p<0.01 ; 10$ $\mathrm{nM}: q=6.59, p<0.01 ; 100 \mathrm{nM}: q=6.62, p<0.01), 1 \mu \mathrm{M}(1 \mathrm{nM}: q=7.10, p<0.01 ; 10 \mathrm{nM}: q$ $=8.00, p<0.01 ; 100 \mathrm{nM}: q=7.35, p<0.01), 3 \mu \mathrm{M}(1 \mathrm{nM}: q=8.76, p<0.01 ; 10 \mathrm{nM}: q=$ 10.19, $p<0.01 ; 100 \mathrm{nM}: q=8.00, p<0.01), 10 \mu \mathrm{M}(1 \mathrm{nM}: q=6.53, p<0.01 ; 10 \mathrm{nM}: q=7.14$, $p<0.01 ; 100 \mathrm{nM}: q=5.85, p<0.01), 30 \mu \mathrm{M}(1 \mathrm{nM}: q=8.06, p<0.01 ; 10 \mathrm{nM}: q=9.22, p<$ $0.01 ; 100 \mathrm{nM}: q=9.89, p<0.01), 100 \mu \mathrm{M}(1 \mathrm{nM}: q=9.44, p<0.01 ; 10 \mathrm{nM}: q=8.71, p<0.01$; $100 \mathrm{nM}: q=8.84, p<0.01), 300 \mu \mathrm{M}(1 \mathrm{nM}: q=8.50, p<0.01 ; 10 \mathrm{nM}: q=8.90, p<0.01 ; 100$ $\mathrm{nM}: q=8.65, p<0.01)$ and $1000 \mu \mathrm{M}(1 \mathrm{nM}: q=7.59, p<0.01 ; 10 \mathrm{nM}: q=7.72, p<0.01 ; 100$ $\mathrm{nM}: q=8.72, p<0.01)$. 

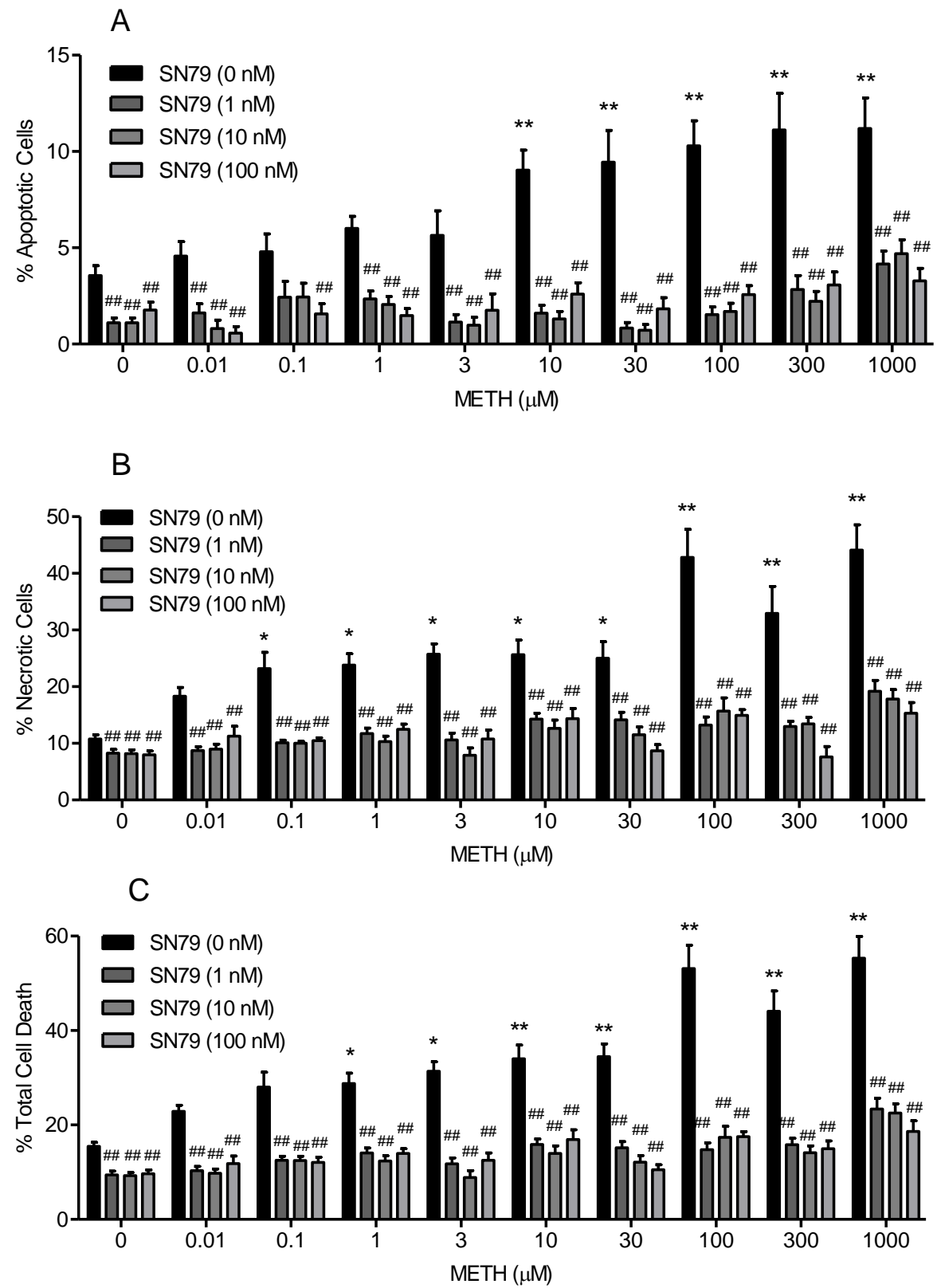

Figure 5.4 Effect of SN79 pretreatment on METH-induced (A) apoptosis, (B) necrosis and (C) total cell death at $40{ }^{\circ} \mathrm{C}$. SN79 protects against methamphetamine (METH) and elevated temperature $\left(40^{\circ} \mathrm{C}\right)$-induced apoptosis (A), necrosis (B) and total cell death (C). NG108-15 cells were pretreated with SN79 (1-100 nM) prior to exposure to METH $(0-1000 \mu \mathrm{M})$ for $24 \mathrm{hr}$ at $40{ }^{\circ} \mathrm{C}$. After $24 \mathrm{hr}$, the wells were incubated with Hoechst 33342 and propidium iodide stains $(20 \mu \mathrm{g} / \mathrm{ml}$ each) to obtain percentages of apoptotic and necrotic cells. Total cell death $=$ Apoptotic cell death + Necrotic cell death Data represent means from two separate experiments ( $n=3$ /experiment) \pm SEM. Significant differences are indicated by ${ }^{*} p<0.05,{ }^{* *} p<0.01$ (control vs. METH treated); \#\#p<0.01 (control/METH alone vs. control/METH with SN79). 
5.3.2 MTT Assay: Figure 5.5A shows a dose response of METH-induced decrease in cell viability. One-way ANOVA shows a significant effect of METH treatment $(F(11,165)=66.67, p$ $<0.0001$ ). Post-hoc Dunnett's tests reveal a significant effect of the following concentrations of METH: $1 \mathrm{mM}(q=8.13, p<0.001), 3 \mathrm{mM}(q=17.24, p<0.001)$ and $10 \mathrm{mM}(q=18.09, p<$ $0.001)$

One-way ANOVA showed that SN79 (0.1-10000 nM) pretreatment significantly attenuated the decrease in cell viability caused by METH $(1 \mathrm{mM})$ (Figure 5.5B, $F(12,269)=$ 13.94, $p<0.0001)$. Post-hoc Dunnett's tests revealed that the following concentration of SN79 pretreatment were significantly different from METH treatment alone $(0.1 \mathrm{nM}: q=3.59, p<$ $0.01 ; 0.3 \mathrm{nM}: q=3.48, p<0.01 ; 1 \mathrm{nM}: q=7.26, p<0.001 ; 3 \mathrm{nM}: q=4.97, p<0.001 ; 10 \mathrm{nM}$ : $q=4.99, p<0.001 ; 30 \mathrm{nM}: q=6.23, p<0.001 ; 100 \mathrm{nM}: q=3.56, p<0.01 ; 300 \mathrm{nM}: q=3.82$, $p<0.01 ; 1000 \mathrm{nM}: q=4.05, p<0.001)$. 


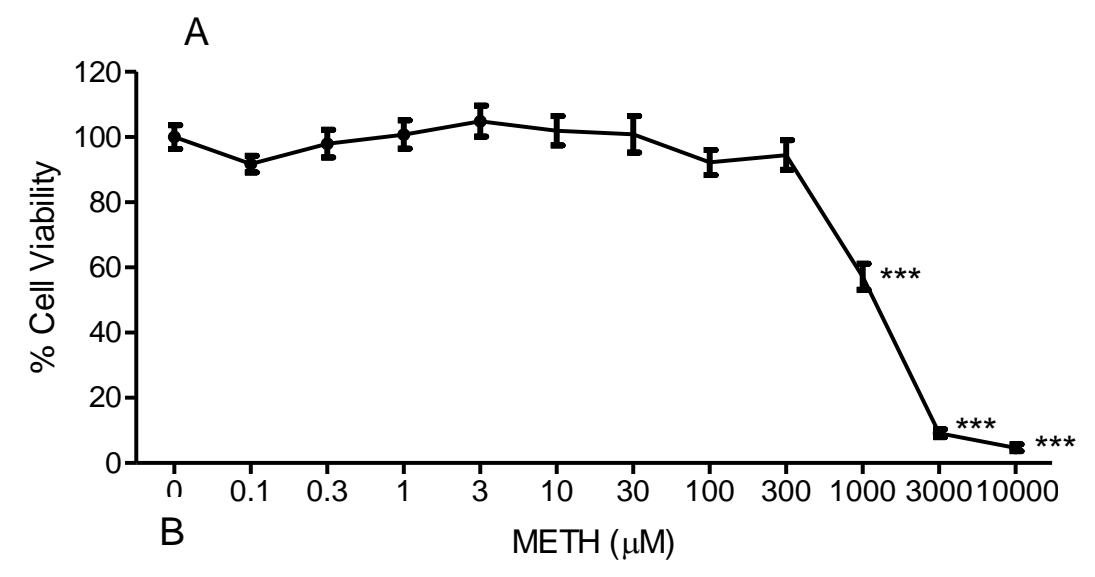

$\mathrm{B}$

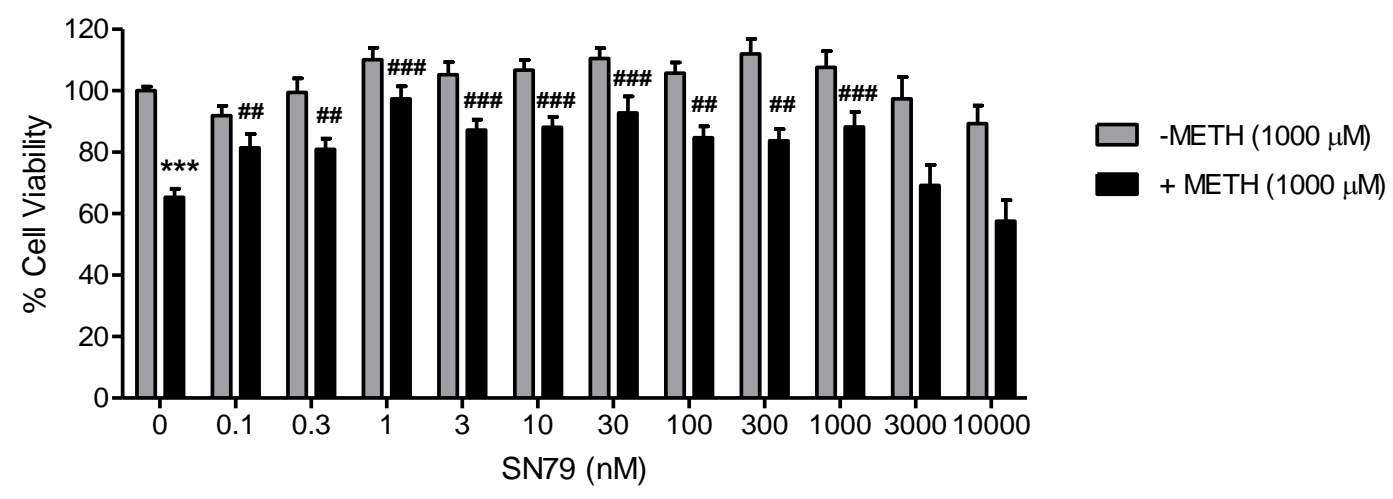

Figure 5.5 MTT Assay: A. Dose response of METH-induced decrease in cell viability B. Effect of SN79 pretreatment on METH (1000 $\mu \mathrm{M})$-induced decrease in cell viability. (A) Differentiated NG108-15 cells were treated with METH $(0-1000 \mu \mathrm{M})$. At 24 hour time point cell viability was determined using MTT assay. METH 1-10 mM caused significant decrease in cell viability. (B) Differentiated NG108-15 cells were pretreated with SN79 (0-10 $\mu \mathrm{M}), 15$ min prior to adding METH (1 mM). SN79 attenuated the decrease in cell viability caused by METH at $1000 \mu \mathrm{M}$ without significantly

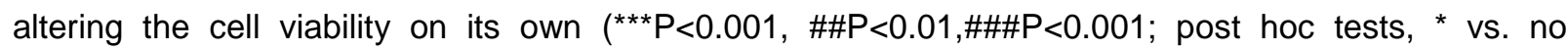
treatment control, \# vs. METH $1000 \mu \mathrm{M}$ ). 
5.3.3 Trypan blue exclusion assay: METH treatment caused a significant decrease in NG108 cell viability (Figure 5.6A). One-way ANOVA showed a significant effect of METH treatment $(F(10,38)=9.64, p<0.0001)$. Dunnett's post-hoc tests confirmed that the following doses of METH cause a significant decrease in cell viability $(1 \mathrm{mM}: q=7.52, p<0.01$ and 3 mM: $q=6.66, p<0.01)$. SN79 pretreatment attenuated METH $(1 \mathrm{mM})$-induced decrease in cell viability (Figure 5.6B). Two-way ANOVA showed a significant effect of METH treatment $(F(1,54)=5.83, p<0.05)$, SN79 pretreatment $(F(4,54)=5.24, p<0.005)$ and METH treatment $\times$ SN79 pretreatment interaction $(F(4,54)=6.11, p<0.0005)$. Bonferroni's post-hoc tests show that SN79 (1, 3, 10 and $30 \mathrm{nM})$ attenuate METH (1 mM)-induced decreases in cell viability $(t=4.10, p<0.001 ; t=5.18, p<0.001 ; t=3.71, p<0.01$ and $t=3.73, p<0.01$ respectively). 

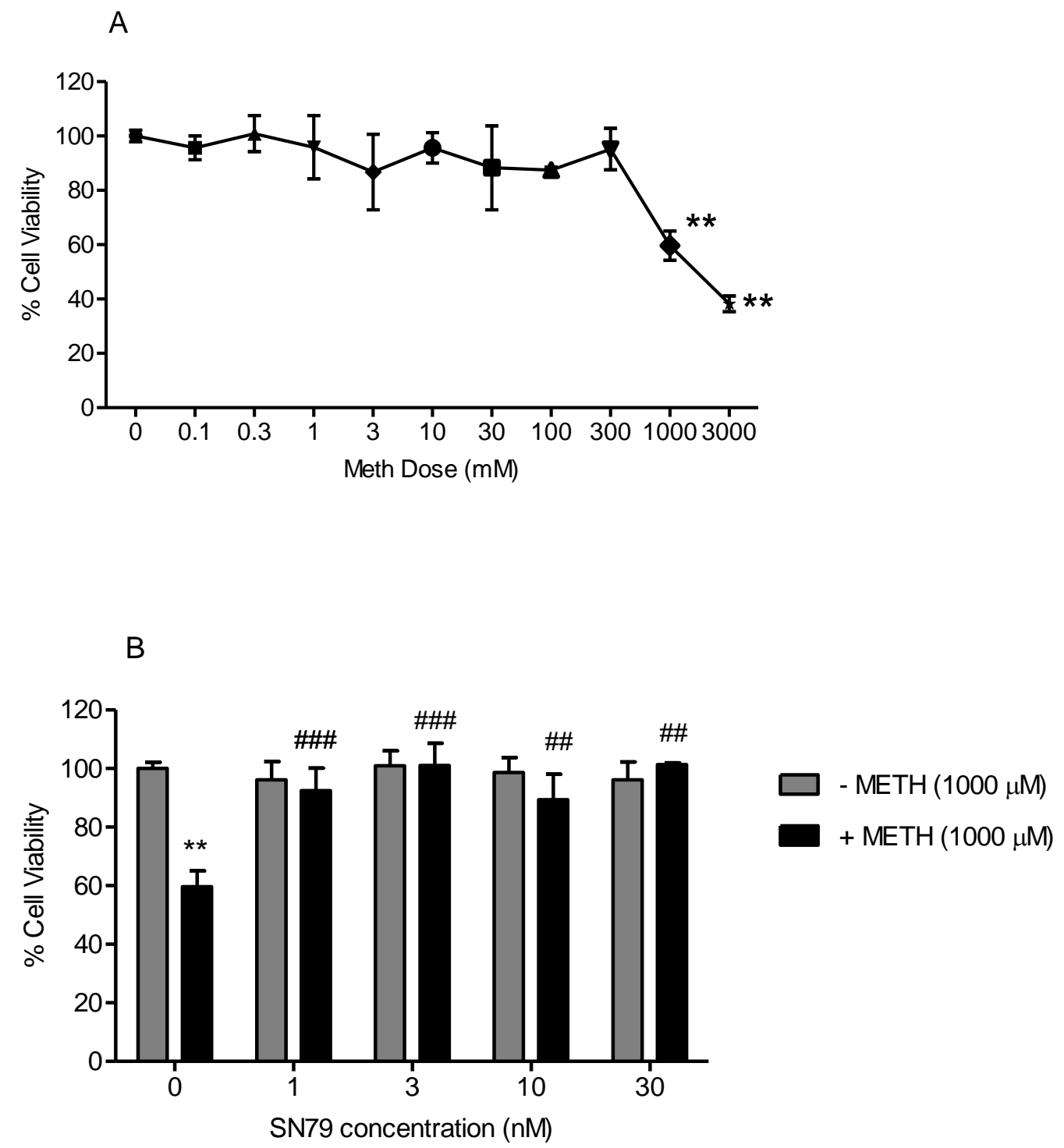

Figure 5.6 A. Dose response of METH-induced decrease in cell viability B. Effect of SN79 pretreatment on METH (1000 $\mu \mathrm{M})$-induced decrease in cell viability. (A) Differentiated NG108-15 cells were treated with METH $(0-3000 \mu \mathrm{M})$ and at 24 hour time point cell viability was determined using Trypan blue exclusion assay. METH 1-3000 $\mu \mathrm{M}$ caused significant decrease in cell viability. (B) Differentiated NG108-15 cells were pretreated with SN79 (0-100 nM), 15 min prior to adding METH $(1000 \mu \mathrm{M})$. SN79 attenuated the decrease in cell viability caused by METH at $1000 \mu \mathrm{M}$ without significantly altering the cell viability on its own $\left({ }^{* *} \mathrm{P}<0.01, \# \# \mathrm{P}<0.01, \# \# \# \mathrm{P}<0.001\right.$; post hoc tests, ${ }^{*}$ vs. no treatment control, \# vs. METH $1000 \mu \mathrm{M})$.

\subsubsection{Caspase-3, $-8,-9$ assay:}


5.3.4.1. Caspase-3 activation: METH treatment caused a significant increase in caspase 3 activation in differentiated NG108-15 cells (Figure 5.7A). Two way ANOVA showed a significant effect of METH treatment $(F(3,104)=16.78, p<0.0001)$, time $(F(4,104)=47.59$, $p<0.0001)$ and METH treatment $\times$ time interaction $(F(12,104)=16.17, p<0.0001)$. Bonferroni's multiple comparison post-hoc tests confirmed that 10,100 and $1000 \mu \mathrm{M}$ concentrations of METH caused a significant increase in caspase-3 activation at the 24 hour time point $(t=3.34, p<0.05 ; t=7.74, p<0.0001$ and $t=19.27, p<0.0001$ respectively).

SN79 pretreatment is significantly able to attenuate METH-induced caspase-3 activation at the 24 hour time point (Figure 5.7B). Two way ANOVA showed a significant effect of METH treatment $(F(4,128)=109.5, p<0.0001)$, SN79 pretreatment $(F(3,128)=14.82, p<$ $0.0001)$ and METH $\times$ SN79 pretreatment interaction $(F(12,128)=4.73, p<0.0001)$. Bonferroni's multiple comparison post-hoc tests showed that the following concentrations of SN79 can attenuate caspase-3 activation caused by METH $100 \mu \mathrm{M}(1 \mathrm{nM}: t=3.2, p<0.05$; $10 \mathrm{nM}: t=4.02, p<0.01)$ and $1000 \mu \mathrm{M}(1 \mathrm{nM}: t=5.33, p<0.0001 ; 10 \mathrm{nM}: t=7.52, p<$ $0.0001 ; 100 \mathrm{nM}: t=5.32, p<0.0001)$ treatment. 

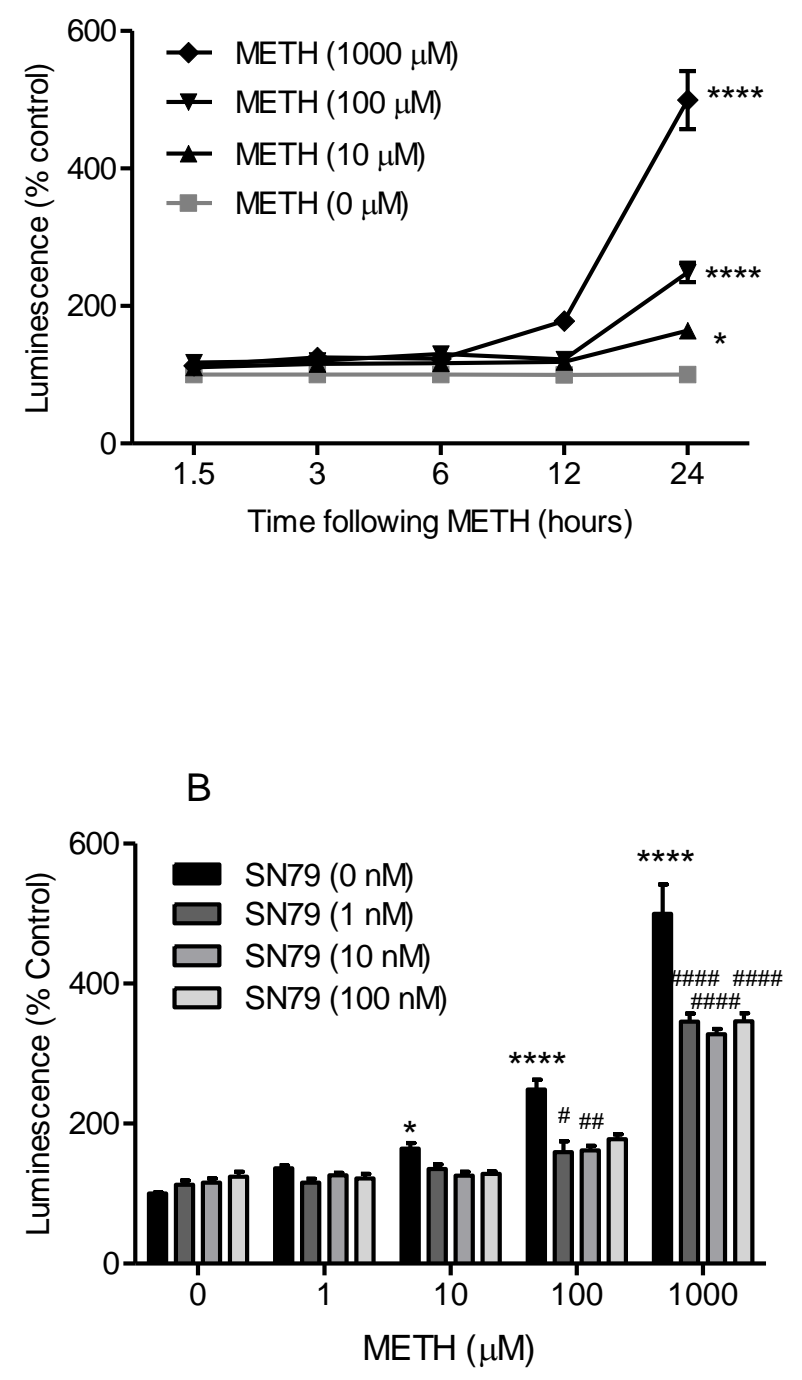

Figure 5.7 A. Dose response and time course of METH treatment on Caspase-3 activation B. Effect of SN79 pretreatment on METH-induced Caspase-3 activation at 24 hours. (A) Differentiated NG108-15 cells were treated with METH $(0-1000 \mu \mathrm{M})$ and caspase-3 activation determined using Caspase-3/7 Glo Luminescence assay at 1.5, 3, 6, 12, 24 hour time points. At 24 hour time point, METH (10, 100 and $1000 \mu \mathrm{M})$ caused significant increase in caspase-3 activation. (B) Differentiated NG108-15 cells were pretreated with SN79 (0-100 nM), 15 min prior to adding METH (1, 10, 100, $1000 \mu \mathrm{M})$. At 24 hour time point, SN79 attenuated the caspase-3 activation caused by METH at 100 and $1000 \mu \mathrm{M}$ without significantly altering the caspase- 3 activation on its own $\left({ }^{*} \mathrm{p}<0.05\right.$, ${ }^{* * * *} \mathrm{p}<$ $0.0001, \# p<0.05, \# \# \mathrm{P}<0.01$,\#\#\#\#P<0.0001; post hoc tests, * vs. no treatment control, \# vs. METH). 
5.3.4.2. Caspase-8 activation: METH treatment caused a significant increase in caspase-8 activation in differentiated NG108-15 cells (Figure 5.8A). Two way ANOVA showed a significant effect of METH treatment $(F(4,319)=41.49, p<0.0001)$, time $(F(5,319)=10.95, p$ $<0.0001)$ and METH treatment $\times$ time interaction $(F(20,319)=3.13, p<0.0001)$. Bonferroni's multiple comparison post-hoc tests confirmed that $1,10,100$ and $1000 \mu \mathrm{M}$ concentrations of METH caused a significant increase in caspase-8 activation at the 9 hour time point $(t=3.56$, $p<0.05 ; t=5.65, p<0.0001, t=9.02, p<0.0001$ and $q=16.39, p<0.0001$ respectively). METH (1000 $\mu \mathrm{M}$ concentration) also caused caspase-8 activation at the 1.5, 3, 6, 12, and 24 hour time points $(t=4.09, p<0.01 ; t=3.37, p<0.05 ; t=4.32, p<0.001 ; t=3.71, p<0.01$ and $t=4.93, p<0.0001$ respectively).

SN79 pretreatment is significantly able to attenuate METH-induced caspase-8 activation at the 9 hour time point (Figure 5.8B). Two way ANOVA showed a significant effect of METH treatment $(F(4,278)=88.61, p<0.0001)$, SN79 pretreatment $(F(3,278)=19.50, p<$ $0.0001)$ and METH $\times$ SN79 pretreatment interaction $(F(12,278)=3.60, p<0.0001)$. Bonferroni's multiple comparison post-hoc tests showed that the following concentrations of SN79 can attenuate caspase-8 activation caused by METH $10 \mu \mathrm{M}$ (100 nM: $t=3.26, p<$ 0.05), $100 \mu \mathrm{M}(1 \mathrm{nM}: \mathrm{t}=4.22, \mathrm{p}<0.001 ; 10 \mathrm{nM}: \mathrm{t}=4.25, \mathrm{p}<0.001$ and $100 \mathrm{nM}: \mathrm{t}=3.36, \mathrm{p}<$ $0.05)$ and $1000 \mu \mathrm{M}(1 \mathrm{nM}: t=3.43, p<0.05 ; 10 \mathrm{nM}: t=3.92, p<0.01$ and $100 \mathrm{nM}: t=3.05, p$ $<0.05)$ treatment. 
A
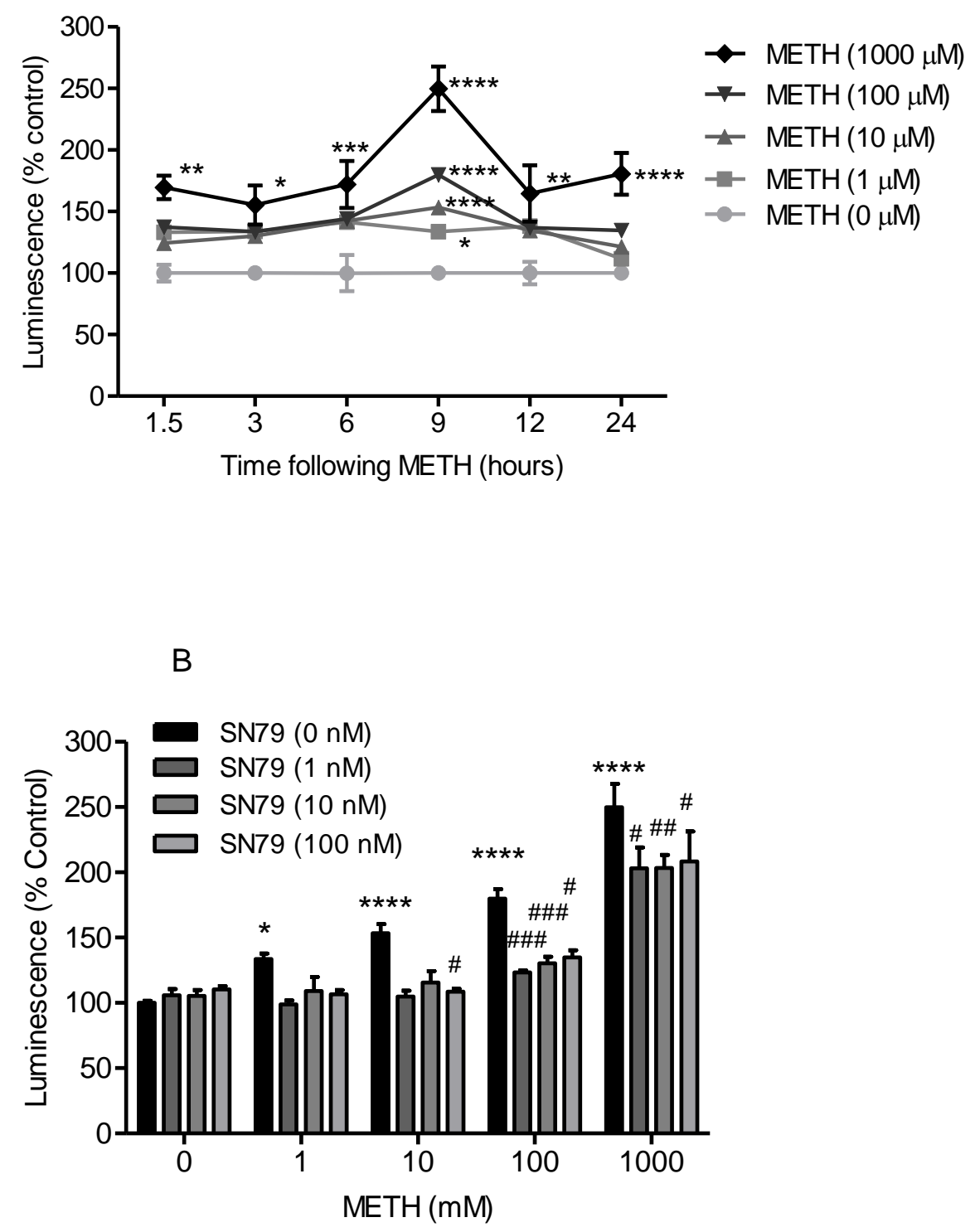

Figure 5.8 A. Dose response and time course of METH treatment on Caspase-8 activation B. Effect of SN79 pretreatment on METH-induced Caspase-3 activation at 9 hours. (A) Differentiated NG108-15 cells were treated with METH $(0-1000 \mu \mathrm{M})$ and caspase-8 activation determined using Caspase-8 Glo Luminescence assay at 1.5, 3, 6, 9, 12, 24 hour time points. At 9 hour time point, METH $(1,10,100$ and $1000 \mu \mathrm{M})$ caused significant increase in caspase-8 activation. (B) Differentiated NG10815 cells were pretreated with SN79 $(0-100 \mathrm{nM}), 15$ min prior to adding METH $(1,10,100,1000 \mu \mathrm{M})$. At 9 hour time point, SN79 attenuated the caspase-8 activation caused by METH at 10, 100 and $1000 \mu \mathrm{M}$ without significantly altering the caspase-8 activation on its own $\left({ }^{*} p<0.05,{ }^{* *} p<0.01,{ }^{* * *} p<0.001,{ }^{* * * *} p\right.$ $<0.0001, \# p<0.05, \# \#<<0.01$,\#\#\#P<0.001; post hoc tests, ${ }^{*}$ vs. no treatment control, \# vs. METH). 
5.3.4.3. Caspase-9 activation: METH treatment caused a significant increase in caspase-9 activation in differentiated NG108-15 cells (Figure 5.9A). Two way ANOVA showed a significant effect of METH treatment $(F(4,511)=52.31, p<0.0001)$, time $(F(6,511)=19.18, p$ $<0.0001)$ and METH treatment $\times$ time interaction $(F(24,511)=3.13, p<0.0001)$. Bonferroni's multiple comparison post-hoc tests confirmed that1000 $\mu \mathrm{M}$ concentration of METH caused a significant increase in caspase-9 activation at the 3 hour $(t=2.74, p<0.05), 6$ hour $(t=3.32$, $p<0.01), 9$ hour $(t=2.76, p<0.05), 12$ hour $(t=5.73, p<0.001), 18$ hour $(t=3.81, p<0.01)$ and 24 hour $(\mathrm{t}=20.93, \mathrm{p}<0.001)$. METH $100 \mu \mathrm{M}$ concentration also caused caspase-9 activation at 9 hour $(t=4.12, p<0.001)$ and 24 hour $(t=6.24, p<0.001)$.

SN79 pretreatment is significantly able to $a$ B ate METH-induced caspase-9 activation at the 24 hour time point (Figure 5.9B). Two way ANOVA showed a significant effect of METH treatment $(F(4,269)=82.60, p<0.0001)$, SN79 pretreatment $(F(3,269)=13.00, p<$ 0.0001) and METH $\times$ SN79 pretreatment interaction $(F(12,269)=3.89, p<0.0001)$. Bonferroni's multiple comparison post-hoc tests showed that $10 \mathrm{nM}$ SN79 concentration can attenuate caspase- 9 activation caused by METH $1000 \mu \mathrm{M}(\mathrm{t}=5.24, \mathrm{p}<0.001)$ and $100 \mathrm{nM}$ SN79 concentration can attenuate caspase- 9 activation caused by METH $100 \mu \mathrm{M}(t=2.91, p$ $<0.05)$ and $1000 \mu \mathrm{M}(\mathrm{t}=7.69, \mathrm{p}<0.001)$ treatment. 


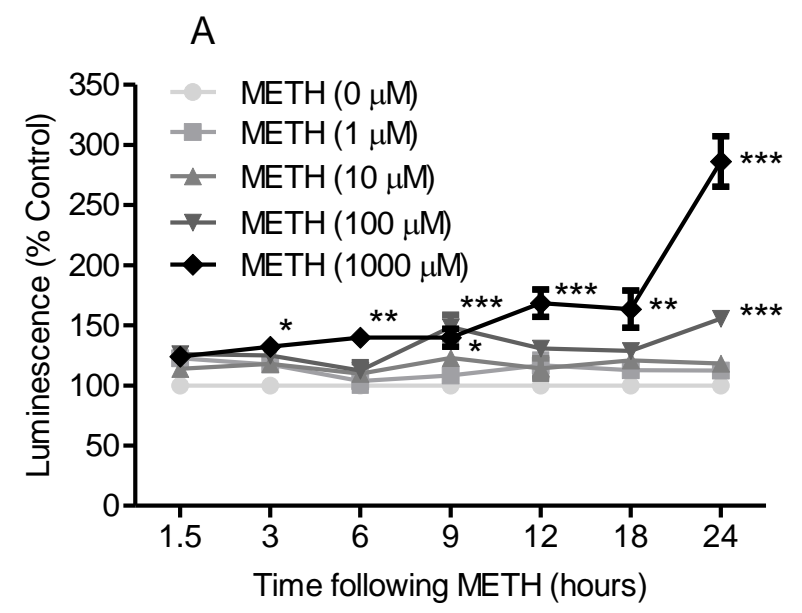

$\mathrm{B}$

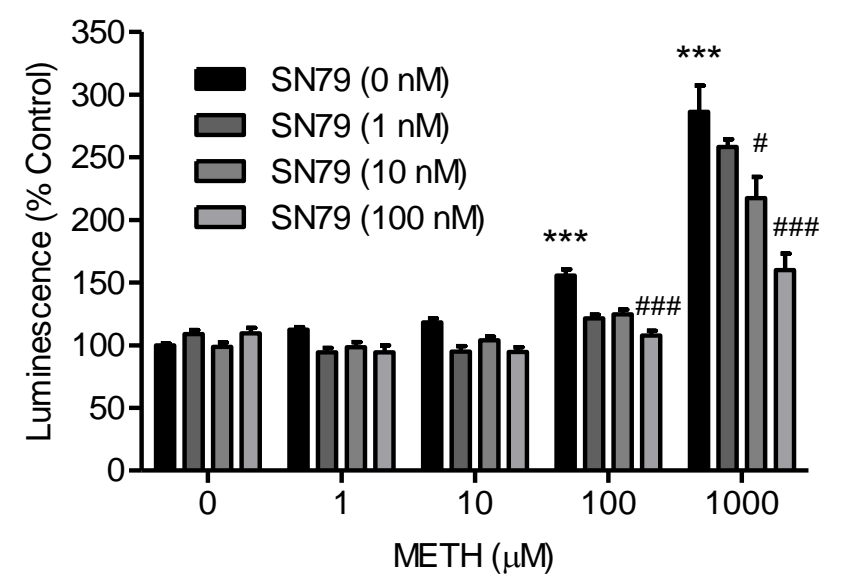

Figure 5.9 A. Dose response and time course of METH treatment on Caspase-9 activation B. Effect of SN79 pretreatment on METH-induced Caspase-9 activation at 24 hours. (A) Differentiated NG108-15 cells were treated with METH $(0-1000 \mu \mathrm{M})$ and caspase-9 activation determined using Caspase-9 Glo Luminescence assay at 1.5, 3, 6, 9, 12, 18, 24 hour time points. At 9 hour time point, METH $(1,10,100$ and $1000 \mu \mathrm{M})$ caused significant increase in caspase- 8 activation. (B) Differentiated NG108-15 cells were pretreated with SN79 (0-100 nM), 15 min prior to adding METH $(1,10,100,1000 \mu \mathrm{M})$. At 24 hour time point, SN79 attenuated the caspase-9 activation caused by METH at 10,100 and $1000 \mu \mathrm{M}$ without significantly altering the caspase-8 activation on its own $\left({ }^{*} \mathrm{p}<0.05,{ }^{* *} \mathrm{p}<0.01,{ }^{* * *} \mathrm{p}<0.001, \# \mathrm{p}<0.05, \# \# \# \mathrm{P}<0.001\right.$; post hoc tests, ${ }^{*}$ vs. no treatment control, \# vs. METH). 


\subsubsection{Reactive oxygen/nitrogen species:}

SN79 pretreatment was able to significantly attenuate the ROS generated by METH (Figure 5.10). Two-way ANOVA shows a significant effect of SN79 pretreatment $(F(4,824)=$ 35.27, $p<0.0001)$, METH or $\mathrm{H}_{2} \mathrm{O}_{2}$ treatment $(F(9,824)=75.77, p<0.0001)$ and SN79 pretreatment $\times \mathrm{METH}$ or $\mathrm{H}_{2} \mathrm{O}_{2}$ treatment interaction $(F(36,824)=2.24, p<0.001)$. Dunnett's post-hoc tests confirmed that the following concentrations of METH and $\mathrm{H}_{2} \mathrm{O}_{2}$ generated ROS: $1 \mu \mathrm{M}(q=5.96, p<0.01), 3 \mu \mathrm{M}(q=4.46, p<0.01), 10 \mu \mathrm{M}(q=4.57, p<0.01), 30 \mu \mathrm{M}(q=$ 4.82, $p<0.01), 100 \mu \mathrm{M}(q=6.32, p<0.01), 300 \mu \mathrm{M}(q=7.03, p<0.01), 1000 \mu \mathrm{M}(q=7.15, p$ $<0.01), 3000 \mu \mathrm{M}(q=5.71, p<0.01)$ and $100 \mu \mathrm{M} \mathrm{H}_{2} \mathrm{O}_{2}(q=14.86, p<0.01)$. Bonferroni's post-hoc tests confirmed that SN79 can inhibit the ROS/RNS generated by the following concentration of METH: $1 \mu \mathrm{M}(1 \mathrm{nM}: t=2.99, p<0.05), 3 \mu \mathrm{M}(1 \mathrm{nM}: t=3.56, p<0.01 ; 10$ $\mathrm{nM}: t=3.18, p<0.05), 30 \mu \mathrm{M}(1 \mathrm{nM}: t=2.91, p<0.05 ; 10 \mathrm{nM}: t=3.71, p<0.01 ; 100 \mathrm{nM}: t=$ 3.30, $p<0.05$ and $1000 \mathrm{nM}: t=4.08, p<0.001), 100 \mu \mathrm{M}(1 \mathrm{nM}: t=3.54, p<0.01), 300 \mu \mathrm{M}(1$ $\mathrm{nM}: t=5.09, p<0.001 ; 10 \mathrm{nM}: t=4.88, p<0.001 ; 100 \mathrm{nM}, t=4.63, p<0.001$ and $1000 \mathrm{nM}: t$ $=5.29, p<0.001), 1000 \mu \mathrm{M}(1 \mathrm{nM}: t=3.07, p<0.05 ; 10 \mathrm{nM}: t=3.64, p<0.01$ and $1000 \mathrm{nM}: t$ $=2.88, p<0.05), 3000 \mu \mathrm{M}(1 \mathrm{nM}: t=3.96, p<0.001 ; 10 \mathrm{nM}: t=4.23, p<0.001 ; 100 \mathrm{nM}: t=$ 3.95, $p<0.001$ and $1000 \mathrm{nM}: t=3.77, p<0.01)$. SN79 $(1000 \mathrm{nM})$ is able to attenuate the ROS generated by $\mathrm{H}_{2} \mathrm{O}_{2}(t=4.26, p<0.001)$. 


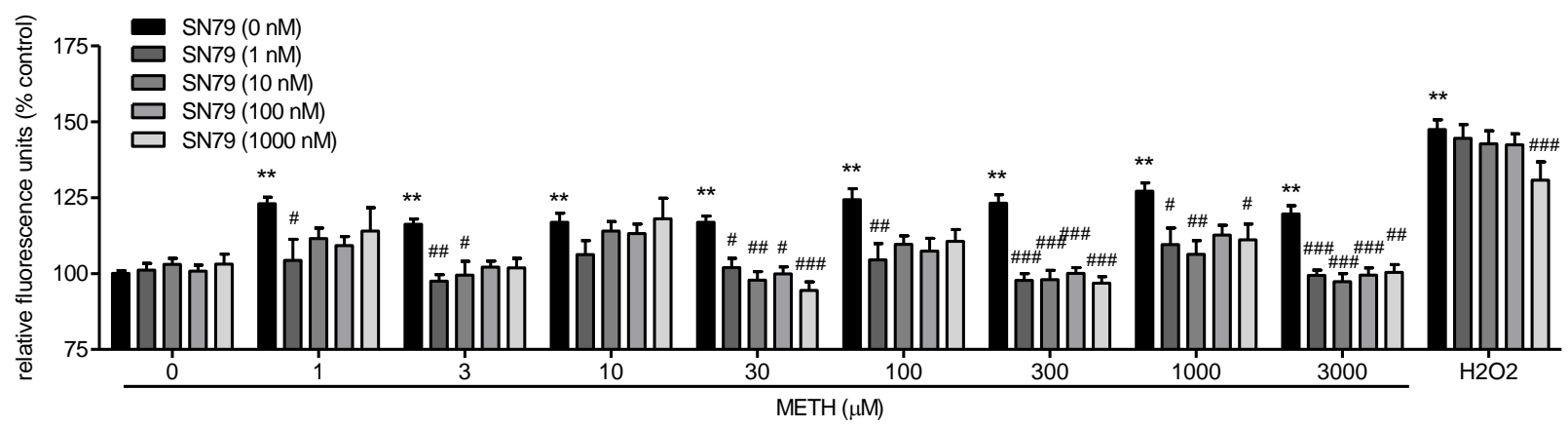

Figure 5.10 Effect of SN79 pretreatment on METH-induced ROS/RNS generation. The production of ROS capable of oxidizing CM- $\mathrm{H}_{2}$ DCFDA was assessed in differentiated NG108-15 cells in the presence of 0 to $300 \mu \mathrm{M} \mathrm{METH}, 100 \square \mu \mathrm{M} \mathrm{H}_{2} \mathrm{O}_{2}$ or $100 \mu \mathrm{M} \mathrm{Na}_{2} \mathrm{Cr}_{2} \mathrm{O}_{7}$ (Cr) in the absence (solid bars) or presence (cross hatched bars) of SN79 (1-1000 nM) as described in the methods. Data represent averages of relative fluorescence units ( $r f u$ ) from 3-6 different experiments ( $n=3-4$ /experiment) obtained 20 min after addition of drug \pm SEM. Significant differences are noted as ${ }^{* *} p<0.01$ (control vs. METH or $\mathrm{H}_{2} \mathrm{O}_{2}$ treated) and $\# p<0.05$, \#\#p $<0.01$, \#\#\#p<0.001 (METH alone vs. METH with SN79). 


\subsection{Discussion}

This study showed that METH caused apoptosis in differentiated NG108-15 cells at physiologically relevant micromolar concentrations and necrosis at higher milimolar concentrations. At earlier time points, caspase-3, -8, and -9 activation, and ROS/RNS generation were also observed. SN79, a $\sigma$ receptor antagonist, attenuated METH-induced cell death as well as the toxicity mediators. The implications of these findings are further discussed below.

In the first part of the study, the neurotoxic concentration range of METH in differentiated NG108-15 cells was determined. METH caused apoptosis at physiologically relevant micromolar concentrations. In contrast to apoptosis, necrotic cell death was observed at higher micromolar concentrations. SN79 attenuated the apoptotic cell death which is consistent with the role of $\sigma$ receptors in this type of cell death in tumor models (Bowen, 2000; Marrazzo et al., 2011). SN79 also attenuated the necrotic cell death caused by METH. Even though there is not much evidence for the role of $\sigma$ receptors in necrotic cell death, the following explanations may help in the better understanding of the results: First, studies suggest there is a considerable overlap between the two forms of cell death as evidenced by coining of terms like 'necroptosis' and 'aponecrosis' (Formigli et al., 2000; Papucci et al., 2004; Yakovlev and Faden, 2004; Galluzzi and Kroemer, 2008; Kroemer et al., 2009; Berghe et al., 2010; Christofferson and Yuan, 2010; Dunai et al., 2011; Jiang et al., 2011; Wu et al., 2011). Second, since the in vitro system lacks the phagocyte cells, these apoptotic cells may appear necrotic at later time points.

Another confirmation that METH-induced cell death is $\sigma$ receptor sensitive comes from the ability of DTG to shift the dose response curve of METH-induced cell death towards the left. At higher concentrations DTG displayed toxicity on its own which is consistent with the ability of $\sigma$ receptor (especially $\sigma-2$ receptor subtype) agonist to cause toxicity (Vilner et al., 
1995a; Bowen, 2000; Crawford and Bowen, 2002). In this study, the necrotic type of cell death was more sensitive to DTG's effect on METH. This is most likely because NG108-15 is a sensitive cell line and induction of stressors/pro-death mediators beyond a certain threshold may shift the cell death from apoptosis to necrosis (Leist et al., 1997; Nicotera et al., 1998; Leist et al., 1999; Proskuryakov et al., 2003; Soti et al., 2003; Nicotera and Melino, 2004).

The next part of the study was conducted to determine whether METH-induced apoptosis in NG108-15 cells is caspase-dependent or independent event. Studies in the literature suggest involvement of both caspase-dependent as well as independent pathways (Jayanthi et al., 2004). Caspase-3 activation was observed at the 24 hour time point, indicating that caspase dependent mechanism is involved in this apoptotic cell death. SN79 attenuated METH-induced caspase-3 activation, which is consistent with the role of $\sigma$ receptors in caspase-dependent cell death mechanisms (Crawford and Bowen, 2002; Hornick et al., 2010; Jonhede et al., 2010).

Caspase-3 can be activated via extrinsic death receptors or intrinsic mitochondrial death pathways. Activation of caspase-8 at 9 hour time point confirms the involvement of an extrinsic cell death pathway. Caspase-8 activation was followed by caspase- 9 activation which peaked at the 24 hour time point. This indicates that NG108-15 cells may be type II cells that involve mitochondrial death loop for the processing of apoptotic cell death. One of the most likely mechanisms of METH-induced caspase-8 activation in NG108-15 cells is ROS/RNS production which can increase the cellular death receptor expression (Bauer et al., 1998), and also ROS-induced death receptor independent caspase-8 activation via p38 MAPK pathway (El Mchichi et al., 2007). Once activated, caspase-8 can cleave Bid and cause cytochrome c release from the mitochondria, resulting in apoptosome formation with Apaf1 and hence caspase-9 activation (Li et al., 1998). 
The ability of SN79 to attenuate caspase-8 activation at 9 hour time point is most likely due to the role of $\sigma$ receptors in modulation of cellular ROS levels (Ostenfeld et al., 2005; Schetz et al., 2007). In addition, the localization of $\sigma$ receptors in lipid rafts (Hayashi and Su, 2003b; Gebreselassie and Bowen, 2004; Gajate and Mollinedo, 2011) may allow them to modulate death receptor signaling (Cahuzac et al., 2006). $\sigma-2$ Receptors may play a predominant role in this pathway as a previous study using SK-N-SH neuroblastoma cells showed that activation of $\sigma-2$ receptors caused caspase-10 activation which in turn cleaved Bid thereby causing activation of mitochondrial death cascade (Wang and Bowen, 2006). The decrease in METH-induced caspase-9 activation at 24 hour time point may be due to the ability of SN79 to attenuate the caspase-8 signal. Alternately, $\sigma$ receptors are located in the ER and mitochondria and can regulate the calcium signaling between these organelles (Vilner and Bowen, 2000; Wei et al., 2006; Cassano et al., 2009). Previous studies in tumor models have indicated a role of $\sigma$ receptor in the modulation of mitochondrial death cascades (Wei et al., 2006). Caspase-9 can also be generated by other cellular stress signals like ROS/RNS generation in the cell (Kadenbach et al., 2004) which is activated by METH, which may also be regulated by $\sigma$ receptors.

ROS/RNS generation is one of the main mediators of METH's neurotoxicity, which occurs through various sources including excessive dopamine release, microglial activation, excessive glutamate release, and mitochondrial dysfunction (Krasnova and Cadet, 2009). These ROS/RNS generated can injure neurons and surrounding cells via oxidative damage to cellular components such as lipids, proteins, and DNA, or cause ER stress and activation of mitochondrial death cascades, ultimately leading to nerve terminal degeneration or cell death (Krasnova and Cadet, 2009). In this study, METH was shown to cause ROS/RNS generation. SN79 pretreatment attenuated the ROS/RNS generated by METH. This effect of SN79 does not seem to be a general antioxidant effect as it is not able to prevent the $\mathrm{H}_{2} \mathrm{O}_{2}$-mediated 
ROS signal. Although, at high concentration of $1000 \mathrm{nM}$, SN79 causes decrease in $\mathrm{H}_{2} \mathrm{O}_{2^{-}}$ mediated ROS, which may be due to some intrinsic antioxidant activity at this concentration or due to potential upregulation of cellular antioxidant defenses. Mechanistically, SN79 can act via $\sigma$ receptors to modulate cellular ROS/RNS generation and antioxidant systems. Previous studies in tumor cells have shown that $\sigma-2$ receptor activation causes ROS generation (Ostenfeld et al., 2005). $\sigma-1$ Receptors are involved in oxidative stress mediated toxicities and have been shown to provide protective effects (Schetz et al., 2007). $\sigma$ Receptors also play a regulatory role in the redox state of the cell, and can also modulate the nNOS and iNOS enzyme activity (Vagnerova et al., 2006; Tsai et al., 2009; Yang et al., 2010).

In addition to modulating the cellular redox system, $\sigma$ receptors can also regulate other systems that are involved in ROS/RNS generation by METH. First, $\sigma$ receptors can regulate glutamate/NMDA release which in turn causes nNOS activation and nitrosative stress (DeCoster et al., 1995). Second, $\sigma$ receptors can modulate microglial activation through calcium dependent mechanisms, which can contribute to the release of inflammatory cytokines and ROS/RNS generation (Hall et al., 2009). Third, $\sigma$ receptors can regulate the release of dopamine which in turn undergoes autooxidation and is a major cause of METH's ROS generation (Gonzalez-Alvear and Werling, 1994; Derbez et al., 2002).

Apart from the activation of cellular death cascades, METH also caused hyperthermia in vivo. In order to separate the contribution of METH, hyperthermia and their interaction, NG108-15 cells were treated with METH at 37 or $40{ }^{\circ} \mathrm{C}$. The results demonstrated that by maintaining the cells at elevated temperature, an increase in cell death (apoptosis and necrosis) was observed. The type of cell death shifted from apoptotic to necrotic cell death. This is consistent with the effect observed with treatment with DTG, where beyond a certain level of stress cell death in NG108-15 cells may be predominantly necrotic. The combination of METH and elevated temperature synergistically enhanced cell death (especially necrosis). 
This potentiation effect is most likely due to high temperature induced increase in DAT activity and enhanced ROS/RNS levels (Fleckenstein et al., 1997; Xie et al., 2000; Kiyatkin et al., 2007; Numachi et al., 2007; Sharma et al., 2007). The ability of SN79 to attenuate both the elevated temperature induced toxicity as well as the enhanced toxicity caused my interaction of METH and elevated temperature is consistent with the potential role of $\sigma$ receptors in various cell stress and death mechanisms. $\sigma$ Receptors, due to their properties of intracellular translocation, protein-protein interaction and chaperone activity can help normalize a disordered system (Tsai et al., 2009).

In summary, the data from both aims of the in vitro studies demonstrates that physiologically significant concentrations of METH can cause apoptosis in an in vitro system representative of a differentiated neuronal cell, which mechanistically involves dopamine release and induction of reactive oxygen/nitrogen radicals, activation of caspase-8, -9 and -3 . Additionally, $\sigma$ receptor antagonist, SN79, can attenuate METH-induced cell death and the causative neurotoxic cascade. $\sigma$ Receptor antagonists can also attenuate the elevated temperature-induced toxicity as well as toxicity caused by the interaction of METH and elevated temperature, which can have important implications in vivo. The ability of $\sigma$ receptor antagonists to intervene at multiple points and mechanisms in the neurotoxic cascade is consistent with the location of $\sigma$ receptors in various subcellular organelles like the ER, mitochondria, lysosomes, cell membrane, and nucleus (McCann et al., 1994; Zeng et al., 2007) and its functional role as a chaperone, with subcellular translocation and participation in protein-protein interactions (Su et al., 2010). Future studies are needed to elucidate the individual contributions of the two subtypes of $\sigma$ receptors, as better tools are developed.

5.5 Contributions: Nidhi Kaushal conducted all the studies in this chapter. Abagail Rosen helped with the data analysis for some of the apoptosis and necrosis assays. 


\section{CHAPTER 6}

EVALUATION OF $\sigma-2$ RECEPTOR ANTAGONIST AGAINST METHINDUCED NEUROTOXICITY IN VITRO 


\subsection{Introduction}

Recent studies suggest that $\sigma-1$ receptors function as a chaperone modulating interorganelle signaling (Su et al., 2010). In comparison, activation of $\sigma-2$ receptors in tumor cells causes cell death by increasing cellular levels of calcium, ceramide and sphingolipids (Bowen, 2000). This effect is inhibited by the administration of $\sigma$ receptor antagonists confirming the role of $\sigma-2$ receptors in these effects (Vilner and Bowen, 2000; Crawford and Bowen, 2002; Crawford et al., 2002). From independent experiments, it has also been shown that $\sigma$ receptor antagonists can attenuate METH's neurotoxicity (Matsumoto et al., 2008; Kaushal et al., 2011b; Seminerio et al., 2011). Taking all this into consideration, $\sigma-2$ receptors seem to play a more dominant role in the neurotoxic effects of METH.

Table 6.1 displays a series of putative selective sigma-2 ligands. CM398 possesses highest affinity and selectivity for sigma-2 receptors over sigma-1 receptors. In vivo functional assay suggests that CM398 is functioning as an antagonist. In this part of the study therefore, it was determined whether METH induced cytotoxicity can be attenuated by CM398 in differentiated NG108-15 cells. This will further help in demonstrating the role of $\sigma-2$ receptors in METH toxicity and also the various signaling pathways that will be involved.

Table 6.1 Binding affinity of compounds for $\sigma-1$ and $\sigma-2$ receptors

\begin{tabular}{|c|c|c|c|}
\hline & $\sigma-1(\mathrm{Ki}$ in $\mathrm{nM})$ & $\sigma-2(\mathrm{Ki}$ in $\mathrm{nM})$ & Ratio ( $\sigma-1 / \sigma-2)$ \\
\hline CM360 & $139.47 \pm 3.51$ & $1.26 \pm 0.06$ & 110.98 \\
\hline CM361 & $3834.33 \pm 580.30$ & $30.53 \pm 13.79$ & 125.59 \\
\hline NF12 & $273.5 \pm 1.33$ & $1.81 \pm 0.019$ & 151 \\
\hline CM781 & $724.6 \pm 15.7$ & $4.55 \pm 0.21$ & 159.12 \\
\hline CM397 & $86.41 \pm 2.02$ & $0.48 \pm 0.02$ & 181.28 \\
\hline SN230 & $3128.00 \pm 70.89$ & $14.70 \pm 1.18$ & 212.79 \\
\hline CM775 & $2274 \pm 186.8$ & $4.27 \pm 0.29$ & 532.55 \\
\hline CM777 & $752.4 \pm 51.44$ & $0.66 \pm 0.01$ & 1140 \\
\hline CM699 & $16.56 \pm 1.09$ & $0.014 \pm 0.0003$ & 1183 \\
\hline CM398 & $560.4 \pm 8.72$ & $0.43 \pm 0.015$ & 1303 \\
\hline
\end{tabular}




\subsection{Materials and Methods}

\subsubsection{Cell line and culture}

6.2.1.1. Cell growth: The neuroblastoma $x$ glioma, hybridoma cell line NG108-15 (Hamprecht et al., 1985) were obtained from ATCC (Rockville, MD). Cells were maintained in $25 \mathrm{~cm}^{2}$ (T25) or $75 \mathrm{~cm}^{2}$ (T75) culture flasks (Corning-Costar, Lowell, MA) in hi-glucose (4.5 g/L) DMEM (Dulbecco's modified Eagle's medium) supplemented with 10\% FBS (fetal bovine serum), penicillin, streptomycin, and HAT (hypoxanthine-aminopterin-thymidine) at $37^{\circ} \mathrm{C}$ in a humidified incubator in $5 \% \mathrm{CO}_{2}$.

6.2.1.2. Cell differentiation: Culture medium was replaced with differentiation medium (DMEM with $0.5 \%$ FBS, penicillin, streptomycin, HAT and $1 \%$ DMSO) and the cells allowed to grow for a further 3-4 days.

6.2.2. Hoechst and propidium iodide staining: NG108-15 cells were grown and differentiated in 96-well culture plates and exposed to various concentrations of METH (0$1000 \mu \mathrm{M})$, CM398 (1-100 nM), CM398 (1-100 nM)+METH (0-1000 $\mu \mathrm{M})$ for $24 \mathrm{hrs}$ at $37{ }^{\circ} \mathrm{C}$. Hoechst stain $(20 \mu \mathrm{g} / \mathrm{ml}$ final concentration) and propidium iodide stain $(20 \mu \mathrm{g} / \mathrm{ml}$ final concentration) were added to each well and incubated at room temperature for $10 \mathrm{~min}$. Three images are taken/well using an UV light microscope. Cells with brightly stained and fragmented nuclei were counted as apoptotic and cells that were red were counted as necrotic. The percentage of apoptotic and necrotic cells were counted with the help of Image $\mathrm{J}$ cell counter $(\mathrm{NIH})$. The sum of percentage of apoptotic and necrotic cells was referred to as "total cell death". 


\subsection{Results}

\subsubsection{CM398 and METH}

Apoptosis: One-way ANOVA showed that METH treatment caused a significant increase in the percentage of apoptotic cells $(F(7,144)=29.38, p<0.0001)$. Post-hoc Dunnett's tests confirmed that the following concentrations of METH caused a significant increase in the percentage of apoptotic cells: $10 \mu \mathrm{M}(q=2.77, p<0.05), 30 \mu \mathrm{M}(q=4.23, p<$ $0.01), 100 \mu \mathrm{M}(q=5.55, p<0.01), 300 \mu \mathrm{M}(q=7.90, p<0.01)$ and $1000 \mu \mathrm{M}(q=12.34, p<$ 0.01). CM398 pretreatment significantly attenuated the apoptotic effects of METH (Figure 6.1A). Two-way ANOVA showed a significant effect of METH treatment $(F(7,519)=46.77, p<$ $0.0001)$, CM398 pretreatment $(F(3,519)=26.15, p<0.0001)$, and CM398 pretreatment $\times$ METH treatment $(F(21,519)=3.68, p<0.0001)$. Bonferroni's post-hoc tests showed that CM398 (1, 10 and $100 \mathrm{nM}$ ) pretreatment is able to attenuate the apoptotic effects of the following concentrations of METH: $300 \mu \mathrm{M}(t=4.10, p<0.001 ; t=4.49, p<0.0001$ and $t=$ 3.03, $p<0.05$ respectively $)$ and $1000 \mu \mathrm{M}(t=4.28, p<0.001 ; t=7.35, p<0.001$ and $t=8.90$, $p<0.001$ respectively)

Necrosis: One-way ANOVA showed that METH treatment caused a significant increase in the percentage of necrotic cells $(F(7,143)=4.76, p<0.0001)$. Post-hoc Dunnett's tests confirmed that $1000 \mu \mathrm{M}$ METH caused a significant increase in the percentage of necrotic cells $(q=5.50, p<0.01)$. CM398 pretreatment significantly attenuated the necrotic effects of METH (Figure 6.1B). Two-way ANOVA showed a significant effect of CM398 pretreatment $(F(3,508)=10.82, p<0.0001)$, METH treatment $(F(7,508)=12.95, p<0.0001)$. Bonferroni posttests confirmed that $1 \mathrm{nM} \mathrm{CM} 398$ attenuated the necrotic effects of $1000 \mu \mathrm{M}$ $\operatorname{METH}(t=3.74, p<0.01)$.

Total cell death: One-way ANOVA showed that METH treatment caused a significant increase in the percentage of total cell death $(F(7,146)=17.65, p<0.0001)$. Post-hoc 
Dunnett's tests confirmed that the following concentrations of METH caused a significant increase in the percentage of total cell death: $10 \mu \mathrm{M}(q=3.54, p<0.01), 30 \mu \mathrm{M}(q=5.10, p<$ $0.01), 100 \mu \mathrm{M}(q=4.10, p<0.01), 300 \mu \mathrm{M}(q=5.55, p<0.01)$ and $1000 \mu \mathrm{M}(q=10.25, p<$ 0.01). CM398 pretreatment significantly attenuated METH-induced cell death (Figure 6.1CB). Two-way ANOVA showed a significant effect of CM398 pretreatment $(F(3,512)=30.88, p<$ 0.0001), METH treatment $(F(7,512)=43.05, p<0.0001)$ and CM398 pretreatment $\times$ METH treatment interaction $(F(21,512)=1.96, p<0.01)$. Bonferroni posttests confirmed that CM398 $(1,10,100 \mathrm{nM})$ attenuate cell death caused by the following concentrations of METH: $10 \mu \mathrm{M}$ $(1 \mathrm{nM}: t=3.08, p<0.05 ; 10 \mathrm{nM}: t=3.61, p<0.01 ; 100 \mathrm{nM}: t=2.94, p<0.05), 30 \mu \mathrm{M}(1 \mathrm{nM}: t$ $=4.83, p<0.001 ; 10 \mathrm{nM}: t=3.84, p<0.01), 100 \mu \mathrm{M}(100 \mathrm{nM}: t=3.05, p<0.05), 300 \mu \mathrm{M}(1$ $\mathrm{nM}: t=4.08, p<0.001 ; 10 \mathrm{nM}: t=3.73, p<0.01 ; 100 \mathrm{nM}: t=3.49, p<0.01)$ and $1000 \mu \mathrm{M}$ METH (1 nM: $t=5.24, p<0.001 ; 10 \mathrm{nM}: t=4.24, p<0.001 ; 100 \mathrm{nM}: t=5.79, p<0.001)$. 

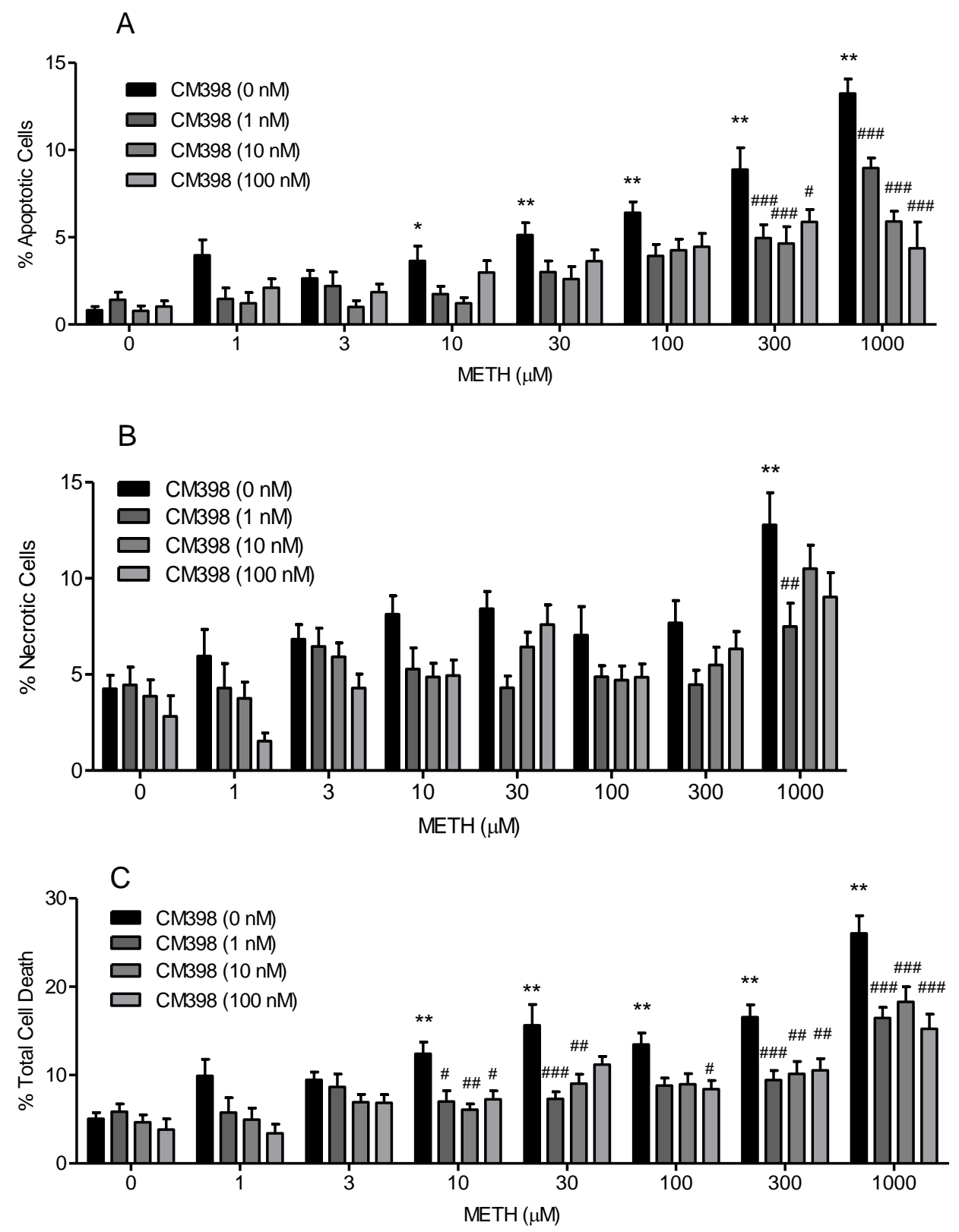

Figure 6.1 Effect of CM398 pretreatment on METH-induced (A) apoptosis, (B) necrosis and (C) total cell death. CM398 protects against methamphetamine (METH)-induced apoptosis (A), necrosis (B) and total cell death (C). Differentiated NG108-15 cells were pretreated with CM398 (0-100 nM) prior to exposure to METH $(0-1000 \mu \mathrm{M})$ for $24 \mathrm{hr}$. After $24 \mathrm{hr}$, the wells were incubated with Hoechst 33342 and propidium iodide stains $(20 \mu \mathrm{g} / \mathrm{ml}$ each) to obtain percentages of apoptotic and necrotic cells. Total cell death $=$ Apoptotic cell death + Necrotic cell death. Data represent means from two separate experiments $\left(n=3\right.$ /experiment) \pm SEM. Significant differences are indicated by ${ }^{*} p<0.05,{ }^{* *} p<0.01$ (control vs. METH); $\# p<0.05, \# \# p<0.01, \# \# p<0.001$ (METH alone vs. METH with CM398). 


\subsection{2. $\underline{C M 775 \text { and METH }}$}

Apoptosis: One-way ANOVA showed that METH treatment caused a significant increase in the percentage of apoptotic cells $(F(7,78)=12.38, p<0.0001)$. Post-hoc Dunnett's tests confirmed that the following concentrations of METH caused a significant increase in the percentage of apoptotic cells: $100 \mu \mathrm{M}(q=3.58, p<0.01), 300 \mu \mathrm{M}(q=3.35, p<0.01)$ and $1000 \mu \mathrm{M}(q=8.46, p<0.001)$. CM775 pretreatment significantly attenuated the apoptotic effects of METH (Figure 6.2A). Two-way ANOVA showed a significant effect of METH treatment $(F(7,286)=23.35, p<0.0001)$, CM775 pretreatment $(F(3,286)=23.35, p<0.0001)$, and CM775 pretreatment $\times$ METH treatment $(F(21,286)=3.89, p<0.0001)$. Bonferroni's posthoc tests showed that $\operatorname{CM} 775(1,10$ and $100 \mathrm{nM})$ pretreatment is able to attenuate the apoptotic effects of the following concentrations of METH: $3 \mu \mathrm{M}(10 \mathrm{nM} \mathrm{CM775;} t=3.44, p<$ 0.05), $100 \mu \mathrm{M}(t=4.29, p<0.001 ; t=4.39, p<0.001$ and $t=3.94, p<0.01$ respectively $), 300$ $\mu \mathrm{M}(t=3.85, p<0.01$ and $t=3.78, p<0.01$ respectively $)$ and $1000 \mu \mathrm{M}(t=9.95, p<0.0001 ; t$ $=5.61, p<0.0001$ and $t=9.32, p<0.0001$ respectively).

Necrosis: One-way ANOVA showed that METH treatment caused a significant increase in the percentage of necrotic cells $(F(7,77)=3.63, p<0.005)$. Post-hoc Dunnett's tests confirmed that 300 and $1000 \mu \mathrm{M}$ METH caused a significant increase in the percentage of necrotic cells ( $q=3.00, p<0.05$ and $q=4.29, p<0.001$ respectively). CM775 pretreatment did not significantly attenuate the necrotic effects of METH (Figure 6.2B).

Total cell death: One-way ANOVA showed that METH treatment caused a significant increase in the percentage of total cell death $(F(7,79)=10.65, p<0.0001)$. Post-hoc Dunnett's tests confirmed that the following concentrations of METH caused a significant increase in the percentage of total cell death: $10 \mu \mathrm{M}(q=3.58, p<0.01), 300 \mu \mathrm{M}(q=3.71, p$ $<0.01)$ and $1000 \mu \mathrm{M}(q=7.71, p<0.001)$. CM775 pretreatment significantly attenuated METH-induced cell death (Figure 6.2C). Two-way ANOVA showed a significant effect of 
CM775 pretreatment $(F(3,287)=13.09, p<0.0001)$, METH treatment $(F(7,287)=20.67, p<$ $0.0001)$ and CM775 pretreatment $\times$ METH treatment interaction $(F(21,287)=2.39, p<0.001)$. Bonferroni posttests confirmed that $\operatorname{CM} 775(1,10,100 \mathrm{nM})$ attenuate cell death caused by the following concentrations of METH: $10 \mu \mathrm{M}(1 \mathrm{nM}: t=3.24, p<0.05 ; 10 \mathrm{nM}: t=4.06, p<0.01)$ and $1000 \mu \mathrm{M}$ METH $(1 \mathrm{nM}: t=6.07, p<0.0001 ; 10 \mathrm{nM}: t=5.20, p<0.0001 ; 100 \mathrm{nM}: t=3.52$, $p<0.05)$. 

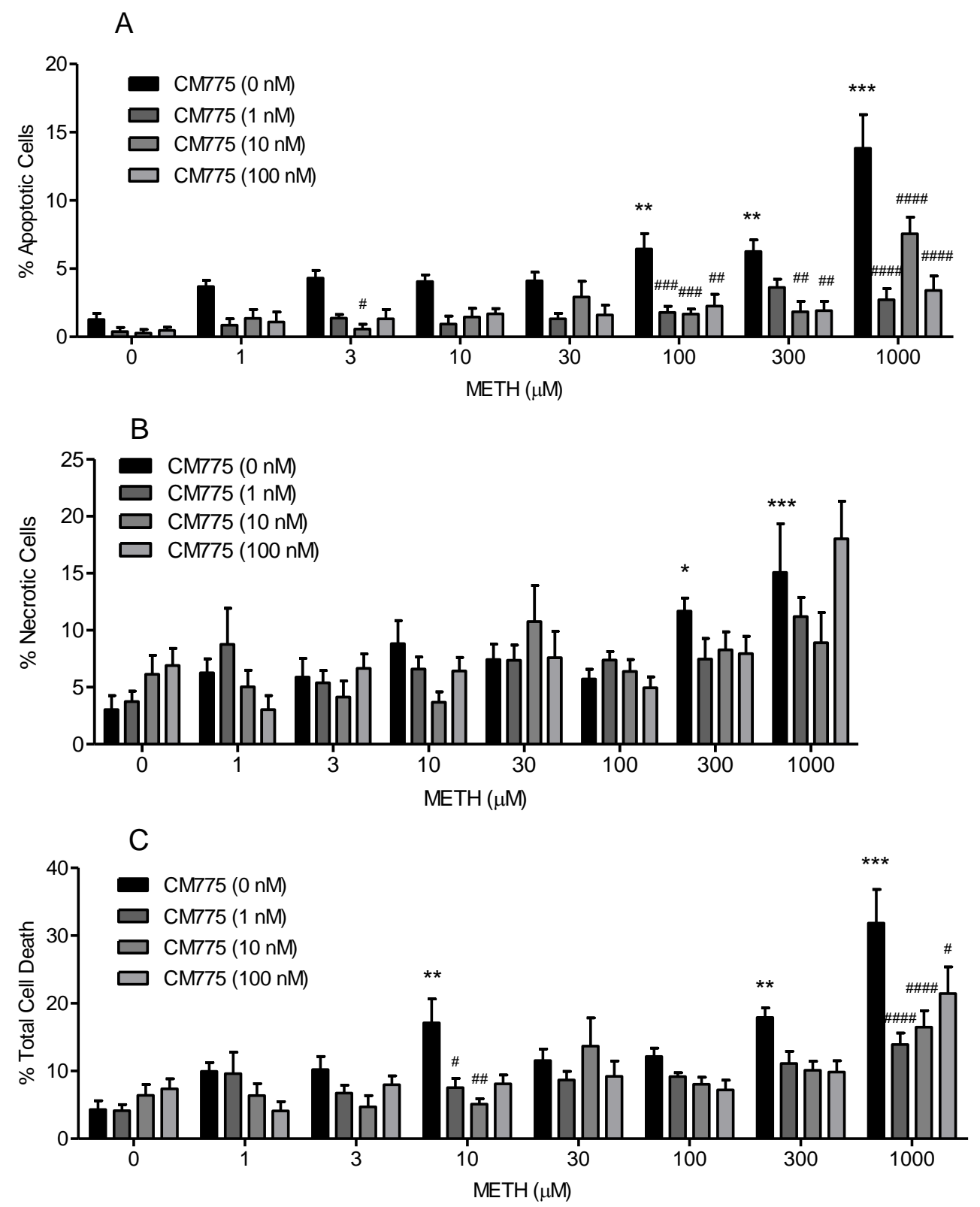

Figure 6.2 Effect of CM775 pretreatment on METH-induced (A) apoptosis, (B) necrosis and (C) total cell death. CM775 protects against methamphetamine (METH)-induced apoptosis (A), necrosis (B) and total cell death $(C)$. Differentiated NG108-15 cells were pretreated with CM775 (0-100 nM) prior to exposure to METH $(0-1000 \mu \mathrm{M})$ for $24 \mathrm{hr}$. After $24 \mathrm{hr}$, the wells were incubated with Hoechst 33342 and propidium iodide stains $(20 \mu \mathrm{g} / \mathrm{ml}$ each) to obtain percentages of apoptotic and necrotic cells. Total cell death $=$ Apoptotic cell death + Necrotic cell death. Data represent means from one experiment $(n=$ 3 /experiment) \pm SEM. Significant differences are indicated by ${ }^{*} p<0.05,{ }^{* *} p<0.01,{ }^{* * *} p<0.001$ (control vs. METH); $\# p<0.05, \# \#<<0.01, \# \# \#<0.001, \# \# \# p<0.0001$ (METH alone vs. METH with CM775). 


\subsection{3. $\underline{\text { CM699 and METH }}$}

Apoptosis: METH treatment on its own caused a significant increase in apoptotic cell death in differentiated NG108-15 cells. One way ANOVA showed a significant effect of METH treatment $(F(6,67)=14.43, p<0.0001)$. Dunnett's post-hoc tests confirmed that the following concentrations of METH cause a significant increase in apoptosis: $100 \mu \mathrm{M}(q=3.60, p<0.01)$ and $1000 \mu \mathrm{M}(q=8.41, p<0.001)$.

Figure 6.3A shows that CM699 pretreatment displayed a trend towards a shift in the dose response curve of METH-induced apoptosis towards the left; however, the effect was not significant.

Necrosis: METH treatment on its own caused a significant increase in necrotic cell death in differentiated NG108-15 cells. One way ANOVA showed a significant effect of METH treatment $(F(6,249)=4.84, p<0.0001)$. Dunnett's post-hoc tests confirmed that METH 100 and $1000 \mu \mathrm{M}$ caused a significant increase in necrosis $(q=3.47, p<0.01$ and $q=8.75, p<$ 0.001 respectively).

Figure 6.3B shows that CM699 pretreatment at intermediate concentrations shifts the dose response curve of METH towards the left. Two way ANOVA showed a significant effect of METH treatment $(F(6,242)=23.23, p<0.0001)$ and CM699 pretreatment $(F(3,242)=$ 11.42, $p<0.0001)$. Bonferroni's post-hoc tests confirm that the following concentrations of CM699 in combination with METH are significantly different than METH treatment alone: CM699 $1 \mathrm{nM}(0.1 \mu \mathrm{M}: t=3.60, p<0.01$ and $1 \mu \mathrm{M}: t=4.14, p<0.01)$ andCM699 $10 \mathrm{nM}(0.1$ $\mu \mathrm{M}: t=3.70, p<0.01 ; 1 \mu \mathrm{M}: t=3.30, p<0.05)$.

Total cell death: METH treatment on its own caused a significant increase in cell death in differentiated NG108-15 cells. One way ANOVA showed a significant effect of METH treatment $(F(6,67)=35.67, p<0.0001)$. Dunnett's post-hoc tests confirmed that the following concentrations of METH caused a significant increase in total cell death: $100 \mu \mathrm{M}(q=4.81, p$ 
$<0.001)$ and $1000 \mu \mathrm{M}(q=11.78, p<0.001)$. Figure $6.3 \mathrm{C}$ shows that CM699 pretreatment at intermediate concentrations shifted the dose response curve of METH-induced cell death towards the left. Two way ANOVA showed a significant effect of METH treatment $(F(6,242)=$ $35.45, p<0.0001)$ and CM699 pretreatment $(F(3,242)=10.38, p<0.0001)$. Bonferroni's posthoc tests confirm that the following concentrations of CM699 in combination with METH are significantly different than METH treatment alone: CM699 $1 \mathrm{nM}(0.1 \mu \mathrm{M}: t=3.09, p<0.05$ and $1 \mu \mathrm{M}: t=3.59, p<0.01)$ and $\mathrm{CM} 69910 \mathrm{nM}(0.1 \mu \mathrm{M}: t=3.10, p<0.05$ and $1 \mu \mathrm{M}: t=3.30, p<$ 0.05). 

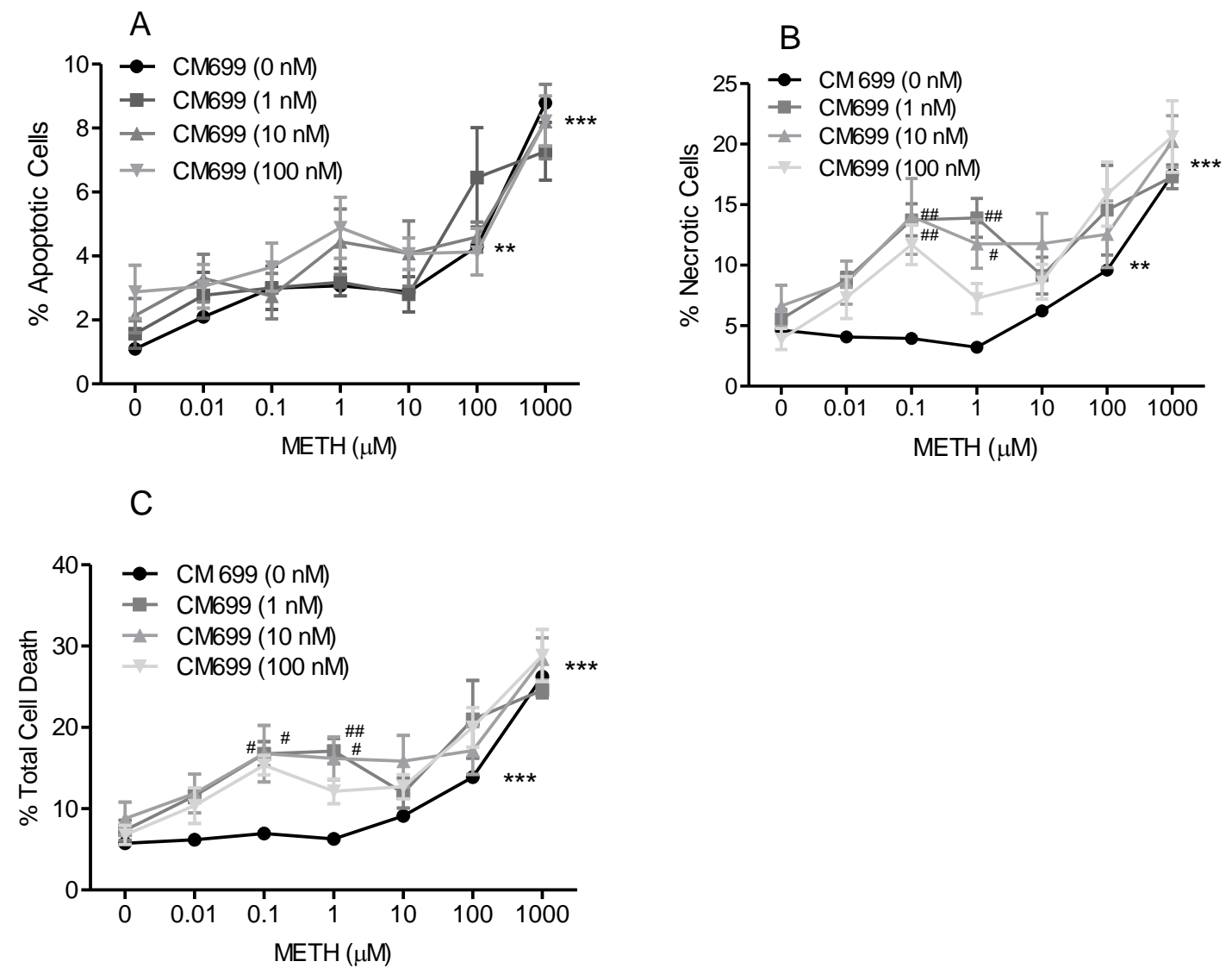

Figure 6.3 Effect of CM699 pretreatment on METH-induced (A) apoptosis, (B) necrosis and (C) total cell death. NG108-15 cells were exposed to CM699 (1-100 nM) and/or METH (0-1000 $\mu \mathrm{M})$ for 24 hr. After $24 \mathrm{hr}$, the wells were incubated with Hoechst 33342 and propidium iodide stains $(20 \mu \mathrm{g} / \mathrm{ml}$ each) to obtain percentages of apoptotic and necrotic cells. Total cell death $=$ Apoptotic cell death + Necrotic cell death. Data represent means from one experiment $(n=3$ /experiment $) \pm$ SEM. Significant differences are indicated by ${ }^{*} p<0.05,{ }^{* *} p<0.01,{ }^{* *} p<0.001$ (control vs. METH); \#p<0.05, \#\#p< 0.01 (CM699+METH vs. METH). 


\subsection{Discussion}

This study demonstrated that $\sigma-2$ receptors may be an important subtype for mediating the effects of METH. CM398 and CM775 attenuated predominantly the apoptotic effect of METH in differentiated NG108-15 cells which is consistent with reports in the literature suggesting activation of $\sigma-2$ receptors can activate apoptotic type of cell death (Bowen, 2000; Crawford and Bowen, 2002). In addition CM669 seems to shift the dose response curve of METH-induced cell death towards the left, indicating that $\sigma-2$ receptors are an important subtype through which METH mediates its effects. This also provides additional evidence that the leftward dose response shift observed with DTG in the previous chapter is most likely due to the engagement of $\sigma-2$ receptor subtype. Additionally, $\sigma-2$ Receptors may play a predominant role in this cell death pathway as a previous study using SK-N-SH neuroblastoma cells showed that activation of $\sigma-2$ receptors caused caspase-10 activation which in turn cleaved Bid thereby causing activation of mitochondrial death cascade (Wang and Bowen, 2006). Similar phenomenon was observed with METH is the previous chapter, whereby METH caused caspse-8 activation followed by mitochondrial death cascase activation in NG108-15 cells. Studies have also shown that activation of $\sigma-2$ receptors has been shown to cause elevation of ceramide levels in the cell which can be linked with caspase activation (Crawford et al., 2002; Wang and Bowen, 2006). Ceramide levels are also elevated by the activation of death receptors like Fas (Cifone et al., 1994; Tepper et al., 1995; Skowronski et al., 1996). Additionally, The localization of both the death receptors and $\sigma-2$ receptors in the cellular lipid raft compartment indicates potential regulation of the death receptor signaling by $\sigma-2$ receptors. In the previous chapter, activation of caspase- 8 levels was observed after METH treatment. This could also involve METH interaction with $\sigma-2$ receptors which in turn may regulate the death receptors to cause caspase- 8 activation. 
A recent study has proposed $\sigma-2$ receptors to be a binding site in the PGRMC1 (progesterone receptor membrane component 1) complex (Xu et al., 2011). PGRMC1 like $\sigma-2$ receptors are highly expressed in tumor cells in comparison to normal cells (Bowen, 2000; Cahill, 2007). They both are studied as important cancer biomarkers and potential therapeutic targets for anticancer drugs (Bowen, 2000; Cahill, 2007; Mir et al., 2011). This study is very promising given the lack of molecular biology tools to study $\sigma-2$ receptors. The novel compounds used in this study are selective for $\sigma-2$ over $\sigma-1$ receptors. However, additional selectivity profile of those tested compounds over other non- $\sigma$ sites may have to be determined in order to further establish the claim.

Additional studies may be performed using other $\sigma-2$ receptor agonists like CB-64D to observe dose response shifts in METH-induced cytotoxicity. In addition, further future studies may be required to fully elucidate and compare the potential involvement of $\sigma-1$ receptors in the neurotoxic effects of METH.

6.5 Contribution: Nidhi Kaushal conducted the apoptosis and necrosis assays. Cory Weaver helped with the data analysis of some of the experiments.

Radioligand binding assays were conducted by Dr. Yantong Xu and Michael Seminerio 


\section{CHAPTER 7 OVERALL CONCLUSIONS AND FUTURE STUDIES}




\subsection{Summary:}

In summary, the studies conducted herewith have demonstrated that:

- $\sigma$ Receptor antagonism (using AC927, CM156 and SN79) attenuated METH-induced striatal dopaminergic and serotonergic neurotoxicity in vivo (measured as depletion in dopamine and 5-HT levels and DAT and SERT expression levels). The presence of $\sigma$ receptors on the dopaminergic and serotonergic neurons along with their role in cell death pathways explains these neuroprotective effects (Campbell et al., 1989; Bastianetto et al., 1995; Derbez et al., 2002; Bowen, 2000). Therefore, AC927, CM156 and SN79 may provide neuroprotection by acting through $\sigma$ receptors and competitively or non-competitively intervening at the previously described (in Chapter 1) METH's downstream mechanisms (Kaushal and Matsumoto, 2011).

- $\sigma$ Receptor antagonists attenuated METH-induced hypertheria in mice. Mechanistically, dopaminergic and serotonergic systems are implicated in METHinduced body temperature alterations (Numachi et al., 2007). In addition, the production of ROS and release of cytokines like IL1 $\beta$ have been implicated in the generation of METH's hyperthermia (Bowyer et al., 1994; Imam et al., 1999; Riedel and Maulik, 1999; Yamashita et al., 2000; Fukami et al., 2004). Moreover, $\sigma$ Receptor ligands, with their ability to modulate these neurotransmitter systems, cytokines, as well as ROS, can attenuate elevations in body temperature (Campbell et al., 1989; Bastianetto et al., 1995; Derbez et al., 2002; Schetz et al., 2007; Matsumoto et al., 2008). Additionally, $\sigma$ receptors are located in the hypothalamic brain region and have previously been shown to modulate body temperature (Gundlach et al., 1986; Rawls et al., 2002). A combination of all these factors may explain how AC927, CM156 and SN79 can prevent METH-induced hyperthermia. 
- Striatal dopamine and serotonin levels in all the treatment groups correlated with their body temperature during the experiment. This indicates that the METH-induced neurotoxicity is related to the body temperature of the mice during treatment. In addition, the ability of AC927, CM156 and SN79 to attenuate the depletions in dopamine and $5-\mathrm{HT}$ levels may be related to their ability to decrease the hyperthermic effects of METH. However, correlation does not always mean causation. As discussed earlier, sigma receptors may be able to attenuate the hyperthermic effects of METH through various mechanisms; they may also be able to prevent METH-induced neurotoxicity at a cellular level independent of temperature influence. However, the separation of these effects in an in vivo system may not be possible or very difficult to interpret.

- $\sigma$ Receptor antagonism provided protection against METH-induced cell death (apoptosis and necrosis) in differentiated NG108-15 cells. Both AC927 and SN79 attenuated METH-induced cell death which is consistent with the role of $\sigma$ receptors in cell death mechanisms (Bowen, 2000; Marrazzo et al., 2011).

- METH caused dopamine release, ROS/RNS generation, caspase-8, -9 and -3 activation in differentiated NG108 cells. Sigma receptor antagonism attenuated all the above mentioned METH-induced neurotoxic endpoints. Figure 7.1 depicts the time frame of METH-induced neurotoxic cascade activation observed using NG108-15 cells. The green boxes indicate the events that were blocked by SN79 and/or AC927. The ability of $\sigma$ receptor antagonists to intervene at multiple points and mechanisms in the neurotoxic cascade is consistent with the location of $\sigma$ receptors in various subcellular organelles like the ER, mitochondria, lysosomes, cell membrane, and nucleus (McCann et al., 1994; Zeng et al., 2007) and its functional role as a 
chaperone, with subcellular translocation and participation in protein-protein interactions (Su et al., 2010).

Figure 7.1 Time course of METH-induced activation of neurotoxic cascades in differentiated NG108-15 cells

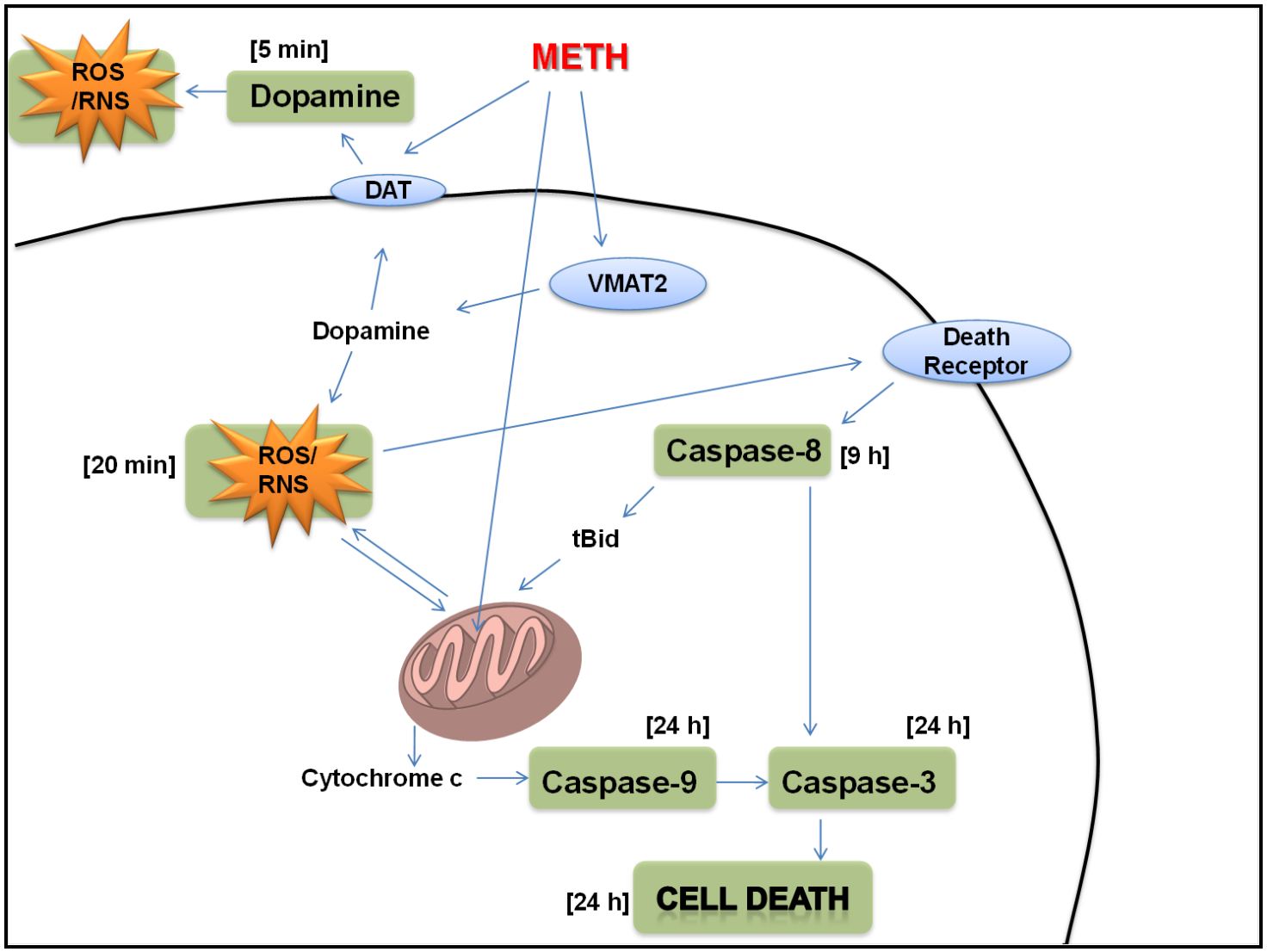


- Elevated temperature $\left(40^{\circ} \stackrel{\circ}{C}\right)$ exacerbated METH-induced neurotoxicity. Sigma receptor antagonism (using SN79) attenuated the enhanced toxicity caused by the interaction of $\mathrm{METH}$ and elevated temperature. Figure 7.2 below depicts the enhancement of METH-induced cell death in differentiated NG108-15 cells which may also have implications in vivo. Green boxes indicate that SN79 was able to attenuate this enhanced toxicity caused by the combination of elevated temperature and METH. The combination of METH and elevated temperature synergistically enhanced cell death (especially necrosis). This potentiation effect is most likely due to high temperature induced increase in DAT activity and enhanced ROS/RNS levels (Fleckenstein et al., 1997; Xie et al., 2000; Kiyatkin et al., 2007; Numachi et al., 2007; Sharma et al., 2007). The ability of SN79 to attenuate both the elevated temperature induced toxicity as well as the enhanced toxicity caused my interaction of METH and elevated temperature is consistent with the potential role of $\sigma$ receptors in various cell stress and death mechanisms. $\sigma$ Receptors, due to their properties of intracellular translocation, protein-protein interaction and chaperone activity can help normalize a disordered system (Tsai et al., 2009). 
Figure 7.2 Effect of elevated temperature on METH-induced cell death in differentaited NG108-15 cells

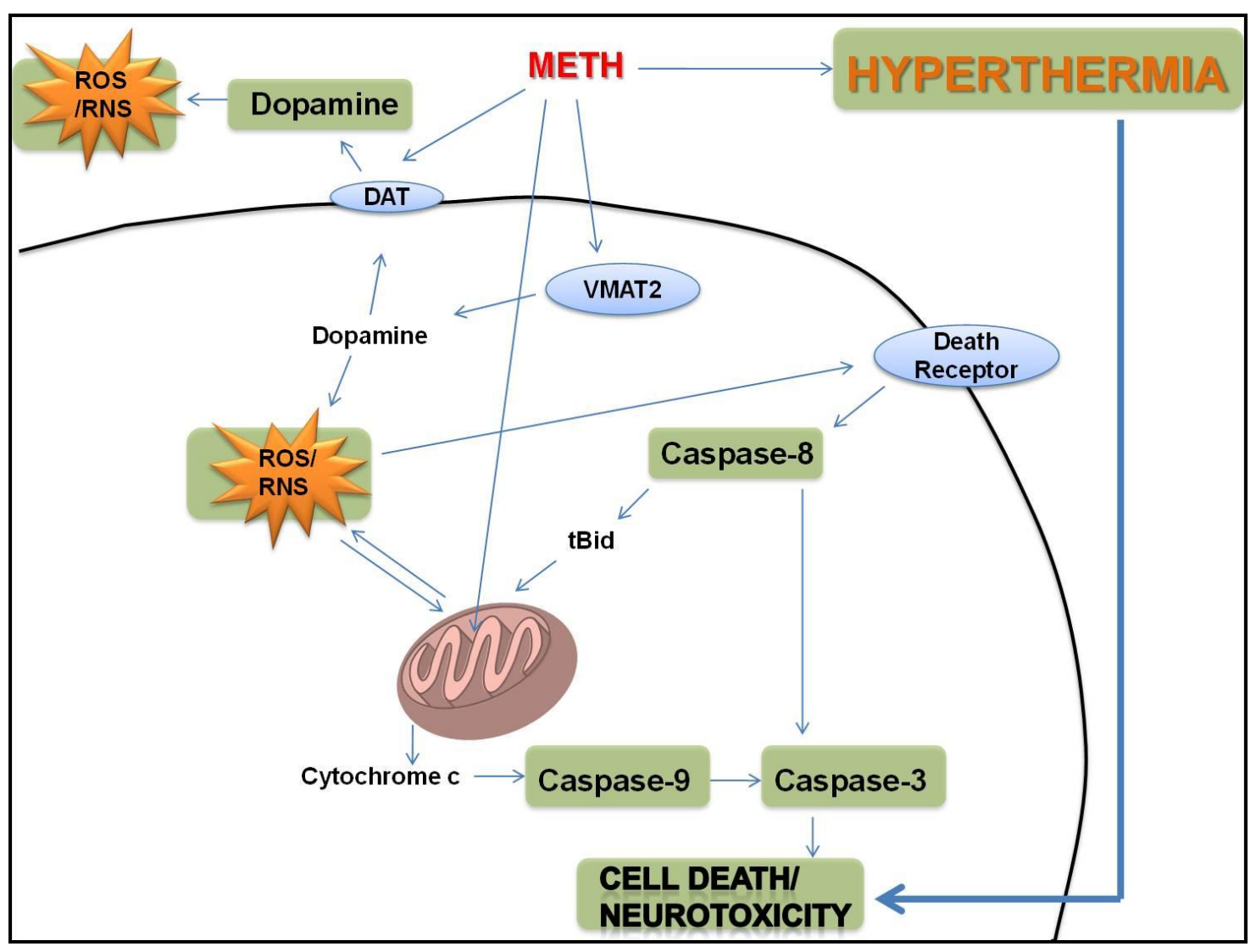


- $\quad \sigma$ - 2 Receptor antagonism (using CM398 and CM775) is able to attenaute METHinduced cell death in differentiated NG108-15 cells, indicating an important role of $\sigma-2$ receptors in METH mediated toxicity. $\sigma-2$ Receptor subtype has previously been shown to play an important role in cell death pathways in tumor cells (Bowen, 2000), further indicating a greater significance of this subype in METH's effects. Further studies may be needed to compare the role of the two $\sigma$ receptor subtypes in METHinduced neurotoxicity.

Overall, the ability of $\sigma$ receptor antagonsits in attenuating multiple end points in METHinduced toxicity may be due to its presence in multiple organelles like ER, mitochondria, lysosomes, nucleus, plasma membrane, and ability to undergo intracellular translocation, protein-protein interaction and chaperone activity which can help normalize a disordered system (Tsai et al., 2009). Alternately, the protective effects may be due to inhibition of early mediators like dopamine release or ROS/RNS generation. In order to determine this, additional posttreatment studies may have to be conducted whereby $\sigma$ receptor antagonist will be administered at various time points after METH administration. 


\section{References}

1. Adams FS, La Rosa FG, Kumar S, Edwards-Prasad J, Kentroti S, Vernadakis A, Freed CR and Prasad KN (1996) Characterization and transplantation of two neuronal cell lines with dopaminergic properties. Neurochem Res 21:619-627.

2. Ali SF and Itzhak $Y$ (1998) Effects of 7-nitroindazole, an NOS inhibitor on methamphetamine-induced dopaminergic and serotonergic neurotoxicity in mice. Ann N Y Acad Sci 844:122-130.

3. Aydar E, Palmer CP, Klyachko VA and Jackson MB (2002) The sigma receptor as a ligand-regulated auxiliary potassium channel subunit. Neuron 34:399-410.

4. Azad N, lyer AK, Manosroi A, Wang $L$ and Rojanasakul $Y$ (2008) Superoxidemediated proteasomal degradation of $\mathrm{Bcl}-2$ determines cell susceptibility to $\mathrm{Cr}(\mathrm{VI})$-induced apoptosis. Carcinogenesis 29:1538-1545.

5. Baldwin HA, Colado MI, Murray TK, De Souza RJ and Green AR (1993) Striatal dopamine release in vivo following neurotoxic doses of methamphetamine and effect of the neuroprotective drugs, chlormethiazole and dizocilpine. $\mathrm{Br} J$ Pharmacol 108:590-596.

6. Barr AM, Panenka WJ, MacEwan GW, Thornton AE, Lang DJ, Honer WG and Lecomte T (2006) The need for speed: an update on methamphetamine addiction. J Psychiatry Neurosci 31:301-313.

7. Bastianetto S, Rouquier L, Perrault G and Sanger DJ (1995) DTG-induced circling behaviour in rats may involve the interaction between sigma sites and nigro-striatal dopaminergic pathways. Neuropharmacology 34:281-287.

8. Bauer MK, Vogt M, Los M, Siegel J, Wesselborg S and Schulze-Osthoff K (1998) Role of reactive oxygen intermediates in activation-induced CD95 (APO-1/Fas) ligand expression. J Biol Chem 273:8048-8055. 
9. Bennett BA, Hyde CE, Pecora JR and Clodfelter JE (1993) Differing neurotoxic potencies of methamphetamine, mazindol, and cocaine in mesencephalic cultures. J Neurochem 60:1444-1452.

10. Berghe TV, Vanlangenakker N, Parthoens E, Deckers W, Devos M, Festjens N, Guerin CJ, Brunk UT, Declercq W and Vandenabeele P (2010) Necroptosis, necrosis and secondary necrosis converge on similar cellular disintegration features. Cell Death Differ 17:922-930.

11. Booth RG and Baldessarini RJ (1991) (+)-6,7-benzomorphan sigma ligands stimulate dopamine synthesis in rat corpus striatum tissue. Brain Res 557:349352.

12. Bouchard $P$ and Quirion $R$ (1997) [3H]1,3-di(2-tolyl)guanidine and $[3 \mathrm{H}](+)$ pentazocine binding sites in the rat brain: autoradiographic visualization of the putative sigma1 and sigma2 receptor subtypes. Neuroscience 76:467-477.

13. Bowen WD (2000) Sigma receptors: recent advances and new clinical potentials. Pharm Acta Helv 74:211-218.

14. Bowen WD, Hellewell SB and McGarry KA (1989) Evidence for a multi-site model of the rat brain sigma receptor. Eur $J$ Pharmacol 163:309-318.

15. Bowyer JF, Davies DL, Schmued L, Broening HW, Newport GD, Slikker W, Jr. and Holson RR (1994) Further studies of the role of hyperthermia in methamphetamine neurotoxicity. J Pharmacol Exp Ther 268:1571-1580.

16. Cadet JL and Brannock C (1998) Free radicals and the pathobiology of brain dopamine systems. Neurochem Int 32:117-131.

17. Cadet JL, Jayanthi $S$ and Deng $X$ (2003) Speed kills: cellular and molecular bases of methamphetamine-induced nerve terminal degeneration and neuronal apoptosis. FASEB J 17:1775-1788.

18. Cadet JL, Ordonez SV and Ordonez JV (1997) Methamphetamine induces apoptosis in immortalized neural cells: protection by the proto-oncogene, bcl-2. Synapse 25:176-184. 
19. Cahill MA (2007) Progesterone receptor membrane component 1: an integrative review. J Steroid Biochem Mol Biol 105:16-36.

20. Cahuzac N, Baum W, Kirkin V, Conchonaud F, Wawrezinieck L, Marguet D, Janssen O, Zornig $M$ and Hueber AO (2006) Fas ligand is localized to membrane rafts, where it displays increased cell death-inducing activity. Blood 107:23842391.

21. Callahan BT and Ricaurte GA (1998) Effect of 7-nitroindazole on body temperature and methamphetamine-induced dopamine toxicity. Neuroreport 9:2691-2695.

22. Campbell BG, Scherz MW, Keana JF and Weber E (1989) Sigma receptors regulate contractions of the guinea pig ileum longitudinal muscle/myenteric plexus preparation elicited by both electrical stimulation and exogenous serotonin. J Neurosci 9:3380-3391.

23. Canete $E$ and Diogene $J$ (2008) Comparative study of the use of neuroblastoma cells (Neuro-2a) and neuroblastomaxglioma hybrid cells (NG108-15) for the toxic effect quantification of marine toxins. Toxicon 52:541-550.

24. Cappon GD, Pu C and Vorhees CV (2000) Time-course of methamphetamineinduced neurotoxicity in rat caudate-putamen after single-dose treatment. Brain Res 863:106-111.

25. Cass WA, Peters LE, Harned ME and Seroogy KB (2006) Protection by GDNF and other trophic factors against the dopamine-depleting effects of neurotoxic doses of methamphetamine. Ann N Y Acad Sci 1074:272-281.

26. Cassano G, Gasparre G, Niso M, Contino M, Scalera V and Colabufo NA (2009) F281, synthetic agonist of the sigma-2 receptor, induces $\mathrm{Ca} 2+$ efflux from the endoplasmic reticulum and mitochondria in SK-N-SH cells. Cell Calcium 45:340345.

27. Chan P, Di Monte DA, Luo JJ, DeLanney LE, Irwin I and Langston JW (1994) Rapid ATP loss caused by methamphetamine in the mouse striatum: relationship 
between energy impairment and dopaminergic neurotoxicity. $J$ Neurochem 62:2484-2487.

28. Choi HJ, Yoo TM, Chung SY, Yang JS, Kim Jl, Ha ES and Hwang O (2002) Methamphetamine-induced apoptosis in a CNS-derived catecholaminergic cell line. Mol Cells 13:221-227.

29. Christofferson DE and Yuan $J$ (2010) Necroptosis as an alternative form of programmed cell death. Curr Opin Cell Biol 22:263-268.

30. Cifone MG, De Maria R, Roncaioli P, Rippo MR, Azuma M, Lanier LL, Santoni A and Testi $R$ (1994) Apoptotic signaling through CD95 (Fas/Apo-1) activates an acidic sphingomyelinase. J Exp Med 180:1547-1552.

31. Crawford KW and Bowen WD (2002) Sigma-2 receptor agonists activate a novel apoptotic pathway and potentiate antineoplastic drugs in breast tumor cell lines. Cancer Res 62:313-322.

32. Crawford KW, Coop A and Bowen WD (2002) sigma(2) Receptors regulate changes in sphingolipid levels in breast tumor cells. Eur J Pharmacol 443:207209.

33. Cruickshank CC and Dyer KR (2009) A review of the clinical pharmacology of methamphetamine. Addiction 104:1085-1099.

34. Cubells JF, Rayport S, Rajendran G and Sulzer D (1994) Methamphetamine neurotoxicity involves vacuolation of endocytic organelles and dopaminedependent intracellular oxidative stress. J Neurosci 14:2260-2271.

35. Davidson C, Gow AJ, Lee TH and Ellinwood EH (2001) Methamphetamine neurotoxicity: necrotic and apoptotic mechanisms and relevance to human abuse and treatment. Brain Res Brain Res Rev 36:1-22.

36. DeCoster MA, Klette KL, Knight ES and Tortella FC (1995) Sigma receptormediated neuroprotection against glutamate toxicity in primary rat neuronal cultures. Brain Res 671:45-53. 
37. Deng X, Cai NS, McCoy MT, Chen W, Trush MA and Cadet JL (2002) Methamphetamine induces apoptosis in an immortalized rat striatal cell line by activating the mitochondrial cell death pathway. Neuropharmacology 42:837-845.

38. Deng $X$, Wang $Y$, Chou $J$ and Cadet JL (2001) Methamphetamine causes widespread apoptosis in the mouse brain: evidence from using an improved TUNEL histochemical method. Brain Res Mol Brain Res 93:64-69.

39. Derbez AE, Mody RM and Werling LL (2002) Sigma(2)-receptor regulation of dopamine transporter via activation of protein kinase C. J Pharmacol Exp Ther 301:306-314.

40. Dun $Y$, Thangaraju M, Prasad P, Ganapathy V and Smith SB (2007) Prevention of excitotoxicity in primary retinal ganglion cells by (+)-pentazocine, a sigma receptor-1 specific ligand. Invest Ophthalmol Vis Sci 48:4785-4794.

41. Dunai Z, Bauer PI and Mihalik R (2011) Necroptosis: biochemical, physiological and pathological aspects. Pathol Oncol Res 17:791-800.

42. El Mchichi B, Hadji A, Vazquez A and Leca G (2007) p38 MAPK and MSK1 mediate caspase- 8 activation in manganese-induced mitochondria-dependent cell death. Cell Death Differ 14:1826-1836.

43. Fleckenstein AE, Wilkins DG, Gibb JW and Hanson GR (1997) Interaction between hyperthermia and oxygen radical formation in the 5hydroxytryptaminergic response to a single methamphetamine administration. $J$ Pharmacol Exp Ther 283:281-285.

44. Formigli L, Papucci L, Tani A, Schiavone N, Tempestini A, Orlandini GE, Capaccioli S and Orlandini SZ (2000) Aponecrosis: morphological and biochemical exploration of a syncretic process of cell death sharing apoptosis and necrosis. J Cell Physiol 182:41-49.

45. Fowler JS, Kroll C, Ferrieri R, Alexoff D, Logan J, Dewey SL, Schiffer W, Schlyer D, Carter P, King P, Shea C, Xu Y, Muench L, Benveniste H, Vaska P and Volkow 
ND (2007) PET studies of d-methamphetamine pharmacokinetics in primates: comparison with I-methamphetamine and ( --)-cocaine. J Nucl Med 48:1724-1732.

46. Fukami G, Hashimoto K, Koike K, Okamura N, Shimizu E and lyo M (2004) Effect of antioxidant $\mathrm{N}$-acetyl-L-cysteine on behavioral changes and neurotoxicity in rats after administration of methamphetamine. Brain Res 1016:90-95.

47. Fukumura M, Cappon GD, Pu C, Broening HW and Vorhees CV (1998) A single dose model of methamphetamine-induced neurotoxicity in rats: effects on neostriatal monoamines and glial fibrillary acidic protein. Brain Res 806:1-7.

48. Gajate $C$ and Mollinedo $F$ (2011) Lipid rafts and Fas/CD95 signaling in cancer chemotherapy. Recent Pat Anticancer Drug Discov 6:274-283.

49. Galluzzi L and Kroemer G (2008) Necroptosis: a specialized pathway of programmed necrosis. Cell 135:1161-1163.

50. Garwood ER, Bekele W, McCulloch CE and Christine CW (2006) Amphetamine exposure is elevated in Parkinson's disease. Neurotoxicology 27:1003-1006.

51. Gebreselassie D and Bowen WD (2004) Sigma-2 receptors are specifically localized to lipid rafts in rat liver membranes. Eur J Pharmacol 493:19-28.

52. Georg A and Friedl A (1991) Identification and characterization of two sigmalike binding sites in the mouse neuroblastoma $x$ rat glioma hybrid cell line NG108-15. J Pharmacol Exp Ther 259:479-483.

53. Gonzalez-Alvear GM and Werling LL (1994) Regulation of [3H]dopamine release from rat striatal slices by sigma receptor ligands. J Pharmacol Exp Ther 271:212219.

54. Gonzalez MC, Arevalo R, Castro R, Diaz-Palarea MD and Rodriguez M (1986) Different roles of intrahypothalamic and nigrostriatal dopaminergic systems in thermoregulatory responses of the rat. Life Sci 39:707-715. 
55. Gorlach A, Klappa P and Kietzmann T (2006) The endoplasmic reticulum: folding, calcium homeostasis, signaling, and redox control. Antioxid Redox Signal 8:1391-1418.

56. Gough B, Imam SZ, Blough B, Slikker W, Jr. and Ali SF (2002) Comparative effects of substituted amphetamines (PMA, MDMA, and METH) on monoamines in rat caudate: a microdialysis study. Ann N Y Acad Sci 965:410-420.

57. Guitart $X$, Codony $X$ and Monroy $X$ (2004) Sigma receptors: biology and therapeutic potential. Psychopharmacology (Berl) 174:301-319.

58. Gunasekar PG, Kanthasamy AG, Borowitz JL and Isom GE (1995) Monitoring intracellular nitric oxide formation by dichlorofluorescin in neuronal cells. $J$ Neurosci Methods 61:15-21.

59. Gundlach AL, Largent BL and Snyder SH (1986) Autoradiographic localization of sigma receptor binding sites in guinea pig and rat central nervous system with (+)3H-3-(3-hydroxyphenyl)-N-(1-propyl)piperidine. J Neurosci 6:1757-1770.

60. Hall AA, Herrera Y, Ajmo CT, Jr., Cuevas J and Pennypacker KR (2009) Sigma receptors suppress multiple aspects of microglial activation. Glia 57:744-754.

61. Han DD and Gu HH (2006) Comparison of the monoamine transporters from human and mouse in their sensitivities to psychostimulant drugs. $B M C$ Pharmacol 6:6.

62. Hashimoto K, Fujita Y and lyo M (2007) Phencyclidine-induced cognitive deficits in mice are improved by subsequent subchronic administration of fluvoxamine: role of sigma-1 receptors. Neuropsychopharmacology 32:514-521.

63. Hashimoto K, Narita N, Tomitaka S, lyo M and Minabe $Y$ (1997) In vivo regulation of serotonin 5-HT2A receptors in rat brain by subchronic administration of sigma receptor ligand NE-100. Life Sci 60:2245-2254.

64. Hayashi T, Justinova Z, Hayashi E, Cormaci G, Mori T, Tsai SY, Barnes C, Goldberg SR and Su TP (2010) Regulation of sigma-1 receptors and endoplasmic 
reticulum chaperones in the brain of methamphetamine self-administering rats. $J$ Pharmacol Exp Ther 332:1054-1063.

65. Hayashi T and Su TP (2001) Regulating ankyrin dynamics: Roles of sigma-1 receptors. Proc Natl Acad Sci U S A 98:491-496.

66. Hayashi T and Su TP (2003a) Intracellular dynamics of sigma-1 receptors (sigma(1) binding sites) in NG108-15 cells. J Pharmacol Exp Ther 306:726-733.

67. Hayashi T and Su TP (2003b) Sigma-1 receptors (sigma(1) binding sites) form raft-like microdomains and target lipid droplets on the endoplasmic reticulum: roles in endoplasmic reticulum lipid compartmentalization and export. $J$ Pharmacol Exp Ther 306:718-725.

68. Hayashi T and Su TP (2007) Sigma-1 receptor chaperones at the ERmitochondrion interface regulate $\mathrm{Ca}(2+)$ signaling and cell survival. Cell 131:596610.

69. Hellewell SB and Bowen WD (1990) A sigma-like binding site in rat pheochromocytoma (PC12) cells: decreased affinity for (+)-benzomorphans and lower molecular weight suggest a different sigma receptor form from that of guinea pig brain. Brain Res 527:244-253.

70. Hellewell SB, Bruce A, Feinstein G, Orringer J, Williams W and Bowen WD (1994) Rat liver and kidney contain high densities of sigma 1 and sigma 2 receptors: characterization by ligand binding and photoaffinity labeling. Eur $J$ Pharmacol 268:9-18.

71. Higuchi M, Honda T, Proske RJ and Yeh ET (1998) Regulation of reactive oxygen species-induced apoptosis and necrosis by caspase 3-like proteases. Oncogene 17:2753-2760.

72. Hirata H, Ladenheim B, Rothman RB, Epstein C and Cadet JL (1995) Methamphetamine-induced serotonin neurotoxicity is mediated by superoxide radicals. Brain Res 677:345-347. 
73. Hom DG, Jiang D, Hong EJ, Mo JQ and Andersen JK (1997) Elevated expression of glutathione peroxidase in $\mathrm{PC12}$ cells results in protection against methamphetamine but not MPTP toxicity. Brain Res Mol Brain Res 46:154-160.

74. Hornick JR, Xu J, Vangveravong S, Tu Z, Mitchem JB, Spitzer D, Goedegebuure P, Mach RH and Hawkins WG (2010) The novel sigma-2 receptor ligand SW43 stabilizes pancreas cancer progression in combination with gemcitabine. Mol Cancer 9:298.

75. Huang YH, Tsai SJ, Su TW and Sim CB (1999) Effects of repeated high-dose methamphetamine on local cerebral glucose utilization in rats. Neuropsychopharmacology 21:427-434.

76. Imam SZ, Newport GD, Islam F, Slikker W, Jr. and Ali SF (1999) Selenium, an antioxidant, protects against methamphetamine-induced dopaminergic neurotoxicity. Brain Res 818:575-578.

77. Itzhak Y (1993) Repeated methamphetamine-treatment alters brain sigma receptors. Eur J Pharmacol 230:243-244.

78. Itzhak $Y$ and Ali SF (1996) The neuronal nitric oxide synthase inhibitor, 7nitroindazole, protects against methamphetamine-induced neurotoxicity in vivo. J Neurochem 67:1770-1773.

79. Itzhak Y, Ali SF and Anderson KL (2003) Fenfluramine-induced serotonergic neurotoxicity in mice: lack of neuroprotection by inhibition/ablation of nNOS. $J$ Neurochem 87:268-271.

80. Itzhak Y, Martin JL, Black MD and Ali SF (1998) Effect of melatonin on methamphetamine- and 1-methyl-4-phenyl-1,2,3,6-tetrahydropyridine-induced dopaminergic neurotoxicity and methamphetamine-induced behavioral sensitization. Neuropharmacology 37:781-791.

81. Jayanthi S, Deng X, Ladenheim B, McCoy MT, Cluster A, Cai NS and Cadet JL (2005) Calcineurin/NFAT-induced up-regulation of the Fas ligand/Fas death 
pathway is involved in methamphetamine-induced neuronal apoptosis. Proc Natl Acad Sci U S A 102:868-873.

82. Jayanthi S, Deng X, Noailles PA, Ladenheim B and Cadet JL (2004) Methamphetamine induces neuronal apoptosis via cross-talks between endoplasmic reticulum and mitochondria-dependent death cascades. FASEB $J$ 18:238-251.

83. Jiang XR, Wrona MZ and Dryhurst G (1999) Tryptamine-4,5-dione, a putative endotoxic metabolite of the superoxide-mediated oxidation of serotonin, is a mitochondrial toxin: possible implications in neurodegenerative brain disorders. Chem Res Toxicol 12:429-436.

84. Jiang YG, Peng $Y$ and Koussougbo KS (2011) Necroptosis: a novel therapeutic target for glioblastoma. Med Hypotheses 76:350-352.

85. John CS, Bowen WD, Fisher SJ, Lim BB, Geyer BC, Vilner BJ and Wahl RL (1999) Synthesis, in vitro pharmacologic characterization, and preclinical evaluation of $\mathrm{N}$-[2-(1'-piperidinyl)ethyl]-3-[125I]iodo-4-methoxybenzamide (P[125I]MBA) for imaging breast cancer. Nucl Med Biol 26:377-382.

86. Jonhede S, Petersen A, Zetterberg M and Karlsson JO (2010) Acute effects of the sigma-2 receptor agonist siramesine on lysosomal and extra-lysosomal proteolytic systems in lens epithelial cells. Mol Vis 16:819-827.

87. Joseph DB, Bowen WD (1998) Sigma receptor ligands robustly stimulate GTPgS binding to intact SK-N-SH neuroblastoma cells but not SK-N-SH cell membrane preparations. Soc. Neurosci. Abstr.24, 627.5.

88. Kadenbach B, Arnold S, Lee I and Huttemann M (2004) The possible role of cytochrome $c$ oxidase in stress-induced apoptosis and degenerative diseases. Biochim Biophys Acta 1655:400-408.

89. Kanthasamy A, Anantharam V, Ali SF and Kanthasamy AG (2006) Methamphetamine induces autophagy and apoptosis in a mesencephalic 
dopaminergic neuronal culture model: role of cathepsin-D in methamphetamineinduced apoptotic cell death. Ann N Y Acad Sci 1074:234-244.

90. Kaushal N, Matsumoto RR (2011) Role of sigma receptors in methamphetamineinduced neurotoxicity. Curr Neuropharmacol 9:54-57.

91. Kaushal N, Robson MJ, Vinnakota H, Narayanan S, Avery BA, McCurdy CR and Matsumoto RR (2011a) Synthesis and Pharmacological Evaluation of 6-Acetyl-3(4-(4-(4-fluorophenyl)piperazin-1-yl)butyl)benzo[d]oxazol-2(3H) -one (SN79), a Cocaine Antagonist, in Rodents. AAPS J.

92. Kaushal N, Seminerio MJ, Shaikh J, Medina MA, Mesangeau C, Wilson LL, McCurdy CR and Matsumoto RR (2011b) CM156, a high affinity sigma ligand, attenuates the stimulant and neurotoxic effects of methamphetamine in mice. Neuropharmacology 61:992-1000.

93. Kekuda R, Prasad PD, Fei YJ, Leibach FH and Ganapathy V (1996) Cloning and functional expression of the human type 1 sigma receptor (hSigmaR1). Biochem Biophys Res Commun 229:553-558.

94. Kita T, Wagner GC and Nakashima T (2003) Current research on methamphetamine-induced neurotoxicity: animal models of monoamine disruption. J Pharmacol Sci 92:178-195.

95. Kitamura O, Tokunaga I, Gotohda T and Kubo S (2007) Immunohistochemical investigation of dopaminergic terminal markers and caspase-3 activation in the striatum of human methamphetamine users. Int $J$ Legal Med 121:163-168.

96. Kiyatkin EA, Brown PL and Sharma HS (2007) Brain edema and breakdown of the blood-brain barrier during methamphetamine intoxication: critical role of brain hyperthermia. Eur J Neurosci 26:1242-1253.

97. Kosaka T, Saito TR and Takahashi KW (1988) Changes in plasma progesterone levels during the estrous cycle and pregnancy in 4-day cyclic mice. Jikken Dobutsu 37:351-353. 
98. Krasnova IN and Cadet JL (2009) Methamphetamine toxicity and messengers of death. Brain Res Rev 60:379-407.

99. Kroemer G, Galluzzi L and Brenner C (2007) Mitochondrial membrane permeabilization in cell death. Physiol Rev 87:99-163.

100. Kroemer G, Galluzzi L, Vandenabeele P, Abrams J, Alnemri ES, Baehrecke EH, Blagosklonny MV, El-Deiry WS, Golstein P, Green DR, Hengartner M, Knight RA, Kumar S, Lipton SA, Malorni W, Nunez G, Peter ME, Tschopp J, Yuan J, Piacentini M, Zhivotovsky B and Melino G (2009) Classification of cell death: recommendations of the Nomenclature Committee on Cell Death 2009. Cell Death Differ 16:3-11.

101.Kuczenski R, Segal DS, Cho AK and Melega W (1995) Hippocampus norepinephrine, caudate dopamine and serotonin, and behavioral responses to the stereoisomers of amphetamine and methamphetamine. J Neurosci 15:13081317.

102. Kuehn BM (2011) Meth use linked to risk of Parkinson disease. JAMA 306:814.

103. Lafon-Cazal M, Culcasi M, Gaven F, Pietri S and Bockaert J (1993a) Nitric oxide, superoxide and peroxynitrite: putative mediators of NMDA-induced cell death in cerebellar granule cells. Neuropharmacology 32:1259-1266.

104. Lafon-Cazal M, Pietri S, Culcasi M and Bockaert J (1993b) NMDA-dependent superoxide production and neurotoxicity. Nature 364:535-537.

105. Larsen KE, Fon EA, Hastings TG, Edwards RH and Sulzer D (2002) Methamphetamine-induced degeneration of dopaminergic neurons involves autophagy and upregulation of dopamine synthesis. J Neurosci 22:8951-8960.

106. LaVoie MJ and Hastings TG (1999a) Dopamine quinone formation and protein modification associated with the striatal neurotoxicity of methamphetamine: evidence against a role for extracellular dopamine. J Neurosci 19:1484-1491. 
107. LaVoie MJ and Hastings TG (1999b) Peroxynitrite- and nitrite-induced oxidation of dopamine: implications for nitric oxide in dopaminergic cell loss. J Neurochem 73:2546-2554.

108. Lee TF, Mora F and Myers RD (1985) Dopamine and thermoregulation: an evaluation with special reference to dopaminergic pathways. Neurosci Biobehav Rev 9:589-598.

109. Leist M, Single B, Castoldi AF, Kuhnle S and Nicotera P (1997) Intracellular adenosine triphosphate (ATP) concentration: a switch in the decision between apoptosis and necrosis. J Exp Med 185:1481-1486.

110. Leist M, Single B, Naumann H, Fava E, Simon B, Kuhnle S and Nicotera P (1999) Inhibition of mitochondrial ATP generation by nitric oxide switches apoptosis to necrosis. Exp Cell Res 249:396-403.

111.Li H, Zhu H, Xu CJ and Yuan J (1998) Cleavage of BID by caspase 8 mediates the mitochondrial damage in the Fas pathway of apoptosis. Cell 94:491-501.

112. Lipton JM and Clark WG (1986) Neurotransmitters in temperature control. Annu Rev Physiol 48:613-623.

113. Ma W, Pancrazio JJ, Coulombe M, Dumm J, Sathanoori R, Barker JL, Kowtha VC, Stenger DA and Hickman JJ (1998) Neuronal and glial epitopes and transmitter-synthesizing enzymes appear in parallel with membrane excitability during neuroblastoma $x$ glioma hybrid differentiation. Brain Res Dev Brain Res 106:155-163.

114. Mach RH, Smith CR, al-Nabulsi I, Whirrett BR, Childers SR and Wheeler KT (1997) Sigma 2 receptors as potential biomarkers of proliferation in breast cancer. Cancer Res 57:156-161.

115. Maeda DY, Williams W, Kim WE, Thatcher LN, Bowen WD and Coop A (2002) Narylalkylpiperidines as high-affinity sigma-1 and sigma-2 receptor ligands: phenylpropylamines as potential leads for selective sigma-2 agents. Bioorg Med Chem Lett 12:497-500. 
116. Malberg JE and Seiden LS (1997) Administration of fenfluramine at different ambient temperatures produces different core temperature and 5-HT neurotoxicity profiles. Brain Res 765:101-107.

117. Malberg JE and Seiden LS (1998) Small changes in ambient temperature cause large changes in 3,4-methylenedioxymethamphetamine (MDMA)-induced serotonin neurotoxicity and core body temperature in the rat. $J$ Neurosci 18:50865094.

118. Marrazzo A, Caraci F, Salinaro ET, Su TP, Copani A and Ronsisvalle G (2005) Neuroprotective effects of sigma-1 receptor agonists against beta-amyloidinduced toxicity. Neuroreport 16:1223-1226.

119. Marrazzo A, Fiorito J, Zappala L, Prezzavento O, Ronsisvalle S, Pasquinucci L, Scoto GM, Bernardini R and Ronsisvalle G (2011) Antiproliferative activity of phenylbutyrate ester of haloperidol metabolite II [(+/-)-MRJF4] in prostate cancer cells. Eur J Med Chem 46:433-438.

120. Martin WR, Eades CG, Thompson JA, Huppler RE and Gilbert PE (1976) The effects of morphine- and nalorphine- like drugs in the nondependent and morphine-dependent chronic spinal dog. J Pharmacol Exp Ther 197:517-532.

121. Matsumoto RR, Bowen WD, de Costa BR and Houk JC (1999) Relationship between modulation of the cerebellorubrospinal system in the in vitro turtle brain and changes in motor behavior in rats: effects of novel sigma ligands. Brain Res Bull 48:497-508.

122. Matsumoto RR, Bowen WD, Tom MA, Vo VN, Truong DD and De Costa BR (1995) Characterization of two novel sigma receptor ligands: antidystonic effects in rats suggest sigma receptor antagonism. Eur J Pharmacol 280:301-310.

123. Matsumoto RR, Hemstreet MK, Lai NL, Thurkauf A, De Costa BR, Rice KC, Hellewell SB, Bowen WD and Walker JM (1990) Drug specificity of pharmacological dystonia. Pharmacol Biochem Behav 36:151-155. 
124. Matsumoto RR, Li SM, Katz JL, Fantegrossi WE and Coop A (2011) Effects of the selective sigma receptor ligand, 1-(2-phenethyl)piperidine oxalate (AC927), on the behavioral and toxic effects of cocaine. Drug Alcohol Depend.

125. Matsumoto RR, Liu Y, Lerner M, Howard EW and Brackett DJ (2003) Sigma receptors: potential medications development target for anti-cocaine agents. Eur J Pharmacol 469:1-12.

126. Matsumoto RR, McCracken KA, Friedman MJ, Pouw B, De Costa BR and Bowen WD (2001) Conformationally restricted analogs of BD1008 and an antisense oligodeoxynucleotide targeting sigma1 receptors produce anti-cocaine effects in mice. Eur J Pharmacol 419:163-174.

127. Matsumoto RR, McCracken KA, Pouw B, Zhang $Y$ and Bowen WD (2002) Involvement of sigma receptors in the behavioral effects of cocaine: evidence from novel ligands and antisense oligodeoxynucleotides. Neuropharmacology 42:1043-1055.

128. Matsumoto RR, Pouw B, Mack AL, Daniels A and Coop A (2007) Effects of UMB24 and (+/-)-SM 21, putative sigma2-preferring antagonists, on behavioral toxic and stimulant effects of cocaine in mice. Pharmacol Biochem Behav 86:8691.

129. Matsumoto RR, Shaikh J, Wilson LL, Vedam S and Coop A (2008) Attenuation of methamphetamine-induced effects through the antagonism of sigma (sigma) receptors: Evidence from in vivo and in vitro studies. Eur Neuropsychopharmacol 18:871-881.

130. Matsuzaki H, Namikawa K, Kiyama H, Mori N and Sato K (2004) Brain-derived neurotrophic factor rescues neuronal death induced by methamphetamine. Biol Psychiatry 55:52-60.

131. McCann DJ, Weissman AD and Su TP (1994) Sigma-1 and sigma-2 sites in rat brain: comparison of regional, ontogenetic, and subcellular patterns. Synapse 17:182-189. 
132. McLawhon RW, West RE, Jr., Miller RJ and Dawson G (1981) Distinct highaffinity binding sites for benzomorphan drugs and enkephalin in a neuroblastoma--brain hybrid cell line. Proc Natl Acad Sci U S A 78:4309-4313.

133. Melega WP, Jorgensen MJ, Lacan G, Way BM, Pham J, Morton G, Cho AK and Fairbanks LA (2008) Long-term methamphetamine administration in the vervet monkey models aspects of a human exposure: brain neurotoxicity and behavioral profiles. Neuropsychopharmacology 33:1441-1452.

134. Mesangeau C, Narayanan S, Green AM, Shaikh J, Kaushal N, Viard E, Xu YT, Fishback JA, Poupaert JH, Matsumoto RR and McCurdy CR (2008) Conversion of a highly selective sigma-1 receptor-ligand to sigma-2 receptor preferring ligands with anticocaine activity. $J$ Med Chem 51:1482-1486.

135. Meunier J, leni $\mathrm{J}$ and Maurice $\mathrm{T}$ (2006) The anti-amnesic and neuroprotective effects of donepezil against amyloid beta25-35 peptide-induced toxicity in mice involve an interaction with the sigma1 receptor. Br J Pharmacol 149:998-1012.

136. Miller DB and O'Callaghan JP (1994) Environment-, drug- and stress-induced alterations in body temperature affect the neurotoxicity of substituted amphetamines in the C57BL/6J mouse. $J$ Pharmacol Exp Ther 270:752-760.

137. Miller DB and O'Callaghan JP (2003) Elevated environmental temperature and methamphetamine neurotoxicity. Environ Res 92:48-53.

138. Mir SU, Ahmed IS, Arnold S and Craven RJ (2011) Elevated Pgrmc1 (progesterone receptor membrane component 1)/sigma-2 receptor levels in lung tumors and plasma from lung cancer patients. Int $J$ Cancer.

139. Mishina M, Ishiwata $K$, Ishii $K$, Kitamura S, Kimura $Y$, Kawamura $K$, Oda K, Sasaki T, Sakayori O, Hamamoto M, Kobayashi $S$ and Katayama $Y$ (2005) Function of sigma1 receptors in Parkinson's disease. Acta Neurol Scand 112:103107. 
140. Moebius FF, Bermoser K, Reiter RJ, Hanner M and Glossmann H (1996) Yeast sterol C8-C7 isomerase: identification and characterization of a high-affinity binding site for enzyme inhibitors. Biochemistry 35:16871-16878.

141. Morin-Surun MP, Collin T, Denavit-Saubie M, Baulieu EE and Monnet FP (1999) Intracellular sigma1 receptor modulates phospholipase $\mathbf{C}$ and protein kinase $\mathbf{C}$ activities in the brainstem. Proc Natl Acad Sci U S A 96:8196-8199.

142. Navarro G, Moreno E, Aymerich M, Marcellino D, McCormick PJ, Mallol J, Cortes A, Casado V, Canela El, Ortiz J, Fuxe K, Lluis C, Ferre S and Franco R (2010) Direct involvement of sigma-1 receptors in the dopamine D1 receptormediated effects of cocaine. Proc Natl Acad Sci U S A 107:18676-18681.

143. Nguyen EC, McCracken KA, Liu Y, Pouw B and Matsumoto RR (2005) Involvement of sigma (sigma) receptors in the acute actions of methamphetamine: receptor binding and behavioral studies. Neuropharmacology 49:638-645.

144. Nicotera P, Leist $M$ and Ferrando-May E (1998) Intracellular ATP, a switch in the decision between apoptosis and necrosis. Toxicol Lett 102-103:139-142.

145. Nicotera P and Melino G (2004) Regulation of the apoptosis-necrosis switch. Oncogene 23:2757-2765.

146. Numachi $Y$, Ohara A, Yamashita M, Fukushima S, Kobayashi H, Hata H, Watanabe H, Hall FS, Lesch KP, Murphy DL, Uhl GR and Sora I (2007) Methamphetamine-induced hyperthermia and lethal toxicity: role of the dopamine and serotonin transporters. Eur J Pharmacol 572:120-128.

147. Ostenfeld MS, Fehrenbacher N, Hoyer-Hansen M, Thomsen C, Farkas $T$ and Jaattela M (2005) Effective tumor cell death by sigma-2 receptor ligand siramesine involves lysosomal leakage and oxidative stress. Cancer Res 65:89758983.

148. Papucci L, Formigli L, Schiavone N, Tani A, Donnini M, Lapucci A, Perna F, Tempestini A, Witort E, Morganti M, Nosi D, Orlandini GE, Zecchi Orlandini S and 
Capaccioli S (2004) Apoptosis shifts to necrosis via intermediate types of cell death by a mechanism depending on c-myc and bcl-2 expression. Cell Tissue Res 316:197-209.

149. Peeters M, Romieu P, Maurice T, Su TP, Maloteaux JM and Hermans E (2004) Involvement of the sigma 1 receptor in the modulation of dopaminergic transmission by amantadine. Eur J Neurosci 19:2212-2220.

150. Prasad PD, Li HW, Fei YJ, Ganapathy ME, Fujita T, Plumley LH, Yang-Feng TL, Leibach FH and Ganapathy V (1998) Exon-intron structure, analysis of promoter region, and chromosomal localization of the human type 1 sigma receptor gene. $J$ Neurochem 70:443-451.

151.Proskuryakov SY, Konoplyannikov AG and Gabai VL (2003) Necrosis: a specific form of programmed cell death? Exp Cell Res 283:1-16.

152. Rawls SM, Baron DA, Geller EB and Adler MW (2002) Sigma sites mediate DTGevoked hypothermia in rats. Pharmacol Biochem Behav 73:779-786.

153. Riddle EL, Fleckenstein AE and Hanson GR (2006) Mechanisms of methamphetamine-induced dopaminergic neurotoxicity. AAPS J 8:E413-418.

154. Riedel W and Maulik G (1999) Fever: an integrated response of the central nervous system to oxidative stress. Mol Cell Biochem 196:125-132.

155.Salmi $P$ and Ahlenius $S$ (1998) Evidence for functional interactions between 5HT1A and 5-HT2A receptors in rat thermoregulatory mechanisms. Pharmacol Toxicol 82:122-127.

156.Samantaray S, Ray SK, Ali SF and Banik NL (2006) Calpain activation in apoptosis of motoneurons in cell culture models of experimental parkinsonism. Ann N Y Acad Sci 1074:349-356.

157.Schetz JA, Perez E, Liu R, Chen S, Lee I and Simpkins JW (2007) A prototypical Sigma-1 receptor antagonist protects against brain ischemia. Brain Res 1181:1-9. 
158. Schmued LC and Bowyer JF (1997) Methamphetamine exposure can produce neuronal degeneration in mouse hippocampal remnants. Brain Res 759:135-140.

159. Schwartz PJ, Wehr TA, Rosenthal NE, Bartko JJ, Oren DA, Luetke C and Murphy DL (1995) Serotonin and thermoregulation. Physiologic and pharmacologic aspects of control revealed by intravenous $\mathrm{m}$-CPP in normal human subjects. Neuropsychopharmacology 13:105-115.

160.Scott JC, Woods SP, Matt GE, Meyer RA, Heaton RK, Atkinson JH and Grant I (2007) Neurocognitive effects of methamphetamine: a critical review and metaanalysis. Neuropsychol Rev 17:275-297.

161.Segal DS and Kuczenski R (2006) Human methamphetamine pharmacokinetics simulated in the rat: single daily intravenous administration reveals elements of sensitization and tolerance. Neuropsychopharmacology 31:941-955.

162. Sekine $Y$, Ouchi $Y$, Sugihara G, Takei N, Yoshikawa E, Nakamura K, Iwata $Y$, Tsuchiya KJ, Suda S, Suzuki K, Kawai M, Takebayashi K, Yamamoto S, Matsuzaki H, Ueki T, Mori N, Gold MS and Cadet JL (2008) Methamphetamine causes microglial activation in the brains of human abusers. $J$ Neurosci 28:5756-5761.

163.Seminerio MJ, Kaushal N, Shaikh J, Huber JD, Coop A and Matsumoto RR (2011) Sigma (sigma) receptor ligand, AC927 (N-phenethylpiperidine oxalate), attenuates methamphetamine-induced hyperthermia and serotonin damage in mice. Pharmacol Biochem Behav 98:12-20.

164. Seth P, Fei YJ, Li HW, Huang W, Leibach FH and Ganapathy V (1998) Cloning and functional characterization of a sigma receptor from rat brain. $J$ Neurochem 70:922-931.

165.Sharkey J, Glen KA, Wolfe S and Kuhar MJ (1988) Cocaine binding at sigma receptors. Eur J Pharmacol 149:171-174.

166. Sharma HS, Sjoquist PO and Ali SF (2007) Drugs of abuse-induced hyperthermia, blood-brain barrier dysfunction and neurotoxicity: neuroprotective effects of a new antioxidant compound H-290/51. Curr Pharm Des 13:1903-1923. 
167. Shen YC, Wang YH, Chou YC, Liou KT, Yen JC, Wang WY and Liao JF (2008) Dimemorfan protects rats against ischemic stroke through activation of sigma-1 receptor-mediated mechanisms by decreasing glutamate accumulation. $J$ Neurochem 104:558-572.

168. Shimazu S, Katsuki H, Takenaka C, Tomita M, Kume T, Kaneko S and Akaike A (2000) sigma receptor ligands attenuate $\mathrm{N}$-methyl-D-aspartate cytotoxicity in dopaminergic neurons of mesencephalic slice cultures. Eur J Pharmacol 388:139146.

169. Shirayama Y, Nishikawa T, Umino A and Takahashi K (1993) pchlorophenylalanine-reversible reduction of sigma binding sites by chronic imipramine treatment in rat brain. Eur J Pharmacol 237:117-126.

170.Skowronski EW, Kolesnick RN and Green DR (1996) Fas-mediated apoptosis and sphingomyelinase signal transduction: the role of ceramide as a second messenger for apoptosis. Cell Death Differ 3:171-176.

171. Soti C, Sreedhar AS and Csermely P (2003) Apoptosis, necrosis and cellular senescence: chaperone occupancy as a potential switch. Aging Cell 2:39-45.

172.Stefanski R, Justinova Z, Hayashi T, Takebayashi M, Goldberg SR and Su TP (2004) Sigma1 receptor upregulation after chronic methamphetamine selfadministration in rats: a study with yoked controls. Psychopharmacology (Berl) 175:68-75.

173.Stephans SE and Yamamoto BK (1994) Methamphetamine-induced neurotoxicity: roles for glutamate and dopamine efflux. Synapse 17:203-209.

174.Su TP (1991) Sigma receptors. Putative links between nervous, endocrine and immune systems. Eur J Biochem 200:633-642.

175.Su TP, Hayashi T, Maurice T, Buch S and Ruoho AE (2010) The sigma-1 receptor chaperone as an inter-organelle signaling modulator. Trends Pharmacol Sci 31:557-566. 
176. Takahashi S, Miwa T and Horikomi K (2000) Involvement of sigma 1 receptors in methamphetamine-induced behavioral sensitization in rats. Neurosci Lett 289:2124.

177.Takebayashi M, Hayashi T and Su TP (2002) Nerve growth factor-induced neurite sprouting in PC12 cells involves sigma-1 receptors: implications for antidepressants. J Pharmacol Exp Ther 303:1227-1237.

178. Tchedre KT and Yorio T (2008) sigma-1 receptors protect RGC-5 cells from apoptosis by regulating intracellular calcium, Bax levels, and caspase-3 activation. Invest Ophthalmol Vis Sci 49:2577-2588.

179. Tepper CG, Jayadev S, Liu B, Bielawska A, Wolff R, Yonehara S, Hannun YA and Seldin MF (1995) Role for ceramide as an endogenous mediator of Fasinduced cytotoxicity. Proc Natl Acad Sci U S A 92:8443-8447.

180. Thomas DM, Walker PD, Benjamins JA, Geddes TJ and Kuhn DM (2004) Methamphetamine neurotoxicity in dopamine nerve endings of the striatum is associated with microglial activation. J Pharmacol Exp Ther 311:1-7.

181.Tsai SY, Hayashi T, Mori T and Su TP (2009) Sigma-1 receptor chaperones and diseases. Cent Nerv Syst Agents Med Chem 9:184-189.

182. Tu Z, Xu J, Jones LA, Li S, Zeng D, Kung MP, Kung HF and Mach RH (2010) Radiosynthesis and biological evaluation of a promising sigma(2)-receptor ligand radiolabeled with fluorine-18 or iodine-125 as a PET/SPECT probe for imaging breast cancer. Appl Radiat Isot 68:2268-2273.

183. Ujike H, Kanzaki A, Okumura K, Akiyama K and Otsuki S (1992) Sigma (sigma) antagonist BMY 14802 prevents methamphetamine-induced sensitization. Life Sci 50:PL129-134.

184. Vagnerova K, Hurn PD, Bhardwaj A and Kirsch JR (2006) Sigma 1 receptor agonists act as neuroprotective drugs through inhibition of inducible nitric oxide synthase. Anesth Analg 103:430-434, table of contents. 
185. Vaupel DB (1983) Naltrexone fails to antagonize the sigma effects of PCP and SKF 10,047 in the dog. Eur J Pharmacol 92:269-274.

186. Villemagne V, Yuan J, Wong DF, Dannals RF, Hatzidimitriou G, Mathews WB, Ravert HT, Musachio J, McCann UD and Ricaurte GA (1998) Brain dopamine neurotoxicity in baboons treated with doses of methamphetamine comparable to those recreationally abused by humans: evidence from [11C]WIN-35,428 positron emission tomography studies and direct in vitro determinations. $J$ Neurosci 18:419-427.

187. Vilner BJ and Bowen WD (2000) Modulation of cellular calcium by sigma-2 receptors: release from intracellular stores in human SK-N-SH neuroblastoma cells. J Pharmacol Exp Ther 292:900-911.

188. Vilner BJ, de Costa BR and Bowen WD (1995a) Cytotoxic effects of sigma ligands: sigma receptor-mediated alterations in cellular morphology and viability. J Neurosci 15:117-134.

189. Vilner BJ, John CS and Bowen WD (1995b) Sigma-1 and sigma-2 receptors are expressed in a wide variety of human and rodent tumor cell lines. Cancer Res 55:408-413.

190. Volkow ND, Chang L, Wang GJ, Fowler JS, Leonido-Yee M, Franceschi D, Sedler MJ, Gatley SJ, Hitzemann R, Ding YS, Logan J, Wong C and Miller EN (2001) Association of dopamine transporter reduction with psychomotor impairment in methamphetamine abusers. Am J Psychiatry 158:377-382.

191. Walker JM, Bowen WD, Goldstein SR, Roberts AH, Patrick SL, Hohmann AG and DeCosta B (1992) Autoradiographic distribution of $[3 \mathrm{H}](+)$-pentazocine and [3H]1,3-di-o-tolylguanidine (DTG) binding sites in guinea pig brain: a comparative study. Brain Res 581:33-38.

192. Wallace TL, Vorhees CV, Zemlan FP and Gudelsky GA (2003) Methamphetamine enhances the cleavage of the cytoskeletal protein tau in the rat brain. Neuroscience 116:1063-1068. 
193. Walsh SL and Wagner GC (1992) Motor impairments after methamphetamineinduced neurotoxicity in the rat. $J$ Pharmacol Exp Ther 263:617-626.

194. Wang $X$ and Bowen WD (2006) Sigma-2 receptors mediate apoptosis in SK-NSH neuroblastoma cells via caspase-10 dependent Bid cleavage and mitochondrial release of endonuclease $G$ and apoptosis inducing factor. SfN Meeting 2006 Abstract \# 2006-A-4745-SfN.

195.Wang J, Xu W, Ali SF and Angulo JA (2008) Connection between the striatal neurokinin-1 receptor and nitric oxide formation during methamphetamine exposure. Ann N Y Acad Sci 1139:164-171.

196. Waterhouse RN, Mardon K, Giles KM, Collier TL and O'Brien JC (1997) Halogenated 4-(phenoxymethyl)piperidines as potential radiolabeled probes for sigma-1 receptors: in vivo evaluation of [123l]-1-(iodopropen-2-yl)-4-[(4cyanophenoxy)methyl]pip eri dine. J Med Chem 40:1657-1667.

197. Wei Z, Mousseau DD, Dai Y, Cao X and Li XM (2006) Haloperidol induces apoptosis via the sigma2 receptor system and Bcl-XS. Pharmacogenomics $J$ 6:279-288.

198. Weiser SD, Patrick SL, Mascarella SW, Downing-Park J, Bai X, Carroll FI, Walker JM and Patrick RL (1995) Stimulation of rat striatal tyrosine hydroxylase activity following intranigral administration of sigma receptor ligands. Eur $\mathbf{J}$ Pharmacol 275:1-7.

199. Wheeler KT, Wang LM, Wallen CA, Childers SR, Cline JM, Keng PC and Mach RH (2000) Sigma-2 receptors as a biomarker of proliferation in solid tumours. $\mathrm{Br} \mathrm{J}$ Cancer 82:1223-1232.

200. Wrona MZ and Dryhurst G (1998) Oxidation of serotonin by superoxide radical: implications to neurodegenerative brain disorders. Chem Res Toxicol 11:639-650.

201. Wrona MZ, Yang Z, McAdams M, O'Connor-Coates S and Dryhurst G (1995) Hydroxyl radical-mediated oxidation of serotonin: potential insights into the neurotoxicity of methamphetamine. J Neurochem 64:1390-1400. 
202. Wrona MZ, Yang Z, Zhang $F$ and Dryhurst G (1997) Potential new insights into the molecular mechanisms of methamphetamine-induced neurodegeneration. NIDA Res Monogr 173:146-174.

203. Wu CW, Ping YH, Yen JC, Chang CY, Wang SF, Yeh CL, Chi CW and Lee HC (2007) Enhanced oxidative stress and aberrant mitochondrial biogenesis in human neuroblastoma SH-SY5Y cells during methamphetamine induced apoptosis. Toxicol Appl Pharmacol 220:243-251.

204. Wu W, Liu P and Li J (2011) Necroptosis: An emerging form of programmed cell death. Crit Rev Oncol Hematol.

205.Xie T, McCann UD, Kim S, Yuan J and Ricaurte GA (2000) Effect of temperature on dopamine transporter function and intracellular accumulation of methamphetamine: implications for methamphetamine-induced dopaminergic neurotoxicity. J Neurosci 20:7838-7845.

206.Xu J, Zeng C, Chu W, Pan F, Rothfuss JM, Zhang F, Tu Z, Zhou D, Zeng D, Vangveravong S, Johnston F, Spitzer D, Chang KC, Hotchkiss RS, Hawkins WG, Wheeler KT and Mach RH (2011) Identification of the PGRMC1 protein complex as the putative sigma-2 receptor binding site. Nat Commun 2:380.

207.Xu YT, Kaushal N, Shaikh J, Wilson LL, Mesangeau C, McCurdy CR and Matsumoto RR (2010) A novel substituted piperazine, CM156, attenuates the stimulant and toxic effects of cocaine in mice. $J$ Pharmacol Exp Ther 333:491-500.

208. Yagasaki Y, Numakawa T, Kumamaru E, Hayashi T, Su TP and Kunugi H (2006) Chronic antidepressants potentiate via sigma-1 receptors the brain-derived neurotrophic factor-induced signaling for glutamate release. $J$ Biol Chem 281:12941-12949.

209. Yakovlev AG and Faden Al (2004) Mechanisms of neural cell death: implications for development of neuroprotective treatment strategies. NeuroRx 1:5-16. 
210. Yamashita N, Hoshida S, Otsu K, Taniguchi N, Kuzuya T and Hori M (2000) Involvement of cytokines in the mechanism of whole-body hyperthermia-induced cardioprotection. Circulation 102:452-457.

211. Yang S, Bhardwaj A, Cheng J, Alkayed NJ, Hurn PD and Kirsch JR (2007) Sigma receptor agonists provide neuroprotection in vitro by preserving bcl-2. Anesth Analg 104:1179-1184, tables of contents.

212. Yang ZJ, Carter EL, Torbey MT, Martin LJ and Koehler RC (2010) Sigma receptor ligand 4-phenyl-1-(4-phenylbutyl)-piperidine modulates neuronal nitric oxide synthase/postsynaptic density-95 coupling mechanisms and protects against neonatal ischemic degeneration of striatal neurons. Exp Neurol 221:166174.

213.Zeng C, Vangveravong S, Xu J, Chang KC, Hotchkiss RS, Wheeler KT, Shen D, Zhuang ZP, Kung HF and Mach RH (2007) Subcellular localization of sigma-2 receptors in breast cancer cells using two-photon and confocal microscopy. Cancer Res 67:6708-6716. 


\section{Nidhi Kaushal}

Address: P.O.Box 9530, School of Pharmacy, West Virginia University, Morgantown, WV 26506

Email: nkaushal@hsc.wvu.edu, Phone: 304-293-3040

\section{EDUCATION}

West Virginia University (2008- May 2012), Pharmaceutical and Pharmacological Sciences [GPA: 4/4] University of Mississippi (2006-2008), MS, Pharmacology and Toxicology [GPA: 3.96/4]

University of Delhi (2002-2006), BS, Pharmacy [I Division]

\section{RESEARCH AND TEACHING EXPERIENCE}

West Virginia University

o Research assistant (Since June 2008): Screened and evaluated the neuroprotective effects of novel sigma receptor antagonists against methamphetamine-induced neurotoxicity in mice and NG108 cells

- Teaching assistant (Fall 2008): PHAR 792 - Introduction to Research elective course for Pharm.D. students

University of Mississippi

o Research assistant (2006-2008): Screened and evaluated novel sigma receptor compounds against behavioral effects of cocaine in rodents

o Teaching assistant and PBL facilitator (2006-2007): PHCL 341, 342 - Human Physiology \& Pathophysiology required course and lab for Pharm.D. students

University of Delhi

o Undergraduate research assistant (2004-2006): Isolated and characterized chemical compounds extracted from medicinal plant (Swertia chirata)

\section{OTHER RESEARCH TRAINING}

- Dr. Wayne D. Bowen's lab at Brown University, Providence, RI (Summer 2010): Summer research trainee - Granted Stitzel award from West Virginia University for career development training in molecular biology techniques

- Tanuk Pharma and KARE Labs, India (2005): Trained in production and quality control of pharmaceutical drugs

\section{HONORS AND AWARDS}

- West Virginia University School of Pharmacy Graduate Student Research Award, 2011

- Behavioral and Biomedical Sciences Training Scholarship, 2010, 2011

- Robert E. Stitzel Graduate Student Award, 2009

- First place, E.J. Van Liere Research Day poster competition, 2009

- Travel Award from the American Society of Pharmacology and Experimental Therapeutics (ASPET) to attend Experimental Biology annual meeting, New Orleans, LA, 2009

- Travel Award from the NIH and the University of Texas San Antonio to attend the Behavior, Biology and Chemistry: Translational Research in Addiction meeting, San Antonio, TX, 2009

- Travel Award from the WVU School of Pharmacy to attend the International Drug Abuse Research Society meeting, Seoul, South Korea, 2009; Experimental Biology meeting, New Orleans, LA, 2009; Society for Neuroscience meeting, San Diego, CA, 2010 
- Natural Products Neuroscience Fellowship, University of Mississippi, 2007

- Honorable Mention, graduate student poster presentation, South Central Society for Toxicology meeting, 2007

\section{MANUSCRIPTS PUBLISHED}

- Kaushal N, Elliott M, Robson MJ, Iyer A, Rojanasakul Y, Coop A, Matsumoto RR (2012) AC927, a $\sigma$ ligand, blocks the release of dopamine and generation of reactive oxygen species by methamphetamine in NG108 cells. Mol Pharmacol 81(3): 299-308.

- Kaushal N, Seminerio MJ, Shaikh J, Medina MA, Mésangeau C, McCurdy CR, Matsumoto RR (2011) CM156, A high affinity sigma receptor ligand attenuates the stimulant and neurotoxic effects of methamphetamine in mice. Neuropharmacology 61(5-6): 992-1000.

- Kaushal N, Robson MJ, Vinnakota H, Narayanan S, Avery BA, McCurdy CR, Matsumoto RR (2011) Synthesis and pharmacological evaluation of SN79, a putative sigma receptor antagonist against cocaine-induced behaviors in mice. AAPS Journal 13(3): 336-346.

- Review: Kaushal N, Matsumoto RR (2011) Role of sigma receptors in methamphetamine-induced neurotoxicity. Curr Neuropharmacol 9(1): 54-57.

- Seminerio MJ, Kaushal N, Shaikh J, Huber JD, Coop A, Matsumoto RR (2010) Sigma receptor ligand AC927 attenuates methamphetamine-induced hyperthermia and serotonin damage in mice. Pharmacol Biochem Behav 98(1): 12-20.

- Xu Y, Kaushal N, Shaikh J, Wilson LL, Mésangeau C, McCurdy CR, Matsumoto RR (2010) A novel substituted piperazine, CM156, attenuates the stimulant and toxic effects of cocaine in mice. JPET 333(2): 491-500.

- Mésangeau C, Narayanan S, Green AM, Shaikh J, Kaushal N, Viard E, Xu Y, Fishback JA, Poupaert JH, Matsumoto RR, McCurdy CR (2008) Conversion of a highly selective sigma-1 receptor ligand to sigma-2 receptor preferring ligands with anti-cocaine activity. J Med Chem 51(5): 14821486.

- Review: Sharma N, Minocha S, Kaushal N, Chawla A, Minocha M, Sharma Y (2008) Butea frondosa [flame of the forest]: A review. Hamdard Medicus 51(2): 46-50.

\section{MANUSCRIPTS UNDER REVIEW AND IN PREPARATION}

- Seminerio MJ, Hansen R, Kaushal N, Zhang H, McCurdy CR, Matsumoto RR. The evaluation of AZ66, an optimized sigma receptor ligand, against methamphetamine-induced dopaminergic neurotoxicity and memory impairment in mice. (Submittted to The International Journal of Neuropsychopharmacology).

- Kaushal N, Seminerio MJ, McCurdy CR, Matsumoto RR. Pharmacological evaluation of SN79, a sigma receptor ligand against methamphetamine-induced neurotoxicity in mice. (In preparation for JPET).

- Kaushal N, McCurdy CR, Matsumoto RR. SN79 attenuates methamphetamine-induced apoptosis and necrosis in NG108 cells: Role of sigma receptors. (In preparation for JPET). 


\section{PRESENTATIONS}

Platform Presentations:

- AC927, a selective sigma receptor ligand, blocks the generation of reactive oxygen species induced by methamphetamine in NG108-15 cells. Society for Neuroscience 2010, San Diego, CA.

- SN79, a novel sigma-2 receptor antagonist, attenuates methamphetamine-induced neurotoxicity. E.J. Van Liere Annual Convocation 2010, Morgantown, WV.

- CM156, a novel sigma receptor antagonist, mitigates stimulant and neurotoxic effects of methamphetamine in mice. 2nd Annual International Drug Abuse Research Society Meeting 2009, Seoul, South Korea.

Poster Presentations and Other Abstracts at National and International Meetings:

- Kaushal N, McCurdy CR, Matsumoto RR. SN79 attenuates the neurotoxic effects of methamphetamine: in vivo and in vitro studies. Society for Neuroscience 2011, Washington, DC.

- Kaushal N, McCurdy CR, Matsumoto RR. Attenuation of methamphetamine-induced neurotoxicity by SN79: Involvement of sigma-2 receptors. Society for Neuroscience 2010, San Diego, CA.

- Kaushal N, McCurdy CR, Matsumoto RR. Attenuation of psychostimulant effects by SN79, a selective sigma-2 receptor ligand: implications for medication development for cocaine and methamphetamine abuse. 2nd Annual International Drug Abuse Research Society Meeting 2009, Seoul, South Korea.

- Kaushal N, Seminerio MJ, Shaikh J, Medina MA, Mésangeau C, McCurdy CR, Matsumoto RR. CM156, a novel sigma receptor antagonist, mitigates stimulant and neurotoxic effects of methamphetamine in mice. Experimental Biology 2009, New Orleans, LA.

- Kaushal N, Croom C, Shaikh J, Narayanan S, Mésangeau C, Poupaert JH, McCurdy CR, Matsumoto RR. SN79, a novel sigma-2 receptor antagonist, attenuates cocaine induced behaviors in mice. Behavior, Biology and Chemistry: Translational Research in Addiction 2009, San Antonio, TX.

- Kaushal N, Seminerio MJ, Shaikh J, Medina MA, Mésangeau C, McCurdy CR, Matsumoto RR. CM156, a novel sigma receptor antagonist, attenuates the neurotoxic effects of methamphetamine in mice," Behavior, Biology and Chemistry: Translational Research in Addiction 2009, San Antonio, TX.

- Seminerio MJ, Kaushal N, Shaikh J, Medina M, McCurdy CR, Coop A, Matsumoto RR. Sigma antagonists, AC927 and CM156, protect against methamphetamine-induced serotonergic neurotoxicity while attenuating hyperthermia. $71^{\text {st }}$ Annual College on Problems of Drug Dependence 2009, Reno, NV.

- Kaushal N, Shaikh J, Croom C, Mésangeau C, Narayanan S, Poupaert J, McCurdy CR, Matsumoto RR. Novel substituted piperazines with high affinity and selectivity for sigma receptors attenuate cocaine-induced behaviors in mice: role for sigma-1 and sigma-2 subtypes. College on Problems of Drug Dependence 2008, San Juan, Peurto Rico.

- Kaushal N, Croom C, Shaikh J, Narayanan S, Mésangeau C, Poupaert JH, McCurdy CR, Matsumoto RR. SN79, A novel sigma-2 receptor antagonist, attenuates cocaine induced behaviors in mice. Experimental Biology 2008, San Diego, CA.

- McCurdy CR, Mésangeau C, Narayanan S, Shaikh J, Kaushal N, Matsumoto RR, Poupaert JH. Discovery of a selective sigma-2 receptor ligand and the potential involvement of sigma-2 receptors in cocaine toxicity. 70th Annual Meeting of the College on Problems of Drug Dependence 2008, San Juan, Puerto Rico. 
- Xu Y, Shaikh J, Viard E, Fishback J, Kaushal N, Mésangeau C, Narayanan S, Poupaert JH, McCurdy CR, Matsumoto RR. Synthesis and evaluation of subtype selective sigma receptor ligands from substituted 2(3H)-Benzoxazolone and 2(3H)-Benzothiazolone derivatives. South Central Society for Toxicology 2007, Oxford, MS.

- Kaushal N, Croom C, Shaikh J, Narayanan S, Mésangeau C, Poupaert JH, McCurdy CR, Matsumoto RR. SN79, a novel sigma-2 receptor antagonist, attenuates cocaine induced behaviors in mice. South Central Society for Toxicology 2007, Oxford, MS.

- Matsumoto RR, Wilson LL, Mésangeau C, Shaikh J, Kaushal N, Poupaert JH, McCurdy CR. CM156, a novel substituted piperazine, attenuates the behavioural effects of cocaine in mice. South Central Society for Toxicology 2007, Oxford, MS.

\section{SOCIETY MEMBERSHIPS}

- Society for Neuroscience (SfN)

- American Association of Pharmaceutical Sciences (AAPS)

- International Drug Abuse Research Society (IDARS)

- American Society of Pharmacology and Experimental Therapeutics (ASPET)

- American Scientists of Indian Origin Association (ASIOA)

- Indian Pharmaceutical Graduate Association (IPGA)

\section{SERVICE}

- Mentored undergraduate research students:

- Ms. Abagail Rosen (West Virginia University, Undergraduate honor's thesis student), 2011

- Mr. Mark A. Medina (West Virginia University, Pharmacy research student), Summer 2008

- Ms. Caroline Croom (University of Mississippi, Natural Products Neuroscience Summer Research Program), Summer 2007

- Served as Senator (Department of Pharmacology), Graduate Student Council, University of Mississippi, 2007

- Participated in the polio campaign organized by the Government of India, 2005

- Participated in the blood donation camp organized by the Rotary Blood Bank, India, 2005

- Participated in social service on the Indian Railway Service Day as a member of the Bharat Scouts and Guides, 1996 